\title{
Response Of Forest Birds To Spotted Wing Drosophila (Drosophila Suzukii Matsumura), A Novel Invasive Fruit Pest, At Allegheny National Forest
}

\author{
Daniel P. Roche \\ West Virginia University, dpr0008@mix.wvu.edu
}

Follow this and additional works at: https://researchrepository.wvu.edu/etd

Part of the Entomology Commons, Ornithology Commons, and the Terrestrial and Aquatic Ecology Commons

\section{Recommended Citation}

Roche, Daniel P., "Response Of Forest Birds To Spotted Wing Drosophila (Drosophila Suzukii Matsumura), A Novel Invasive Fruit Pest, At Allegheny National Forest" (2021). Graduate Theses, Dissertations, and Problem Reports. 10251.

https://researchrepository.wvu.edu/etd/10251

This Thesis is protected by copyright and/or related rights. It has been brought to you by the The Research Repository @ WVU with permission from the rights-holder(s). You are free to use this Thesis in any way that is permitted by the copyright and related rights legislation that applies to your use. For other uses you must obtain permission from the rights-holder(s) directly, unless additional rights are indicated by a Creative Commons license in the record and/ or on the work itself. This Thesis has been accepted for inclusion in WVU Graduate Theses, Dissertations, and Problem Reports collection by an authorized administrator of The Research Repository @ WVU. For more information, please contact researchrepository@mail.wvu.edu. 


\title{
RESPONSE OF FOREST BIRDS TO SPOTTED WING DROSOPHILA (DROSOPHILA SUZUKII MATSUMURA), A NOVEL INVASIVE FRUIT PEST, AT ALLEGHENY NATIONAL FOREST
}

\author{
Daniel P. Roche \\ Thesis submitted \\ to the Davis College of Agriculture, Natural Resources, and Design \\ at West Virginia University \\ in partial fulfillment of the requirements for the degree of \\ Master of Science in \\ Wildlife and Fisheries Resources
}

\author{
Christopher M. Lituma, Ph.D., Chair \\ Christopher T. Rota, Ph.D. \\ William K. Oldland, M.S. \\ Scott H. Stoleson, Ph.D. \\ Wildlife and Fisheries Resources Program, \\ Division of Forestry and Natural Resources
}

Morgantown, West Virginia

2021

Keywords: abundance, bird community, body condition, early successional, forest, frugivorous birds, fruit consumption, fruit parasitism, invasive species, migration, post-breeding, black cherry (Prunus serotina), species interactions, species richness, spotted wing Drosophila (Drosophila suzukii)

Copyright 2021 Daniel P. Roche 


\title{
ABSTRACT
}

\section{RESPONSE OF FOREST BIRDS TO SPOTTED WING DROSOPHILA (DROSOPHILA SUZUKII MATSUMURA), A NOVEL INVASIVE FRUIT PEST, AT ALLEGHENY NATIONAL FOREST}

\author{
Daniel P. Roche
}

Non-native invasive insect pests can have dramatic impacts on native ecosystems, feeding on plant foliage, wood, or sap. Little is known, however, about how fruit-targeting NNIIPs may affect native ecosystems. Spotted wing Drosophila (Drosophila suzukii Matsumura, SWD) is a recently introduced invasive vinegar fly that parasitizes the fruits of many plant species in the United States. While its activity in agricultural systems is well-documented, little is known about its activity in forest ecosystems, despite growing evidence of its presence and parasitism of fruits there. Parasitism could reduce fruit attractiveness for vertebrate fruit consumers, including migratory birds. As such, this may reduce soft mast food availability for birds in early successional habitat during the post-breeding season and fall migration, interfering with energy accumulation when demands are greatest. This thesis includes 4 chapters focused on understanding factors influencing SWD in invaded forest habitat and whether SWD activity associates with avian abundances, species richness, body condition, and fruit consumption at Allegheny National Forest in northwestern Pennsylvania.

In Chapter 1, I provide context and justification for this research. I first describe how NNIIPs are known to influence forest ecosystems. I then review information on how SWD affects fruit crops in agricultural systems and provide a framework detailing how fruit parasitism by SWD may alter forest ecosystems. I lay out the research on fruit parasitism and fruit consumption by wildlife, especially fruit-consuming birds. I relate this to cascading effects on the following: 1) seed dispersal, 2) forest community structure and composition, and 3) food resources for wildlife. Finally, I highlight important research needs to uncover how SWD may affect forest ecosystems.

In Chapter 2, I investigate how SWD distribution and abundance are influenced by forest composition, with respect to dominance by black cherry (Prunus serotina), a highly parasitized host, and local fruit resources in a forested ecosystem. From July to October 2019 and 2020 I trapped SWD in 21 regenerating timber harvests and surrounding forest canopies, representing 2 different cover types, and I collected Allegheny blackberry (Rubus allegheniensis) fruit samples in those regenerating timber harvests to observe for emergence of SWD. Relative abundance of SWD in regenerating timber harvests and surrounding forest canopy correlated to host resources at the local (i.e., sampling point) level but not the adjacent cover type. Parasitism of $R$.

allegheniensis fruits positively correlated with local $R$ allegheniensis fruits and basal area of $P$. serotina in adjacent mature forest. The results of this study provide the first evidence for the importance of local resources over those in an adjacent cover type or surrounding forest for predicting SWD trap captures, and the importance of local fruit resources and host plant density in adjacent cover type for SWD fruit parasitism in invaded forest ecosystems. I suggest these relationships can help predict the timing and abundance of SWD in both natural and semi-natural 
systems where wild fruiting plants are abundant, providing valuable information for monitoring and management planning.

In Chapter 3, I identify factors, primarily those related to SWD abundance and fruit parasitism, influencing frugivorous and non-frugivorous bird relative abundance and species richness in regenerating timber harvests invaded by SWD during the post-breeding season and fall migration. From July to September 2019 and 2020 I sampled bird communities using mist net captures in 21 regenerating timber harvests, and I trapped SWD and sampled $R$. allegheniensis fruits for SWD parasitism at each mist net. One species, eastern towhee (Pipilo erythrophthalmus), correlated negatively with SWD trap captures. Two species, hooded warbler (Setophaga citrina) and ovenbird (Seiurus aurocapilla), correlated negatively and positively to parasitism of fruits, respectively. Post-breeding and migratory bird relative abundances were otherwise unrelated to SWD variables in regenerating harvests. Frugivorous birds either did not alter fruit consumption in response to SWD, or birds' abilities to alter diet and foraging behavior masked relationships to SWD. Eastern towhee likely perceived fruits covered with flies as less desirable for consumption or may have been deterred by SWD swarms. Ovenbirds and hooded warblers altered their fruit consumption based on their responses to parasitism in modeling results. Alternatively, SWD activity may have affected arthropod communities, shifting composition and affecting some birds via trophic cascading effects. I highlight the importance of investigating arthropod community responses and the actual consumption of fruit resources in habitats invaded by SWD as critical next steps to understanding the ecological effects of SWD.

In Chapter 4, I evaluate how factors, primarily those related to SWD abundance and fruit parasitism, relate to body condition of several bird species, and probability of fruit consumption by frugivorous birds in regenerating timber harvests invaded by SWD during the post-breeding season and fall migration. From July to September 2019 and 2020 I gathered data on body condition indices - subcutaneous fat, feather molt progression, and scaled mass index (SMI) and collected fecal samples for evidence of fruit consumption for individuals of several bird species captured using mist nets in 21 regenerating timber harvests. I also trapped SWD and sampled $R$. allegheniensis fruits for SWD parasitism at each mist net. Multiple condition indices for several species correlated with relative abundance of SWD and parasitism of fruits, though the directions of relationships varied and were species-specific. Probability of $R$. allegheniensis fruit consumption by frugivorous birds correlated positively with parasitism of fruits at both the guild and species level. Frugivorous birds were more likely to consume parasitized fruits, and one species, gray catbird, experienced changes to nutritional intake and subsequent condition as a result. Fruit parasitism and greater abundances of adult SWD may have altered arthropod communities, altering composition and changing an additional food resource for both nonfrugivorous and frugivorous birds. Most species improved condition indices as the season progressed, likely due to dietary flexibility. I list several critical avenues for research to better understand the relationships observed in this study: 1) how bird condition changes in relation to foraging microhabitat selection and SWD, 2) selection or rejection of SWD-parasitized fruits by frugivores related to nutritional metrics, and 3) arthropod community responses to SWD. 


\section{ACKNOWLEDGMENTS}

I wish to extend all the gratitude in the world to each of my committee members. I thank my advisor, Dr. Christopher Lituma, for his unwavering guidance and support every step of my academic life at WVU. I learned so much about science, research, and mentorship as a member of his lab, and I am beyond grateful to have had such a positive relationship with him.

I thank Dr. Christopher Rota for putting me through the statistical ringer and challenging me to think critically about the science in this thesis, strengthening my understanding of the scientific process. Without his patience and generosity, I would not have succeeded in half of what I accomplished. I thank William Oldland for offering logistical guidance and serving as an advocate at the U.S. Forest Service (USFS). He was an integral part of emphasizing the importance of this research and was invaluable in reminding me of this importance each step of the way. Finally, I thank Dr. Scott Stoleson for being a constant resource of knowledge, for being an integral part of project planning and data collection, for keeping the field crew's mood up and light with his endless repository of field research stories and trivia, for putting up with my incessant drive to collect data in the field, and so much more. I cannot express how much his advocacy, guidance, and friendship has meant to me. I thank the U.S. Department of Agriculture's National Institute of Food and Agriculture and Forest Service and West Virginia University for funding that supported this project. I thank the Allegheny Forest Health Cooperative (including Kane Hardwood), Pennsylvania's Department of Conservation and Natural Resources (DCNR), and the Pennsylvania Game Commission for offers of logistical support, including access to field sites necessary for the completion of this project. Thank you to Lee Swoger with DCNR in particular for expressing an interest and advocating for this project. 
I also thank Dr. Rick Turcotte and Andrea Hille with USFS and Timothy Tomon with DCNR for logistical support, guidance, and advocacy within the USFS and DCNR since the inception of this project. I also thank members of the USFS Northern Research Station office in Irvine, Pennsylvania, for welcoming me and all my smelly fly traps into their lab, especially Dr. Todd Ristau, who always showed an interest in this project and investment in ensuring my crew and I had everything we needed to succeed. I extend a tremendous amount of gratitude to my technicians, Kim Geissler and Chelsea Beck, and Forest Service technicians, Eduardo Rosales and Joe Elias, for their endless hard work, dedication, and toleration of my field season craziness, without which this project would not have succeeded. I also thank undergraduate lab assistants, Peyton Caylor, Brandi Jett, and Julia Burkheimer, for spending countless hours at the microscope identifying flies and collecting data integral to the findings of this project. I extend that same thank you to the dozens of volunteers from northwestern Pennsylvania for offering up their own time to help with early-morning bird banding, especially Don Watts, who went the extra mile to sacrifice his own body cutting through massive Rubus brambles and still brought coffee and donuts for the most grateful field crew in the world. I also thank my fellow graduate students in the Lituma lab, Lincoln Oliver, Laura Graham, and Alex Clark, for lending their ears, their advice, and their friendship anytime I needed it. And I extend that same thank you to my close friends in the Rota lab, Stephanie Augustine and Hannah Clipp, who offered help and friendship anytime I needed it. Finally, I cannot thank my partner, Lindsay Forrette, enough for being my biggest supporter, advocate, friend, and so much more since my first day at WVU. And that same thanks I express for my family, for always being there for me and cheering me on every step of the way. I could not have succeeded without all their support every step of the way. To everyone, thank you! 


\section{TABLE OF CONTENTS}

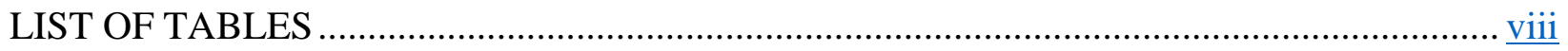

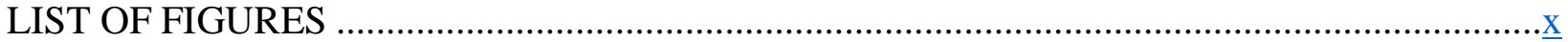

CHAPTER 1. INVASION OF EASTERN DECIDUOUS FORESTS BY THE SPOTTED

WING DROSOPHILA: IMPACTS AND KNOWLEDGE GAPS .......................................1

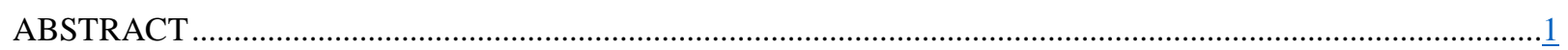

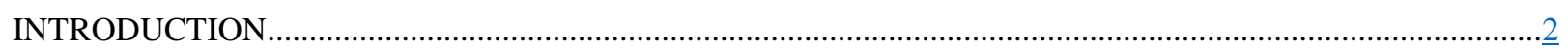

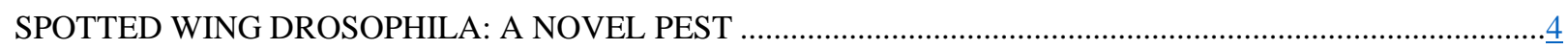

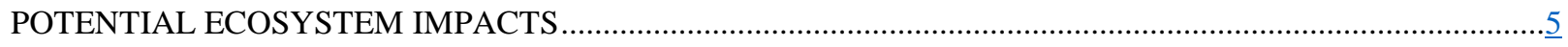

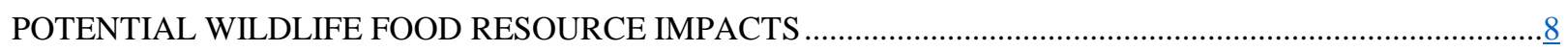

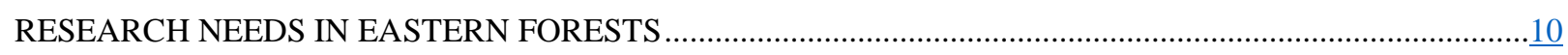

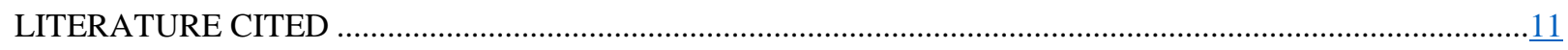

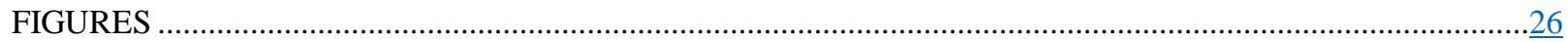

CHAPTER 2. HOST SPECIES LOCALLY AND IN SURROUNDING HABITAT

DIFFERENTIALLY INFLUENCE THE RELATIVE ABUNDANCE OF SPOTTED

WING DROSOPHILA AND FRUIT PARASITISM ACROSS THE ALLEGHENY

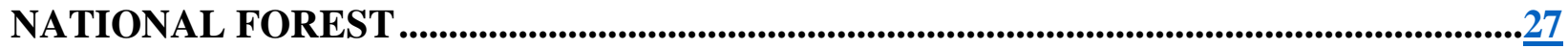

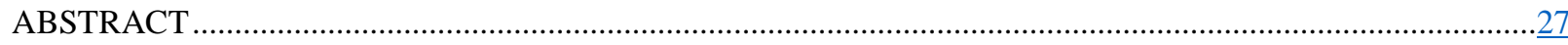

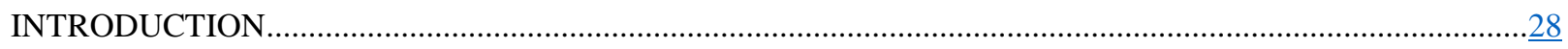

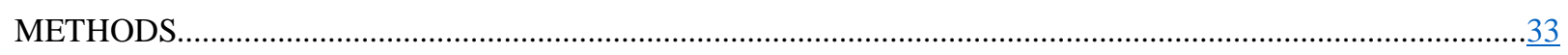

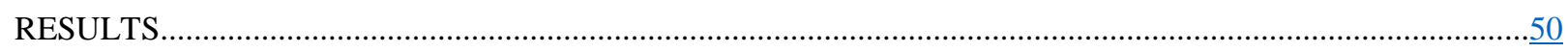

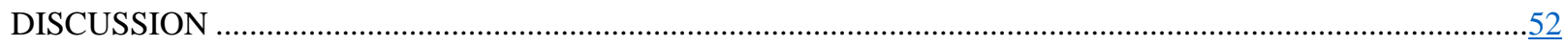

MANAGEMENT IMPLICATIONS ……………...............................................................................61

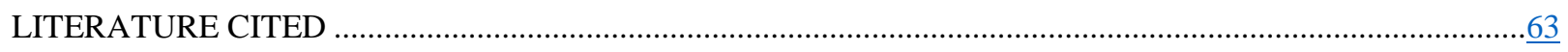

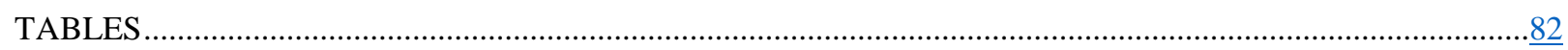

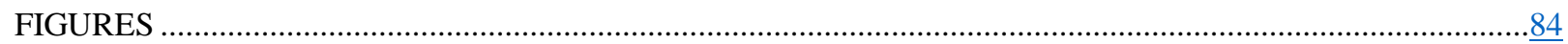

CHAPTER 3. RESPONSE OF FOREST BIRD ABUNDANCE AND SPECIES RICHNESS

TO SPOTTED WING DROSOPHILA AT ALLEGHENY NATIONAL FOREST .............92

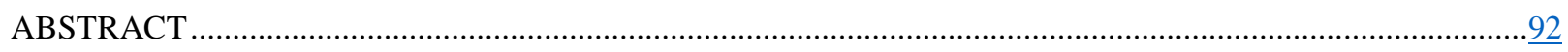

INTRODUCTION

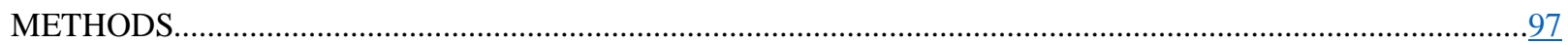

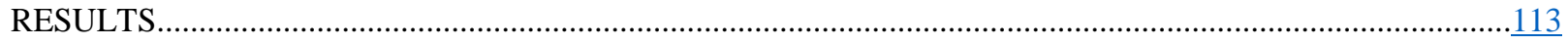

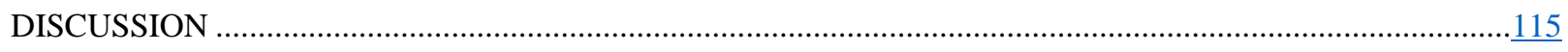

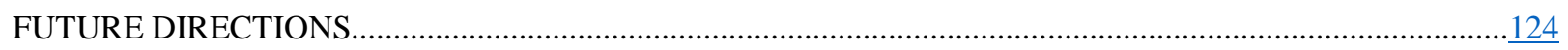




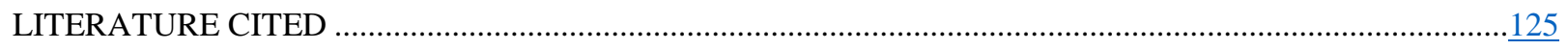

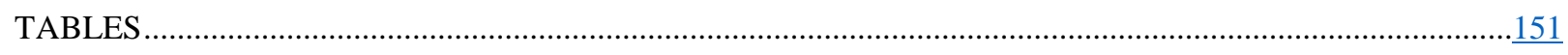

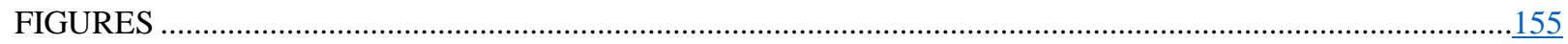

CHAPTER 4. DIFFERENCES IN FOREST BIRD BODY CONDITION AND FRUIT CONSUMPTION IN RELATION TO SPOTTED WING DROSOPHILA ABUNDANCE AND FRUIT PARASITISM AT ALLEGHENY NATIONAL FOREST ................................161

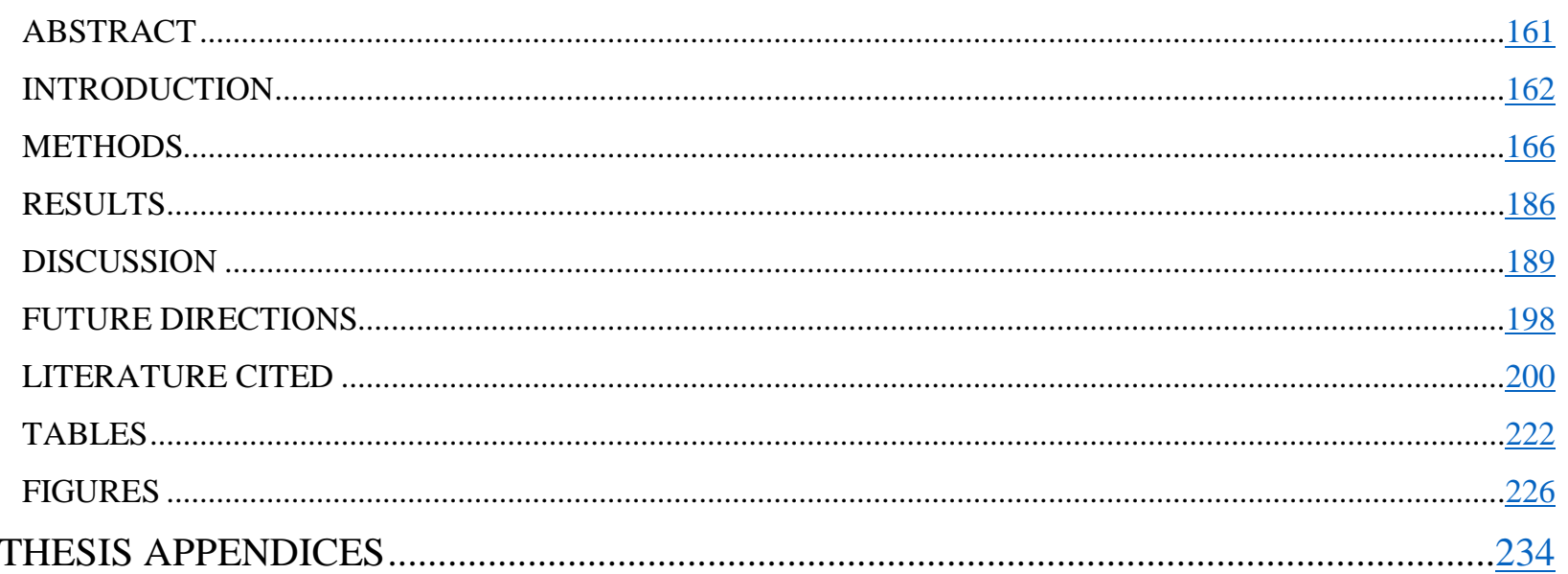




\section{LIST OF TABLES}

\section{Chapter 1}

None

\section{Chapter 2}

Table 2.1. Final covariates used to model relative abundance of spotted wing Drosophila (Drosophila suzukii, SWD) in mature forest and regenerating harvests during the summer and fall (Jul-Oct) at Allegheny National Forest (ANF), Clear Creek State Forest (CCSF), and State Game Lands (SGL) 86, Pennsylvania, in 2019 and 2020. Multiple measures were pooled for a single value of each covariate at each point and checked for collinearity $(r \geq 0.7)$. Covariates were included in the following models: 1) relative abundance of SWD at regenerating harvest points ("harvest"), 2) relative abundance of SWD at mature forest points ("forest"), and 3) relative abundance emerged from Allegheny blackberry (Rubus allegheniensis) fruit samples from regenerating harvest points ("infest"). Covariates were then excluded from final models using a stepwise removal process.

Table 2.2. Final regression models for relative abundance of spotted wing Drosophila (Drosphila suzukii, SWD) during the summer and fall (Jul-Oct) in regenerating timber harvests ("harvest"), mature forest ("forest"), and Allegheny blackberry (Rubus allegheniensis) fruit samples ("infest") at Allegheny National Forest (ANF), Clear Creek State Forest (CCSF), and State Game Lands (SGL) 86, Pennsylvania, in 2019 and 2020. Each final model was created with a stepwise removal process of covariates from global models containing 10 initial covariates for the "harvest" and "infest" models and 9 covariates for the "forest" model. Posterior estimates and $90 \%$ credible intervals (CIs) are given for each covariate's slope coefficient. Contrast is the difference in posterior estimate between Allegheny (Allegh) and mixed upland (Mixed) forest types $\left(\beta_{\text {Allegh }}-\beta_{\text {Mixed }}\right)$.

\section{Chapter 3}

Table 3.1. Final covariates used to model bird captures at mist nets in regenerating harvests during the post-breeding season and fall migration (Jul-Sep) at Allegheny National Forest (ANF), Clear Creek State Forest (CCSF), and State Game Lands (SGL) 86, Pennsylvania, in 2019 and 2020. Multiple measures were pooled for a single value of each covariate at each mist net and checked for collinearity $(r \geq 0.7)$. All covariates were included in a global model for each bird variable, which were then excluded from final models using a stepwise removal process. 151

Table 3.2. Captures and dietary guild identity of focal bird species captured in regenerating harvests at Allegheny National Forest (ANF), Clear Creek State Forest (CCSF), and State Game Lands (SGL) 86, Pennsylvania, during the post-breeding season and fall migration (Jul-Sep) in 2019 and 2020. Sampling periods 1 and 2 correspond approximately to the post-breeding and migration periods, respectively.

Table 3.3. Summary of covariate data collected at mist nets in regenerating harvests during the post-breeding season and fall migration (Jul-Sep) at Allegheny National Forest (ANF), Clear Creek State Forest (CCSF), and State Game Lands (SGL) 86, Pennsylvania, in 2019 and 2020. Data are separated into sampling period 1 (18 Jul-22 Aug 2019 and 20 Jul-25 Aug 2020), 
sampling period 2 (24 Aug-25 Sep 2019 and 27 Aug-25 Sep 2020), and both sampling periods combined. If values at each mist net did not differ from sampling period 1 to 2 , values are only reported for period 1 .

Table 3.4. Final regression models for bird captures by species and guild during the postbreeding season and fall migration (Jul-Sep) in regenerating harvests at Allegheny National Forest (ANF), Clear Creek State Forest (CCSF), and State Game Lands (SGL) 86, Pennsylvania, in 2019 and 2020. Each final model was created with a stepwise removal process of covariates from a global model containing all 9 covariates. Posterior estimates and $90 \%$ credible intervals (CIs) are given for each covariate's slope coefficient.

\section{Chapter 4}

Table 4.1. Sample sizes of species for each condition index (subcutaneous fat ["fat"], body molt progression ["molt"], and scaled mass index ["SMI"]) captured in regenerating harvests at Allegheny National Forest (ANF), Clear Creek State Forest (CCSF), and State Game Lands (SGL) 86, Pennsylvania, during the post-breeding season and fall migration (Jul-Sep) in 2019 and 2020. The morphological measurement most strongly correlated on the log-log scale with body mass and used in scaled major axis (SMA) regression is specified. The coefficient of determination $\left(R^{2}\right)$ for the SMA regression using the morphological measurement and body mass is also specified. The SMA regression slope was used to calculate SMI values for individual birds.

Table 4.2. Final covariates used to model bird condition indices (subcutaneous fat ["fat"], body molt progression ["molt"], and scaled mass index ["SMI"]) and proportions of frugivore fecal samples containing evidence of Allegheny blackberry (Rubus allegheniensis) fruit consumption ("fecal") at mist nets in regenerating harvests during the post-breeding season and fall migration (Jul-Sep) at Allegheny National Forest (ANF), Clear Creek State Forest (CCSF), and State Game Lands (SGL) 86, Pennsylvania, in 2019 and 2020. Multiple measures were pooled for a single value of each covariate at each mist net and checked for collinearity $(r \geq 0.7)$. All covariates were included in a global model for each bird variable, which were then excluded from final models using a stepwise removal process.

Table 4.3. Final regression models for bird condition indices (subcutaneous fat ["fat"], body molt score ["molt"], scaled mass index ["SMI"]) and proportions of frugivore fecal samples containing evidence of Allegheny blackberry (Rubus allegheniensis) fruit consumption ("fecal") at mist nets during the post-breeding season and fall migration (Jul-Sep) in regenerating harvests at Allegheny National Forest (ANF), Clear Creek State Forest (CCSF), and State Game Lands (SGL) 86, Pennsylvania, in 2019 and 2020. Each final model was created with a stepwise removal process of covariates from global models containing 5 (condition indices) or 3 (fecal) initial covariates. If no covariates were retained for a species, no model is presented. Posterior estimates and 90\% credible intervals (CIs) are given for each covariate's slope coefficient......224 


\section{LIST OF FIGURES}

\section{Chapter 1}

Figure 1.1. Potential ecological interactions and trophic consequences of fruit parasitism by spotted wing Drosophila (SWD) in eastern forests of North America. Arrows indicate directions of interactions and signs indicate negative consequences of the effect. Loss of fruit to SWD will reduce fruit available for vertebrate frugivores, thereby disrupting seed dispersal, and ultimately reduce plant diversity and impede ecosystem function and resilience.

\section{Chapter 2}

Figure 2.1. Study area used for surveys of spotted wing Drosophila (Drosophila suzukii) during the summer and fall in Pennsylvania in 2019 and 2020. Twenty-one sites were surveyed across Allegheny National Forest (ANF), Clear Creek State Forest (CCSF) due south, and State Game Lands (SGL) 86 west of the ANF along the Allegheny River in northwestern Pennsylvania. ...... 84

Figure 2.2. Example placement of sampling points used for sampling spotted wing Drosophila (Drosophila suzukii) in mature forest and regenerating timber harvests during the summer and fall at Allegheny National Forest (ANF), Clear Creek State Forest (CCSF), and State Game Lands (SGL) 86, Pennsylvania, in 2019 and 2020.

Figure 2.3. Trap design used to sample for spotted wing Drosophila (Drosophila suzukii) in regenerating harvests and mature forest at Allegheny National Forest (ANF), Clear Creek State Forest (CCSF), and State Game Lands (SGL) 86, Pennsylvania, in 2019 and 2020..................86

Figure 2.4. Transect survey design used to place spotted wing Drosophila (Drosophila suzukii, SWD) traps and count fruit resources at sampling points in regenerating harvests at Allegheny National Forest (ANF), Clear Creek State Forest (CCSF), and State Game Lands (SGL) 86, Pennsylvania, in 2019 and 2020. The side of the central transect each fruit transect was placed and the side of the transect each SWD trap was placed were randomly chosen.

Figure 2.5. Comparison of captures/trap/day of spotted wing Drosophila (Drosophila suzukii, SWD) in A) regenerating timber harvests and B) mature forest canopy of different forest typesAllegheny, mixed upland, and oak - at Allegheny National Forest (ANF), Clear Creek State Forest (CCSF), and State Game Lands (SGL) 86, Pennsylvania, in 2019 and 2020.................. 88

Figure 2.6. Relationship of relative abundance of spotted wing Drosophila (Drosophila suzukii, SWD) in regenerating timber harvests ("harvest" model) to A) relative abundance of ripening and ripe Allegheny blackberry ( $R$. allegheniensis) fruits, B) trap captures of SWD at paired mature forest points, $\mathrm{C}$ ) proportion of ripening and ripe $R$. allegheniensis fruits, and D) ordinal date (including $90 \%$ credible intervals) during summer and fall (Jul-Oct) at Allegheny National Forest (ANF), Clear Creek State Forest (CCSF), and State Game Lands (SGL) 86, Pennsylvania, in 2019 and 2020.

Figure 2.7. Relationship of relative abundance of spotted wing Drosophila (Drosophila suzukii, SWD) in mature forest ("forest" model) to A) black cherry (Prunus serotina) basal area/quarter of each 50-m radius plot, B) trap captures of SWD at paired regenerating timber harvest points, 
and C) ordinal date (including 90\% credible intervals) during summer and fall (Jul-Oct) at Allegheny National Forest (ANF), Clear Creek State Forest (CCSF), and State Game Lands (SGL) 86, Pennsylvania, in 2019 and 2020.

Figure 2.8. Relationship of relative abundance of spotted wing Drosophila (Drosophila suzukii, SWD) emerged from Allegheny blackberry (Rubus allegheniensis) fruit samples from regenerating timber harvests ("infest" model) to A) relative abundance of ripening and ripe $R$. allegheniensis fruits, B) black cherry (Prunus serotina) basal area/quarter of each 50-m radius plot at paired mature forest points, C) forest type, and D) ordinal date (including $90 \%$ credible intervals) during summer and fall (Jul-Oct) at Allegheny National Forest (ANF), Clear Creek State Forest (CCSF), and State Game Lands (SGL) 86, Pennsylvania, in 2019 and 2020. Relative abundances in fruit samples were separated by forest type, because forest type was retained in the final regression model for SWD emerged from fruit.

\section{Chapter 3}

Figure 3.1. Study area used for surveys of forest bird communities and spotted wing Drosophila (Drosophila suzukii) during the post-breeding season and fall in Pennsylvania in 2019 and 2020. Twenty-one sites were surveyed across Allegheny National Forest (ANF), Clear Creek State Forest (CCSF) due south, and State Game Lands (SGL) 86 west of the ANF along the Allegheny River in northwestern Pennsylvania.

Figure 3.2. Example placement of mist nets used for sampling forest bird communities in regenerating harvests during the post-breeding season and fall migration at Allegheny National Forest (ANF), Clear Creek State Forest (CCSF), and State Game Lands (SGL) 86, Pennsylvania, in 2019 and 2020.

Figure 3.3. Transect survey design used to place spotted wing Drosophila (Drosophila suzukii, SWD) traps, count fruit resources, and measure vegetation structure at mist nets in regenerating harvests at Allegheny National Forest (ANF), Clear Creek State Forest (CCSF), and State Game Lands (SGL) 86, Pennsylvania, in 2019 and 2020. The side of the mist net each transect was placed and the side of the transect each SWD trap was placed were randomly chosen.

Figure 3.4. Trap design used to sample for spotted wing Drosophila (Drosophila suzukii) at mist nets during the post-breeding season and fall migration in regenerating harvests at Allegheny National Forest (ANF), Clear Creek State Forest (CCSF), and State Game Lands (SGL) 86, Pennsylvania, in 2019 and 2020.

Figure 3.5. Relationship of trap captures of spotted wing Drosophila (Drosophila suzukii, SWD) with relative abundance of A) all frugivores and B) eastern towhee (including $90 \%$ credible intervals) per mist net in regenerating harvests during the post-breeding season and fall migration (Jul-Sep) at Allegheny National Forest (ANF), Clear Creek State Forest (CCSF), and State Game Lands (SGL) 86, Pennsylvania, in 2019 and 2020.

Figure 3.6. Relationship of infestation rates (counts of spotted wing Drosophila [Drosophila suzukii]/g) of Allegheny blackberry (Rubus allegheniensis) fruits with relative abundance of A) ovenbird and B) hooded warbler (including $90 \%$ credible intervals) per mist net in regenerating 
harvests during the post-breeding season and fall migration (Jul-Sep) and fall migration at Allegheny National Forest (ANF), Clear Creek State Forest (CCSF), and State Game Lands (SGL) 86, Pennsylvania, in 2019 and 2020.

\section{Chapter 4}

Figure 4.1. Study area used for sampling forest bird body condition and fruit consumption and spotted wing Drosophila (Drosophila suzukii) during the post-breeding season and fall in Pennsylvania in 2019 and 2020. Twenty-one sites were used across Allegheny National Forest (ANF), Clear Creek State Forest (CCSF) due south, and State Game Lands (SGL) 86 west of the ANF along the Allegheny River in northwestern Pennsylvania..

Figure 4.2. Example placement of mist nets used for sampling forest birds in regenerating timber harvests during the post-breeding season and fall migration at Allegheny National Forest (ANF), Clear Creek State Forest (CCSF), and State Game Lands (SGL) 86, Pennsylvania, in 2019 and 2020 .

Figure 4.3. Transect survey design used to place spotted wing Drosophila (Drosophila suzukii, SWD) traps, count fruit resources, and measure vegetation structure at mist nets in regenerating timber harvests at Allegheny National Forest (ANF), Clear Creek State Forest (CCSF), and State Game Lands (SGL) 86, Pennsylvania, in 2019 and 2020. The side of the mist net each transect was placed and the side of the transect each SWD trap was placed were randomly chosen.......228

Figure 4.4. Trap design used to sample for spotted wing Drosophila (Drosophila suzukii) at mist nets during the post-breeding season and fall migration in regenerating timber harvests at Allegheny National Forest (ANF), Clear Creek State Forest (CCSF), and State Game Lands (SGL) 86, Pennsylvania, in 2019 and 2020.

Figure 4.5. Bayesian posterior estimates for relationships between probability of the presence of subcutaneous fat and A) infestation rate of Allegheny blackberry (Rubus allegheniensis) fruits by spotted wing Drosophila (Drosophila suzukii, SWD), B) SWD trap captures, C) $R$. allegheniensis fruit counts, D) coefficient of variation for vertical vegetation cover, and E) ordinal date (including $90 \%$ credible intervals) for focal frugivorous and non-frugivorous bird species in regenerating harvests during the post-breeding season and fall migration (Jul-Sep) at Allegheny National Forest (ANF), Clear Creek State Forest (CCSF), and State Game Lands (SGL) 86, Pennsylvania, in 2019 and 2020. Vertical lines are fixed at 0 to represent lack of a relationship. Species for which a covariate was dropped during stepwise regression are fixed at 0 on that covariate plot. Species for which fat was not modeled are present on the plot but have no point estimate.

Figure 4.6. Bayesian posterior estimates for relationships between probability of being in later stages of molt progression and A) infestation rate of Allegheny blackberry (Rubus allegheniensis) fruits by spotted wing Drosophila (Drosophila suzukii, SWD), B) SWD trap captures, C) $R$. allegheniensis fruit counts, D) coefficient of variation for vertical vegetation cover, and E) ordinal date (including 90\% credible intervals) for focal frugivorous bird species, non-frugivorous bird species, and all focal non-frugivorous wood warblers pooled in regenerating harvests during the post-breeding season and fall migration (Jul-Sep) at Allegheny 
National Forest (ANF), Clear Creek State Forest (CCSF), and State Game Lands (SGL) 86, Pennsylvania, in 2019 and 2020. Vertical lines are fixed at 0 to represent lack of a relationship. Species for which a covariate was dropped during stepwise regression are fixed at 0 on that covariate plot. Species for which molt was not modeled are present on the plot but have no point estimate.

Figure 4.7. Bayesian posterior estimates for relationships between scaled mass index and A) infestation rate of Allegheny blackberry (Rubus allegheniensis) fruits by spotted wing Drosophila (Drosophila suzukii, SWD), B) SWD trap captures, C) $R$. allegheniensis fruit counts, D) coefficient of variation for vertical vegetation cover, and E) ordinal date (including $90 \%$ credible intervals) for focal frugivorous and non-frugivorous bird species in regenerating harvests during the post-breeding season and fall migration (Jul-Sep) at Allegheny National Forest (ANF), Clear Creek State Forest (CCSF), and State Game Lands (SGL) 86, Pennsylvania, in 2019 and 2020. Vertical lines are fixed at 0 to represent lack of a relationship. Species for which a covariate was dropped during stepwise regression are fixed at 0 on that covariate plot.

Figure 4.8. Relationship between infestation rates of Allegheny blackberry (Rubus allegheniensis) fruits (spotted wing Drosophila [Drosophila suzukii, SWD]/g of fruit) and probability a fecal sample from A) a frugivore, B) a cedar waxwing, C) an eastern towhee, or D) a gray catbird contained $R$. allegheniensis (including $90 \%$ credible intervals) at each mist net in regenerating harvests during the post-breeding season (Jul-Sep) and fall migration at Allegheny National Forest (ANF), Clear Creek State Forest (CCSF), and State Game Lands (SGL) 86, Pennsylvania, in 2019 and 2020. 
This is the pre-peer reviewed version of the following article:

Roche, D. P., S. H. Stoleson, and C. M. Lituma. 2021. Invasion of eastern deciduous forests by the spotted wing Drosophila: impacts and knowledge gaps. Wildlife Society Bulletin: 10.1002/wsb.1234.

It is available online under the following DOI: $10.1002 / \mathrm{wsb} .1234$. This article may be used for non-commercial purposes in accordance with Wiley Terms and Conditions for Use of SelfArchived Versions."

\section{CHAPTER 1. Invasion of eastern deciduous forests by the spotted wing Drosophila:} impacts and knowledge gaps

\section{ABSTRACT}

Invasion of forest ecosystems by non-native invasive insect pests (NNIIPs) can alter native animal and plant communities by disrupting species interactions. However, little is known about how fruit-targeting NNIIPs may alter forest ecosystems. Recently introduced to the western United States, spotted wing Drosophila (Drosophila suzukii, SWD) is a parasite of soft-skinned fruits. Its ability to parasitize still-ripening fruits of many plant species led to its rapid expansion in agricultural systems across North America. Recent surveys have documented widespread parasitizing of wild fruits in forests, although its impacts remain unexplored. We explore how this fruit-targeting NNIIP may produce ecological changes to eastern forests through disruption of plant-animal seed dispersal interactions and subsequent alterations to plant community composition, and changes in fruit consumption by wildlife. Parasitism of fruits by SWD produces morphological changes to fruit and opens fruit to infection by pathogens. Insect parasites often reduce attractiveness of fruits to wildlife by producing similar alterations, reducing overall consumption. Reduced consumption and subsequent changes in seed dispersal may shift future plant communities away from fruit-producing species. Invasion by SWD may therefore have both short-term and long-term consequences for food resources for wildlife and ecosystem function. We highlight frugivorous birds because of their importance as consumers and dispersers of fruits in eastern North America and their well-documented rejection of 
parasitized fruits. We propose several critical avenues of research and call for a large-scale collaborative effort to understand the complex relationship SWD may play with plants and wildlife in forest ecosystems.

Keywords: Drosophila suzukii, frugivorous birds, fruit parasitism, fruit selection, invasive species, plant community composition, seed dispersal, species interactions, spotted wing Drosophila, trophic impacts.

\section{INTRODUCTION}

Biological invasions can alter or interfere with interactions among species. Specifically, nonnative invasive insect pests (NNIIPs) in eastern North American forests can dramatically alter plant and animal communities. Gypsy moths (Lymantria dispar) defoliate oak (Quercus spp.), increasing tree mortality by $20-40 \%$ in the Appalachian Plateau (Fajvan and Wood 1996), reducing species richness (greater than $60 \%$ under severe defoliation) and survival of native butterflies associated with killed trees (Redman and Scriber 2000, Work and McCullough 2000), and increasing densities of disturbance-associated songbirds (i.e., 500\% increase in eastern towhee [Pipilo erythrophthalmus]) and predators of gypsy moth larvae (Bell and Whitmore 1997, Gale et al. 2001, Showalter and Whitmore 2002, Barber et al. 2008). Gypsy moth defoliation also causes shifts in plant community composition to subdominant species (e.g., red maple [Acer rubrum], sugar maple [A. saccharum]) due to oak mortality (Fajvan and Wood 1996, Morin and Liebhold 2016).

Sap-sucking by hemlock woolly adelgid (Adelges tsugae) kills eastern hemlock (Tsuga canadenisis) throughout the eastern United States, decreasing density of live hemlock trees by more than $80 \%$ and basal area by $75 \%$ in New England forests, changing the forest canopy composition to hardwood species (e.g., black oak [Quercus velutina], red maple, birch [Betula 
spp.]), and increasing understory vegetation cover (7,000\% increase in sapling density, 25\% increase in herbaceous species frequency; Small et al. 2005). Such changes have induced decreases in density of redback salamander (Plethodon cinereus; 50\%) and abundances of blackthroated green warbler (Setophaga virens; 93\%), hermit thrush (Catharus guttatus; 34\%), and Acadian flycatcher (Empidonax virescens; 70\%; Brooks 2001, Tingley et al. 2002, Allen et al. 2009). Declines in eastern hemlock caused by hemlock wooly adelgid can also alter forest succession favoring beech (Fagus grandifolia) and maple (Morin and Liebhold 2015).

Emerald ash borer (Agrilus planipennis) larvae cause widespread mortality of ash trees (Fraxinus spp.) in the eastern United States, killing more than 99\% in some Michigan forests (Klooster et al. 2014) and shifting the community composition of ash forests towards oak and maple dominance (Herms and McCullough 2014, Klooster et al. 2018). Abundant emerald ash borer larvae provide food resources to support elevated avian predator abundances (30\% increase in red-bellied woodpecker [Melanerpes carolinus] and 40\% increase in white-breasted nuthatch [Sitta carolinensis]; Koenig et al. 2013), but heavy mortality of ash trees threatens as many as 282 native and exotic ash-associated arthropod species (Gandhi and Herms 2010).

Balsam woolly adelgid (Adelges piceae) targets native fir (Picea spp.) trees for sapsucking, killing as many as 50\% in Appalachian forests and causing several forest canopyassociated bird species (e.g., golden-crowned kinglet [Regulus satrapa], blue-headed vireo [Vireo solitarius], and black-capped chickadee [Poecile atricapillus]) to decline in density by more than 50\% (Rabenold et al. 1998). While dramatic alterations to forest ecosystems by wood, sap-, and vegetation-consuming NNIIPs are well-documented in the literature, impacts of seed-, nut-, or fruit-targeting NNIIPs on forest plant and wildlife communities remain poorly known 
(Kenis et al. 2017).

\section{SPOTTED WING DROSOPHILA: A NOVEL PEST}

The non-native invasive spotted wing Drosophila (Drosophila suzukii, SWD) is native to east Asia, but over the past decade, inadvertent introductions have resulted in it becoming a significant global pest of many cultivated fruiting species, including berries (Vaccinium spp., Rubus spp.), grapes (Vitis spp.), and stone fruits (Prunus spp.; Lee et al. 2011, Walsh et al. 2011, Bellamy et al. 2013). In North America, SWD was first detected in 2008 in commercial fruit crops in California. It has since spread rapidly across the continent, apparently facilitated via shipped fruit (Rota-Stabelli et al. 2013), reaching Florida on the east coast by 2009, Michigan by 2010, and most northeastern states by 2011 (Hauser 2011). Similar rapid expansions of SWD have occurred in both Europe and South America at about the same time (Calabria et al. 2012, Cini et al. 2012, Deprá et al. 2014).

Unlike other fruit flies that feed on overripe or decaying fruit or other organic matter, female SWD have a hardened, serrated ovipositor that enables them to pierce the skin of ripening fruits to deposit eggs (Atallah et al. 2014). Emerging larvae destroy the fruit by consuming the flesh as they develop; further loss often results from secondary pathogens that infect the fruit through oviposition incisions or premature fruit drop (Walsh et al. 2011). The females' preference for ripening fruit (Lee et al. 2011), coupled with its capacity for exponential population growth (Lee et al. 2011, Walsh et al. 2011, Kinjo et al. 2014, Tochen et al. 2014), makes it capable of enormous damage to commercial fruit crops.

In the United States, estimates of annual revenue losses from SWD-damaged fruit crops now exceed approximately $\$ 500$ million in the Pacific Northwest and \$200 million in the Northeast, in addition to expenses for intensified monitoring and pesticide treatments (Bolda et 
al. 2010, Goodhue et al. 2011, Burrack 2013, Farnsworth et al. 2017). Overall, losses in commercial fruit crop yield have initially ranged from estimates of negligible to $80 \%$ in the United States alone (Walsh et al. 2011), and recent surveys of berry growers estimate average national crop losses to SWD in 2014 from 6\% in strawberries to $41 \%$ in raspberries (Burrack 2015). Losses in the eastern United States in cultivated blueberries and caneberries (Rubus spp.) ranged $0-30 \%$ and $10-80 \%$, respectively (Burrack 2013). These early reports suggest a significant, widespread impact by SWD on fruit production in United States agricultural systems.

Many agricultural systems in the eastern United States occur in forested landscapes that might exacerbate or facilitate these yield losses. Greater forest cover and closer proximity increase activity of a variety of insect pests in agricultural fields (With 2002, Gardiner et al. 2009, Venugopal et al. 2014, Rice et al. 2017), including SWD. Abundance of SWD in agricultural land increased in blueberry orchards that were surrounded by more forest cover (Schmidt et al. 2019). Plant community composition in surrounding forests can promote the spread and increase abundance of SWD populations in agricultural landscapes by providing alternative food resources and acting as reservoirs for re-infestation (Klick et al. 2016). However, other than how forest cover affects infestations of nearby agricultural areas, data about the occurrence in or impacts of SWD in forested systems are lacking.

\section{POTENTIAL ECOSYSTEM IMPACTS}

In North America, SWD has been found in forests surrounding agricultural lands where it parasitizes the fruits of wild, non-crop plants (Walsh et al. 2011, Lee et al. 2015, Ballman and Drummond 2017). To date, more than 100 species worldwide have been identified as viable hosts for SWD, including many wild species (Lee and Sial 2016). In the United States, numerous native and non-native plants bearing soft-skinned fruits have been documented as hosts of SWD, 
including brambles (Rubus spp.), cherries (Prunus spp.), honeysuckles (Lonicera spp.),

blueberries and huckleberries (Vaccinium and Gaylussacia spp.), dogwoods (Cornus spp.), elderberries (Sambucus spp.), pokeweed (Phytolacca spp.), buckthorns (Rhamnus and Frangula spp.), and nightshades (Solanum spp.), among others (Lee et al. 2015; Ballman and Drummond 2017; W. K. Oldland and C. Larcenaire, Forest Service, personal communication). Damage to fruit crops in forests may have significant impacts for forest ecosystems.

Fruits are used by plants as an attractant to vertebrate seed dispersers, including many birds and mammals (Ridley 1930, Van der Pijl 1972, Herrera 1982, Sallabanks and Courtney 1992). Plants possess traits to effectively advertise fruits to these different dispersers. Many birddispersed fruits are bright and conspicuously colored (Willson and Thompson 1982). Primarily mammal-dispersed fruits are often scented, dull in color, and large (Snow 1971, but see Willson 1993). Bat-dispersed fruits grow away from plant foliage, allowing easy access for frugivorous bats (Van der Pijl 1957).

Because many plants rely on vertebrate dispersers to transport seeds to germination sites for recruitment, fruits provide a nutritional reward, incentivizing dispersers to consume fruits (Snow 1971, McKey 1975, Sallabanks and Courtney 1992). By directly targeting reproductive tissues of wild fruit-producing plants, frugivorous insects like SWD may inhibit plant seed dispersal in forests, though the effects of SWD larvae on fruit seed viability remain unknown. Insects can disrupt plant-disperser relationships by altering the attractiveness of fruits.

Insect pests can inhibit the maturation of fruit, stopping color change that vertebrate seed dispersers cue in on to select fruits for consumption (Jordano 1987, Krischik et al. 1989, Traveset 1993). Infestation of fruits by insect larvae can change other fruit traits, including the texture (Carter 1939), size, and shapes of fruits (Highland 1964). Attack of fruits by insect pests can also 
expose fruits to microbial or fungal infection, making them less palatable to potential dispersers (Manzur and Courtney 1984, Jordano 1987, Borowicz 1988, Traveset et al. 1995, García et al. 1999). Indeed, vertebrate consumption of fruits often decreases when fruits are infested by insect pests (Sallabanks and Courtney 1992, but see Redford et al. 1984). Janzen (1971) found that rodents reject moth-infested fruits of a legume tree (Cassia grandis), and Engriser (1995) found that phyllostomid bats select against fruits of a small shrub-tree (Acnistus arborescens) infested by insect larvae (Sturnia ludovici, Carollia brevicauda) in early successional habitats.

Frugivorous birds will discriminate against blueberries based on changes to fruit shape caused by moths (i.e., Lotisma trigonana) and sawflies (i.e., Melastola resincolor; Traveset et al. 1995). Similarly, blackbirds (Turdus merula) will reject insect-infested hawthorn (Crataegus monogyna) fruits based on color and palatability changes, resulting in failure to remove up to $15 \%$ of the healthy fruit crop (Manzur and Courtney 1984). Infestation of fruits is likely to be most detrimental for seed dispersal if important dispersers refuse to consume infested fruits. However, fruit parasitism by insects might produce no change to avian consumption (Piper 1986, Nalepa and Piper 1994). Valburg (1992a,b) even reported discrimination in favor of fruits infested with pulp-eating insects. Others have suggested parasitism makes fruit more attractive to avian frugivores (Webber and Woodrow 2004); that insect larvae within the fruit increase the palatability, levels of secondary compounds, or protein content of the fruit and make the fruit more rewarding (Piper 1986, Drew 1988). Despite these potential benefits of insect infestation on avian fruit consumption in some contexts, widely observed selection against infested fruits suggests a decrease in fruit resource consumption for at least some frugivorous birds in response to SWD infestation. Foraging birds will leave as much as $75 \%$ of insectinfested fruits on a plant (Burger 1987), which might mask and reduce the consumption of 
healthy fruits. Birds select plants for foraging based upon traits including fruit size and pulpiness (Sallabanks 1993), which might further explain the failure to remove all healthy fruits from plants with many infested fruits. Further, experimental reduction of fruit decreases the local abundance of frugivorous birds (Moegenburg and Levey 2003, Major and Desrochers 2012). Soft-fleshed fruits (soft mast) are clearly a critical resource for wildlife, and alterations to abundant fruit resources for consumption due to insect infestation could have negative consequences for wildlife.

Frugivorous birds play a critical role as seed dispersers for many fruiting plants (Thompson and Willson 1979; Snow and Snow 1988; García et al. 2010, 2011). They may disperse seeds of up to $40 \%$ of woody plant species in temperate forests (Jordano 2000, Herrera 2002). In eastern North America, birds serve as the primary seed dispersers for most plants bearing soft mast and can consume up to $80 \%$ of a standing fruit crop (Baird 1980, Willson 1986). Further, processing of fruit in the gizzard, stomach, or gut often increases the probability of subsequent seed germination (Traveset and Verdú 2002, Fricke et al. 2013). Seed deposition by birds can strongly influence patterns of plant regeneration and therefore plant community composition (Howe and Smallwood 1982, McDonnell and Stiles 1983, Caves et al. 2013). Over time, reductions in frugivorous birds due to SWD may lead to shifts in plant communities away from fruit-producing species, and ultimately to declines in ecosystem function (Farwig and Berens 2012) and resilience (Gunderson 2000, Folke et al. 2004).

\section{POTENTIAL WILDLIFE FOOD RESOURCE IMPACTS}

In eastern North America, soft mast provides a critical food resource for many wildlife species (Martin et al. 1961, McCarty et al. 2002), in particular many migratory birds and mammals such as American black bear (Ursus americanus) and fisher (Pekania pennanti; Willson 1986, Parrish 
1997, Inman and Pelton 2002, McNeil et al. 2017). The availability of soft mast can influence populations of different wildlife. Abundant soft mast increases American black bear productivity and survival (Rogers 1976, Eiler et al. 1989) and wild turkey (Meleagris gallopavo) harvests (e.g., Ryan et al. 2004). Many soft mass species ripen in the fall, providing a highly nutritious, valuable fruit resource to many vertebrates, including white-tailed deer (Odocoileus virginianus), white-footed mice (Peromyscus leucopus), game birds (e.g., wild turkey, ruffed grouse [Bonasa umbellus]), mesocarnivores (e.g., red fox [Vulpes vulpes], raccoon [Procyon lotor], squirrels [Family: Sciuridae]), and American black bears (Uchytil 1991, Ryan et al. 2004, Rose et al. 2014). Because many songbird species shift from a completely insectivorous diet during the breeding season to include substantial fruit post-breeding, in migration, and over winter (Fuentes 1994; Parrish 1997, 2000; Suthers et al. 2000), bird abundance varies with soft mast abundance in the post-breeding and migration periods (Baird 1980, Rodewald and Brittingham 2004, Gleditsch and Carlo 2011, Major and Desrochers 2012).

Potential reductions in fruit consumption due to SWD might be especially damaging to populations of frugivorous forest birds. Avian frugivore abundance and foraging behavior are positively correlated with fruit availability in many different regions: in tropical forests (Levey 1988, Loiselle and Blake 1991, Saracco et al. 2004), in temperate European forests (Plein et al. 2013), and in temperate North American forests (McCusker et al. 2010). Frugivorous birds will also respond directly to changes in abundance of fruit resources. Two frugivorous birds, Eurasian blackcap (Sylvia atricapilla) and song thrush (Turdus philomelos), respond to human harvesting of olive fruits in Spanish olive orchards by redistributing to unharvested patches (Rey 1995). In mature longleaf (Pinus palustris) and loblolly (Pinus taeda) pine stands in the southeastern United States, yellow-rumped warbler (Setophaga coronata) abundance increases when southern 
wax myrtle (Myrica cerifera) fruit increases during the winter (Borgmann et al. 2004). In temperate ecosystems, many bird species rely on nutrient- and energy-rich fruit resources as a valuable dietary component for at least part of the year (Thompson and Willson 1979, Howe and Smallwood 1982, Suthers et al. 2000, Major and Desrochers 2012). Consumption of soft mast fruits aids in building energy reserves (Snow 1971, Martin 1985, Parrish 1997, Schaub and Jenni 2000, but see Bairlein and Simons 1995). Without these vital fruit resources, frugivorous birds might fail to build and maintain sufficient energy stores, increasing mortality at certain times of year (Parrish 2000). Figure 1.1 demonstrates these potential ecological interactions and consequences of fruit parasitism by SWD in eastern forests of North America.

\section{RESEARCH NEEDS IN EASTERN FORESTS}

The impacts of SWD on native ecosystems may be indirect through the cascading effects of altered seed dispersal, plant regeneration, and fruit loss on wildlife populations, or through direct exploitative competition with native frugivores. Indirect effects of biological invasions are often

neglected in studies of invasive species, yet may have varied and long-term consequences (White et al. 2006). The potential for significant short- and long-term changes to eastern forest ecosystems from frugivorous NNIIPs requires greater investigation.

There are some immediate questions regarding SWD infestation. Basic information about SWD distribution, abundance, and phenology in forest ecosystems are lacking. Thus, research focused on understanding the limiting factors affecting SWD distribution will be imperative for guiding broader ecological questions and developing mitigation or control strategies.

Broader ecological questions about SWD can then focus on addressing knowledge gaps related to other ecological relationships. For instance, how does infestation affect fruit selection or rejection by different vertebrate dispersers, and do vertebrate dispersers respond differently to 
infestation? Or, does infestation affect the viability of parasitized seeds? And does that viability vary among fruiting species? Answering these questions is imperative to understanding potential impacts to plant regeneration and composition of future forest plant and wildlife communities. Similarly, because ecosystem impacts of SWD invasion may not be obvious in the short-term, long-term monitoring of forest plant communities will be critical to identifying whether changes occur in response to continued SWD activity. Unfortunately, evidence suggests that SWD are present throughout much of the eastern forests, so designing experiments to compare infested vs noninfested areas will be problematic. Instead, monitoring potential changes in regenerating forest community composition can provide insights into long-term effects. Wildlife community responses can also be prioritized, considering shifting forest tree species composition and effects of SWD on soft-mast food resources. Long-term wildlife monitoring will provide information about any lasting ecological effects of SWD on wildlife populations. The broad scope of potential impacts calls for an organized effort to study SWD in forests. Collaboration between forest managers, wildlife biologists, entomologists, plant ecologists, and other relevant fields will be critical to understanding the complex relationship SWD may play with plants and wildlife in forest ecosystems.

\section{LITERATURE CITED}

Allen, M. C., J. Sheehan, T. L. Master, and R. S. Mulvihill. 2009. Responses of acadian flycatchers (Empidonax virescens) to hemlock woolly adelgid (Adelges tsugae) infestation in Appalachian riparian forests. Auk 126:543-553.

Atallah, J., L. Teixeira, R. Salazar, G. Zaragoza, and A. Kopp. 2014. The making of a pest: the evolution of a fruit-penetrating ovipositor in Drosophila suzukii and related species. Proceedings of the Royal Society B: Biological Sciences 281:20132840. 
Baird, J. W. 1980. The selection and use of fruit by birds in an eastern forest. Wilson Bulletin 92:63-73.

Bairlein, F., and D. Simons. 1995. Nutritional adaptations in migrating birds. Israel Journal of Zoology 41:357-367.

Ballman, E. S., and F. A. Drummond. 2017. Infestation of wild fruit by Drosophila suzukii surrounding Maine wild blueberry fields. Journal of Agricultural and Urban Entomology 33:61-70.

Barber, N. A., R. J. Marquis, and W. P. Tori. 2008. Invasive prey impacts the abundance and distribution of native predators. Ecology 89:2678-2683.

Bell, J. L., and R. C. Whitmore. 1997. Eastern towhee numbers increase following defoliation by gypsy moths. Auk 114:708-716.

Bellamy, D. E., M. S. Sisterson, and S. S. Walse. 2013. Quantifying host potentials: indexing postharvest fresh fruits for spotted wing drosophila, Drosophila suzukii. PLoS ONE 8(4):e61227.

Bolda, M. P., R. E. Goodhue, and F. G. Zalom. 2010. Spotted wing drosophila: potential economic impact of a newly established pest. Agricultural Resource Economics Update $13: 5-8$.

Borgmann, K. L., S. F. Pearson, D. J. Levey, and C. H. Greenberg. 2004. Wintering yellow rumped warblers (Dendroica coronata) track manipulated abundance of Myrica cerifera fruits. Auk 121:74-87.

Borowicz, V. A. 1988. Do vertebrates reject decaying fruit? An experimental test with Cornus amomum fruits. Oikos 53:74-78. 
Brooks, R. T. 2001. Effects of the removal of overstory hemlock from hemlock-dominated forests on eastern redback salamanders. Forest Ecology and Management 149:197-204.

Burger, A. E. 1987. Fruiting and frugivory of Cornus canadensis in boreal forest in Newfoundland. Oikos 49:3-10.

Burrack, H. J. 2013. SWD impacts, 2012. < https://swd.ces.ncsu.edu/eastern-us-swd-impacts/>. Accessed 7 Feb 2019.

Burrack, H. J. 2015. SWD impacts, 2014. <https://swd.ces.ncsu.edu/swd-impacts-2014/>. Accessed 3 Feb 2019.

Calabria, G., J. Máca, G. Bächli, L. Serra, and M. Pascual. 2012. First records of the potential pest species Drosophila suzukii (Diptera: Drosophilidae) in Europe. Journal of Applied Entomology 136:139-147.

Carter, W. 1939. Injuries to plants caused by insect toxins. Botanical Review 5:273-326.

Caves, E. M., S. B. Jennings, J. HilleRisLambers, J. J. Tewksbury, and H. S. Rogers. 2013. Natural experiment demonstrates that bird loss leads to cessation of dispersal of native seeds from intact to degraded forests. PLoS ONE 8(5):e65618.

Cini, A., C. Ioriatti, and G. Anfora. 2012. A review of the invasion of Drosophila suzukii in Europe and a draft research agenda for integrated pest management. Bulletin of Insectology 65:149-160.

Deprá, M., J. L. Poppe, H. J. Schmitz, D. C. De Toni, and V. L. S. Valente. 2014. The first records of the invasive pest Drosophila suzukii in the South American continent. Journal of Pest Science 87:379-383.

Drew, R. A. I. 1988. Amino acid increases in fruit infested by fruit flies of the family Tephritidae. Zoological Journal of the Linnaean Society 93:107-112. 
Eiler, J. H., W. G. Wathen, and M. R. Pelton. 1989. Reproduction in black bears in the southern Appalachian Mountains. Journal of Wildlife Management 53:353-360.

Engriser, E. M. 1995. The effect of insect larvae infestation on fruit choice in phyllostomid fruit bats: an experimental study. Biotropica 27:523-525.

Fajvan, M. A., and J. M. Wood. 1996. Stand structure and development after gypsy moth defoliation in the Appalachian Plateau. Forest Ecology and Management 89:79-88.

Farnsworth, D., K. A. Hamby, M. Bolda, R. E. Goodhue, J. C. Williams, and F. G. Zalom. 2017. Economic analysis of revenue losses and control costs associated with the spotted wing drosophila, Drosophila suzukii (Matsumura), in the California raspberry industry. Pest Management Science 73:1083-1090.

Farwig, N., and D. G. Berens. 2012. Imagine a world without seed dispersers: a review of threats, consequences and future directions. Basic and Applied Ecology 13:109-115.

Folke, C., S. Carpenter, B. Walker, M. Scheffer, T. Elmqvist, L. Gunderson, and C. S. Holling. 2004. Regime shifts, resilience, and biodiversity in ecosystem management. Annual Review of Ecology, Evolution, and Systematics 35:557-581.

Fricke, E. C., M. J. Simon, K. M. Reagan, D. J. Levey, J. A. Riffell, T. A. Carlo, and J. J. Tewksbury. 2013. When condition trumps location: seed consumption by fruit-eating birds removes pathogens and predator attractants. Ecology Letters 16:1031-1036.

Fuentes, M. 1994. Diets of fruit-eating birds: what are the causes of interspecific differences? Oecologia 97:134-142.

Gale, G. A., J. A. DeCecco, M. R. Marshall, W. R. McClain, and R. J. Cooper. 2001. Effects of gypsy moth defoliation on forest birds: an assessment using breeding bird census data. Journal of Field Ornithology 72:291-304. 
Gandhi, K. J. K., and D. A. Herms. 2010. North American arthropods at risk due to widespread Fraxinus mortality caused by the alien emerald ash borer. Biological Invasions 12:18391846.

García, D., R. Zamora, and G. C. Amico. 2010. Birds as suppliers of seed dispersal in temperate ecosystems: conservation guidelines from real-world landscapes. Conservation Biology 24:1070-1079.

García, D., R. Zamora, and G. C. Amico. 2011. The spatial scale of plant-animal interactions: effects of resource availability and habitat structure. Ecological Monographs 81:103-121.

García, D., R. Zamora, J. M. Gomez, and J. A. Hodar. 1999. Bird rejection of unhealthy fruits reinforces the mutualism between juniper and its avian dispersers. Oikos 85:536-544.

Gardiner, M. M., D. A. Landis, C. Gratton, N. Schmidt, M. O’Neal, E. Mueller, J. Chacon, G. E. Heimpel, and C. D. Difonzo. 2009. Landscape composition influences patterns of native and exotic lady beetle abundance. Diversity and Distributions 15:554-564.

Gleditsch, J. M., and T. A. Carlo. 2011. Fruit quantity of invasive shrubs predicts the abundance of common native avian frugivores in central Pennsylvania. Diversity and Distributions $17: 244-253$.

Goodhue, R. E., M. Bolda, D. Farnsworth, J. C. Williams, and F. G. Zalom. 2011. Spotted wing drosophila infestation of California strawberries and raspberries: economic analysis of potential revenue losses and control costs. Pest Management Science 67:1396-1402.

Gunderson, L. H. 2000. Ecological resilience - in theory and application. Annual Review of Ecology and Systematics 31:425-439. 
Hauser, M. 2011. A historic account of the invasion of Drosophila suzukii (Matsumura) (Diptera: Drosophilidae) in the continental United States, with remarks on their identification. Pest Management Science 67:1352-1357.

Herms, D. A., and D. G. McCullough. 2014. Emerald ash borer invasion of North America: history, biology, ecology, impacts, and management. Annual Review of Entomology 59:13-30.

Herrera, C. M. 1982. Defense of ripe fruit from pests: its significance in relation to plant disperser interactions. American Naturalist 120:218-241.

Herrera, C. M., editor. 2002. Seed dispersal by vertebrates. Pages 185-208 in C. M. Herrera and O. Pellmyr, editors. Plant-animal interactions: an evolutionary approach. Blackwell Science, Oxford, United Kingdom.

Highland, H. A. 1964. Life history of Asphondylia ilicicola (Diptera: Cecidomyiidae), a pest of American holly. Journal of Economic Entomology 57:81-83.

Howe, H. F., and J. Smallwood. 1982. Ecology of seed dispersal. Annual Review of Ecology and Systematics 13:201-228.

Inman, R. M., and M. R. Pelton. 2002. Energetic production by soft and hard mast foods of American black bears in the Smoky Mountains. Ursus 13:57-68.

Janzen, D. H. 1971. Escape of Cassia grandis L. beans from predators in time and space. Ecology 52:964-979.

Jordano, P. 1987. Avian fruit removal: effects of fruit variation, crop size, and insect damage. Ecology 68:1711-1723. 
Jordano, P. 2000. Fruits and frugivory. Pages 125-165 in M. Fenner, editor. Seeds: the ecology of regeneration in plant communities. Second edition. CAB International, Wallingford, United Kingdom.

Kenis, M., A. Roques, A. Santini, and A. M. Liebhold. 2017. Impact of non-native invertebrates and pathogens on market forest tree resources. Pages 103-117 in M. Vilà and P. Hulme, editors. Impact of biological invasions on ecosystem services. Invading nature - Springer series in invasion ecology. Volume 12. Springer Nature, Cham, Switzerland.

Kinjo, H., Y. Kunimi, and M. Nakai. 2014. Effects of temperature on the reproduction and development of Drosophila suzukii (Diptera: Drosophilidae). Applied Entomology and Zoology 49:297-304.

Klick, J., W. Q. Yang, V. M. Walton, D. T. Dalton, J. R. Hagler, A. J. Dreves, J. C. Lee, and D. J. Bruck. 2016. Distribution and activity of Drosophila suzukii in cultivated raspberry and surrounding vegetation. Journal of Applied Entomology 140:37-46.

Klooster, W. S., K. J. K. Gandhi, L. C. Long, K. I. Perry, K. B. Rice, and D. A. Herms. 2018. Ecological impacts of emerald ash borer in forests at the epicenter of the invasion in North America. Forests 9:250.

Klooster, W. S., D. A. Herms, K. S. Knight, C. P. Herms, D. G. McCullough, A. Smith, K. J. K. Gandhi, and J. Cardina. 2014. Ash (Fraxinus spp.) mortality, regeneration, and seed bank dynamics in mixed hardwood forests following invasion by emerald ash borer (Agrilus planipennis). Biological Invasions 16:859-873.

Koenig, W. D., A. M. Liebhold, D. N. Bonter, W. M. Hochachka, and J. L. Dickinson. 2013. Effects of the emerald ash borer invasion on four species of birds. Biological Invasions 15:2095-2103. 
Krischik, V., E. S. McCloud, and J. A. Davidson. 1989. Selective avoidance by vertebrate frugivores of green holly berries infested with a cecidomyiid fly (Diptera: Cecidomyiidae). American Midland Naturalist 121:350-354.

Lee, J. C., D. J. Bruck, H. Curry, D. Edwards, D. R. Haviland, R. A. Van Steenwyk, and B. M. Yorgey. 2011. The susceptibility of small fruits and cherries to the spotted-wing drosophila, Drosophila suzukii. Pest Management Science 67:1358-1367.

Lee, J. C., A. J. Dreves, A. M. Cave, S. Kawai, R. Isaacs, J. C. Miller, S. Van Timmeren, and D. J. Bruck. 2015. Infestation of wild and ornamental noncrop fruits by Drosophila suzukii (Diptera: Drosophilidae). Annals of the Entomological Society of America 108:117-129.

Lee, J. C., and A. Sial. 2016. Reference list of fruits with Drosophila suzukii. 〈https://eorganic.info/sites/eorganic.info/files/u461/SWD-hostlist-by_reference.pdf〉. Accessed 13 Oct 2020.

Levey, D. J. 1988. Spatial and temporal variation in Costa Rican fruit and fruit-eating bird abundance. Ecological Monographs 58:251-269.

Loiselle, B. A., and J. G. Blake. 1991. Temporal variation in birds and fruits along an elevational gradient in Costa Rica. Ecology 72:180-193.

Major, M., and A. Desrochers. 2012. Avian use of early-successional boreal forests in the postbreeding period. Auk 129:419-426.

Manzur, M. I., and S. P. Courtney. 1984. Influence of insect damage in fruits of hawthorn on bird foraging and seed dispersal. Oikos 43:265-270.

Martin, T. E. 1985. Selection of second-growth woodlands by frugivorous migrating birds in Panama: an effect of fruit size and plant density? Journal of Tropical Ecology 1:157-170. 
Martin, A. C., H. S. Zim, and A. L. Nelson. 1961. American wildlife \& plants: a guide to wildlife food habits: the use of trees, shrubs, weeds, and herbs by birds and mammals of the United States. Dover, New York, New York, USA.

McCarty, J. P., D. J. Levey, C. H. Greenberg, and S. Sargent. 2002. Spatial and temporal variation in fruit use by wildlife in a forested landscape. Forest Ecology and Management $164: 277-291$.

McCusker, C. E., M. P. Ward, and J. D. Brawn. 2010. Seasonal responses of avian communities to invasive bush honeysuckles (Lonicera spp.). Biological Invasions 12:2459-2470.

McDonnell, M. J., and E. W. Stiles. 1983. The structural complexity of old field vegetation and the recruitment of bird-dispersed plant species. Oecologia 56:109-116.

McKey, D. 1975. The ecology of coevolved seed dispersal systems. Pages 159-191 in L. E. Gilbert and P. H. Raven, editors. Coevolution of animals and plants. University of Texas Press, Austin, USA.

McNeil, D. J., C. A. Nicks, J. C. Wester, J. L. Larkin, and M. J. Lovallo. 2017. Diets of fishers (Pekania pennanti) and evidence of intraspecific consumption in Pennsylvania. American Midland Naturalist 177:200-210.

Moegenburg, S. M., and D. J. Levey. 2003. Do frugivores respond to fruit harvest? An experimental study of short-term responses. Ecology 84:2600-2612.

Morin, R. S., and A. M. Liebhold. 2015. Invasions by two non-native insects alter regional forest species composition and successional trajectories. Forest Ecology and Management $341: 67-74$.

Morin, R. S., and A. M. Liebhold. 2016. Invasive forest defoliator contributes to the impending downward trend of oak dominance in eastern North America. Forestry 89:284-289. 
Nalepa, C. A., and W. H. Piper. 1994. Bird dispersal of the larval stage of a seed predator. Oecologia 100:200-202.

Parrish, J. D. 1997. Patterns of frugivory and energetic condition in Nearctic landbirds during autumn migration. Condor 99:681-697.

Parrish, J. D. 2000. Behavioral, energetic, and conservation implications of foraging plasticity during migration. Studies in Avian Biology 20:53-70.

Piper, J. K. 1986. Seasonality of fruit characters and seed removal. Oikos 46:303-310.

Plein, M., L. Längsfeld, E. L. Neuschulz, C. Schultheiß, L. Ingmann, T. Töpfer, K. Böhning Gaese, and M. Schleuning. 2013. Constant properties of plant-frugivore networks despite fluctuations in fruit and bird communities in space and time. Ecology 94:1296-1306.

Rabenold, K. N., P. T. Fauth, B. W. Goodner, J. A. Sadowski, and P. G. Parker. 1998. Response of avian communities to disturbances by an exotic insect in spruce-fir forest of the Southern Appalachians. Conservation Biology 12:177-189.

Redford, K. H., G. A. Bouchardet da Fonseca, and T. E. Lacher. 1984. The relationship between frugivory and insectivory in primates. Primates 25:433-440.

Redman, A. M., and J. M. Scriber. 2000. Competition between the gypsy moth, Lymantria dispar, and the northern tiger swallowtail, Papilio canadensis: interactions mediated by host plant chemistry, pathogens, and parasitoids. Oecologia 125:218-228.

Rey, P. J. 1995. Spatio-temporal variation in fruit and frugivorous bird abundance in olive orchards. Ecology 76:1625-1635.

Rice, K. B., R. R. Troyer, K. M. Watrous, J. F. Tooker, and S. J. Fleischer. 2017. Landscape factors influencing stink bug injury in Mid-Atlantic tomato fields. Journal of Economic Entomology 110:94-100. 
Ridley, H. N. 1930. The dispersal of plants throughout the world. Reeve, Ashford, United Kingdom.

Rodewald, P. G., and M. C. Brittingham. 2004. Stopover habitats of landbirds during fall: use of edge-dominated and early-successional forests. Auk 121:1040-1055.

Rogers, L. L. 1976. Effects of mast and berry crop failures on survival, growth, and reproductive success of black bears. Transactions, Forty-First North American Wildlife and Natural Resources Conference 41:431-438.

Rose, C. L., P. J. Turk, S. M. Selego, and J. T. Anderson. 2014. White-footed mice (Peromyscus leucopus) select fruits of native species over invasive honeysuckle fruits. Journal of Mammalogy 95:108-116.

Rota-Stabelli, O., M. Blaxter, and G. Anfora. 2013. Drosophila suzukii. Current Biology 23:R8R9.

Ryan, C. W., J. C. Pack, W. K. Igo, J. C. Rieffenberger, and A. B. Billings. 2004. Relationship of mast production to big-game harvests in West Virginia. Wildlife Society Bulletin $32: 786-794$.

Sallabanks, R. 1993. Hierarchical mechanisms of fruit selection by an avian frugivore. Ecology 74:1326-1336.

Sallabanks, R., and S. P. Courtney. 1992. Frugivory, seed predation, and insect-vertebrate interactions. Annual Review of Entomology 37:377-400.

Saracco, J. F., J. A. Collazo, and M. J. Groom. 2004. How do frugivores track resources? Insights from spatial analyses of bird foraging in a tropical forest. Oecologia 139:235245. 
Schaub, M., and L. Jenni. 2000. Fuel deposition of three passerine bird species along the migration route. Oecologia 122:306-317.

Schmidt, J. M., T. S. Whitehouse, K. Green, H. Krehenwinkel, R. Schmidt-Jeffris, and A. A. Sial. 2019. Local and landscape-scale heterogeneity shape spotted wing drosophila (Drosophila suzukii) activity and natural enemy abundance: implications for trophic interactions. Agriculture, Ecosystems and Environment 272:86-94.

Showalter, C. R., and R. C. Whitmore. 2002. The effect of gypsy moth defoliation on cavity nesting bird communities. Forest Science 48:273-281.

Small, M. J., C. J. Small, and G. D. Dreyer. 2005. Changes in a hemlock-dominated forest following woolly adelgid infestation in southern New England. Journal of the Torrey Botanical Society 132:458-470.

Snow, B. K., and D. W. Snow. 1988. Birds and berries: a study of an ecological interaction. Poyser, Calton, United Kingdom.

Snow, D. W. 1971. Evolutionary aspects of fruit-eating by birds. Ibis 113:194-202.

Suthers, H. B., J. M. Bickal, and P. G. Rodewald. 2000. Use of successional habitat and fruit resources by songbirds during autumn migration in central New Jersey. Wilson Bulletin 112:249-260.

Thompson, J. N., and M. F. Willson. 1979. Evolution of temperate fruit/bird interactions: phenological strategies. Evolution 33:973-982.

Tingley, M. W., D. A. Orwig, R. Field, and G. Motzkin. 2002. Avian response to removal of a forest dominant: consequences of hemlock woolly adelgid infestations. Journal of Biogeography 29:1505-1516.

Tochen, S., D. T. Dalton, N. Wiman, C. Hamm, P. W. Shearer, and V. M. Walton. 2014. 
Temperature-related development and population parameters for Drosophila suzukii (Diptera: Drosophilidae) on cherry and blueberry. Environmental Entomology 43:501- 510.

Traveset, A. 1993. Weak interactions between avian and insect frugivores: the case of Pistacia terebinthus L. (Anacardiaceae). Vegetatio 107:191-203.

Traveset, A., and M. Verdú. 2002. A meta-analysis of the effect of gut treatment on seed germination. Pages 339-350 in D. J. Levey, W. Silva, and M. Galetti, editors. Seed dispersal and frugivory: ecology, evolution, and conservation. CAB International, Wallingford, United Kingdom.

Traveset, A., M. F. Willson, and J. C. Gaither. 1995. Avoidance by birds of insect-infested fruits of Vaccinium ovalifolium. Oikos 73:381-386.

Uchytil, R. J. 1991. U.S. Department of Agriculture, Forest Service, Rocky Mountain Research Station, Fire Sciences Laboratory (Producer). Prunus serotina. In: Fire effects information system. <https://www.fs.fed.us/database/feis/plants/tree/pruser/all.html>. Accessed 26 Jan 2019.

Valburg, L. K. 1992a. Eating infested fruits: interactions in a plant-disperser-pest triad. Oikos 65:25-28.

Valburg, L. K. 1992b. Feeding preferences of common bush-tanagers for insect-infested fruits: avoidance or attraction? Oikos 65:29-33.

Van der Pijl, L. 1957. The dispersal of plants by bats (chiropterochory). Acta Botanica Neerlandica 6:291-315.

Van der Pijl, L. 1972. Principles of dispersal in higher plants. Second edition. Springer-Verlag, New York, New York, USA. 
Venugopal, P. D., P. L. Coffey, G. P. Dively, and W. O. Lamp. 2014. Adjacent habitat influence on stink bug (Hemiptera: Pentatomidae) densities and the associated damage at field corn and soybean edges. PLoS ONE 9(10):e109917.

Walsh, D. B., M. P. Bolda, R. E. Goodhue, A. J. Dreves, J. Lee, D. J. Bruck, V. M. Walton, S. D. O’Neal, and F. G. Zalom. 2011. Drosophila suzukii (Diptera: Drosophilidae): invasive pest of ripening soft fruit expanding its geographic range and damage potential. Journal of Integrated Pest Management 2:G1-G7.

Webber, B. L., and I. E. Woodrow. 2004. Cassowary frugivory, seed defleshing and fruit fly infestation influence the transition from seed to seedling in the rare Australian rainforest tree, Ryparosa sp. nov. 1 (Achariaceae). Functional Plant Biology 31:505-516.

White, E. M., J. C. Wilson, and A. R. Clarke. 2006. Biotic indirect effects: a neglected concept in invasion biology. Diversity and Distributions 12:443-455.

Willson, M. F. 1986. Avian frugivory and seed dispersal in eastern North America. Pages 223279 in R. F. Johnston, editor. Current ornithology. Volume 3. Springer, Boston, Massachusetts, USA.

Willson, M. F. 1993. Mammals as seed-dispersal mutualists in North America. Oikos 67:159176.

Willson, M. F., and J. N. Thompson. 1982. Phenology and ecology of color in bird-dispersed fruits, or why some fruits are red when they are "green." Canadian Journal of Botany 60:701-713.

With, K. 2002. The landscape ecology of invasive spread. Conservation Biology 16:1192-1203. 
Work, T. T., and D. G. McCullough. 2000. Lepidopteran communities in two forest ecosystems during the first gypsy moth outbreaks in northern Michigan. Environmental Entomology 29:884-900. 


\section{FIGURES}

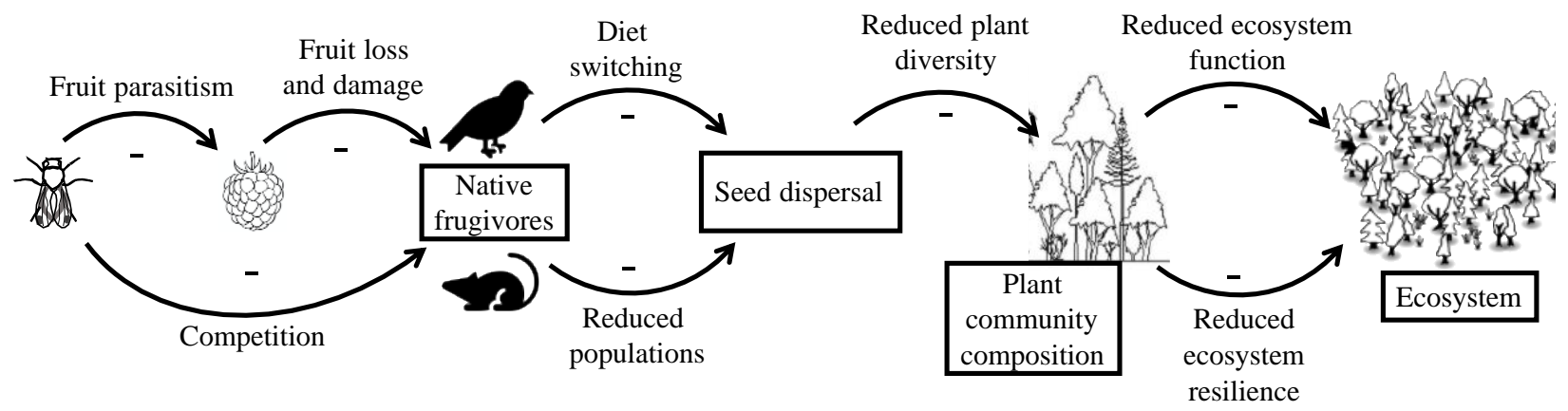

Figure 1.1. Potential ecological interactions and trophic consequences of fruit parasitism by spotted wing Drosophila (Drosophila suzukii, SWD) in eastern forests of North America. Arrows indicate directions of interactions and signs indicate negative consequences of the effect. Loss of fruit to SWD will reduce fruit available for vertebrate frugivores, thereby disrupting seed dispersal, and ultimately reduce plant diversity and impede ecosystem function and resilience. 
CHAPTER 2. Host plant species locally and in an adjacent cover type differentially influence the relative abundance of spotted wing Drosophila and fruit parasitism across the Allegheny National Forest

\author{
ABSTRACT \\ Non-native invasive insect pests (NNIIPs) can cause widespread damage to fruits in agricultural \\ systems. Abundance of NNIIPs and damage to crops are exacerbated by greater forest cover in \\ the landscape, in part due to the presence of wild, non-crop plant hosts. Spotted wing Drosophila \\ (Drosophila suzukii, SWD) is a recently-introduced NNIIP to the eastern United States that \\ parasitizes the fruits of wild, non-crop plants in forests, but little is known about SWD activity in \\ forests or how factors associated with fruit resources locally and in an adjacent cover type may \\ influence SWD abundance or parasitism of forest fruits. My objective was to determine how \\ forest composition and local fruit resources influence: 1) the relative abundance of SWD in 2 \\ cover types: early successional forest (i.e., regenerating timber harvests) and mature (i.e., closed \\ canopy) forest, and 2) the parasitism of fruits in regenerating harvests. I investigated forest \\ composition with respect to dominance by black cherry (Prunus serotina), a highly valuable \\ resource for the local timber industry, wildlife, and SWD. I trapped SWD at regenerating timber \\ harvests and in surrounding mature forest at Allegheny National Forest from July to October in \\ 2019 and 2020. I assessed fruit resources at each cover type using transect surveys, and I \\ surveyed for $P$. serotina using 50-m radius plots at SWD trap locations. I collected fruit samples \\ at regenerating harvest traps to determine the extent of fruit parasitism. I modeled relative \\ abundance of SWD in each cover type and emerged from fruit samples as functions of fruit \\ counts, $P$. serotina basal area, and proximity to high density $P$. serotina forest stands using \\ negative binomial regression in a stepwise model approach. Relative abundance of SWD in \\ timber harvests and surrounding forest canopy correlated to host resources at the local (i.e.,
}


point) level but not the adjacent cover type. Number of SWD/g of Allegheny blackberry (Rubus allegheniensis) fruits correlated with both local host resources and host basal area in adjacent forest. The results of this study provide the first evidence for the importance of local resources over those in an adjacent cover type or surrounding forest for predicting SWD trap captures, and the importance of local fruit resources and host density in adjacent cover type for SWD fruit parasitism in invaded forest ecosystems. These relationships can be used to predict the timing and abundance of SWD in both natural and semi-natural systems where wild fruiting plants are abundant, providing valuable information for monitoring and management planning.

Keywords: black cherry, dilution, forest canopy, Drosophila suzukii, early successional, forest composition, fruit parasitism, invasive species, Prunus serotina, spotted wing Drosophila.

\section{INTRODUCTION}

Non-native invasive insect pests (NNIIPs) can dramatically impact habitats in their invaded range. In agricultural habitats, NNIIPs target crop plants, dramatically decreasing crop yields. For example, losses from brown marmorated stink bug (Halyomorpha halys) damage can range from $>25 \%$ in New Jersey apple (Malus domestica) and pear (Pyrus spp.) orchards to nearly 100\% in Maryland peach (Prunus persica) orchards (Nielsen and Hamilton 2009, Leskey et al. 2012). Larvae of other insect pests, such as codling moth (Cydia pomonella L.) and plum curculio (Conotrachelus nenuphar Herbst), similarly damage fruits such as apples from the fruit interior and decrease fruit yield (Clark and Gage 1997 and citations within). Presence of forest (in particular, deciduous forest) surrounding agricultural systems can benefit NNIIP populations and increase pest pressure on crop plants (With 2002, Gardiner et al. 2009, but see ChaplinKramer et al. 2011). Proximity to forest cover can promote increased populations of NNIIPs and increase the percentage of fruits damaged by NNIIPs in agricultural fields (Rusch et al. 2013, 
Venugopal et al. 2014, Rice et al. 2017b). Alternative non-crop host plants in surrounding forests can increase pest pressure (Bahlai et al. 2010, Rodriguez-Saona et al. 2018), providing NNIIP populations with overwintering sites, food, or reproduction resources to increase before spilling over into adjacent crop fields (Moeser and Vidal 2004, Tscharntke et al. 2005). In forest ecosystems, NNIIPs can cause widespread tree mortality, producing long-term changes to forest plant and animal community composition through extensive feeding on foliage (Fajvan and Wood 1996, Work and McCullough 2000), sap (Tingley et al. 2002), or wood (Herms and McCollough 2014). Widespread tree mortality can also produce long term changes to ecosystem processes (Ellison et al. 2005, Lovett et al. 2006, Gandhi and Herms 2010) and ecosystem services (Stadler et al. 2005, Kenis et al. 2009, Boyd et al. 2013). It is unclear how fruit-targeting NNIIPs, well-documented in agricultural systems, may impact native forest ecosystems, but NNIIPs capable of utilizing many alternative plant species are more likely to exploit and benefit from non-crop host plants in forest ecosystems (Rice et al. 2017b).

Spotted wing Drosophila (SWD, Drosophila suzukii) is an increasingly prominent frugivorous NNIIP of many fruiting plant species in the United States. Native to east Asia, it first appeared in California in 2008 and has since spread as far east as Maine (Asplen et al. 2015). Females use a serrated ovipositor (Walsh et al. 2011, Atallah et al. 2014) to parasitize their preferred ripe and ripening fruit hosts (Mitsui et al. 2006, Lee et al. 2011a) and not just overripe or damaged fruits that other drosopholids are restricted to (Sasaki and Sato 1995). Oviposition also exposes the fruit to further parasitism by other drosophilids and to infection by microbes (Walsh et al. 2011, Ioriatti et al. 2015). The ability of SWD to exploit ripe and ripening fruits reduces their direct competition with native fruit fly species and creates a unique new ecological relationship. Following egg-laying in ripe or ripening fruit, hatching larvae consume fruit pulp 
before emerging as pupae. This causes the fruit to have a sunken, desiccated appearance (Walsh et al. 2011). This secondary exposure can further rot and decay the fruit, which might result in its premature drop from the plant (Walsh et al. 2011).

Because of this ability to oviposit in ripe and ripening fruit, SWD parasitizes and reduces the yields of many different fruiting plants in the U.S. (Lee et al. 2011a, Bellamy et al. 2013), causing crop losses as high as $80 \%$ and severe economic losses to fruit production estimated at more than $\$ 500$ million annually, in American crops (Bolda et al. 2010, Goodhue et al. 2011, Walsh et al. 2011). However, SWD activity in crop fields and orchards, like other NNIIPs, is positively correlated to proximity of adjacent forest (Cahenzli et al. 2018, Hennig and Mazzi 2018, Santoiemma et al. 2018b), and greater forest cover in the surrounding landscape is positively correlated with earlier invasion of crop fields (Pelton et al. 2016), increased abundance (Haro-Barchin et al. 2018), and increased crop damage (Santoiemma et al. 2018b). In addition to serving as overwintering habitat or as refugia during adverse climatic conditions (Dalton et al. 2011, Tochen et al. 2016, Evans et al. 2017), forests benefit SWD by providing alternative noncrop host plants to parasitize (Iglesias et al. 2014, Pelton et al. 2016). Globally, researchers have documented more than 100 different cultivated, ornamental, and wild-growing host plant species for SWD, observing parasitism rates in fruit samples as high as $90-100 \%$ for some wild growing plants (Lee et al. 2015, Poyet et al. 2015, Roche et al. 2021). Non-crop host plants, thus, provide valuable resources for SWD to persist in forested ecosystems, where crop host plants are absent (Poyet et al. 2015, Garantonakis et al. 2016).

Currently, little is known about the factors affecting the abundance of SWD and the parasitism of wild, non-crop host fruits in forested ecosystems. Multiple factors influence SWD activity (e.g., forest cover, time of year, fruit developmental stage, fruit host identity), but these 
remain largely unexplored outside of their connection to agricultural systems (Harris et al. 2014, Burrack et al. 2015, Jaffe et al. 2018, Haro-Barchin et al. 2018, Schmidt et al. 2019). Wild fruits in forest ecosystems typically occur in early successional forest (e.g., regenerating timber harvests) in greater abundance than in mature forest (McDiarmid et al. 1977). Early successional forest provides dense vegetation and high concentrations of food resources, including fruit, for wildlife in the summer and fall (Suthers et al. 2000, McCarty et al. 2002). However, the concentration of fruit resources into patches in the landscape may make them a susceptible resource for SWD to exploit (Mitsui et al. 2006, Cloonan et al. 2018). As fruits in these stands ripen, they may attract SWD both to the stand and to surrounding mature (i.e., closed canopy) forest and experience heavy parasitism, resulting in a greater relative abundance of SWD and greater parasitism of fruits (Root 1973). Meanwhile, forested landscapes with a greater abundance of a commonly parasitized host tree species in mature forest might similarly attract SWD to both mature forest and nearby early successional habitat and provide the necessary resources for the population to increase, producing increases in SWD and fruit parasitism. Black cherry (Prunus serotina) trees are a commonly parasitized fruit resource for SWD (Beers et al. 2011, Poyet et al. 2014) and occur throughout the eastern, central, and southern U.S. (Uchytil 1991)

$P$. serotina fruits are also an important food resource for many wildlife species in the late summer and early fall (Uchytil 1991), and P. serotina timber can be a valuable economic resource in certain regions (Marquis 1975). If infestation of fruits reduces the abundance of healthy fruits on plants and the attractiveness of remaining fruits to wildlife (Poyet et al. 2014, Roche et al. 2021), increased abundance of SWD and infestation of fruits by SWD due to abundant $P$. serotina in the landscape could reduce wildlife food resources (Turcotte et al. 2018). 
Many of the plant species parasitized by SWD in forests are important food resources for wildlife (Martin et al. 1961, McCarty et al. 2002). For P. serotina, increased infestation of fruits by SWD could exacerbate regional declines in regeneration (Turcotte et al. 2018), causing longterm economic and wildlife food resource loss. Understanding how the surrounding forest and local plant communities influence SWD distribution, abundance, and fruit parasitism in forests is an important first step in understanding the potential ecological impacts of this novel frugivorous NNIIP in eastern forest ecosystems.

I investigated multiple factors affecting SWD abundance and parasitism of fruits in 2 cover types with different structure in a forested ecosystem during summer and early autumn months, a time coinciding with fruiting of many plant species in the eastern U.S. (Thompson and Willson 1979, McCarty et al. 2002). These cover types were early successional forest (i.e., regenerating timber harvests, or "harvests") and mature forest, or "forest." My objectives were to determine the following: 1) how relative abundance of SWD in harvests and in forest relate to surrounding forest composition (with respect to dominance by P. serotina), local fruit resources, and relative abundance of SWD in the adjacent cover type; and 2) how relative abundance of SWD emerged from fruits in harvests relate to surrounding forest composition (with respect to dominance by $P$. serotina), local fruit resources, and relative abundance of SWD. For objective 1, I hypothesized that relative abundance of SWD in harvest and forest cover types would be positively correlated with 1) a greater amount of $P$. serotina-dominated mature forest in the surrounding forest matrix than intermediate or low $P$. serotina mature forest, 2) closer proximity to $P$. serotina-dominated forest patches, 3) P. serotina-specific variables (greater basal area and relative abundance of $P$. serotina fruits), 4) fruiting plant specific variables (relative abundance of ripe and ripening fruits and relative proportion of ripe and ripening fruits), and 5) relative 
abundance of SWD in the adjacent cover type. For objective 2, I hypothesized that the relative abundance of SWD emerged from fruits (per gram of fruit; Pelton et al. 2016) would be positively correlated with 1) relative SWD abundance in both harvest and mature cover types, 2) the same forest composition variables (with respect to $P$. serotina-dominated mature forest), 3) the same $P$. serotina variables, and 4) the same fruiting plant specific variables as in objective 1.

\section{METHODS}

\section{Study Area}

I conducted this study throughout the Allegheny National Forest (ANF) and nearby forest in the Allegheny High Plateau of northwestern Pennsylvania $\left(41^{\circ} 40^{\prime} \mathrm{N}, 78^{\circ} 05^{\prime} \mathrm{W}\right)$. The ANF covers approximately 209,000 ha (187,500 forested, 17,000 non-forested, and 4,500 covered by water, mostly the Allegheny Reservoir) and includes land in Elk, Forest, McKean, and Warren counties. Elevation throughout the forest ranges from approximately $305 \mathrm{~m}$ above sea level to $700 \mathrm{~m}$ above sea level. Annual precipitation is approximately $1 \mathrm{~m}$ (Morin et al. 2006).

The Allegheny High Plateau was historically dominated by northern hardwoods until the late 1800s and early 1900s when industrialization and unregulated logging left much of the forest clear-cut and brush-covered (U.S. Forest Service 2007). The ANF was established in 1923, which led to a halt of these practices and the growth of an altered forest (U.S. Forest Service 2007). P. serotina emerged as a widespread species, comprising greater than $50 \%$ basal area in the new major forest type, Allegheny hardwood (Royo et al. 2021). P. serotina is an important ecological and economic species, providing food resources to wildlife and timber for commercial harvest dictated by Forest Service guidelines. P. serotina fruits are high in nutritional content and consumed by white-tailed deer (Odocoileus virginianus), birds, rodents, mesocarnivores, and American black bears (Ursus americana; Uchytil 1991, Rose et al. 2014). High-quality $P$. 
serotina timber is sold across the U.S. and globally, generating important income for the local economy (Marquis 1975, Wiedenbeck et al. 2004).

Dominant forest types occurring at the ANF include the following: 1) Allegheny hardwoods (dominated by at least $50 \%$ basal area $P$. serotina [greater than $70 \%$ in some forest stands; Eyre 1980], white ash [Fraxinus americana], yellow poplar [Liriodenron tulipifera], American beech [Fagus grandifolia], yellow birch [Betula alleghaniensis], red maple [Acer rubrum], sugar maple [Acer saccharum], and eastern hemlock [Tsuga canadensis]); 2) mixed upland hardwoods (similar to Allegheny hardwoods but dominated by red maple and containing fewer P. serotina [approximately 23\% basal area]); 3 ) northern hardwoods (similar to upland hardwoods but dominated by eastern hemlock, American beech, and maple spp., and containing even fewer $P$. serotina [approximately $13 \%$ basal area]); and 4) oak-hickory (at least $25 \%$ oak [Quercus spp.] species, dominated by red oaks [Quercus spp.]; U.S. Forest Service 2007).

Large blocks of contiguous and connected mature forest exist throughout the landscape. A diversity of forest structure also exists, including even-age forest with trees $90-110$ years old and forest with a larger number of older, larger trees along with a greater amount of younger structural stages (U.S. Forest Service 2007). Extensive, long-term browsing by high deer densities has resulted in a loss of understory and midstory vegetation through much of the ANF (Morin et al. 2006). Because the ANF contains many forest compartments harvested for $P$. serotina, maple, and yellow poplar timber or marked for even-aged management, there are many regenerating harvests distributed throughout the forest (U.S. Forest Service 2007). However, less than $8 \%$ of forested land comprising the ANF is under 20 years old. Most harvests at the ANF use the shelterwood system, which involves an initial shelterwood seed harvest, leaving half to most trees (50-70\%) as residual canopy trees, and a second shelterwood removal harvest after a 
minimum of approximately 10 years. However, clear-cutting of all trees is also used under certain resource objectives (see U.S. Forest Service 2007). Minimum rotation age for final harvest (i.e., shelterwood removal harvest, clear-cutting) is 100 years for the major forest types. Maximum size of openings created by even-aged management is approximately 16 ha, per Forest Service regulations. Regenerating patches contain seedlings and saplings representative of adjacent forest types. These patches also include many fruiting plants, including blackberry (Rubus spp.), pokeweed (Phytolacca americana), pin cherry (Prunus pennsylvanica), and spikenard (Aralia spp.). Mature forest patches typically have much lower numbers of these plants in the understory (Stoleson 2013).

I conducted additional sampling at Clear Creek State Forest (CCSF), located south of the ANF in Jefferson County in the Allegheny High Plateau ( $\left.41^{\circ} 18^{\prime} \mathrm{N}, 79^{\circ} 00^{\prime} \mathrm{W}\right)$. It is a property of approximately 5,460 ha managed by the Pennsylvania Department of Conservation and Natural Resources (DCNR). Geology and climate are similar to that of the ANF. Most of the mature forest stands within the CCSF are approximately 100 years old. There are 3 major forest types: Allegheny hardwood, mixed oak, and northern hardwood. Mixed oak is the dominant type, with northern red oak as the dominant species. Other species include white oak (Quercus alba), black oak (Quercus velutina), chestnut oak (Quercus montana), red maple, American beech, $P$. serotina, and eastern hemlock (Brose 2011). Timber harvesting has created multiple regenerating harvests in the CCSF. Seedlings and saplings are representative of adjacent forest communities, and many herbaceous fruiting species can be found in these harvests, including blackberry, Vaccinium spp., partridgeberry (Mitchella repens), sassafras (Sassafras albidum), Smilax spp., serviceberry (Amelanchier spp.), pin cherry, devil's walking stick (Aralia spinosa), grapes (Vitis spp.), and American (Sambucus canadensis) and red elderberry (S. racemosa). 
I conducted sampling at one site on Pennsylvania State Game Lands (SGL) 86, located west of the ANF along the western bank of the Allegheny River and within the Allegheny High Plateau $\left(41^{\circ} 43^{\prime} 31^{\prime \prime} \mathrm{N}, 079^{\circ} 21^{\prime} 29^{\prime \prime} \mathrm{W}\right)$. It is comprised of a single contiguous tract of land of approximately 5,800 ha in Warren County and lies within the Pennsylvania Game Commission's (PGC) Northwest Region. Lands along the Allegheny River, including SGL 86, contain large hills and steep slopes. The vast majority of SGL 86 was logged in the early 1900s (PGC 2014) and now contains a mix of plant communities from lower elevation streambed valleys dominated by conifers, maple, and birch to higher elevation (approximately $531 \mathrm{~m}$ ) plateaus dominated by oak, maple, hickory (Carya spp.), birch, and American beech. The harvest I used in this study was along a northern facing slope and contained seedlings and saplings representative of adjacent plant communities and a variety of herbaceous fruiting plants, including blackberry, pokeweed, maple leaf viburnum (Viburnum acerifolium), Vaccinium spp., partridgeberry, multiflora rose (Rosa multiflora), currants (Ribes sp.), grapes, and elderberry.

SWD was first recorded at the ANF in 2012 and has since spread across the forest, parasitizing the fruits of many plant species (e.g., dogwood [Cornus spp.], elderberry, serviceberry, spikenard) and dramatically damaging wild blackberry crops in harvests (S. H. Stoleson, Forest Service, personal communication). P. serotina fruits are also a known host at the ANF (Turcotte et al. 2018).

\section{Site Selection}

I conducted all sampling on sites within the ANF, CCSF, and SGL 8618 July-30 October in 2019 and 19 July-28 October in 2020. This timing coincides with the observed appearances of SWD at the ANF in previous years (Turcotte et al. 2018). Previous studies have also identified first captures of SWD in the first half of July (Joshi et al. 2017, Elsensohn and Loeb 2018), with 
large increases occurring in August (Pelton et al. 2016) and captures continuing through midOctober (Briem et al. 2018, Thistlewood et al. 2019). Each site consisted of a regenerating harvest selected for this study using multiple criteria. I defined regenerating harvests as forest stands aged 3 to 8 years post-timber harvest as of 2019 to ensure time for fruiting plant regrowth. From this list of all available harvests meeting my criteria, I randomly selected regenerating harvests such that each harvest was at least $2 \mathrm{~km}$ apart from any other harvest within a season. While some studies have suggested large-distance dispersal capabilities (more than $2 \mathrm{~km}$ ) of SWD over the course of a few months (Wang et al. 2016, Tait et al. 2018), others showed shorter movement patterns (less than 100 m) over a few days (Klick et al. 2016, Kirkpatrick et al. 2018), suggesting flies remain within a limited area (e.g., within a site) in the summer and early fall (Mitsui et al. 2010, Hennig and Mazzi 2018, Wong et al. 2018). In 2019, I chose 4 regenerating harvest sites situated within Allegheny hardwood forest, 4 within mixed upland hardwood forest, and 4 within oak forest, representing a gradient of different forest types. In 2020, I chose 3 sites within Allegheny forest, 3 within mixed upland forest, and 3 within oak forest, giving 7 Allegheny sites, 7 mixed upland sites, and 7 oak sites over both years (Figure 2.1, Appendix A).

To determine locations of sampling points at each site, I covered each site with a grid of points placed $100 \mathrm{~m}$ apart oriented north-south and greater than $25 \mathrm{~m}$ from a patch edge in all regenerating harvests. I randomly selected 5 points to standardize the sampling effort at each regenerating harvest. I removed any regenerating harvests unable to fit at least 5 candidate sampling points from the list of candidate sites.

For each regenerating harvest sampling point, I established a paired sampling point in surrounding mature forest spaced $500 \mathrm{~m}$ away, a spatial scale influencing SWD activity in seminatural habitats (Santoiemma et al. 2018a, b). I placed mature forest points using the following 
criteria: 1) they were within mature forest stands, 2) the straight line between each point and its paired regenerating harvest point crosses the regenerating harvest border closest to the harvest point, and 3) points in mature forest were at least $100 \mathrm{~m}$ apart (Figure 2.2). I used the Vegetation dataset from the Allegheny National Forest Geographic Information System (GIS) Dataset collection (U.S. Forest Service 2019) in ArcGIS Pro v. 2.3.0 (ESRI, Redlands, CA, USA) to identify forest types for site selection and for placing sampling points. This dataset is a vegetation polygon layer, with polygons representing forest compartments or stands and nonforest areas across the entire spatial extent of the ANF. Each polygon is identified by the dominant land cover and, if forested, forest type. From 2019 to 2020, I sampled 105 points across 21 sites.

\section{SWD Sampling}

I conducted sampling for SWD simultaneously at regenerating harvest and paired mature forest points at each site. To maximize the number of adult SWD captured over each 3-day sampling period, I made traps using a methodology described by Pelton et al. (2016; Figure 2.3). I made 10 evenly distributed 5-mm holes near the top of a clear 710-mL plastic cup with a lid (Webstaurant Store, Lancaster, PA, USA). The bait in each trap was a mixture of $3.5 \mathrm{~g}$ dry active baker's yeast, $14 \mathrm{~g}$ granulated white cane sugar, and $177 \mathrm{~mL}$ water, with a drop of unscented soap used to improve capture of SWD by reducing surface tension. Use of yeast-sugar bait shows earlier capture and capture rates comparable to or better than other bait types (Lee et al. 2012,

Iglesias et al. 2014, Jaffe et al. 2018) and is more predictive of fruit infestation than other baits (Burrack et al. 2015), likely due to the production of $\mathrm{CO}_{2}$ and ethanol, the latter of which represents a food source produced by ripening and ripe fruit (Becher et al. 2012, Hamby et al. 2012, Krause Pham and Ray 2015). I lined the area directly below the holes with a strip of red 
tape and the area directly above the holes with a strip of black tape to improve captures (Lee et al. 2013, Lasa et al. 2017).

I placed a central transect centered on each sampling point. At the central transect, I placed 2 parallel transects on a randomly selected side: one "inner" transect $1 \mathrm{~m}$ away and one “outer" transect $25 \mathrm{~m}$ away from the central transect (Figure 2.4; modified from fruit sampling by Levey 1988). In regenerating harvests, I placed one trap at a single end of the "inner" (1 m) transect and one trap at a single end of the "outer" $(25 \mathrm{~m})$ transect (Figure 2.4). Previous studies have spaced traps at a single sampling location as close as 1-2 $\mathrm{m}$ apart (Lee et al. 2012, Tochen et al. 2016) or as far as 10-20 m apart (Pelton et al. 2016, Wang et al. 2016). I suspended traps approximately $1 \mathrm{~m}$ off the ground and close to vegetation to minimize exposure to direct sun and increase likelihood of trap capture (Diepenbrock and Burrack 2017, Rice et al. 2017a). At paired mature forest points, vegetation was denser in the canopy than the understory. Because SWD favor canopies of trees (Toda 1987, Tonina et al. 2018), I sampled for SWD in the canopy. I first placed a central transect and one inner and outer transect similar to regenerating harvest points. I suspended one trap at a single end of the inner and one trap at a single end of the outer transect by shooting arrows tied to high-tension fishing line over large tree branches using a recurve bow, replacing the fishing line with twine, and raising the trap into the tree using the twine line. I suspended traps high enough in a tree to lie completely within the contiguous canopy layer and shielded from direct sun and wind. Thus, the approximate height of each trap varied with the canopy height at each forest point.

Sampling at a single site spanned 3 days, for approximately 48 hours. On the first day, I hung traps at each mature forest point in the morning. On the second day, I hung traps at each regenerating harvest point in the morning. On the third day, I collected all traps by midday for 
approximately 48 sampling hours for mature forest traps and approximately 24 hours for regenerating harvest traps. I sampled at each site 3 times during the season (mid-Jul to late Oct). Sampling period 1 spanned 18 July-22 August in 2019 and 19 July-25 August in 2020, sampling period 2 spanned 23 August-25 September in 2019 and 26 August-25 September in 2020, and sampling period 3 spanned 26 September-30 October in 2019 and 27 September-28 October in 2020.

After I collected the contents of each trap, I strained all invertebrates from the trap medium and stored them in 70\% ethanol before later separating out and counting all adult SWD in each trap. If a trap fell or was damaged such that the contents were lost, I discarded the trap and saved no sample. I pooled counts of SWD in each trap at each of the 10 total sampling points at each site (5 regenerating harvest points and 5 mature forest points) to determine a single count of SWD at each point, separated into counts of SWD at regenerating harvest points and counts of SWD at mature forest points.

\section{Allegheny Blackberry (Rubus allegheniensis) Sampling}

To determine the number of fruit resources at each sampling point, I conducted fruit surveys at each regenerating harvest and paired mature forest point simultaneously with SWD sampling. I conducted surveys the same day of the site visit traps were hung: the first day at mature forest points, and the second day at regenerating harvest points. At $3 \mathrm{~m}, 6 \mathrm{~m}$, and $9 \mathrm{~m}$ along each inner and outer transect, I randomly choose a side and placed a 0.50-m $\times 0.50-\mathrm{m}$ quadrat. I identified all individual plants in the understory producing fruit within each quadrat $\left(0.75 \mathrm{~m}^{2} / \operatorname{transect}, 1.50\right.$ $\mathrm{m}^{2} /$ sampling point) and recorded the species and number of fruits, separated into the following age categories: unripe (green, still growing), ripening (full size, undergoing color change), and ripe (full size, completed color change). At each mature forest point, I also checked for fruits 
immediately overhead (i.e., in the canopy) within each quadrat. However, I only found fruiting plants in the canopy during 2 of 291 (0.7\%) fruit surveys along transects at mature forest points and therefore excluded fruit surveys at forest points from further consideration.

I pooled all fruit counts at each regenerating harvest sampling point to determine a single count of fruits for each category. After pooling, I chose to focus on counts of ripening and ripe fruits combined for Allegheny blackberry (Rubus allegheniensis) specifically. R. allegheniensis was the most abundant fruit encountered across all fruit surveys, with few other species found fruiting during most surveys ( $8 \%$ of all regenerating harvest surveys). Ripening and ripe fruits are susceptible to parasitism by SWD (Mitsui et al. 2006, Lee et al. 2011a), and the sum of ripening and ripe fruit are strongly correlated with total fruit during sampling periods 1 and $2(r$ $=0.76$ ); no R. allegheniensis fruits were found during period 3. I used total number of fruits to calculate the proportion of ripening and ripe fruits at each point.

\section{R. allegheniensis Parasitism Sampling}

To determine the extent that SWD were parasitizing fruits at each sampling point in harvests, I collected a random sample of ripening and ripe fruits from each fruiting plant species along each transect and monitored for emergence of adult, pupal, or larval SWD (20 fruits each, when possible). I collected fruits from individual fruiting plants found along the entire transect, throughout the structure of the plant to avoid missing fruits in microhabitats where SWD may be more active (Diepenbrock and Burrack 2017). I weighed fruits (g) within 2 hours of collection and stored them, separated by species and transect, at room temperature $\left(\sim 20^{\circ} \mathrm{C}\right)$ under ambient light in a sealed, vented 473-mL clear container (Webstaurant Store, Lancaster, PA, USA). I checked samples after a minimum of 2 weeks and counted adult, larval, and pupal SWD (Walsh et al. 2011, Burrack et al. 2015). 
I pooled total SWD counts and fruit sample masses between transects to determine a single count of SWD for each fruiting species at each regenerating harvest sampling point. While larvae and pupae of SWD are difficult to differentiate from other Drosophila species, I used total counts of all stages of SWD for multiple reasons. First, I found only SWD emerged from fruit samples as adults. Second, ripening and ripe fruits, unless damaged, are likely not susceptible to parasitism by most native Drosophila species, which lack a serrated ovipositor (Mitsui et al. 2006, Lee et al. 2011b, Atallah et al. 2014). Third, counting only adult SWD would have underestimated actual parasitism of many samples. Finally, using only adult SWD strongly correlated with using all life stages $(r=0.87)$. In some fruit samples, decay of fruit and growth of fungi made adult flies difficult to find and counts of adult SWD were lower than counts of pupal shells. Because pupal shells indicate an emerged adult fly and adult counts likely would have underestimated the total number of SWD, I used pupal shell counts rather than adult counts when calculating total SWD counts (all life stages) in these samples. I chose to focus on $R$. allegheniensis because most fruits surveyed and therefore sampled were $R$. allegheniensis (85\% of all fruit samples). Because no fruits were present after the second period, I did not sample any fruits during period 3 .

\section{$P$. serotina Surveying}

At each point, I collected information describing the extent of $P$. serotina at each sampling point. I identified all actively fruiting trees within $50 \mathrm{~m}$ of both mature forest and regenerating harvest sampling points and counted the number of fruits on each plant using a strategy employed by Saracco et al. (2004). To count fruits, I used binoculars to scan the entire tree crown. For trees with many fruits, I counted the number of fruits on a portion of the crown and extrapolated to the remainder of the tree. For a single score of $P$. serotina fruits at each point, I summed the 
approximate count of fruits across all trees and categorized that total estimate using a fruit abundance index (FAI) score. This converted the number of fruits of each fruit category into a single-digit categorical variable following a logarithmic scale: $0=$ no fruits, $1=1-10$ fruits, $2=$ $11-100$ fruits, $3=101-1,000$ fruits, $4=1,001-10,0000$ fruits, and $5=10,001+$ fruits.

For each $P$. serotina tree within $50 \mathrm{~m}$ of each point, I measured the $\mathrm{dbh}$, which I used to calculate basal area. I then summed basal area of all trees to find total P. serotina basal area within $50 \mathrm{~m}$ of each sampling point. For 7 mature forest points with an extensive number of $P$. serotina trees (i.e., greater than 100 stems), I measured trees for a subsection of the 50-m radius plot. I conducted half-plot surveys for 4 points and quarter-plot surveys for 3 points. Each of these points had relatively uniform distribution of $P$. serotina trees across the entire plot. To standardize basal area across points, I calculated the basal area/quarter plot of the 50-m radius plot at each point. Few regenerating harvest points had $P$. serotina trees within $50 \mathrm{~m}(8 \%$ of all points), so I dropped basal area of $P$. serotina at regenerating harvest points. Instead, I included basal area of $P$. serotina at paired mature forest points as a measure of $P$. serotina density in the surrounding forest.

\section{Forest Composition Metrics}

To determine how the forest composition (dominance by $P$. serotina) influenced SWD relative abundance and fruit infestation, I quantified multiple metrics from the Vegetation dataset in the ANF GIS Geospatial Dataset collection (U.S. Forest Service 2019) using ArcGIS Pro v. 2.3.0 (ESRI, Redlands, CA, USA). Polygons cover the spatial extent of the ANF, overlaying forest stands and identifying forest type of individual stands. For each sampling point, I identified the forest type of the regenerating harvest or mature forest stand within which the point was located. I also measured 1) distance from each sampling point to the nearest mature Allegheny hardwood 
forest (high P. serotina density) stand, and 2) percent of mature Allegheny hardwood forest within a 500-m buffer of each sampling point. Features within $500 \mathrm{~m}$ can influence SWD abundance in semi-forested landscapes (Santoiemma et al. 2018a, b). For mature forest points located within Allegheny hardwood forest stands (polygons), I recorded distance as $0 \mathrm{~m}$. For points located on non-ANF land (i.e., CCSF and SGL 86), I used additional forest type data from Pennsylvania DCNR's Pennsylvania State Forest Recent Timber Harvests, Pennsylvania State Forest Mature Oak Stands, and Pennsylvania State Forest Young Aspen Stands GIS datasets (PA DCNR 2020) to visualize forest cover. I used Pennsylvania National Agricultural Imagery Program (NAIP) ortho imagery (USDA-FSA 2019) to cross-check landscape features (e.g., roads, timber harvests, openings) with those in the Vegetation dataset.

\section{Statistical Analyses}

Prior to analysis, I tested for collinearity between predictor variables ( $r \geq 0.70$; Dormann et al. 2013). I found no fruits during $98 \%$ of $P$. serotina fruit surveys (surveys within $50 \mathrm{~m}$ of forest points) in 2019, so I dropped $P$. serotina fruit as a covariate. Because many sites occurred near non-ANF land, gaps in forest cover existed for 20 of 105 (19\%) regenerating harvest sampling points and 65 of 105 (62\%) mature forest sampling points. The percent of Allegheny hardwood within $500 \mathrm{~m}$ of regenerating harvest and mature forest sampling points correlated strongly with the basal area of $P$. serotina at points with no gaps in forest cover $(r=0.65$ and 0.75 , respectively). Thus, I dropped percent Allegheny hardwood and used basal area of P. serotina as a measure of $P$. serotina density at the local (i.e., sampling point) level for forest points or the forest stand level for harvest points. Proximity of forest points to the nearest Allegheny hardwood stand correlated strongly with one level of the categorical variable for forest type within which forest points occurred-specifically, Allegheny hardwood ( $r=-0.77)$. I chose to 
drop proximity for forest points and retain forest type because one my primary interests with analyses was whether different forest types, as defined by the U.S. Forest Service, showed any connection to SWD relative abundances at the ANF. I chose 8 final covariates for analyses (Table 2.1). I log transformed proximity data to create a scaling relationship such that smaller distance values (e.g., 0-1 km) would be more powerful than larger values (e.g., 5-6 km), since SWD typically travel shorter distances over shorter time intervals (Mitsui et al. 2010, Klick et al. 2016, Hennig and Mazzi 2018, Kirkpatrick et al. 2018, Wong et al. 2018). To use captures of SWD at regenerating harvest points and mature forest points as predictor variables for trap captures in adjacent cover types and for SWD emerged from fruit samples, I addressed differences in 1) number of trap samples at each point, and 2) number of days traps were out at a site due to adverse weather delaying site visits by 1-2 days by calculating the number of adult SWD captured/trap/24 hours for each sampling point. These covariates correlated strongly ( $r=$ 0.73). As such, I refrained from including both in the same model.

From SWD trap capture data, I derived the following response variables at each sampling point during each sampling period: 1) total captures of SWD at regenerating harvest points ("harvest" model), 2) total captures of SWD at mature forest points ("forest" model), and 3) total SWD (all life stages) emerged from samples of $R$. allegheniensis fruits collected at regenerating harvest points ("infest" model). Several regenerating harvest and mature forest points lacked trap capture data during a sampling period (5 of 315 [2\%] and 11 of 315 [4\%] data points, respectively) because I was unable to hang traps or lost traps prior to collection. I discarded the 11 missing point samples from SWD trap capture analyses to avoid modeling missing values (304 total data points). For the "infest" analysis, I only included sampling locations at which I 
collected a $R$. allegheniensis fruit sample and a SWD trap sample at both the harvest and paired forest point (117 total data points).

To model all SWD response variables, I fit generalized linear mixed models (GLMMs) using a Bayesian approach with Markov-chain Monte-Carlo (MCMC) parameter estimation techniques. I chose a Bayesian approach for its ability to provide less biased estimates with smaller sample sizes than frequentist approaches (Gelman and Hill 2007). I incorporated a random point effect to account for repeated observations at each sampling location. In addition, I included offset terms to account for differences in sampling effort. In the "harvest" and "forest" models, I included a term for the log-transformed product of the number of traps and number of days traps were at each sampling point. In the "infest" model, I included a term for the logtransformed mass of the fruit sample at each sampling point. To aid in model convergence, I first scaled and centered all continuous covariates.

I first modeled each SWD response variable as Poisson random variables using simple Poisson regression:

$$
y_{i} \sim \operatorname{Pois}\left(\lambda_{i}\right)
$$

where $i$ is sampling point identity, $y_{i}$ is count data for each sampling point during each sampling period, and $\lambda_{i}$ is expected count for each sampling point during each sampling period. To assess the goodness-of-fit (GOF) of individual models, I calculated a Bayesian p-value using the sum of squared Pearson residuals for every model run (Gelman et al. 2004). If the model for a response variable failed this GOF test (p-value less than 0.10 or greater than 0.90 ), I treated that response variable as a negative binomial (NB) random variable and re-ran the model using NB regression:

$$
\begin{gathered}
y_{i} \sim \operatorname{NB}\left(p_{i}, r\right), \\
p_{i}=\frac{r}{r+\lambda_{i}},
\end{gathered}
$$


where $p_{i}$ is the probability of success at each sampling point during each sampling period, and $r$ is the dispersion parameter. This allowed the mean and variance to differ from a Poisson regression, allowing for over-dispersion. All 3 response variables had poor-fitting Poisson models but successfully ran with NB global models and passed the GOF test.

I modeled each response variable with a different set of covariates (Table 2.1). I analyzed captures of SWD at regenerating harvest points ("harvest" model) using the following model:

$$
\begin{gathered}
\log \left(\lambda_{i}\right)=\alpha_{i}+\log (\text { traps } \times \text { days })+\beta_{1} \times \text { date }_{i}+\beta_{2} \times \text { date }_{i}^{2}+\beta_{3} \times \text { date }_{i}^{3}+ \\
\beta_{4} \times \text { ripen.ripe }_{i}+\beta_{5} \times \text { prop }_{i}+\beta_{6} \times \text { cherryBA }_{i}+\beta_{7} \times \text { Allegheny }_{i}+\beta_{8} \times \\
\text { MixedUpland }_{i}+\beta_{9} \times \text { proximity }_{i}+\beta_{10} \times \text { swdFORESTcov }_{i},
\end{gathered}
$$

where $\alpha_{i}$ is the intercept for a random sampling point effect. I included a cubic term for date based upon visualization of raw capture data and past research identifying multiple peaks in SWD captures over summer and fall months (Briem et al. 2018, Thistlewood et al. 2018). The "swdFORESTcov" covariate represented the capture rate of SWD at each harvest point's paired mature forest point (Table 2.1). I analyzed captures of SWD at mature forest points ("forest" model) using the following model:

$$
\begin{gathered}
\log \left(\lambda_{i}\right)=\alpha_{i}+\log (\text { traps } \times \text { days })+\beta_{1} \times \text { date }_{i}+\beta_{2} \times \text { date }_{i}^{2}+\beta_{3} \times \text { date }_{i}^{3}+ \\
\beta_{4} \times \text { ripen.ripe }_{i}+\beta_{5} \times \operatorname{prop}_{i}+\beta_{6} \times \text { cherryBA }_{i}+\beta_{7} \times \text { Allegheny }_{i}+\beta_{8} \times \\
\text { MixedUpland }_{i}+\beta_{9} \times \operatorname{swdCUTCov}_{i} .
\end{gathered}
$$

Again, I included a cubic term for date based upon visualization of raw capture data and past research identifying multiple peaks in SWD captures. The "swdCUTcov" covariate represented the capture rate of SWD at each forest point's paired regenerating harvest point (Table 2.1). I analyzed SWD emerged from samples of $R$. allegheniensis fruits collected at regenerating harvest points ("infest" model) using the following model: 


$$
\begin{gathered}
\log \left(\lambda_{i}\right)=\alpha_{i}+\log (\text { fruit mass })+\beta_{1} \times \text { date }_{i}+\beta_{2} \times \text { date }_{i}^{2}+\beta_{3} \times \text { ripen. } \text { ripe }_{i}+ \\
\beta_{4} \times \text { prop }_{i}+\beta_{5} \times \text { cherryBA }_{i}+\beta_{6} \times \text { Allegheny }_{i}+\beta_{7} \times \text { MixedUpland }_{i}+\beta_{8} \times \\
\text { proximity }_{i}+\beta_{9} \times \text { swdCUTcov }_{i} .
\end{gathered}
$$

I included a quadratic term for date based upon visualization of raw data. In all 3 models, I also included a derived contrast term to identify whether a difference existed between Allegheny sites and mixed upland sites (i.e., $\beta$ Allegheny $-\beta_{\text {MixedUpland). }}$

I performed a stepwise regression model approach on each response variable using NB regression. I chose a stepwise regression process because I had a priori hypotheses about each covariate and reason to believe — based on previous studies of SWD in agricultural and semiforested landscapes - each would explain some of the variation observed in SWD relative abundance in traps and in fruit samples. I used a strict process to conduct stepwise removal from a global model to a final reduced model for inference on individual covariates. First, I ran a global model for each response variable containing all covariates specified for that response variable. Second, I removed all covariates with a marginal posterior estimate for a slope coefficient $(\beta)$ that had a $90 \%$ credible interval (CI) overlapping 0 with the exception of 1 ) “date," if "date 2 " or "date" 3 " was not removed, 2) "date" 2 ", if "date" 3 " was not removed, and 3) categorical levels of the forest type covariate, if "Allegheny," "MixedUpland," or the derived contrast term was not removed. The credible interval indicates the bounds within which the value of the parameter of interest $(\beta)$ lies at a certain probability (in this case $90 \%$ ), given the assumptions of the Bayesian model. I re-ran the reduced model and used the same criterion to remove covariates. I repeated this process until all remaining covariates had a $90 \% \mathrm{CI}$ that didn't overlap 0 . I conducted covariate removal and final inference using $90 \%$ CIs to identify 
potentially weak but ecologically meaningful effects, while utilizing a small sample size and properly accounting for uncertainty through random effects.

I ran all models using software JAGS version 4.3.0 (Plummer 2003) called from R version 4.0.3 (R Core Team 2021) using communicator package jagsUI (Kellner 2019). For all NB models I specified vague (i.e., noninformative) priors (Kéry 2010). I drew random sampling point intercept terms $\left(\alpha_{i}\right)$ from a Normal distribution with a population-level intercept mean $\alpha$ and precision $\tau_{\alpha}(1 /$ variance $)$ :

$$
\alpha_{i} \sim \mathrm{N}\left(\alpha, \tau_{\alpha}\right) .
$$

I specified Normal priors for the population-level intercept mean $(\alpha)$ :

$$
\alpha \sim \mathrm{N}(0,0.01),
$$

where 0 is the mean and 0.01 is the precision. I derived precision $\tau_{\alpha}$ from a standard deviation with a uniform prior:

$$
\begin{gathered}
\tau_{\alpha}=\frac{1}{\sigma_{\alpha}^{2}}, \\
\sigma_{\alpha} \sim \operatorname{Unif}(0,10) .
\end{gathered}
$$

I specified the same Normal priors for slope coefficients for each covariate as the hyper-prior for the intercept:

$$
\beta_{\text {covs }} \sim \mathrm{N}(0,0.01) .
$$

I used a uniform prior for the dispersion parameter, $r$, with a large upper bound:

$$
r \sim \operatorname{Unif}(0,50) .
$$

As $r$ becomes large (e.g., 50), the NB approaches a Poisson distribution (Jackman 2009).

I ran $3 \mathrm{MCMC}$ chains for each model. I used traceplots to determine an appropriate burn-in for each model, and I ran each model for a sufficient number of iterations to achieve convergence. I confirmed convergence of models by visually inspecting chain mixing and checking that 
Gelman-Rubin diagnostic (Rhat) values for all model parameters were below 1.1 (Gelman et al. 2004). Burn-in lengths and number of iterations and necessary for convergence of all models ranged 8,000 to 20,000 and 15,000 to 36,000 , respectively. I thinned iterations by 2 to help reduce autocorrelation between posterior draws. I drew initial values for all parameters from a uniform distribution with parameters Unif(-10,10).

\section{RESULTS}

\section{SWD Trap and Fruit Sample Data}

From 2019 to 2020 I collected a total 618 traps in regenerating harvests and 588 traps in mature forest. I captured 152,839 SWD in regenerating harvest traps and 282,375 SWD in mature forest traps. Trap captures at regenerating harvest points ranged from a minimum of $2 \mathrm{SWD} /$ trap/day (30-31 Jul and 23-24 Oct 2019) to a maximum of 4,945 SWD/trap/day (29-30 Oct 2019; Figure

2.5A). Trap captures at mature forest points ranged from a minimum of $0 \mathrm{SWD} /$ trap/day (18-19 Jul and 30-31 Jul 2019, and 27-28 Jul 2020) to a maximum of 2,820 SWD/trap/day (1-2 Sep 2019; Figure 2.5B). From 2019 to 2020, I collected 202 R. allegheniensis fruit samples, 158 of which $(78 \%)$ were parasitized by SWD. I counted 6,326 SWD emerged from fruit samples, with a maximum of approximately $22 \mathrm{SWD} / \mathrm{g}$ of fruit (collected 14 Aug 2019). R. allegheniensis fruits became absent from sites during sampling period 2 (period 1 mean total $=106.80$, period 2 mean total $=3.07)$, so no fruit samples were collected after 13 September 2019 and 8 September 2020 .

\section{Model Results}

All models exhibited good fit based on derived Bayesian p-values. Five covariates with non-zero slope coefficients were retained in the "harvest" model (Table 2.2). Relative abundance of SWD in harvest traps was correlated with the following: 1) relative abundance of ripening and ripe $R$. 
allegheniensis fruits ( 0.46 decrease in log expected count for every 1 standard deviation increase in relative abundance of fruits, scaled; $\beta=-0.46[-0.57,-0.33]$; Figure 2.6A), 2) trap captures of SWD at paired forest points $(0.68$ increase in log expected count for every 1 standard deviation increase in SWD forest trap captures, scaled; $\beta=0.68$ [0.51, 0.87]; Figure 2.6B), 3) proportion of R. allegheniensis fruits ripening and ripe ( 0.27 increase in $\log$ expected count for every 1 standard deviation increase in proportion, scaled; $\beta=0.27[0.13,0.40]$; Figure 2.6C), and 4) ordinal date (peak: 18 Aug [15 Aug, 20 Aug], valley: 3 Oct [28 Sep, 9 Oct]; Figure 2.6D).

Four covariates with non-zero slope coefficients were retained in the final "forest" model (Table 2.2). Relative abundance of SWD in forest traps was correlated with the following: 1) basal area of $P$. serotina ( 0.30 increase in $\log$ expected count for every 1 standard deviation increase in basal area, scaled; $\beta=0.30[0.19,0.42]$; Figure 2.7A), 2) trap captures of SWD at paired regenerating harvest points ( 0.33 increase in log expected count for every 1 standard deviation increase in SWD harvest trap captures, scaled; $\beta=0.33$ [0.19, 0.47]; Figure 2.7B), and 3) ordinal date, cubed (peak: $11 \mathrm{Sep}$ [7 Sep, $17 \mathrm{Sep}$ ], valley: 20 Oct [1 Oct, $16 \mathrm{Nov}$; Figure 2.7C).

Five covariates with non-zero slope coefficients were retained in the "infest" model (Table 2.2). Relative abundance of SWD in fruit samples was correlated with the following: 1) relative abundance of ripening and ripe $R$. allegheniensis fruits ( 0.29 decrease in log expected count for every 1 standard deviation increase in relative abundance of fruits, scaled; $\beta=-0.29[-$ $0.51,-0.06]$; Figure 2.8A), 2) basal area of $P$. serotina ( 0.26 decrease in log expected count for every 1 standard deviation increase in basal area, scaled; $\beta=-0.26[-0.48,-0.05]$; Figure 2.8B), 3) forest type ( 0.55 increase in log expected count at Allegheny points compared to oak points, $\beta$ $=0.55[0.06,1.07] ; 0.53$ increase at Allegheny points compared to mixed upland points, $\beta_{\text {Allegheny }}$ 
$-\beta_{\text {MixedUpland }}=0.53$ [0.09, 0.97]; Figure 2.8C), and 4) ordinal date (peak: 13 Aug [12 Aug, 15 Aug]; Figure 2.8D).

To determine whether more SWD emerged from R. allegheniensis fruits at Allegheny harvest points compared to mixed upland or oak harvests could be attributed to differences in relative abundance of $R$. allegheniensis fruits in harvests of different types, I used a one-way analysis of variance (ANOVA) with forest type as the predictor variable. I found Allegheny sampling points had higher counts of ripening and ripe fruits than mixed upland or oak points $\left(\mu_{\text {Allegh }}-\mu_{\text {Mixed }}[\mathrm{SE}]: 1.07[0.31], \mu_{\text {Allegh }}-\mu_{\text {Oak }}[\mathrm{SE}]: 0.81[0.30]\right)$.

\section{DISCUSSION}

To my knowledge, this is the first study to investigate how host species both locally and in the surrounding forest influence the abundance and parasitism of a novel non-native agricultural pest in different cover types in invaded forest ecosystems. Adult SWD relative abundances at the ANF were connected strongly to local plant factors, but not those in the adjacent cover type as predicted. Relative abundances in forest canopies correlated to basal area of $P$. serotina locally (i.e., within $50 \mathrm{~m}$ ), while those in timber harvests correlated to $R$. allegheniensis crops locally (i.e., within $25 \mathrm{~m}$ ). In contrast, relative abundance of SWD emerged from $R$. allegheniensis correlated with both local $R$. allegheniensis crop size and $P$. serotina in the adjacent cover type (i.e., $500 \mathrm{~m}$ away). These results demonstrate a difference in how adult SWD relative abundance and parasitism of fruits in timber harvests relate to resources in adjacent mature forest. I am unaware of any such demonstrated patterns for SWD in natural ecosystems in the literature. Previous studies found a spatial scale of $500 \mathrm{~m}$ important for predicting SWD abundances and crop damage in agricultural or semi-natural ecosystems (Santoiemma et al. 2018a, b), and many including these attributed relationships between forest cover and SWD to non-crop hosts in 
nearby forests (Santoiemma et al. 2018a, b; Haro-Barchin et al. 2018; Schmidt et al. 2019). Forest cover is a general characteristic regularly treated as a proxy for non-crop resources in SWD studies, though rarely investigated further. While my analyses did not broadly analyze forest cover as in these studies, distances between forest and harvest points aligned with this spatial scale (i.e., $500 \mathrm{~m}$ ) but produced no such relationship of host species to SWD relative abundances in the adjacent cover type. It's possible the sum of resources within $500 \mathrm{~m}$ is more important than at a single point $500 \mathrm{~m}$ away, though this explanation requires further study. Or, resources closer than $500 \mathrm{~m}$ (e.g., closer to the forest edge) may influence activity more strongly, as SWD typically don't move large distances over short timeframes (e.g., a few days; Klick et al. 2016, Kirkpatrick et al. 2018), and increasing distances appear to reduce SWD abundances in agricultural studies (Klick et al. 2016, Hennig and Mazzi 2018, Tonina et al. 2018, Schmidt et al. 2019). The results for SWD trap captures in each cover type support this interpretation, at least for SWD relative abundances. Alternatively, favorable microclimate conditions for SWD produced by forest cover could have explained the relationship of forest cover to SWD in previous studies (Pelton et al. 2016), rather than abundance of wild, non-crop hosts, which were not surveyed. In the current study, abundance of non-crop hosts at the forest stand level did not yield results as expected.

Contrary to predictions, SWD relative abundances did not differ by forest type (i.e., dominance of the entire surrounding forest stand by $P$. serotina). I hypothesized greater densities of $P$. serotina trees in the surrounding forest would support larger SWD populations, correlating with increased trap captures (Pelton et al. 2016, Cahenzli et al. 2018, Santoiemma et al. 2018b). Alternatively, resources at larger spatial scales could decrease local relative abundances of SWD as individuals aggregate at clusters of resources or are diluted in the landscape (Parsa et al. 2011, 
Schneider et al. 2015). However, I did not observe either of these possibilities. Modeling results suggested SWD were similarly abundant in different forest types when accounting for other predictor variables. This is supported by my observations of large captures of SWD in traps from each forest type, despite dramatically large captures in a few traps at locations in particular forest types (Figure 2.5). This finding also reinforces the argument that local resources were more important for predicting SWD relative abundances than composition of the larger stand in forest ecosystems, likely due to the production of attractive food and reproductive resources at smaller spatial scales. It remains unclear whether different forest types produced sufficient resources to sustain similar relative abundances of SWD.

Relative abundance of SWD emerged from $R$. allegheniensis fruits, however, was correlated to forest type. As predicted, more SWD emerged from fruits in Allegheny harvests than either mixed upland or oak harvests (Figure 2.8C). Results of the one-way ANOVA confirmed that sampling locations in Allegheny harvests had more R. allegheniensis fruits. As such, the greater parasitism of fruits at Allegheny harvest points was likely due to generally larger fruit crops in Allegheny harvests compared to other forest types, producing a concentration effect of pest pressure on fruits at the harvest level (Root 1973, Rhainds and English-Loeb 2003). Based on modeling results, adult SWD abundances and parasitism of fruit resources appeared to respond differently to resources at smaller (point-level) compared to larger (stand-level) spatial scales. Adult SWD and SWD emerging from fruit also responded differently to different resources at forest and harvest points.

Trap captures of SWD in forest canopy correlated positively with $P$. serotina basal area (Figure 2.7A). A greater abundance of resources at small spatial scales increases relative abundances of insect pests (Root 1973, Rhainds and English-Loeb 2003), which supports this 
relationship. Additionally, P. serotina is a highly parasitized fruit host (Poyet et al. 2014,

Turcotte et al. 2018). Importantly, I found few P. serotina fruits during surveys in 2019 and thus did not include actual fruit counts as a covariate. Spatial heterogeneity in fruit production by individual trees could have meant more fruits existed in the surrounding forest where more $P$. serotina trees occurred (Wheelwright 1986), but the lack of an effect of forest type on SWD relative abundances reinforces the importance of resources within $50 \mathrm{~m}$, not on how abundant trees were in the forest stand within which I trapped SWD. However, SWD can also utilize attractive, non-fruit resources provided by $P$. serotina trees, including tree sap and flowers (Kanzawa 1939, Kimura 1976, Mitsui et al. 2010), contributing to the exploitability of $P$. serotina trees, even if fruits weren't present. Other possible resources not accounted for in my analyses may have correlated with $P$. serotina basal area (e.g., fungi or other wild fruit host species; Kimura 1976, Uchytil 1991, Roche et al. 2021). However, I only found a few other fruiting species (e.g., pin cherry, serviceberry, mountain holly [Medeola virginiana], black tupelo [Nyssa sylvatica]) at mature forest points, and the only fruits were on understory species (1-6 total fruits, 7 of 291 fruit surveys), so this possibility remains unclear. In contrast, harvest SWD abundances correlated negatively with $R$. allegheniensis fruits (Figure 2.6A). This finding runs counter to earlier studies in crop fields (Klick et al. 2016, Drummond et al. 2019), though this discrepancy could be the result of documenting an overall site-level change in SWD as opposed to a point-level change, the latter of which I did in this study. While this result was unexpected, it is consistent with the observation that relative abundance of SWD emerged from R. allegheniensis in timber harvests decreased as fruit abundance increased (Figure 2.8A). $R$. allegheniensis appeared to reduce local pest pressure on itself with larger fruit crops, creating a dilution effect (Schneider et al. 2015, Scheiner and Martin 2020). While I did not directly 
observe activity of adult SWD, flies seemed to distribute among plants and individual fruits. This strategy of producing large fruit crops, known as masting, could be an effective method for reducing pest pressure on fruit crops (Janzen 1971, Silvertown 1980, Kelly and Sork 2002, Satake et al. 2004, Roche et al. 2021). Recall that harvests with generally larger crops saw higher rates of parasitism at individual sampling locations, which is consistent with previous work (Klick et al. 2016, Drummond et al. 2019). As such, SWD activity appears to differ between sites and within individual sites, again emphasizing differences with spatial scale. $P$. serotina exerted a similar effect on fruit parasitism in timber harvests.

As with $R$. allegheniensis fruit abundances, greater $P$. serotina density in nearby forest reduced parasitism of fruits in harvests (Figure 2.8B), contrary to predictions. No previous study, to my knowledge, has established a quantified relationship between parasitism of fruits by a nonnative fruit pest and a host species several hundred meters away in adjacent forest in an invaded agricultural or forested ecosystem. The negative relationship suggests a similar dilution effect of $P$. serotina in adjacent forest on fruit parasitism as $R$. allegheniensis relative abundance on fruit parasitism (Schneider et al. 2015, Scheiner and Martin 2020). As noted previously, P. serotina trees provide multiple resources for SWD to exploit, including fruit, flower nectar, and tree sap (Kanzawa 1939, Mitsui et al. 2010, Turcotte et al. 2018). Even if one of these resources is limited (e.g., fruit), a high concentration of such resources would be highly susceptible to SWD (Mitsui et al. 2006, Cloonan et al. 2018), possibly serving to attract more SWD to these locations in mature forest and away from $R$. allegheniensis crops and producing the observed relationships of forest SWD trap captures and parasitism to P. serotina basal area. As such, the simultaneous production of exploitable resources by multiple species may serve to dilute the pest pressure on individual species (Shibata et al. 1998, Kelly et al. 2000). 
As I predicted, relative abundances of SWD in harvests and nearby forest strongly correlated in both SWD trap models (Figures 2.6B and 2.7B). As such, there appeared to be a strong connection between SWD in mature forest and in timber harvests. At the very least, the strong correlation of trap captures suggests a similar underlying factor driving SWD relative abundances. Abiotic factors, notably temperature and humidity, are critical factors driving SWD abundances during the year (Tochen et al. 2014, 2016; Enriquez and Colinet 2017; Evans et al. 2017). While these factors were beyond the scope of this study, daily climatic conditions could have exerted a similar influence on SWD and thus determined relative abundances in both cover types. Additionally, microclimate conditions (e.g., within forest canopy or Rubus thickets), if similar, may have also exerted a similar influence on SWD in each cover type (Diepenbrock and Burrack 2017, Schöneberg et al. 2020). Alternatively, while I did not investigate movement of SWD at the ANF, this strong correlation may be indicative of movement between cover types. Adult SWD are highly mobile, capable of moving between habitats to exploit different resources as they become available (Wang et al. 2016, Hennig and Mazzi 2018, Tait et al. 2018, Wong et al. 2018). Whether individual adult SWD moved between timber harvests and canopies of surrounding forest at the ANF, however, requires further investigation.

Interestingly, I found no relationship between SWD trap captures and SWD emerged from fruit in the "infest" model, though previous studies made the same observation (Lee et al. 2012, Hamby et al. 2014, Burrack et al. 2015). Two findings of this study-consistent identification of $R$. allegheniensis fruit effects on SWD found in traps and parasitizing fruits, and the observed increases in trap captures over time (Figures 2.6D, 2.7C, and 2.8D) - suggest my trap captures of SWD were accurate representations of the abundances of SWD at each sampling location, relative to other sampling locations. As such, I'm confident the lack of an observed 
relationship of trap captures to SWD emerged from fruit reflected a true relationship and not an inability of my traps to capture SWD when present. It is unclear what ecological process may explain this lack of a relationship, as the dynamics of SWD oviposition and development in wild fruits in natural systems remain largely unknown. Individual female SWD produce and oviposit several eggs a day on average and produce up to several hundred during a lifespan (Emiljanowicz et al. 2014, Tochen et al. 2014, Asplen et al. 2015, Hamby et al. 2016), demonstrating a capacity of populations to parasitize many fruits even at low adult SWD densities. Laboratory studies have demonstrated density-dependent effects on larval development and survival mediated by host quality (Hardin et al. 2015), suggesting SWD emerging from fruit may not simply increase at higher densities. As such, the relationship between SWD abundance and parasitism rates of fruit may be more complex, requiring further investigation.

Relative abundances of SWD in both cover types and relative abundance of SWD emerged from $R$. allegheniensis showed strong, nonlinear patterns over the summer and fall. Harvest captures of SWD began low, peaked in mid-August (18 Aug [15-20 Aug]), declined to numbers slightly greater than the start of the season, and began to spike again at the end of sampling in October (28-30 Oct; Figure 2.6D). Forest captures of SWD showed a similar pattern, spiking later in September (11 Sep [7-17 Sep]), declining less afterwards, and apparently stabilizing at the end of sampling in October (Figure 2.7C). Relative abundance of SWD emerged from $R$. allegheniensis began similarly low before spiking approximately one week prior to trap captures in harvests (13 Aug [12-15 Aug]) and subsequently dropping until fruits were absent in mid-September (Figure 2.8D). Patterns in adult SWD trap captures match those in early studies investigating SWD abundances in forest ecosystems, emphasizing the importance of date for predicting both SWD abundances and SWD emergence from fruit (Briem et al. 2018, 
Thistlewood et al. 2018). Multiple factors can influence the timing of SWD populations during the year, especially climatic conditions and resource availability (Wiman et al. 2014, Poyet et al. 2015, Enriquez and Colinet 2017, Elsensohn and Loeb 2018). Extensive winter mortality and sparse spring populations (Dalton et al. 2011, Jakobs et al. 2015, Ryan et al. 2016) are consistent with low captures and parasitism in early to mid-July. While $R$. allegheniensis fruit counts did not correlate strongly with date $(r<0.50)$, the spike in $R$. allegheniensis parasitism and SWD harvest trap captures shortly after occurred during the July-August ripening period for $R$. allegheniensis at the ANF. The spike in forest SWD trap captures occurred during the AugustSeptember ripening period for P. serotina at the ANF (Uchytil 1991). Again, while I did not account for abiotic factors or other non- $R$. allegheniensis or non- $P$. serotina resources that likely influenced populations throughout the summer and fall (Thistlewood et al. 2019), exploitation of both these host species probably contributed to the dramatic increase in trap captures in each cover type (Kenis et al. 2016). The late-season peak in SWD captures is particularly interesting, as I found no $R$. allegheniensis fruits and few fruits of any other species after mid-September. Captures of SWD at forest points also appeared as if they were to again increase, as observed in previous studies (Briem et al. 2018, Thistlewood et al. 2018). Populations of SWD can exploit other resources, such as dropped fruit persisting on the ground (Kienzle et al. 2020) or non-fruit, such as tree sap, fall-fruiting fungi, or animal feces (Kanzawa 1939, Kimura 1976, Stockton et al. 2019). These may have sustained high populations through October, when flies then aggregated in timber harvests in search of fall- or winter-fruiting species. Additionally, while I did not examine SWD movement at the ANF as previously stated, populations may have moved between timber harvests and forest canopies to search out and exploit resources, thanks to high mobility 
over the course of a season (Wang et al. 2016, Tait et al. 2018). These possible explanations, while consistent with the correlations of captures between cover types, require further study.

An interesting but predicted result of this study was the strong relationship between SWD harvest captures and proportion of $R$. allegheniensis crop susceptible to parasitism at each harvest point (Figure 2.6C). Why this relationship was opposite that of ripening and fruit abundance is unclear. Additionally, no such relationship to relative abundance of SWD emerged from fruit existed, unlike that of fruit abundance. Literature on the importance of the proportion of fruit crop ripeness to relative abundance of fruit pests is limited. However, if fruit crop ripeness proportion is a strong predictor for SWD relative abundances, it may serve as a useful tool for predicting SWD populations in fruit-rich agricultural and natural systems.

In addition to possible resources both locally and in adjacent cover types, other considerations of factors influencing SWD abundances and fruit parasitism should be taken. As stated previously, abiotic factors were beyond the scope of this study but are consistently important predictors for SWD activity and population dynamics (Tochen et al. 2014, 2016; Enriquez and Colinet 2017; Evans et al. 2017). In addition to the microclimate level (Diepenbrock and Burrack 2017, Schöneberg et al. 2020), multi-year studies of SWD showed interannual variation in population dynamics exists, possibly due to climatic factors (Briem et al. 2018, Thistlewood et al. 2018). I did not separate observations by year due to the short duration of the study (2 years) but still observed strong connections of SWD to local R. allegheniensis fruit and $P$. serotina basal area. Incorporating temperature and humidity with fruit resources will provide a valuable avenue of future research when studying SWD populations in forest ecosystems (Wiman et al. 2014), especially across several years. 
Many important gaps in our understanding of SWD in forest ecosystems remain and require addressing. For instance, what alternative fruit hosts do SWD utilize to persist and grow in the spring, fall, and winter before and after the emergence of $R$. allegheniensis fruits, and what are SWD parasitism rates for fruiting species other than $R$. allegheniensis? This is especially important for P. serotina, which may be critically important for increasing SWD abundance in mature forests, and for predicting SWD fruit parasitism in regenerating harvests. A second important knowledge gap is understanding whether SWD parasitism of fruits affects consumption of fruits and seed dispersal by wildlife, seed germination, or recruitment of plants into future plant communities. Fruit resources are critical for many wildlife species (Martin et al. 1961, McCarty et al. 2002), and parasitism of fruits by insects may reduce consumption by wildlife (Sallabanks and Courtney 1992, Traveset et al. 1995). P. serotina is especially valued for its timber (Marquis 1975) and consumed by many wildlife species (Uchytil 1991). Loss of forest fruits may therefore have extensive impacts to forest ecosystems and, consequently, both wildlife and humans that rely on the resources in these ecosystems (Poyet et al. 2015, Turcotte et al. 2018, Roche et al. 2021). However, if plant reproductive strategies such as masting reduce pest pressure on individual fruits, negative impacts to fruit consumption and seed dispersal, if existent, may be dampened (Roche et al. 2021).

\section{MANAGEMENT IMPLICATIONS}

This study demonstrates a potential for widespread parasitism of fruit resources and population growth by SWD in both mature forest and regenerating harvests in forest ecosystems. It also demonstrates parasitism in timber harvests is affected by factors beyond the local scale and should include variables in the surrounding forest. Continued monitoring should be used to further understand the implications of SWD invasion of forest ecosystems and whether 
management action is warranted. Findings of this study may help in guiding considerations for SWD monitoring in forest ecosystems. Initiation of SWD monitoring in forests in the summer should consider the fruiting phenology of local plant species, especially those that produce large crops in concentrated locations (e.g., in regenerating harvests or mature forest stands). Ideally, summer monitoring at the ANF in both mature forest and regenerating harvests should begin before mid-July, when SWD were first captured in this study. When possible, monitoring for SWD should consider monitoring proportions of susceptible fruits, which correlate positively to trap captures compared to fruit abundances. Identifying thresholds of proportion ripeness and abundances of SWD may be an effective tool for determining thresholds for management action, if needed. However, fruit samples should be collected as soon as fruits begin ripening, to best confirm presence of SWD and parasitism of fruits (Pelton et al. 2016).

If management of SWD is made a priority in the future, results of this study suggest actions in forest ecosystems will experience serious challenges. Adult SWD associate with hosts in different habitats and likely move between habitats to exploit them. Mobility of SWD in seminatural systems already poses a challenge to SWD management for crop producers (Lee et al. 2015). If SWD moves between habitats in forest ecosystems, action in any single habitat would likely be insufficient. More likely, a multi-habitat, forest-wide effort would be necessary.

Additionally, findings of this study can inform local fruit producers in planning and management for SWD. Management for SWD can be financially costly (Farnsworth et al. 2017, Drummond et al. 2019), making information on SWD activity in nearby forest reservoirs valuable for decision-making. The lack of a strong relationship to forest type suggests SWD are likely to become abundant in different forest types, making it difficult for producers to avoid possible invasion of crop lands from forest by simply avoiding stands of a certain forest type. At 
the very least, producers should avoid planting at least $500 \mathrm{~m}$ from forest when possible.

Producers should also avoid planting at least $500 \mathrm{~m}$ from regenerating harvests with large fruit crops of wild plants (at least 3 years post-harvest), where SWD populations exploit fruiting species and increase dramatically in the summer. Producers growing crops near forest habitat should invest in management for SWD regardless of the forest type, though producers near fruitrich Allegheny harvests should take extra precautions. Initiation of monitoring and management should reflect the phenology of SWD, while considering the fruiting of $R$. allegheniensis in regenerating harvests and $P$. serotina throughout the forest. Specifically, producers should prepare for management to take effect as early as mid-July, with risk of cropland invasion by SWD heaviest once populations have spiked, apparently facilitated by $R$. allegheniensis crops in mid-July to early August and P. serotina crops in late August-September.

\section{LITERATURE CITED}

Asplen, M. K., G. Anfora, A. Biondi, D. S. Choi, D. Chu, K. M. Daane, P. Gibert, A. P. Gutierrez, K. A. Hoelmer, W. D. Hutchison, et al. 2015. Invasion biology of spotted wing Drosophila (Drosophila suzukii): a global perspective and future priorities. Journal of Pest Science 88:469-494.

Atallah, J., L. Teixeira, R. Salazar, G. Zaragoza, and A. Kopp. 2014. The making of a pest: the evolution of a fruit-penetrating ovipositor in Drosophila suzukii and related species. Proceedings of the Royal Society B: Biological Sciences 281:20132840.

Bahlai, C. A., S. Sikkema, R. H. Hallett, J. Newman, and A. W. Schaafsma. 2010. Modeling distribution and abundance of soybean aphid in soybean fields using measurements from the surrounding landscape. Environmental Entomology 39:50-56. 
Becher, P. G., G. Flick, E. Rozpedowska, A. Schmidt, A. Hagman, S. Lebreton, M. C. Larsson, B. S. Hansson, J. Piškur, P. Witzgall, et al. 2012. Yeast, not fruit volatiles mediate Drosophila melanogaster attraction, oviposition and development. Functional Ecology $26: 822-828$.

Beers, E. H., R. A. Van Steenwyk, P. W. Shearer, W. W. Coates, and J. A. Grant. 2011. Developing Drosophila suzukii management programs for sweet cherry in the western United States. Pest Management Science 67:1386-1395.

Bellamy, D. E., M. S. Sisterson, and S. S. Walse. 2013. Quantifying host potentials: indexing postharvest fresh fruits for spotted wing drosophila, Drosophila suzukii. PLoS ONE 8(4):e61227.

Bolda, M. P., R. E. Goodhue, and F. G. Zalom. 2010. Spotted wing drosophila: potential economic impact of a newly established pest. Agricultural Resource Economics Update 13:5-8.

Boyd, I. L., P. H. Freer-Smith, C. A. Gilligan, and H. C. J. Godfray. 2013. The consequence of tree pests and diseases for ecosystem services. Science 342:1235773.

Briem, F., A. R. Dominic, B. Golla, C. Hoffmann, C. Englert, A. Herz, and H. Vogt. 2018. Explorative data analysis of Drosophila suzukii trap catches from a seven-year monitoring program in southwest Germany. Insects 9:125.

Brose, P. 2011. Fate of the 2001 acorn crop at Clear Creek State Forest, Pennsylvania. Pages 253-261 in. Proceedings, 17th central hardwood forest conference. S. Fei, J. M. Lhotka, J. W. Stringer, K. W. Gottschalk, and G. W. Miller, editors. U.S. Forest Service General Technical Report NRS-P-78, Newtown Square, Pennsylvania, USA. 
Burrack, H. J., M. Asplen, L. Bahder, J. Collins, F. A. Drummond, C. Guédot, R. Isaacs, D. Johnson, A. Blanton, J. C. Lee, et al. 2015. Multistate comparison of attractants for monitoring Drosophila suzukii (Diptera: Drosophilidae) in blueberries and caneberries. Environmental Entomology 44:704-712.

Cahenzli, F., I. Bühlmann, C. Daniel, and J. Fahrentrapp. 2018. The distance between forests and crops affects the abundance of Drosophila suzukii during fruit ripening, but not during harvest. Environmental Entomology 47:1274-1279.

Chaplin-Kramer, R., M. E. O’Rourke, E. J. Blitzer, and C. Kremen. 2011. A meta-analysis of crop pest and natural enemy response to landscape complexity. Ecology Letters 14:922932.

Clark, M. S., and S. H. Gage. 1997. Relationship between fruit yield and damage by codling moth and Plum curculio in a biologically-managed apple orchard. Great Lakes Entomologist 30:161-168.

Cloonan, K. R., J. Abraham, S. Angeli, Z. Syed, and C. Rodriguez-Saona. 2018. Advances in the chemical ecology of the spotted wing drosophila (Drosophila suzukii) and its applications. Journal of Chemical Ecology 44:922-939.

Dalton, D. T., V. M. Walton, P. W. Shearer, D. B. Walsh, J. Caprile, and R. Isaacs. 2011. Laboratory survival of Drosophila suzukii under simulated winter conditions of the Pacific Northwest and seasonal field trapping in five primary regions of small and stone fruit production in the United States. Pest Management Science 67:1368-1374.

Diepenbrock, L. M., and H. J. Burrack. 2017. Variation of within-crop microhabitat use by Drosophila suzukii (Diptera: Drosophilidae) in blackberry. Journal of Applied Entomology 141:1-7. 
Dormann, C. F., J. Elith, S. Bacher, C. Buchmann, G. Carl, G. Carré, J. R. G. Marquéz, B. Gruber, B. Lafourcade, P. J. Leitão, et al. 2013. Collinearity: a review of methods to deal with it and a simulation study evaluating their performance. Ecography 36:027-046.

Drummond, F., E. Ballman, and J. Collins. 2019. Population dynamics of spotted wing drosophila (Drosophila suzukii (matsumura)) in Maine wild blueberry (Vaccinium angustifolium Aiton). Insects 10:1-22.

Ellison, A. M., M. S. Bank, B. D. Clinton, E. A. Colburnm, K. Elliott, C. R. Ford, D. R. Foster, B. D. Kloeppel, J. D. Knoepp, G. M. Lovett, et al. 2005. Loss of foundation species: consequences for the structure and dynamics of forested ecosystems. Frontiers in Ecology and Evolution 3:479-486.

Elsensohn, J. E., and G. M. Loeb. 2018. Non-crop host sampling yields insights into small-scale population dynamics of Drosophila suzukii (Matsumura). Insects 9:5.

Emiljanowicz, L. M., G. D. Ryan, A. Langille, and J. Newman. 2014. Development, reproductive output and population growth of the fruit fly pest Drosophila suzukii (Diptera: Drosophilidae) on artificial diet. Journal of Economic Entomology 107:13921398.

Enriquez, T., and H. Colinet. 2017. Basal tolerance to heat and cold exposure of the spotted wing drosophila, Drosophila suzukii. PeerJ.5:e3112.

Evans, R. K., M. D. Toews, and A. A. Sial. 2017. Diel periodicity of Drosophila suzukii (Diptera: Drosophilidae) under field conditions. PLoS ONE 12(2):e0171718.

Eyre, F. H. 1980. Forest cover types of the United States and Canada. Society of American Foresters. Washington, DC, USA. 
Fajvan, M. A., and J. M. Wood. 1996. Stand structure and development after gypsy moth defoliation in the Appalachian Plateau. Forest Ecology and Management 89:79-88.

Farnsworth, D., K. A. Hamby, M. Bolda, R. E. Goodhue, J. C. Williams, and F. G. Zalom. 2017. Economic analysis of revenue losses and control costs associated with the spotted wing drosophila, Drosophila suzukii (Matsumura), in the California raspberry industry. Pest Management Science 73:1083-1090.

Gandhi, K. J. K., and D. A. Herms. 2010. Direct and indirect effects of alien insect herbivores on ecological processes and interactions in forests of eastern North America. Biological Invasions 12:389-405.

Garantonakis, N., K. Varikou, and A. Birouraki. 2016. Spread of Drosophila suzukii in orchards of Crete. Entomologia Generalis 36:63-70.

Gardiner, M. M., D. A. Landis, C. Gratton, N. Schmidt, M. O’Neal, E. Mueller, J. Chacon, G. E. Heimpel, and C. D. Difonzo. 2009. Landscape composition influences patterns of native and exotic lady beetle abundance. Diversity and Distributions 15:554-564.

Gelman, A., J. B. Carlin, H. S. Stern, and D. B. Rubin. 2004. Bayesian data analysis. Second edition. Chapman and Hall/CRC, New York, New York, USA.

Gelman, A., and J. Hill. 2007. Data analysis using regression and multilevel/hierarchical models. Cambridge University Press, New York, NY, USA.

Goodhue, R. E., M. Bolda, D. Farnsworth, J. C. Williams, and F. G. Zalom. 2011. Spotted wing drosophila infestation of California strawberries and raspberries: economic analysis of potential revenue losses and control costs. Pest Management Science 67:1396-1402.

Hamby, K. A., D. E. Bellamy, J. C. Chiu, J. C. Lee, V. M. Walton, N. G. Wiman, R. M. York, and A. Biondi. 2016. Biotic and abiotic factors impacting development, behavior, 
phenology, and reproductive biology of Drosophila suzukii. Journal of Pest Science 89:605-619.

Hamby, K. A., M. P. Bolda, M. E. Sheehan, and F. G. Zalom. 2014. Seasonal monitoring for Drosophila suzukii (Diptera: Drosophilidae) in California commercial raspberries. Environmental Entomology 43:1008-1018.

Hamby, K. A., A. Hernández, K. Boundy-Mills, and F. G. Zalom. 2012. Associations of yeasts with spotted-wing Drosophila (Drosophila suzukii; Diptera: Drosophilidae) in cherries and raspberries. Applied and Environmental Microbiology 78:4869-4873.

Hardin, J. A., D. A. Kraus, and H. J. Burrack. 2015. Diet quality mitigates intraspecific larval competition in Drosophila suzukii. Entomologia Experimentalis et Applicata 156:59-65.

Haro-Barchin, E., J. Scheper, C. Ganuza, G. A. De Groot, F. Colombari, R. van Kats, and D. Kleijn. 2018. Landscape-scale forest cover increases the abundance of Drosophila suzukii and parasitoid wasps. Basic and Applied Ecology 31:33-43.

Harris, D. W., K. A. Hamby, H. E. Wilson, and F. G. Zalom. 2014. Seasonal monitoring of Drosophila suzukii (Diptera: Drosophilidae) in a mixed fruit production system. Journal of Asia-Pacific Entomology 17:857-864.

Hennig, E. I., and D. Mazzi. 2018. Spotted wing drosophila in sweet cherry orchards in relation to forest characteristics, bycatch, and resource availability. Insects 9:118.

Herms, D. A., and D. G. McCullough. 2014. Emerald ash borer invasion of North America: history, biology, ecology, impacts, and management. Annual Review of Entomology 59:13-30. 
Iglesias, L. E., Nyoike, T. W., Liburd, O. E. 2014. Effect of trap design, bait type, and age on captures of Drosophila suzukii (Diptera: Drosophilidae) in berry crops. Journal of Economic Entomology 107:1508-1518.

Ioriatti, C., V. Walton, D. Dalton, G. Anfora, A. Grassi, S. Maistri, and V. Mazzoni. 2015. Drosophila suzukii (Diptera: Drosophilidae) and its potential impact to wine grapes during harvest in two cool climate wine grape production regions. Journal of Economic Entomology 108:1148-1155.

Jackman, S. 2009. Bayesian analysis for the social sciences. John Wiley and Sons, Chichester, United Kingdom.

Jaffe, B. D., A. Avanesyan, H. K. Bal, Y. Feng, J. Grant, M. J. Grieshop, J. C. Lee, O. E. Liburd, E. Rhodes, C. Rodriguez-Saona, et al. 2018. Multistate comparison of attractants and the impact of fruit development stage on trapping Drosophila suzukii (Diptera:

Drosophilidae) in raspberry and blueberry. Environmental Entomology 47:935-945.

Jakobs, R., T. D. Gariepy, and B. J. Sinclair. 2015. Adult plasticity of cold tolerance in a continental-temperate population of Drosophila suzukii. Journal of Insect Physiology 79:1-9.

Janzen, D. H. 1971. Escape of Cassia grandis L. beans from predators in time and space. Ecology 52:964-979.

Joshi, N. K., B. Butler, K. Demchak, and D. Biddinger. 2017. Seasonal occurrence of spotted wing drosophila in various small fruits and berries in Pennsylvania and Maryland. Journal of Applied Entomology 141:156-160.

Kanzawa, T. 1939. Studies on Drosophila suzukii Mats. Kofu, Yamanashi agricultural experiment station. Abstract in Review of Applied Entomology 29: 622. 
Kellner, K. 2019. jagsUI: a wrapper around "rjags" to streamline "JAGS" analyses (R package version 1.5.1). Retrieved from http://CRAN.R-project.org/package=jagsUI.

Kelly, D., A. L. Harrison, W. G. Lee, I. J. Payton, P. R. Wilson, and E. M. Schauber. 2000. Predator satiation and extreme mast seeding in 11 species of Chionochloa (Poaceae). Oikos 90:477-488.

Kelly, D., and V. L. Sork. 2002. Mast seeding in perennial plants: why, how, where? Annual Review of Ecology and Systematics 33:427-447.

Kenis, M., M. A. Auger-Rozenberg, A. Roques, L. Timms, C. Péré, M. J. W. Cock, J. Settele, S. Augustin, and C. Lopez-Vaamonde. 2009. Ecological effects of invasive alien insects. Biological Invasions 11:21-45.

Kenis, M., L. Tonina, R. Eschen, B. van der Sluis, M. Sancassani, N. Mori, T. Haye, and H. Helsen. 2016. Non-crop plants used as hosts by Drosophila suzukii in Europe. Journal of Pest Science 89:735-748.

Kéry, M. 2010. Introduction to WinBUGS for ecologists. Academic Press, Waltham, Massachusetts, USA.

Kienzle, R., L. B. Groß, S. Caughman, and M. Rohlfs. 2020. Resource use by individual Drosophila suzukii reveals a flexible preference for oviposition into healthy fruits. Scientific reports 10:3132.

Kimura, M. T. 1976. Drosophila survey of Hokkaido, XXXII. A field survey of fungus preferences of Drosophilid flies in Sapporo. Journal of the Faculty of Science Hokkaido University Series VI. Zoology 20:288-298. 
Kirkpatrick, D. M., L. J. Gut, and J. R. Miller. 2018. Estimating monitoring trap plume reach and trapping area for Drosophila suzukii (Diptera: Drosophilidae) in Michigan tart cherry. Journal of Economic Entomology 111:1285-1289.

Klick, J., W. Q. Yang, V. M. Walton, D. T. Dalton, J. R. Hagler, A. J. Dreves, J. C. Lee, and D. J. Bruck. 2016. Distribution and activity of Drosophila suzukii in cultivated raspberry and surrounding vegetation. Journal of Applied Entomology 140:37-46.

Krause Pham, C., and A. Ray. 2015. Conservation of olfactory avoidance in Drosophila species and identification of repellents for Drosophila suzukii. Scientific Reports 5:11527.

Lasa, R., E. Tadeo, R. A. Toledo-Hérnandez, L. Carmona, I. Lima, and T. Williams. 2017. Improved capture of Drosophila suzukii by a trap baited with two attractants in the same device. PLoS ONE 12(11):e0188350.

Lee, J. C., D. J. Bruck, H. Curry, D. Edwards, D. R. Haviland, R. A. Van Steenwyk, and B. M. Yorgey. 2011a. The susceptibility of small fruits and cherries to the spotted-wing drosophila, Drosophila suzukii. Pest Management Science 67:1358-1367.

Lee, J. C., D. J. Bruck, A. J. Dreves, C. Ioriatti, H. Vogt, and P. Baufeld. 2011b. In focus: Spotted wing drosophila, Drosophila suzukii, across perspectives. Pest Management Science 67:1349-1351.

Lee, J. C., H. J. Burrack, L. D. Barrantes, E. H. Beers, A. J. Dreves, K. A. Hamby, D. R. Haviland, R. Isaacs, T. A. Richardson, P. W. Shearer, et al. 2012. Evaluation of monitoring traps for Drosophila suzukii (Diptera: Drosophilidae) in North America. Journal of Economic Entomology 105:1350-1357. 
Lee, J. C., A. J. Dreves, A. M. Cave, S. Kawai, R. Isaacs, J. C. Miller, S. Van Timmeren, and D. J. Bruck. 2015. Infestation of wild and ornamental noncrop fruits by Drosophila suzukii (Diptera: Drosophilidae). Annals of the Entomological Society of America 108:117-129.

Lee, J. C., P. W. Shearer, L. D. Barrantes, E. H. Beers, H. J. Burrack, D. T. Dalton, A. J. Dreves, L. J. Gut, K. A. Hamby, D. R. Haviland, et al. 2013. Trap designs for monitoring Drosophila suzukii (Diptera: Drosophilidae). Environmental Entomology 42:1348-1355.

Leskey, T. C., G. C. Hamilton, A. L. Nielson, D. F. Polk, C. Rodriguez-Saona, J. C. Bergh, D. A. Herbert, T. P. Kuhar, D. Pfeiffer, G. P. Dively, et al. 2012. Pest status of the brown marmorated stink bug, Halymorpha halys in the USA. Outlooks on Pest Management 23:218-226.

Levey, D. J. 1988. Spatial and temporal variation in Costa Rican fruit and fruit-eating bird abundance. Ecological Monographs 58:251-269.

Lovett, G. M., C. D. Canham, M. A. Arthur, K. C. Weathers, and R. D. Fitzhugh. 2006. Forest ecosystem responses to exotic pests and pathogens in eastern North America. BioScience 56:395-405.

Marquis, D. A. 1975. The Allegheny hardwood forests of Pennsylvania. General Technical Report NE-15. U.S. Forest Service, Northeast Forest and Experiment Station, Upper Darby, Pennsylvania, USA.

Martin, A. C., H. S. Zim, and A. L. Nelson. 1961. American wildlife \& plants: a guide to wildlife food habits: the use of trees, shrubs, weeds, and herbs by birds and mammals of the United States. Dover, New York, New York, USA. 
McCarty, J. P., D. J. Levey, C. H. Greenberg, and S. Sargent. 2002. Spatial and temporal variation in fruit use by wildlife in a forested landscape. Forest Ecology and Management 164:277-291.

McDiarmid, R. W., R. E. Ricklefs, and M. S. Foster. 1977. Dispersal of Stemmadenia donnellsmithii (Apocynaceae) by birds. Biotropica 9:9-25.

Mitsui, H., K. Beppu, and M. T. Kimura. 2010. Seasonal life cycles and resource uses of flowerand fruit-feeding drosophilid flies (Diptera: Drosophilidae) in central Japan. Entomological Science 13:60-67.

Mitsui, H., K. H. Takahashi, and M. T. Kimura. 2006. Spatial distributions and clutch sizes of Drosophila species ovipositing on cherry fruits of different stages. Population Ecology 48:233-237.

Moeser, J., and S. Vidal. 2004. Do alternative host plants enhance the invasion of the maize pest Diabrotica virgifera virgifera (Coleoptera: Chrysomelidae, Galerucinae) in Europe? Environmental Entomology 33:1169-1177.

Morin, R. S., A. M. Liebhold, K. W. Gottschalk, D. B. Twardus, R. E. Acciavatti, R. L. White, S. B. Horsley, W. D. Smith, and E. R. Luzader. 2006. Analysis of forest health monitoring surveys on the Allegheny National Forest (1998-2001). General Technical Report NE339. U.S. Forest Service, Northeastern Research Station, Newtown Square, Pennsylvania, USA.

Nielsen, A. L., and G. C. Hamilton. 2009. Seasonal occurrence and impact of Halyomorpha halys (Hemiptera: Pentatomidae) in tree fruit. Journal of Economic Entomology 102:1133-1140. 
PA DCNR 2020. Open data. <https://newdata-denr.opendata.arcgis.com>. Accessed 1 May 2021.

Panel, A. D. C., L. Zeeman, B. J. van der Sluis, P. van Elk, B. A. Pannebakker, B. Wertheim, and H. H. M. Helsen. 2018. Overwintered Drosophila suzukii are the main source for infestations of the first fruit crops of the season. Insects 9:145.

Parsa, S., R. Ccanto, and J. A. Rosenheim. 2011. Resource concentration dilutes a key pest in indigenous potato agriculture. Ecological Applications 21:539-546.

Pelton, E., C. Gratton, R. Isaacs, S. Van Timmeren, A. Blanton, and C. Guédot. 2016. Earlier activity of Drosophila suzukii in high woodland landscapes but relative abundance is unaffected. Journal of Pest Science 89:725-733.

PGC (Pennsylvania Game Commission). 2014. State Game Lands No. 86. <https://www.pgc.pa.gov/HuntTrap/StateGameLands/Documents/SGL\%20Maps/SGL 086.pdf>. Accessed 29 Apr 2021.

Plummer, M. 2003. JAGS: a program for analysis of Bayesian graphical models using Gibbs sampling. Proceedings of the 3rd International Workshop on Distributed Statistical Computing 124:1-10.

Poyet, M., P. Eslin, M. Héraude, V. Le Roux, G. Prévost, P. Gibert, and O. Chabrerie. 2014. Invasive host for invasive pest: when the Asiatic cherry fly (Drosophila suzukii) meets the American black cherry (Prunus serotina) in Europe. Agricultural and Forest Entomology 16:251-259.

Poyet, M., V. Le Roux, P. Gibert, A. Meirland, G. Prévost, P. Eslin, and O. Chabrerie. 2015. The wide potential trophic niche of the Asiatic fruit fly Drosophila suzukii: the key of its invasion success in temperate Europe? PLoS ONE 10(11):e0142785. 
R Core Team. 2021. R: A language and environment for statistical computing. R Foundation for Statistical Computing, Vienna, Austria.

Rhainds, M., and G. English-Loeb. 2003. Testing the resource concentration hypothesis with tarnished plant bug on strawberry: density of hosts and patch size influence the interaction between abundance of nymphs and incidence of damage. Ecological Entomology 28:348-358.

Rice, K. B., S. K. Jones, W. Morrison, and T. C. Leskey. 2017a. Spotted wing drosophila prefer low hanging fruit: insights into foraging behavior and management strategies. Journal of Insect Behavior 30:645-661.

Rice, K. B., R. R. Troyer, K. M. Watrous, J. F. Tooker, and S. J. Fleischer. 2017b. Landscape factors influencing stink bug injury in Mid-Atlantic tomato fields. Journal of Economic Entomology 110:94-100.

Roche, D. P., S. H. Stoleson, and C. M. Lituma. 2021. Invasion of eastern deciduous forests by the spotted wing Drosophila: impacts and knowledge gaps. Wildlife Society Bulletin:10.1002/wsb.1234.

Rodriguez-Saona, C. R., D. Polk, P. V. Oudemans, R. Holdcraft, F. U. Zaman, R. Isaacs, and D. P. Cariveau. 2018. Landscape features determining the occurrence of Rhagoletis mendax (Diptera: Tephritidae) flies in blueberries. Agriculture, Ecosystems and Environment 258:113-120.

Root, R. B. 1973. Organization of a plant-arthropod association in simple and diverse habitats: the fauna of collards (Brassica oleracea). Ecological Monographs 43:95-124. 
Rose, C. L., P. J. Turk, S. M. Selego, and J. T. Anderson. 2014. White-footed mice (Peromyscus leucopus) select fruits of native species over invasive honeysuckle fruits. Journal of Mammalogy 95:108-116.

Royo, A. A., L. A. Vickers, R. P. Long, T. E. Ristau, S. H. Stoleson, and S. L. Stout. 2021. The forest of unintended consequences: Anthropogenic actions trigger the rise and fall of black cherry. BioScience 71:683-696.

Rusch, A., R. Bommarco, M. Jonsson, H. G. Smith, and B. Ekbom. 2013. Flow and stability of natural pest control services depend on complexity and crop rotation at the landscape scale. Journal of Applied Ecology 50:345-354.

Ryan, G. D., L. Emiljanowicz, F. Wilkinson, M. Kornya, and J. A. Newman. 2016. Thermal tolerances of the spotted-wing drosophila Drosophila suzukii (Diptera: Drosophilidae). Journal of Economic Entomology 109:746-752.

Sallabanks, R., and S. P. Courtney. 1992. Frugivory, seed predation, and insect-vertebrate interactions. Annual Review of Entomology 37:377-400.

Santoiemma, G., D. Fioretto, D. Corcos, N. Mori, and L. Marini. 2018a. Spatial synchrony in Drosophila suzukii population dynamics along elevational gradients. Ecological Entomology 44:182-189.

Santoiemma, G., N. Mori, L. Tonina, and L. Marini. 2018b. Semi-natural habitats boost Drosophila suzukii populations and crop damage in sweet cherry. Agriculture, Ecosystems and Environment 257:152-158.

Saracco, J. F., J. A. Collazo, and M. J. Groom. 2004. How do frugivores track resources? Insights from spatial analyses of bird foraging in a tropical forest. Oecologia 139:235245. 
Sasaki, M., and R. Sato. 1995. Bionomics of the cherry drosophila, Drosophila suzukii Matsumura (Diptera: Drosophilidae) in Futeushima prefecture (Japan). Annual Report of the Society of Plant Protection of North Japan 46:164-172.

Satake, A., O. N. Bjørnstad, and S. Kobro. 2004. Masting and trophic cascades: interplay between rowan trees, apple fruit moth, and their parasitoid in southern Norway. Oikos 104:540-550.

Scheiner, C., and E. A. Martin. 2020. Spatiotemporal changes in landscape crop composition differently affect density and seasonal variability of pests, parasitoids and biological pest control in cabbage. Agriculture, Ecosystems and Environment 301:107051.

Schmidt, J. M., T. S. Whitehouse, K. Green, H. Krehenwinkel, R. Schmidt-Jeffris, and A. A. Sial. 2019. Local and landscape-scale heterogeneity shape spotted wing drosophila (Drosophila suzukii) activity and natural enemy abundance: implications for trophic interactions. Agriculture, Ecosystems and Environment 272:86-94.

Schneider, G., J. Krauss, V. Riedinger, A. Holzschuh, and I. Steffan-Dewenter. 2015. Biological pest control and yields depend on spatial and temporal crop cover dynamics. Journal of Applied Ecology 52:1283-1292.

Schöneberg, T., A. Arsenault-Benoit, C. M. Taylor, B. R. Butler, D. T. Dalton, V. M. Walton, A. Petran, M. A. Rogers, L. M. Diepenbrock, H. J. Burrack, et al. 2020. Pruning of small fruit crops can affect habitat suitability for Drosophila suzukii. Agriculture, Ecosystems and Environment 294:106860.

Shibata, M., H. Tanaka, and T. Nakashizuka. 1998. Causes and consequences of mast seed production of four co-occurring Carpinus species in Japan. Ecology 79:54-64. 
Silvertown, J. W. 1980. The evolutionary ecology of mast seeding in trees. Biological Journal of the Linnean Society 14:235-250.

Stadler, B., T. Müller, D. Orwig, and R. Cobb. 2005. Hemlock woolly adelgid in New England forests: canopy impacts transforming ecosystem processes and landscapes. Ecosystems $8: 233-247$.

Stockton, D. G., R. Brown, and G. M. Loeb. 2019. Not berry hungry? Discovering the hidden food sources of a small fruit specialist, Drosophila suzukii. Ecological Entomology 44:810-822.

Stoleson, S. H. 2013. Condition varies with habitat choice in postbreeding forest birds. Auk $130: 417-428$.

Suthers, H. B., J. M. Bickal, and P. G. Rodewald. 2000. Use of successional habitat and fruit resources by songbirds during autumn migration in central New Jersey. Wilson Bulletin 112:249-260.

Tait, G., A. Grassi, F. Pfab, C. M. Crava, D. T. Dalton, R. Magarey, L. Ometto, S. Vezzulli, M. V. Rossi-Stacconi, A. Gottardello, et al. 2018. Large-scale spatial dynamics of Drosophila suzukii in Trentino, Italy. Journal of Pest Science 91:1213-1224.

Thistlewood, H. M. A., P. Gill, E. H. Beers, P. W. Shearer, D. B. Walsh, B. M. Rozema, S. Acheampong, S. Castagnoli, W. L. Yee, P. Smytheman, et al. 2018. Spatial analysis of seasonal dynamics and overwintering of Drosophila suzukii (Diptera: Drosophilidae) in the Okanagan-Columbia Basin, 2010-2014. Environmental Entomology 47:221-232.

Thistlewood, H. M. A. B. Rozema, and S. Acheampong. 2019. Infestation and timing of use of non-crop plants by Drosophila suzukii (Matsumura) (Diptera: Drosophilidae) in the Okanagan Basin, Canada. Canadian Entomologist 151:34-48. 
Thompson, J. N., and M. F. Willson. 1979. Evolution of temperate fruit/bird interactions: phenological strategies. Evolution 33:973-982.

Tingley, M. W., D. A. Orwig, R. Field, and G. Motzkin. 2002. Avian response to removal of a forest dominant: consequences of hemlock woolly adelgid infestations. Journal of Biogeography 29:1505-1516.

Tochen, S., D. T. Dalton, N. Wiman, C. Hamm, P. W. Shearer, and V. M. Walton. 2014. Temperature-related development and population parameters for Drosophila suzukii (Diptera: Drosophilidae) on cherry and blueberry. Environmental Entomology 43:501510.

Tochen, S., J. M. Woltz, D. T. Dalton, J. C. Lee, N. G. Wiman, and V. M. Walton. 2016. Humidity affects populations of Drosophila suzukii (Diptera: Drosophilidae) in blueberry. Journal of Applied Entomology 140:47-57.

Toda, M. J. 1987. Vertical microdistribution of Drosophilidae (Diptera) within various forests in Hokkaido III. The Tomakomai Experiment Forest, Hokkaido University. Ecology. Volume 52.

Tonina, L., N. Mori, M. Sancassani, P. Dall'Ara, and L. Marini. 2018. Spillover of Drosophila suzukii between noncrop and crop areas: implications for pest management. Agricultural and Forest Entomology 20:575-581.

Traveset, A., M. F. Willson, and J. C. Gaither. 1995. Avoidance by birds of insect-infested fruits of Vaccinium ovalifolium. Oikos 73:381-386.

Tscharntke, T., T. A. Rand, and F. J. J. Bianchi. 2005. The landscape context of trophic interactions: insect spillover across the crop-noncrop interface. Annales Zoologici Fennici 42:421-432. 
Turcotte, R. M., C. Larcenaire, R. Long, D. K. H. Martin, and L. Barringer. 2018. The spotted wing drosophila, Drosophila suzukii (Diptera: Drosophilidae): a new pest of concern for black cherry, Prunus serotina, on the High Allegheny Plateau in Pennsylvania.

Entomological News 127:390-399.

Uchytil, R. J. 1991. U.S. Department of Agriculture, Forest Service, Rocky Mountain Research Station, Fire Sciences Laboratory (Producer). Prunus serotina. Fire effects information system. <https://www.fs.fed.us/database/feis/plants/tree/pruser/all.html>. Accessed 26 Jan 2019.

USDA-FAS 2019. National Agriculture Imagery Program (NAIP) 2019 for Pennsylvania. Pennsylvania Spatial Data Access. <https://www.pasda.psu.edu/uci/DataSummary.aspx?dataset=3211>. Accessed 1 May 2020.

U.S. Forest Service. 2007. Allegheny National Forest record of decision for final environmental impact statement and the land and resource management plan. Warren, PA.

U.S. Forest Service. 2019. Allegheny National Forest GIS datasets. <https://www.fs.usda.gov/main/allegheny/landmanagement/gis>. Accessed 30 April 2020.

Venugopal, P. D., P. L. Coffey, G. P. Dively, and W. O. Lamp. 2014. Adjacent habitat influence on stink bug (Hemiptera: Pentatomidae) densities and the associated damage at field corn and soybean edges. PLoS ONE 9(10):e109917.

Walsh, D. B., M. P. Bolda, R. E. Goodhue, A. J. Dreves, J. Lee, D. J. Bruck, V. M. Walton, S. D. O’Neal, and F. G. Zalom. 2011. Drosophila suzukii (Diptera: Drosophilidae): invasive 
pest of ripening soft fruit expanding its geographic range and damage potential. Journal of Integrated Pest Management 2:G1-G7.

Wang, X. G., T. J. Stewart, A. Biondi, B. A. Chavez, C. Ingels, J. Caprile, J. A. Grant, V. M. Walton, and K. M. Daane. 2016. Population dynamics and ecology of Drosophila suzukii in Central California. Journal of Pest Science 89:701-712.

Wheelwright, N. T. 1986. A seven-year study of individual variation in fruit production in tropical bird-dispersed tree species in the family Lauraceae. Pages 19-35 in A. Estrada and T. H. Fleming, editors. Frugivores and seed dispersal. Tasks for vegetation science, Volume 15. Springer, Dordrecht, Netherlands.

Wiedenbeck, J., M. Wiemann, D. Alderman, J. Baumgras, and W. Luppold. 2004. Defining hardwood veneer log quality attributes. General Technical Report No. NE-313. USDA Forest Service, Northeastern Research Station. Newtown Square, Pennsylvania, USA.

Wiman, N. G., V. M. Walton, D. T. Dalton, G. Anfora, H. J. Burrack, J. C. Chiu, K. M. Daane, A. Grassi, B. Miller, S. Tochen, et al. 2014. Integrating temperature-dependent life table data into a matrix projection model for Drosophila suzukii population estimation. PLoS ONE 9(9):e106909.

With, K. 2002. The landscape ecology of invasive spread. Conservation Biology 16:1192-1203. Wong, J. S., A. C. Cave, D. M. Lightle, W. F. Mahaffee, S. E. Naranjo, N. G. Wiman, J. M. Woltz, and J. C. Lee. 2018. Drosophila suzukii flight performance reduced by starvation but not affected by humidity. Journal of Pest Science 91:1269-1278.

Work, T. T., and D. G. McCullough. 2000. Lepidopteran communities in two forest ecosystems during the first gypsy moth outbreaks in northern Michigan. Environmental Entomology 29:884-900. 


\section{TABLES}

Table 2.1. Final covariates used to model relative abundance of spotted wing Drosophila (Drosophila suzukii, SWD) in mature forest and regenerating harvests during the summer and fall (Jul-Oct) at Allegheny National Forest (ANF), Clear Creek State Forest (CCSF), and State Game Lands (SGL) 86, Pennsylvania, in 2019 and 2020. Multiple measures were pooled for a single value of each covariate at each point and checked for collinearity $(r \geq 0.7)$. Covariates were included in the following models: 1$)$ relative abundance of SWD at regenerating harvest points ("harvest"), 2) relative abundance of SWD at mature forest points ("forest"), and 3) relative abundance emerged from Allegheny blackberry (Rubus allegheniensis) fruit samples from regenerating harvest points ("infest"). Covariates were then excluded from final models using a stepwise removal process.

\begin{tabular}{|c|c|c|c|}
\hline $\begin{array}{l}\text { Covariate } \\
\text { category }\end{array}$ & Covariate name & Description & $\begin{array}{l}\text { Used ir } \\
\text { models }\end{array}$ \\
\hline Date & date & Ordinal date of first day traps were suspended at each sampling point & $1,2,3$ \\
\hline Date & date $^{2}$ & Ordinal date of first day traps were suspended at each sampling point, squared & $1,2,3$ \\
\hline Date & date $^{3}$ & Ordinal date of first day traps were suspended at each sampling point, cubed & 1,2 \\
\hline Fruit & ripen.ripe & $\begin{array}{l}\text { Number of ripening and ripe Allegheny blackberry (Rubus allegheniensis) fruits at each } \\
\text { harvest point }\end{array}$ & $1,2,3$ \\
\hline Fruit & Prop & Proportion of ripening and ripe $R$. allegheniensis fruits at each harvest point & $1,2,3$ \\
\hline Cherry & cherryBA & $\begin{array}{l}\text { Black cherry (Prunus serotina) basal area/quarter of 50-m radius plot, centered at each } \\
\text { forest point }\end{array}$ & $1,2,3$ \\
\hline $\begin{array}{l}\text { Forest } \\
\text { Composition }\end{array}$ & Allegheny & Sampling points located in Allegheny hardwood (categorical variable for Forest Type) & $1,2,3$ \\
\hline $\begin{array}{l}\text { Forest } \\
\text { Composition }\end{array}$ & MixedUpland & Sampling points located in mixed upland hardwood (categorical variable for Forest Type) & $1,2,3$ \\
\hline $\begin{array}{l}\text { Forest } \\
\text { Composition }\end{array}$ & Proximity & Distance from sampling point to the nearest mature Allegheny hardwood stand & 1,3 \\
\hline SWD & swdCUTcov & Number of SWD/trap/24 hours captured at paired regenerating harvest point & 2,3 \\
\hline SWD & swdFORESTcov & Number of SWD/trap/24 hours captured at paired mature forest point & 1 \\
\hline
\end{tabular}


Table 2.2. Final regression models for relative abundance of spotted wing Drosophila (Drosphila suzukii, SWD) during the summer and fall (Jul-Oct) in regenerating timber harvests ("harvest"), mature forest ("forest"), and Allegheny blackberry (Rubus allegheniensis) fruit samples ("infest") at Allegheny National Forest (ANF), Clear Creek State Forest (CCSF), and State Game Lands (SGL) 86, Pennsylvania, in 2019 and 2020. Each final model was created with a stepwise removal process of covariates from global models containing 10 initial covariates for the "harvest" and "infest" models and 9 covariates for the "forest" model. Posterior estimates and 90\% credible intervals (CIs) are given for each covariate's slope coefficient. Contrast is the difference in posterior estimate between Allegheny (Allegh) and mixed upland (Mixed) forest types ( $\beta_{\text {Allegh }}-\beta_{\text {Mixed }}$ ).

\begin{tabular}{|c|c|c|}
\hline Model & Distribution & Covariates $^{\mathrm{b}}$ (Estimate [90\% CI]) \\
\hline harvest & $\begin{array}{l}\text { Negative } \\
\text { binomial }\end{array}$ & $\begin{array}{l}\text { date }(-1.670[-1.982,-1.354]) ; \text { date }^{2}(-0.067[-0.183,0.046])^{\mathrm{a}} ; \text { date }^{3}(0.915[0.785,1.046]) ; \\
\text { ripen.ripe }(-0.459[-0.573,-0.334]) ; \text { prop }(0.267[0.134,0.403]) ; \\
\text { swdFORESTcov }(0.682[0.507,0.866])\end{array}$ \\
\hline forest & $\begin{array}{l}\text { Negative } \\
\text { binomial }\end{array}$ & $\begin{array}{l}\text { date }(0.162[-0.069,0.385])^{\mathrm{a}} ; \text { date }^{2}(-1.014[-1.120,-0.908]) ; \text { date }^{3}(0.444[0.319,0.573]) \\
\text { cherryBA }(0.301[0.187,0.418]) ; \operatorname{swdCUTcov}(0.312[0.198,0.433])\end{array}$ \\
\hline infest & $\begin{array}{l}\text { Negative } \\
\text { binomial }\end{array}$ & $\begin{array}{l}\text { date }(0.220[0.030,0.409]) ; \text { date }^{2}(-0.750[-0.956,-0.547]) \\
\text { ripen.ripe }(-0.289[-0.512,-0.060]) ; \text { cherryBA }(-0.261[-0.480,-0.046]) \text {; } \\
\text { Allegh }(0.553[0.060,1.066]) ; \text { Mixed }(0.022[-0.455,0.510])^{\mathrm{a}} \text {; } \\
\text { contrast }(0.530[0.093,0.974])\end{array}$ \\
\hline \multicolumn{3}{|c|}{$\begin{array}{l}\text { adenotes a covariate retained but did not meet the } 90 \% \text { CI criterion } \\
\text { bdefinitions of covariates included in final models: } \\
\text { date = ordinal date of first day traps were suspended at each sampling point; } \\
\text { ripen.ripe = number of ripening and ripe } R \text {. allegheniensis fruits at each harvest point; } \\
\text { prop = proportion of ripening and ripe } R \text {. allegheniensis fruits at each harvest point; } \\
\text { cherryBA = black cherry (Prunus serotina) basal area/quarter of } 50 \text {-m radius plot, centered at each forest point } \\
\text { Allegh = sampling points located in Allegheny hardwood (categorical variable for Forest Type); } \\
\text { Mixed = sampling points located in mixed upland hardwood (categorical variable for Forest Type); } \\
\text { swdFORESTcov = number of SWD/trap/24 hours captured at paired mature forest point; and } \\
\text { swdCUTcov = number of SWD/trap/24 hours captured at paired regenerating harvest point. }\end{array}$} \\
\hline
\end{tabular}




\section{FIGURES}

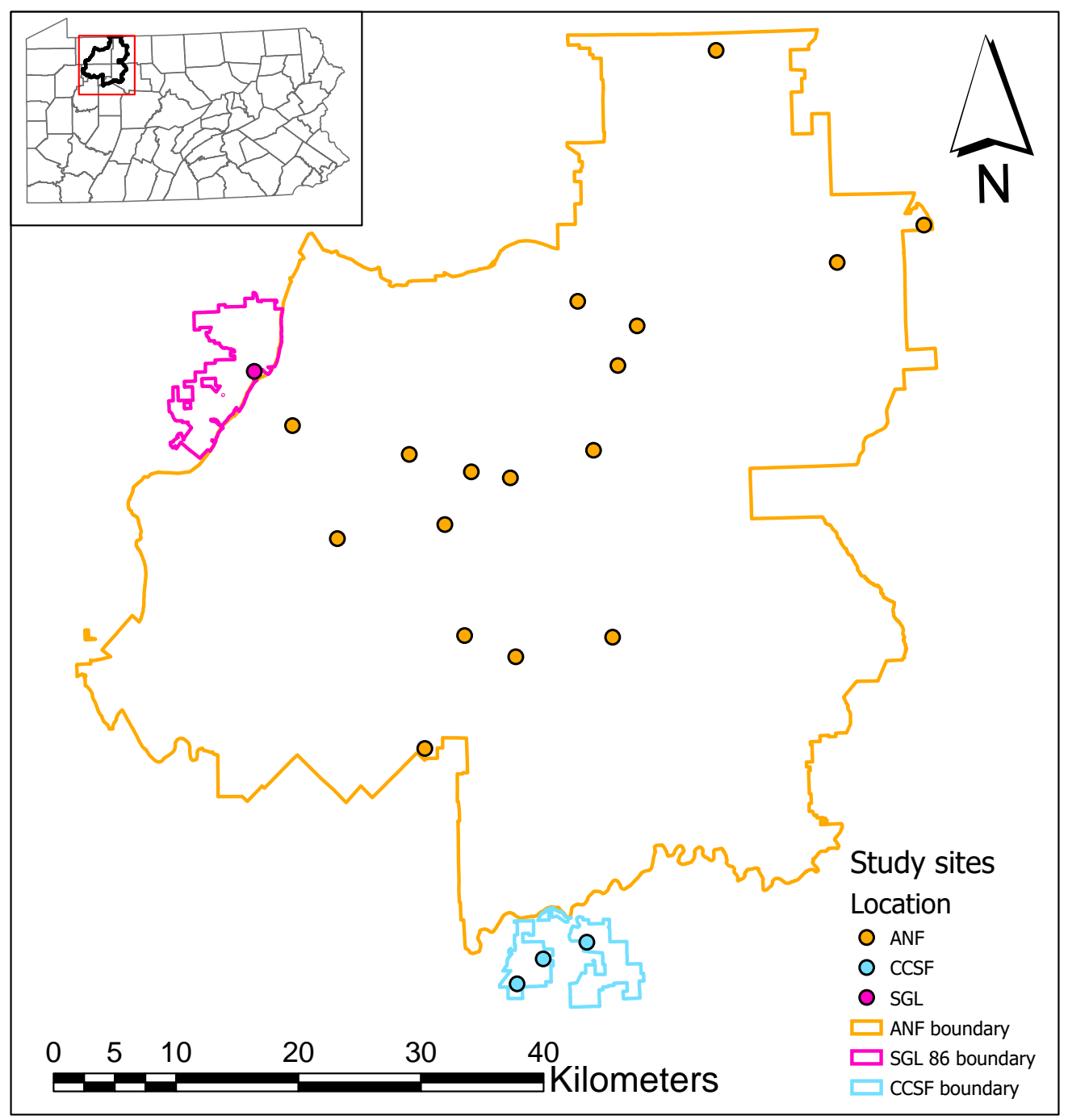

Figure 2.1. Study area used for surveys of spotted wing Drosophila (Drosophila suzukii) during the summer and fall in Pennsylvania in 2019 and 2020. Twenty-one sites were surveyed across Allegheny National Forest (ANF), Clear Creek State Forest (CCSF) due south, and State Game Lands (SGL) 86 west of the ANF along the Allegheny River in northwestern Pennsylvania. 


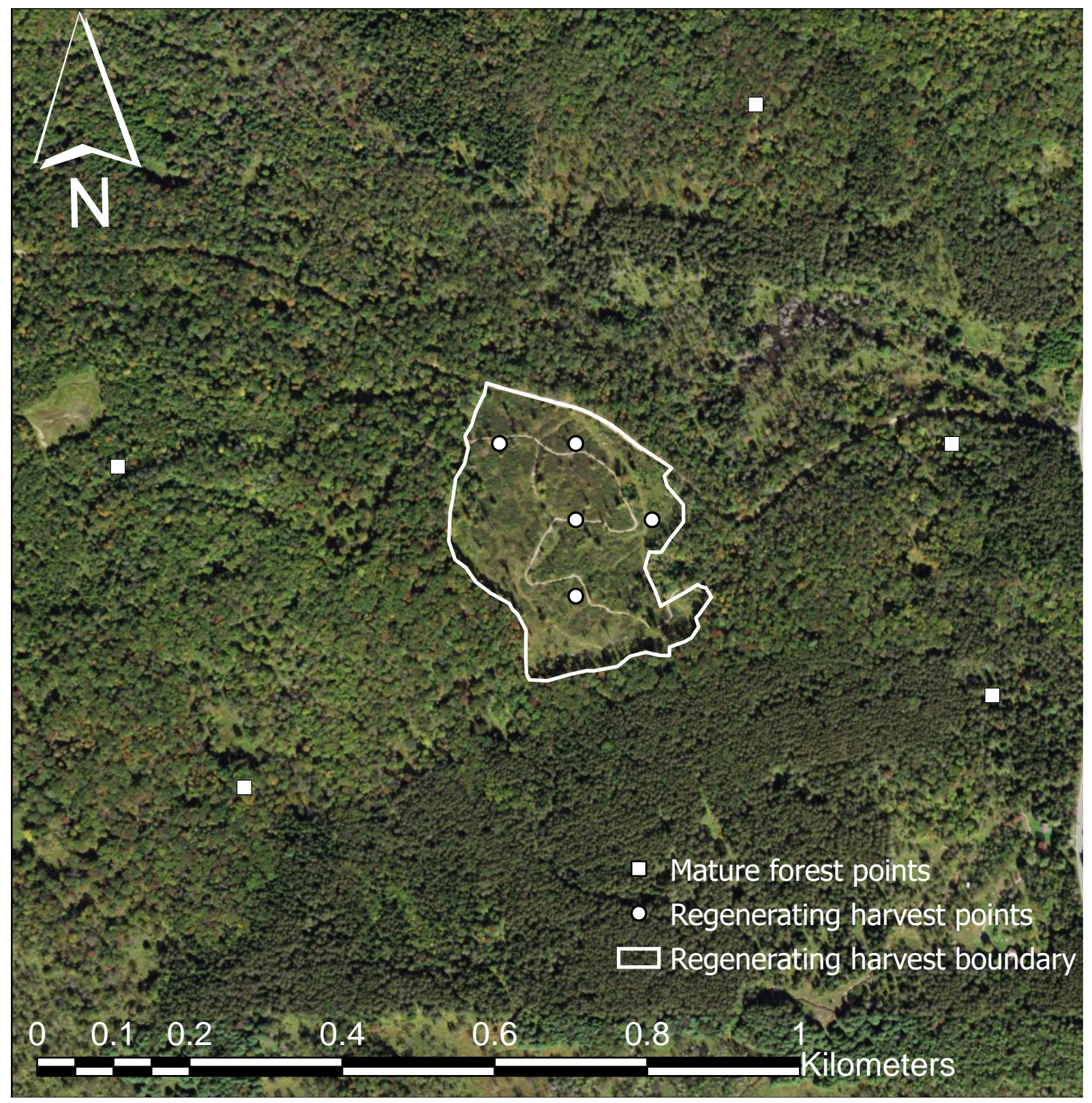

Figure 2.2. Example placement of sampling points used for sampling spotted wing Drosophila (Drosophila suzukii) in mature forest and regenerating timber harvests during the summer and fall at Allegheny National Forest (ANF), Clear Creek State Forest (CCSF), and State Game Lands (SGL) 86, Pennsylvania, in 2019 and 2020. 


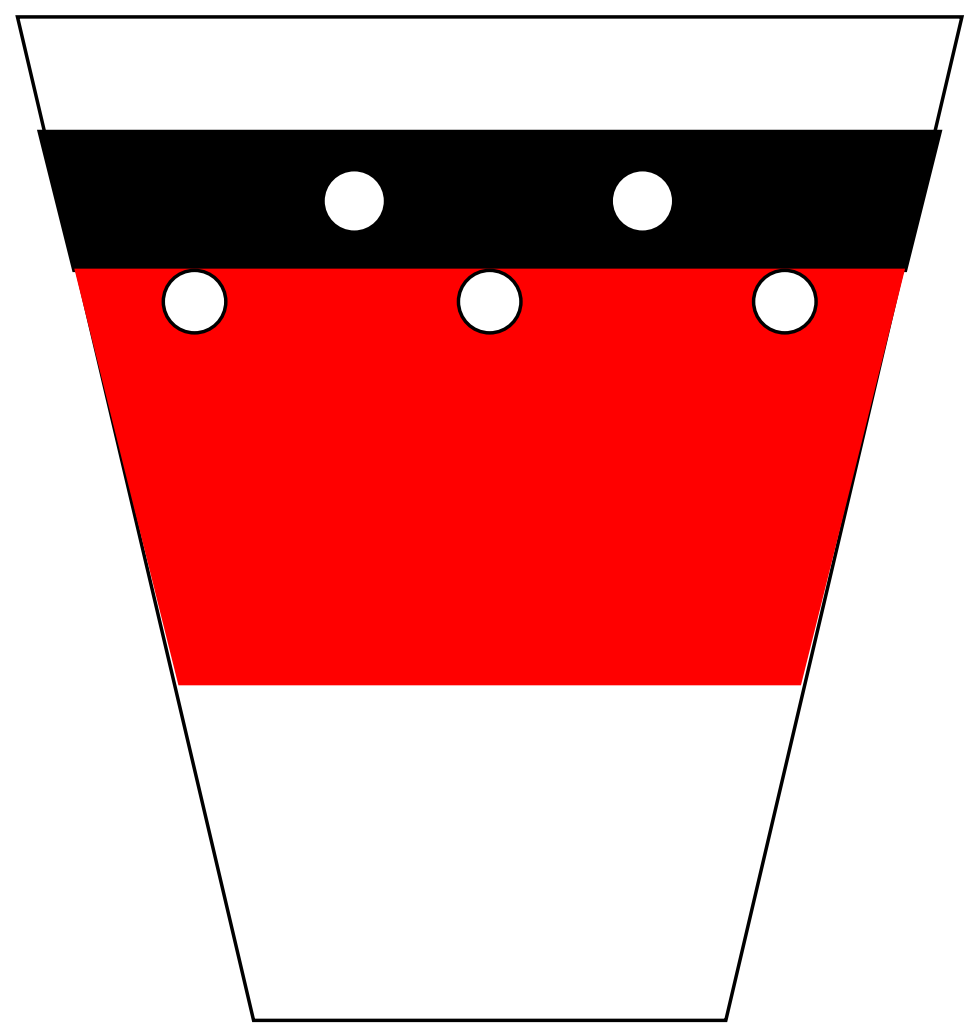

Figure 2.3. Trap design used to sample for spotted wing Drosophila (Drosophila suzukii) in regenerating harvests and mature forest at Allegheny National Forest (ANF), Clear Creek State Forest (CCSF), and State Game Lands (SGL) 86, Pennsylvania, in 2019 and 2020. 


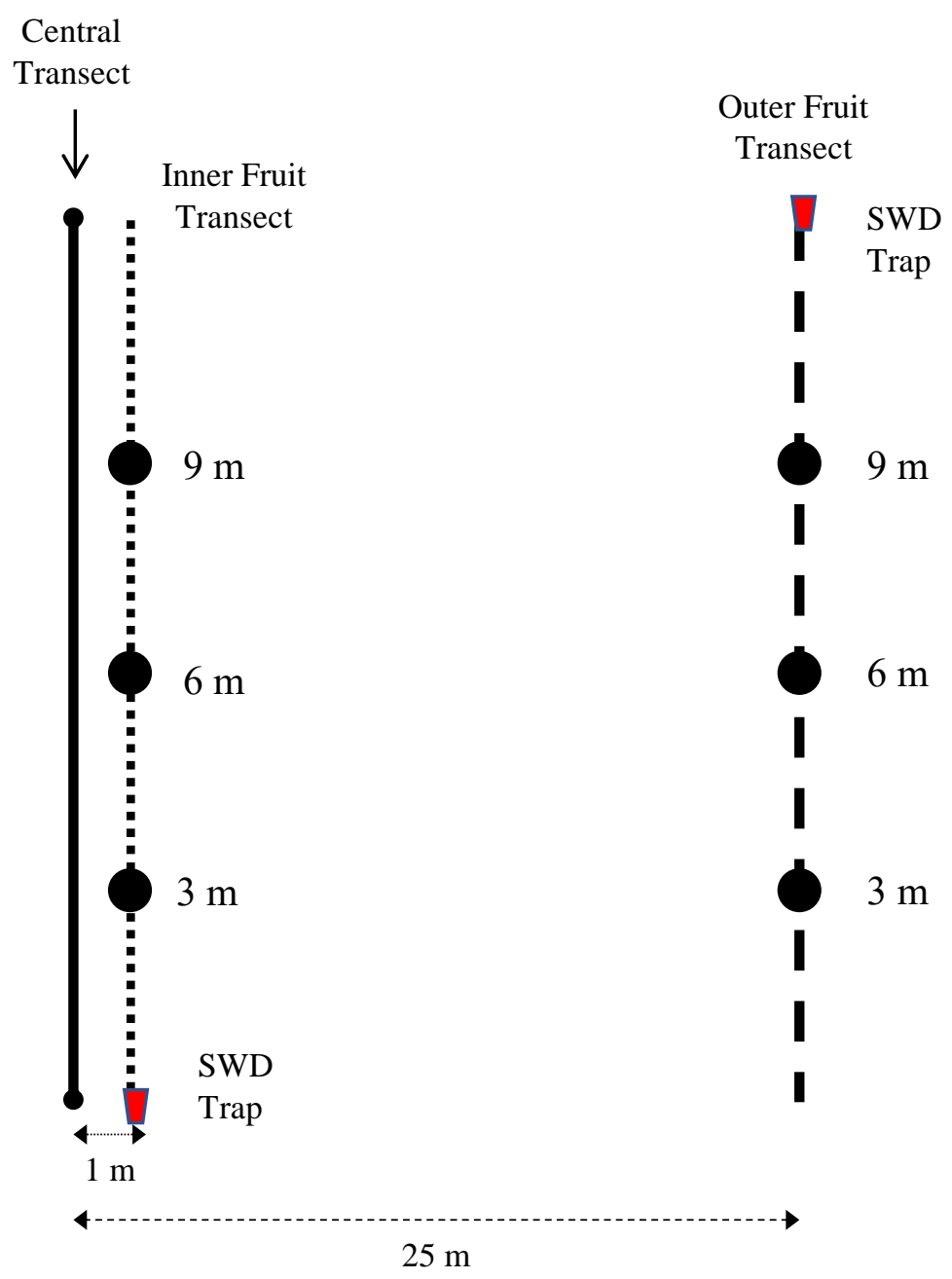

Figure 2.4. Transect survey design used to place spotted wing Drosophila (Drosophila suzukii, SWD) traps and count fruit resources at sampling points in regenerating harvests at Allegheny National Forest (ANF), Clear Creek State Forest (CCSF), and State Game Lands (SGL) 86, Pennsylvania, in 2019 and 2020. The side of the central transect each fruit transect was placed and the side of the transect each SWD trap was placed were randomly chosen. 

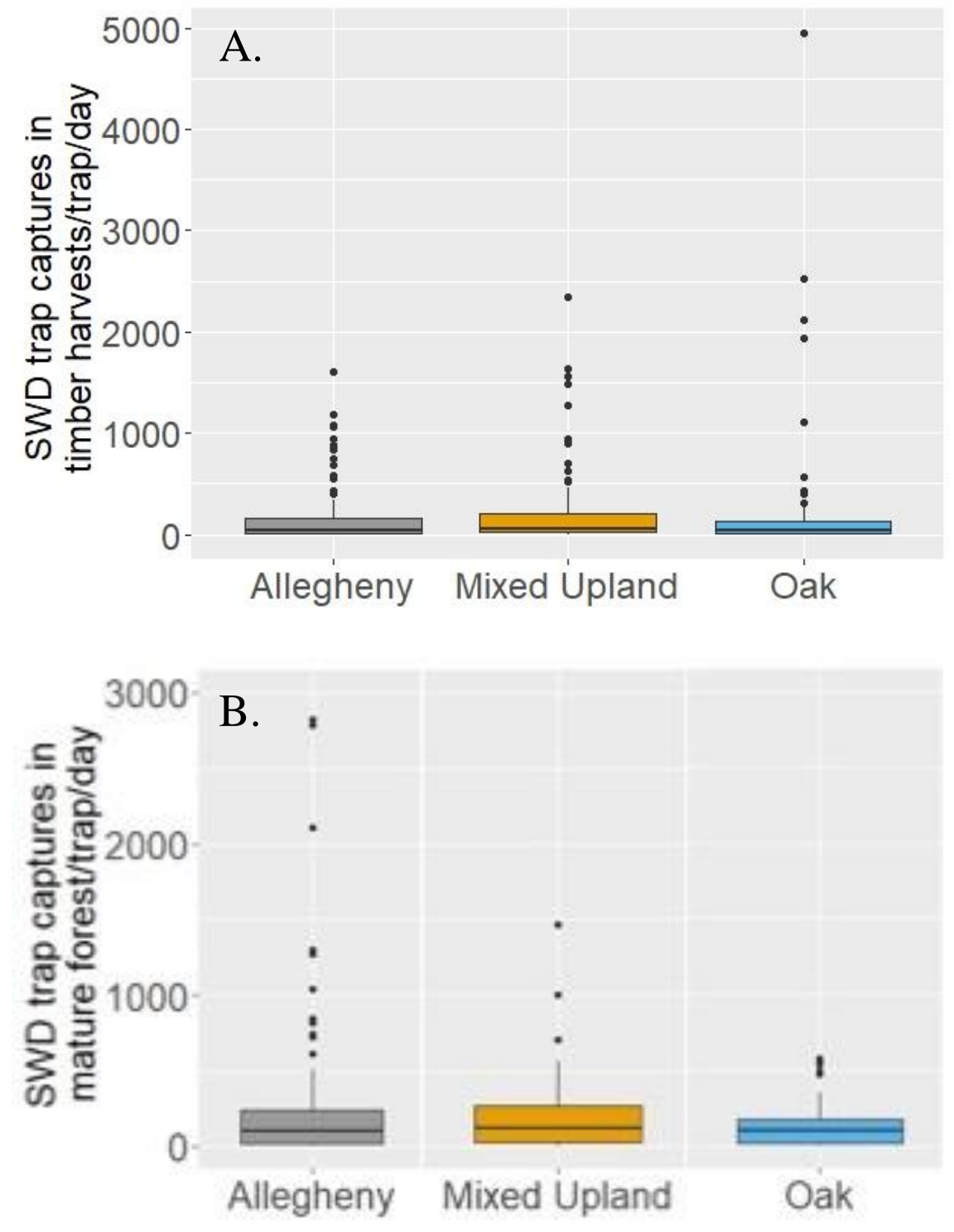

Figure 2.5. Comparison of captures/trap/day of spotted wing Drosophila (Drosophila suzukii, SWD) in A) regenerating timber harvests and B) mature forest canopy of different forest typesAllegheny, mixed upland, and oak - at Allegheny National Forest (ANF), Clear Creek State Forest (CCSF), and State Game Lands (SGL) 86, Pennsylvania, in 2019 and 2020. 


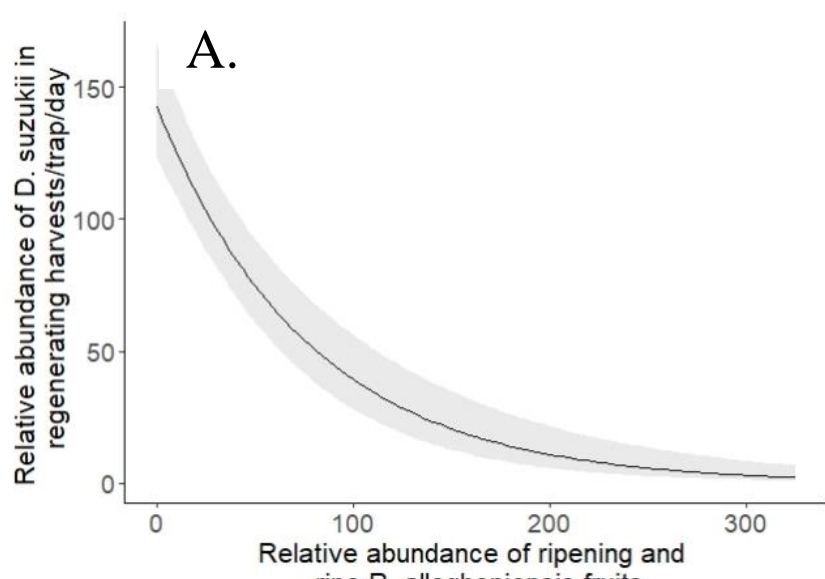

ripe $R$. allegheniensis fruits

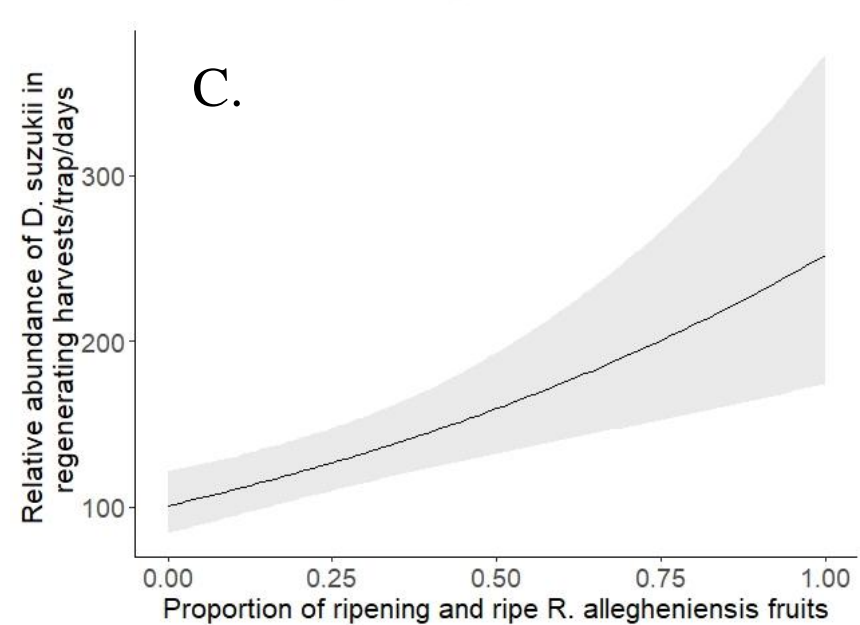

B.
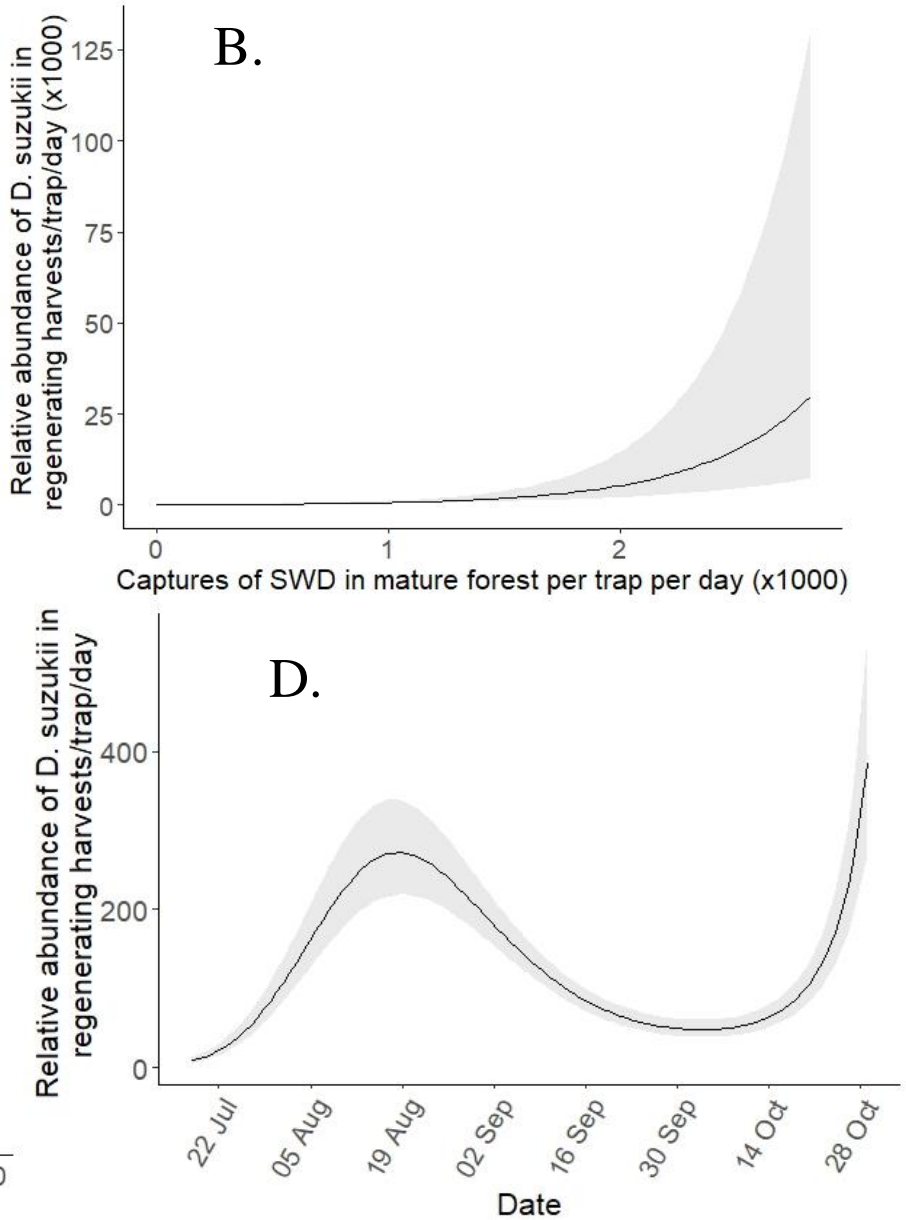

Figure 2.6. Relationship of relative abundance of spotted wing Drosophila (Drosophila suzukii, SWD) in regenerating timber harvests ("harvest" model) to A) relative abundance of ripening and ripe Allegheny blackberry ( $R$. allegheniensis) fruits, B) trap captures of SWD at paired mature forest points, C) proportion of ripening and ripe $R$. allegheniensis fruits, and D) ordinal date (including $90 \%$ credible intervals) during summer and fall (Jul-Oct) at Allegheny National Forest (ANF), Clear Creek State Forest (CCSF), and State Game Lands (SGL) 86, Pennsylvania, in 2019 and 2020. 

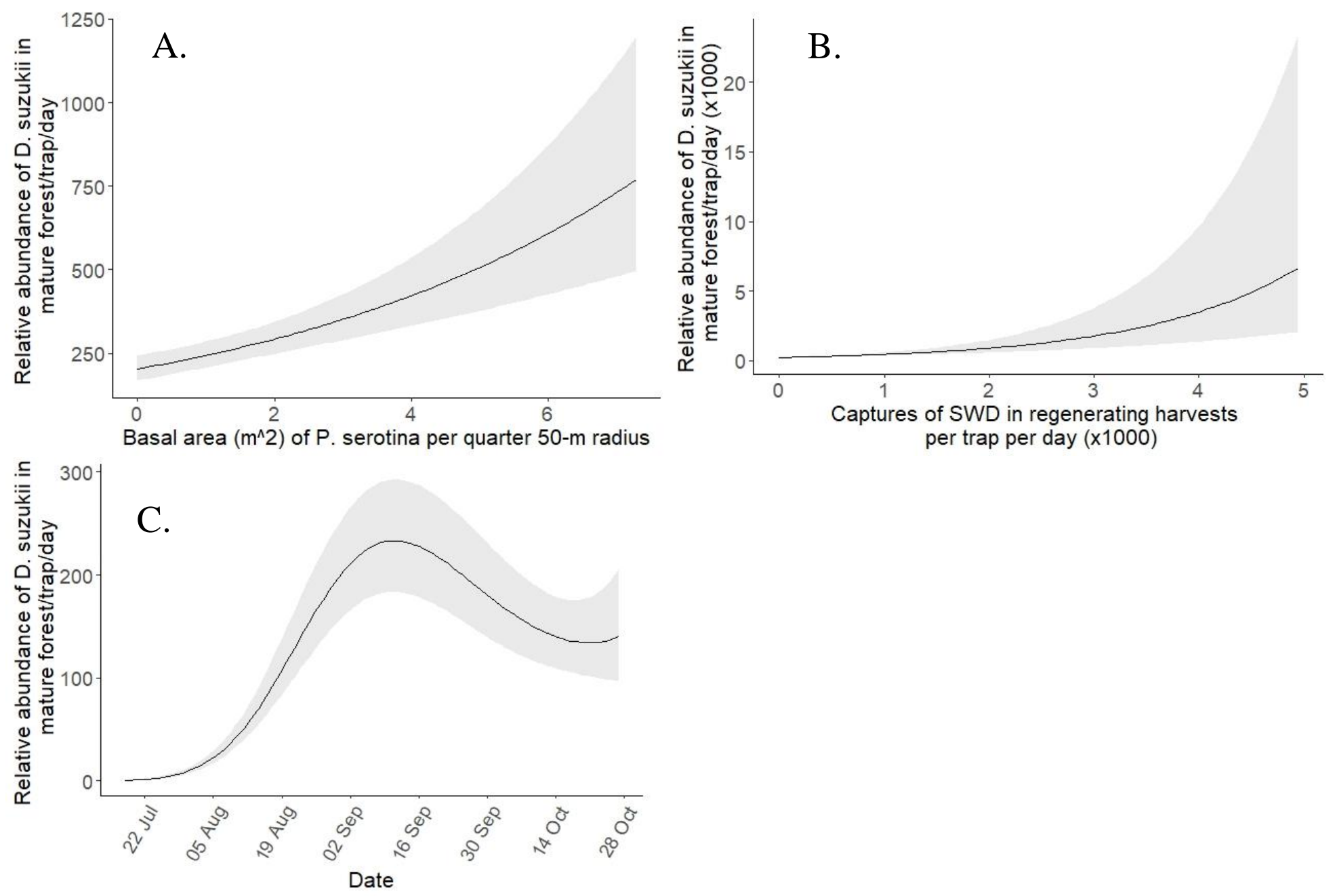

Figure 2.7. Relationship of relative abundance of spotted wing Drosophila (Drosophila suzukii, SWD) in mature forest ("forest" model) to A) black cherry (Prunus serotina) basal area/quarter of each 50-m radius plot, B) trap captures of SWD at paired regenerating timber harvest points, and C) ordinal date (including 90\% credible intervals) during summer and fall (Jul-Oct) at Allegheny National Forest (ANF), Clear Creek State Forest (CCSF), and State Game Lands (SGL) 86, Pennsylvania, in 2019 and 2020. 

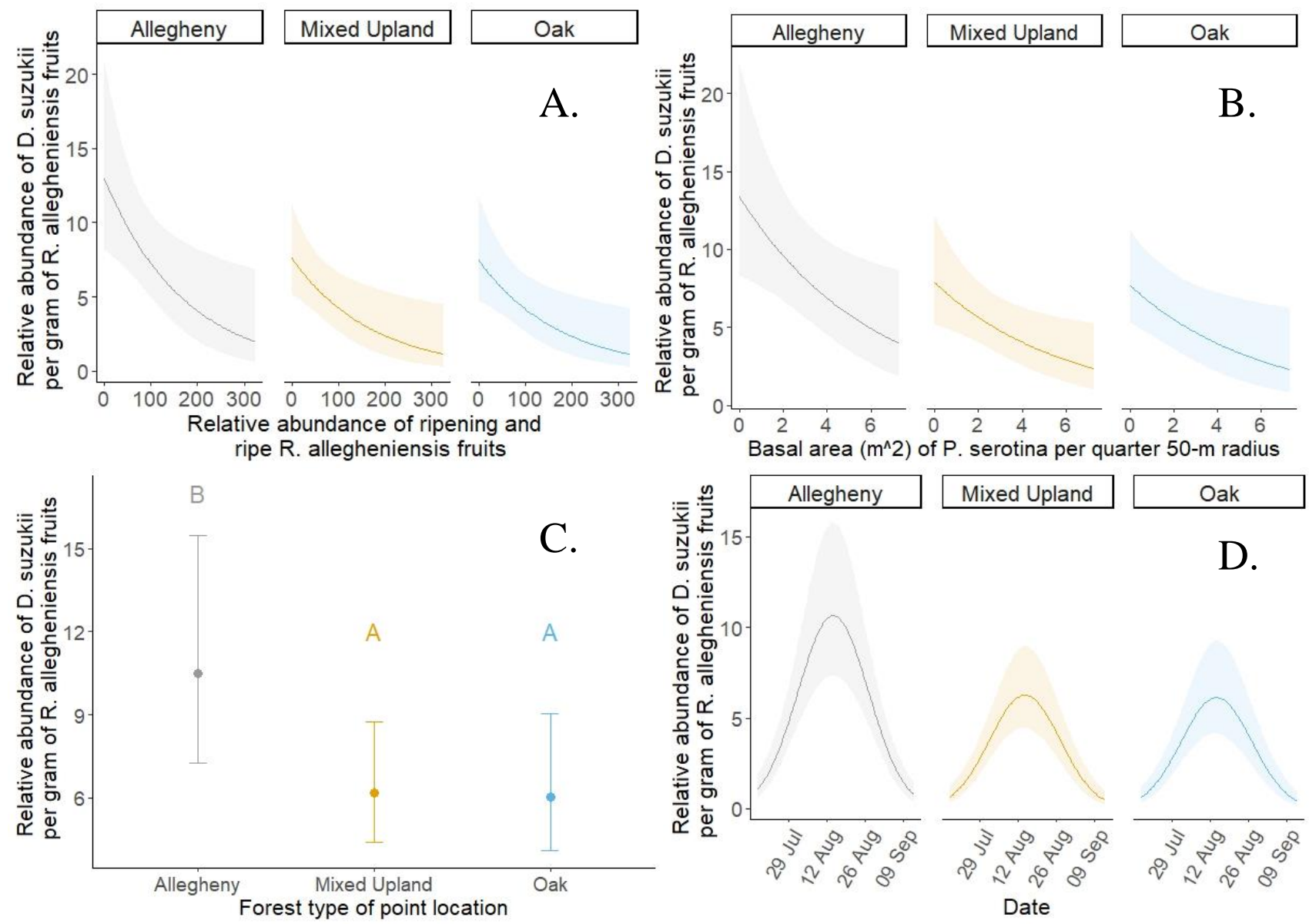

Figure 2.8. Relationship of relative abundance of spotted wing Drosophila (Drosophila suzukii, SWD) emerged from Allegheny blackberry (Rubus allegheniensis) fruit samples from regenerating timber harvests ("infest" model) to A) relative abundance of ripening and ripe $R$. allegheniensis fruits, B) black cherry (Prunus serotina) basal area/quarter of each 50-m radius plot at paired mature forest points, C) forest type, and D) ordinal date (including 90\% credible intervals) during summer and fall (Jul-Oct) at Allegheny National Forest (ANF), Clear Creek State Forest (CCSF), and State Game Lands (SGL) 86, Pennsylvania, in 2019 and 2020. Relative abundances in fruit samples were separated by forest type, because forest type was retained in the final regression model for SWD emerged from fruit. 


\section{CHAPTER 3. Response of forest bird abundance and species richness to spotted wing Drosophila at Allegheny National Forest}

\section{ABSTRACT}

Non-native invasive insect pests (NNIIPs) can have significant effects on forest ecosystems. By targeting forest fruit resources, NNIIPs may make fruits undesirable to frugivorous wildlife, including migratory songbirds. Because frugivorous birds track fruit resources, extensive damage to fruits may lead to reduced food resources used by those species. Parasitism of forest fruits by spotted wing Drosophila (Drosophila suzukii, SWD) may put it in competition for fruit resources with forest birds during their post-breeding and migration season, when energetic demands are greatest and consumption of fruits by birds increases significantly. My objective was to identify factors influencing frugivorous and non-frugivorous bird relative abundance and species richness in regenerating timber harvests invaded by SWD during the post-breeding season and fall migration, with primary focus on variables related to SWD abundance and fruit parasitism. I sampled the bird communities in regenerating harvests at Allegheny National Forest from July to October in 2019 and 2020 using mist net captures. I assessed fruit resources and vegetation structure at each mist net using transect surveys. I trapped SWD at each mist net for the duration of mist netting sessions and collected fruit samples to determine the extent of fruit parasitism by SWD at each net. Eastern towhee (Pipilo erythrophthalmus) was negatively correlated with SWD counts. Hooded warbler (Setophaga citrina) and ovenbird (Seiurus aurocapilla) were negatively and positively correlated to parasitism of fruits, respectively. Post-breeding and migratory bird relative abundances were mostly unrelated to SWD variables in regenerating harvests. Frugivorous birds either did not alter fruit consumption, or birds' abilities to alter diet and foraging behavior masked relationships to SWD. Eastern towhee either viewed fruits covered with flies as less desirable for consumption or were deterred by SWD swarms. 
Ovenbirds and hooded warblers altered their fruit consumption based on their responses to parasitism in modeling results. Alternatively, SWD activity may have affected arthropod communities, shifting composition and affecting some birds via trophic cascading effects. Insight into arthropod community responses and the actual consumption of fruit resources in habitats invaded by SWD will be critical next steps to understanding the ecological effects of SWD. Keywords: abundance, Drosophila suzukii, early successional, frugivorous birds, fruit parasitism, invasive species, migration, post-breeding, species interactions, spotted wing Drosophila.

\section{INTRODUCTION}

Non-native invasive insect pests (NNIIPs) can have significant, harmful effects on the forest ecosystem they inhabit by feeding extensively on plant material such as leaves, bark, or sap (Kenis et al. 2009, Lovett et al. 2016, Brockerhoff and Liebhold 2017). NNIIP activity causes widespread tree mortality and subsequent changes to the forest, which forest birds consistently respond to by increasing or decreasing as species-specific habitat characteristics are created or lost (Bell and Whitmore 1997, Rabenold et al. 1998, Tingley et al. 2002, Allen et al. 2009, Long 2013, Buchanan et al. 2016). Reductions in abundance of fruit resources due to NNIIPs could negatively affect many forest bird populations. Many forest bird species rely on fruit as a dietary component at least part of the year (Thompson and Willson 1979, Howe and Smallwood 1982, Suthers et al. 2000, Major and Desrochers 2012), and abundance of frugivorous birds is consistently positively associated with fruit availability across the Neotropics, temperate Europe, and the temperate U.S. (Blake and Hoppes 1986, Levey 1988b, Loiselle and Blake 1991, Rey 1995, Moegenburg and Levey 2003, Saracco et al. 2004, McCusker et al. 2010, Plein et al. 2013). Frugivorous insects affect bird consumption of fruits by changing physical characteristics 
of fruits such as color, size, or texture (Carter 1939, Highland 1964, Jordano 1987, Krischik et al. 1989, Traveset 1993, García et al. 1999). Frugivorous birds will discriminate against blueberries (Vaccinium ovalifolium) based on changes to shape caused by larvae of different fruit parasites (Traveset et al. 1995). Similarly, blackbirds (Turdus merula) will reject insect-infested hawthorn (Crataegus monogyna) fruits because of color and palatability changes, resulting in failure to remove up to $15 \%$ of the healthy fruit crop (Manzur and Courtney 1984). Foraging birds might leave as much as $75 \%$ of insect-infested fruits on a plant (Burger 1987), which might mask healthy fruits from foraging birds and reduce fruit consumption. However, little is known about how fruit parasitism affects changes to bird abundance in forested ecosystems.

The loss of fruit resources from forested ecosystems has the potential to be especially harmful for migratory songbirds at particular times of year in the northeastern United States. The post-breeding season is the period between fledging of juvenile songbirds and the initiation of fall migration (Baker 1993, Pagen et al. 2000). It is during this period that both juveniles and adults must increase energy expenditure by $30 \%$ or more to complete a post-breeding molt (Murphy 1996, Pagen et al. 2000, Cyr et al. 2008) and build sufficient fat deposits for fall migration (Blem 1976, Bonier et al. 2007), making food resources especially critical. Many songbird species, even those that are not usually frugivorous, utilize abundant fruit as an important, energy-rich food resource to build energy reserves during the post-breeding season (i.e., later summer; Snow 1971, Thompson and Willson 1979, Martin 1985, Parrish 2000, McCarty et al. 2002, Major and Desrochers 2012). Indeed, scarlet tanagers (Piranga olivacea) and red-eyed vireos (Vireo olivaceus) will transition from a mostly insectivorous diet during the breeding season to regularly consume fruits of many plants that ripen after the breeding season (Mowbray 1999, Cimprich et al. 2018). Adult and juvenile birds of many species will utilize 
early successional habitat (e.g., regenerating timber harvests, forest gaps or edges, wildlife openings) during the post-breeding season, where fruit resources are more abundant than in mature forest (McDiarmid et al. 1977; Rappole and Ballard 1987; Levey 1988a, b; Pagen et al. 2000; Marshall et al. 2003; Porneluzi et al. 2014). While bird use of early successional habitat is hypothesized as being driven by vegetative cover for concealment from predation (King et al. 2006; Vitz and Rodewald 2006, 2007; McDermott and Wood 2010), fruit-consuming species use early successional habitat to exploit abundant fruit resources (Anders et al. 1998; Vega Rivera et al. 1998b; White et al. 2005; Vitz and Rodewald 2006, 2007; Streby et al. 2011b; Labbe and King 2014). Frugivorous birds in regenerating timber harvests will decrease in abundance if abundant fruit resources are removed (Major and Desrochers 2012), highlighting the importance of early successional habitat to frugivorous birds during a time of year when fruit consumption is vital for energy acquisition.

In the northeastern U.S., use of early successional habitat and fruit resources by forest birds extends into the fall migratory season, which is roughly from mid-August to November. Birds are under immense energetic demands to rest and replenish fat deposits at migratory stopover sites to reduce mortality rates during migration, which can be 15 times greater than during non-migratory periods (Blem 1980, Moore et al. 1995, Sillett and Holmes 2002). Energy expenditure at stopover sites to replenish fat deposits can be as much as 2 times greater than during flight, highlighting the importance of building and maintaining energy stores for completion of migration (Hedenström and Alerstam 1997, McWilliams et al. 2004). Many species actively consume fruit as a critical migration stopover food resource to replenish fat deposits (Bairlein and Gwinner 1994, Parrish 1997), which coincides with fruiting phenology of many plant species (Thompson and Willson 1979, but see McCarty et al. 2002). Frugivorous 
birds will select stopover sites based on seasonal frugivory opportunities, correlated with greater abundance of fruiting plants (Martin and Karr 1986, Parrish 2000, Suthers et al. 2000). These stopover sites are frequently early successional habitat (Rodewald and Brittingham 2004, Packett and Dunning 2009, Carlise et al. 2012). Overall, food resources seem to be the main driver of stopover site selection by migrating birds (Buler et al. 2007). However, the extent to which migratory forest bird communities will respond to the infestation of fruiting plants by a frugivorous NNIIP in forested ecosystems during post-breeding and migratory seasons remains unknown.

Spotted wing Drosophila (Drosophila suzukii, SWD) is a frugivorous NNIIP with the potential to negatively affect fruit abundance in forested ecosystems. Native to east Asia, this species of vinegar fly parasitizes many soft-skinned cultivated fruits in agricultural landscapes (Lee et al. 2011a, Bellamy et al. 2013). Since its initial introduction to California in 2008, SWD has colonized forested ecosystems in the eastern U.S. and has been documented as parasitizing more than 100 different fruiting plant species, including cultivated crops, and ornamental and wild plants (Roche et al. 2021). Female SWD use a serrated ovipositor to oviposit into ripe and ripening fruits (Mitsui et al. 2006, Walsh et al. 2011), which can't normally be accessed by native fruit fly species. Larvae bore through fruits and consume pulp, resulting in fruits developing a sunken, desiccated appearance, and parasitism by SWD can promote further infection by microbes and premature drop from the parent plant (Walsh et al. 2011). However, the response of vertebrate frugivores to SWD infestation of fruits remains unknown.

I investigated the response of the bird community to SWD invasion in regenerating timber harvests during the post-breeding season and fall migration of birds at and around Allegheny National Forest, Pennsylvania. My objectives were to: 1) measure relative abundance 
and species richness of frugivorous and non-frugivorous birds in regenerating harvests during the post-breeding season and fall migration; and 2) determine what factors in regenerating harvests (i.e., SWD counts, fruit resources, fruit infestation by SWD, and cover provided by vegetation structure) influence frugivore and non-frugivore relative abundance and species richness. For objective 2, I hypothesized that relative abundance and species richness of frugivores, but not non-frugivores, in regenerating harvests would be negatively associated with SWD variables. I also hypothesized that frugivores, but not non-frugivores, would be positively associated with fruit variables; both guilds would be positively associated with vegetative cover variables representing more complex structure (Anders et al. 1998, White et al. 2005, Vitz and Rodewald 2007, Chandler et al. 2012, Labbe and King 2014).

\section{METHODS}

\section{Study Area}

I conducted this study throughout the Allegheny National Forest (ANF) and nearby forest in the Allegheny High Plateau of northwestern Pennsylvania $\left(41^{\circ} 40^{\prime} \mathrm{N}, 78^{\circ} 05^{\prime} \mathrm{W}\right)$. The ANF covers approximately 209,000 ha (187,500 forested, 17,000 non-forested, and 4,500 covered by water, mostly the Allegheny Reservoir) and includes land in Elk, Forest, McKean, and Warren counties. Elevation throughout the forest ranges from approximately $305 \mathrm{~m}$ above sea level to $700 \mathrm{~m}$ above sea level. Annual precipitation is approximately $1 \mathrm{~m}$ (Morin et al. 2006).

The Allegheny High Plateau was historically dominated by northern hardwoods until the late 1800 s and early 1900 s when industrialization and unregulated logging left much of the forest clear-cut and brush-covered (U.S. Forest Service 2007). The ANF was established in 1923, which led to a halt of these practices and the growth of an altered forest (U.S. Forest Service 2007). Timber harvest of hardwood species at the ANF (e.g., black cherry [Prunus serotina], oak 
[Quercus spp.], yellow poplar [Liriodendron tulipifera], red maple [Acer rubrum], sugar maple [Acer saccharum], white ash [Fraxinus americana]) is used for economic gains and for vegetation management to maintain a mix of habitat types for plants and animals, aimed at maintaining plant and animal diversity and overall ecosystem resilience.

Dominant forest types occurring at the ANF include the following: 1) Allegheny hardwoods (dominated by at least $50 \%$ basal area black cherry [greater than $70 \%$ in some stands; Eyre 1980], white ash, yellow poplar, American beech [Fagus grandifolia], yellow birch [Betula alleghaniensis], red maple, sugar maple, and eastern hemlock [Tsuga canadensis]); 2) mixed upland hardwoods (similar to Allegheny hardwoods but dominated by red maple and containing fewer black cherry); 3) northern hardwoods (similar to upland hardwoods but dominated by eastern hemlock, American beech, and maple spp., and containing even fewer black cherry); and 4) oak-hickory (at least $25 \%$ oak species, dominated by northern red oak [Quercus rubra]; U.S. Forest Service 2007).

Large blocks of contiguous and connected mature forest exist throughout the landscape. A diversity of forest structure also exists, including even-age forest with trees 90-110 years old and forest with a larger number of older, larger trees along with a greater amount of younger structural stages (U.S. Forest Service 2007). Extensive, long-term browsing by high deer densities has resulted in a loss of understory and midstory vegetation through much of the ANF (Morin et al. 2006). Because the ANF contains many forest compartments harvested for black cherry, maple, and yellow poplar timber or marked for even-aged management, there are many regenerating stands distributed throughout the forest (U.S. Forest Service 2007). However, less than $8 \%$ of forested land comprising the ANF is under 20 years old. Most harvests at the ANF use the shelterwood system, which involves an initial shelterwood seed harvest, leaving half to 
most trees (50-70\%) as residual canopy trees, and a second shelterwood removal harvest after a minimum of approximately 10 years. However, clear-cutting of all trees is also used under certain resource objectives (see U.S. Forest Service 2007). Minimum rotation age for final harvest (i.e., shelterwood removal harvest, clear-cutting) is 100 years for the major forest types. Maximum size of openings created by even-aged management is approximately 16 ha, per Forest Service regulations. Regenerating patches contain seedlings and saplings representative of adjacent forest types. These patches also include many fruiting plants, including blackberry (Rubus spp.), pokeweed (Phytolacca americana), pin cherry (Prunus pennsylvanica), and spikenard (Aralia spp). Mature forest patches typically have much lower numbers of these plants in the understory (Stoleson 2013).

I conducted additional sampling at Clear Creek State Forest (CCSF), located south of the ANF in Jefferson County in the Allegheny High Plateau ( $\left.41^{\circ} 18^{\prime} \mathrm{N}, 79^{\circ} 00^{\prime} \mathrm{W}\right)$. It is a property of approximately 5,460 ha managed by the Pennsylvania Department of Conservation and Natural Resources (DCNR). Geology and climate are similar to that of the ANF. Most of the mature forest stands within the CCSF are approximately 100 years old. There are 3 major forest types: Allegheny hardwood, mixed oak, and northern hardwood. Mixed oak is the dominant type, with northern red oak as the dominant species. Other species include white oak (Quercus alba), black oak (Quercus velutina), chestnut oak (Quercus montana), red maple, American beech, black cherry, and eastern hemlock (Brose 2011). Timber harvesting has created multiple regenerating harvests in the CCSF. Seedlings and saplings are representative of adjacent forest communities, and many herbaceous fruiting species can be found in these harvests, including blackberry, Vaccinium spp., partridgeberry (Mitchella repens), sassafras (Sassafras albidum), Smilax spp., 
serviceberry (Amelanchier spp.), pin cherry, devil's walking stick (Aralia spinosa), grapes (Vitis spp.), and American (Sambucus canadensis) and red elderberry (S. racemosa).

I conducted sampling at one site on Pennsylvania State Game Lands (SGL) 86, located west of the ANF along the western bank of the Allegheny River and within the Allegheny High Plateau ( $\left.41^{\circ} 43^{\prime} 31^{\prime \prime} \mathrm{N}, 079^{\circ} 21^{\prime} 29^{\prime \prime} \mathrm{W}\right)$. It is comprised of a single contiguous tract of land of approximately 5,800 ha in Warren County and lies within the Pennsylvania Game Commission's (PGC) Northwest Region. Lands along the Allegheny River, including SGL 86, contain large hills and steep slopes. The vast majority of SGL 86 was logged in the early 1900s (PGC 2014) and now contains a mix of plant communities from lower elevation streambed valleys dominated by conifers, maple, and birch to higher elevation (approximately $531 \mathrm{~m}$ ) plateaus dominated by oak, maple, hickory (Carya spp.), birch, and American beech. The regenerating harvest I used in this study was along a northern facing slope and contained seedlings and saplings representative of adjacent plant communities and a variety of herbaceous fruiting plants, including blackberry, pokeweed, maple leaf viburnum (Viburnum acerifolium), Vaccinium spp., partridgeberry, multiflora rose (Rosa multiflora), currants (Ribes sp.), grapes, and elderberry.

\section{Site Selection}

I conducted all sampling on sites within the ANF, CCSF, and SGL 86, 18 July-30 October in 2019 and 20 July-28 October in 2020. This timing coincides with post-breeding phenology (JunAug; Pagen et al. 2000; McDermott and Wood 2010, 2011; Stoleson 2013; Labbe and King 2014; Burke et al. 2017), mid-August onset of migration (mid-Aug-Nov) of locally occurring bird species (S. H. Stoleson, Forest Service, unpublished data), and the observed emergence of SWD in previous years (Turcotte et al. 2018). Previous studies have also identified first captures of SWD in the first half of July (Elsensohn and Loeb 2018), with large increases occurring in 
August (Pelton et al. 2016) and captures continuing through mid-October (Briem et al. 2018, Thistlewood et al. 2019). Each site consisted of a regenerating harvest patch selected for this study using the following criteria. I defined regenerating harvests as forest stands aged 3 to 8 years post-timber harvest as of 2019 to ensure time for vegetative regrowth and fruiting plant regrowth (Labbe and King 2014, Porneluzi et al. 2014). I characterized these harvests as early successional habitat. Regenerating harvests on the ANF that fit these criteria ranged in size of 828 ha. From this list of all available harvests meeting my criteria, I randomly selected regenerating harvests for use as sites. I chose sites such that regenerating harvests within a season were at least $2 \mathrm{~km}$ apart (Vitz and Rodewald 2006, 2007). In 2019, I chose 4 regenerating harvest sites situated within Allegheny hardwood forest, 4 within mixed upland hardwood forest, and 4 within oak forest, representing a gradient of different forest types. In 2020, I chose 3 sites within Allegheny forest, 3 within mixed upland forest, and 3 within oak forest, giving 7 Allegheny sites, 7 mixed upland sites, and 7 oak sites over both years (Appendix A, Figure 3.1). To determine locations of avian sampling points at each site, I covered each site with a grid of points placed $100 \mathrm{~m}$ apart and oriented north-south. I removed any points within each harvest that were less than $25 \mathrm{~m}$ from the harvest boundaries to avoid edge effects (Pagen et al. 2000, Chandler et al. 2012, Stoleson 2013, Labbe and King 2014). From these remaining points, I randomly selected 5 to serve as sampling points and standardize the avian surveying effort at each regenerating harvest (Figure 3.2). Therefore, each sampling point was at least $100 \mathrm{~m}$ from any other sampling point. I removed any regenerating harvests unable to fit at least 5 candidate sampling points from the list of candidate sites. I used the Vegetation dataset from the Allegheny National Forest Geographic Information System (GIS) Dataset collection (U.S. Forest Service 2019) in ArcGIS Pro v. 2.3.0 (ESRI, Redlands, CA, USA) to identify forest types for site 
selection and for placing sampling points. From 2019 to 2020, I sampled 105 points across 21 sites.

\section{Avian Sampling}

I used constant-effort, passive mist netting (Dunn and Ralph 2004) to sample the bird communities in each regenerating harvest. Birds are less vocal during the post-breeding season, and regenerating harvests have low visibility for detection purposes due to dense vegetation (Pagen et al. 2000). By using ground mist nets, I had a greater probability of capturing rare or secretive species. Also, observer bias, which can affect detection probabilities in avian point counts, is avoided when using mist nets (Karr 1981, Pagen et al. 2000, Stoleson 2013). However, mesh size can influence capture probability of different species, with smaller birds more often captured in smaller-meshed nets and larger birds in larger-meshed nets (Pardieck and Waide 1992).

At each regenerating harvest, I used standard mist nets (12 m long, $2.6 \mathrm{~m}$ high, 30-mm mesh), a size useful for capturing small passerines (Heimerdinger and Leberman 1966). I placed individual nets at each of the 5 sampling points at least $100 \mathrm{~m}$ apart to minimize chance of recapture between nets. Previous netting efforts in regenerating harvests at the ANF resulted in low individual recaptures (approximately $2 \%$ of all captures) between nets placed 50-100 m apart during the post-breeding season (S. H. Stoleson, unpublished data), and recaptures were similarly low during our study (2.81\% of all captures). Thus, I considered nets to be independent sample units. I sampled sites 2 days in a row (McDermott and Wood 2010, 2011), unless adverse weather required a delay of 1-2 days between sampling days, in each of 3 periods during the season (mid-Jul to late Oct). Because net captures decline with each additional netting day (MacArthur and MacArthur 1974, Karr 1981, Marques et al. 2013), visits lasted 2 days to 
increase efficiency of detecting birds. Sampling period 1 spanned 18 July-22 August in 2019 and 20 July-25 August in 2020, sampling period 2 spanned 24 August-25 September in 2019 and 27 August-25 September in 2020, and sampling period 3 spanned 27 September-30 October in 2019 and 28 September-28 in October 2020.

I opened nets 30 minutes before sunrise and kept nets open for 5 hours (Ralph et al. 2004). I banded all birds captured (except Ruby-throated hummingbird [Archilochus colubris]) with a United States Geological Survey (USGS) aluminum band. I grouped all captured birds into foraging guilds (non-frugivorous or frugivorous) using existing life history data (i.e., Birds of the World species account) and evidence of extensive frugivory from past mist-netting at the ANF (e.g., stains on bill or in fecal samples; S. H. Stoleson, unpublished data) to determine whether species' diet played a role in any changes to total relative abundance or species richness (Appendices B and $\underline{C}$ ).

\section{Fruit Sampling}

To determine the counts of fruit resources at each mist net, I conducted fruit surveys during mistnetting visits to each site. I conducted surveys immediately after the first day of netting (McDermott and Wood 2010). At each net lane, I placed 2 parallel transects on a randomly selected side: one "inner" transect $1 \mathrm{~m}$ away and one "outer" transect $25 \mathrm{~m}$ away from the net (Figure 3.3; modified from fruit sampling by Vitz and Rodewald 2006, Carlisle et al. 2012, and vegetation sampling from Schemske and Brokaw 1981, McDermott and Wood 2010). At 3 m, 6 $\mathrm{m}$, and $9 \mathrm{~m}$ along each inner and outer transect, I randomly chose a side and placed a 0.5-m $\times$ 0.5-m quadrat. I identified all plants producing fruit within each quadrat $\left(0.75 \mathrm{~m}^{2} /\right.$ transect, 1.5 $\mathrm{m}^{2} /$ sampling point) and recorded the species and the counts of fruits, separated into the following age categories: unripe (green, still growing), ripening (full size, undergoing color change), and 
ripe (full size, completed color change). I included unripe, ripening, and ripe fruits because only counting ripe fruits, especially for rapidly ripening plants such as Rubus spp., does not reflect the potential availability of fruits to birds (Blake et al. 1990, Rodewald and Vitz 2005, Vitz and Rodewald 2006). I also identified all species within each quadrat that produce fleshy fruits, even if not actively fruiting. Fruit production can be highly variable spatially with individual plants differing in the number of fruits produced during a season (Wheelwright 1986), so species richness may serve as a proxy for the diversity of fruit resources in the area, if other individual plants of the same species occurred nearby and were actively fruiting.

I pooled all fruit counts at each mist net to determine a single count of fruits for each category. After pooling, I chose to focus on counts of unripe fruits and the sum of ripening and ripe fruits, each for Allegheny blackberry (Rubus allegheniensis) specifically. R. allegheniensis was the most abundant fruit encountered across all fruit surveys, with few other species found fruiting during surveys (7.7\% of all surveys). Ripening and ripe fruit together represent food resources for birds susceptible to SWD, and the inclusion of unripe fruits represents the potential availability of all fruits to birds (Blake et al. 1990) and SWD. Both unripe fruit and the sum of ripening and ripe fruit are also strongly correlated with total fruit during sampling periods 1 and 2 ( $r=0.89$ and $r=0.76$, respectively); no R. allegheniensis fruits were found during period 3 . Only 3 other species (devil's walking stick, multiflora rose, and partridgeberry) produced fruits across 4 different mist nets during period 3 (3.8\% of surveys).

To estimate fruiting species richness at each mist net, I summed the count of fruiting species from all fruit surveys ( 3 sampling periods). I did this because 1) placement of the quadrat on either side of the survey transect affected what fruiting species were counted during any given fruit survey; and 2) plant communities remained unchanged across all 3 sampling periods. 


\section{Fruit Parasitism Sampling}

To determine the extent that fruits on plants were parasitized by SWD at each mist net, I

collected a random sample of ripening and ripe fruits from each fruiting plant species along each

transect and monitored for emergence of adult, pupal, and larval SWD (20 fruits each, when

possible). I weighed fruits within 2 hours of collection and stored them, separated by species and transect, at room temperature (approximately $20^{\circ} \mathrm{C}$ ) under ambient light in a sealed, vented 473$\mathrm{mL}$ clear container (Webstaurant Store, Lancaster, PA, USA). I checked after a minimum of 2 weeks for adult, larval, and pupal SWD (Walsh et al. 2011, Burrack et al. 2015). I used these counts and total fruit mass to determine the infestation rate of each plant species, measured as the count of SWD/g of fruit (Kenis et al. 2016, Elsensohn and Loeb 2018).

I pooled total SWD counts and fruit sample masses between transects to determine a single measure of infestation rates for each fruiting species at each mist net. While larvae and pupae of SWD are difficult to differentiate from other Drosophila species, I used total counts of all stages of SWD for multiple reasons. First, I found only SWD emerged from fruit samples as adults. Second, ripening and ripe fruits, unless damaged, are likely not susceptible to parasitism by most native Drosophila species, which lack a serrated ovipositor (Mitsui et al. 2006, Lee et al. 2011b, Atallah et al. 2014). Third, counting only adult SWD would have underestimated actual parasitism rates of many samples. Finally, infestation rate using only adult SWD was strongly correlated with infestation rate using all life stages $(r=0.87)$. In some fruit samples, decay of fruit and growth of fungi made adult flies difficult to find and counts of adult SWD were lower than counts of pupal shells. Because pupal shells indicate an emerged adult fly and adult counts likely would have underestimated the total number of SWD, I used pupal shell counts rather than adult counts when calculating total SWD counts (all life stages) in these samples. I chose to 
focus on infestation rates of $R$. allegheniensis because most fruits surveyed and therefore sampled were R. allegheniensis (85.4\% of all fruit samples). If no R. allegheniensis fruit sample was collected (i.e., no fruit present), I considered infestation rate to be 0 . Therefore, since no fruits remained after 13 September 2019 and 8 September 2020, infestation rates for part of sampling period 2 and all of sampling period 3 were 0.

\section{SWD Sampling}

I conducted sampling for SWD simultaneously with mist-netting at each site. To maximize the number of adult SWD captured during each 2-day mist-netting period, I made traps using a methodology described by Pelton et al. (2016; Figure 3.4). I made 10 evenly-distributed 5-mm holes near the top of a clear 710-mL plastic cup with a lid (Webstaurant Store, Lancaster, PA, USA). The bait in each trap was a mixture of $3.5 \mathrm{~g}$ dry active baker's yeast, $14 \mathrm{~g}$ granulated white cane sugar, and $177 \mathrm{~mL}$ water, with a drop of unscented soap used to improve capture of SWD by reducing surface tension. I also lined the area directly below the holes with a strip of red tape and the area directly above the holes with a strip of black tape to improve captures (e.g., Lee et al. 2013, Lasa et al. 2017). I placed one trap at a single end of each "inner" $(1 \mathrm{~m})$ transect and one trap at a single end of each "outer" (25 m) transect (Figure 3.3). Previous studies have spaced traps at a single sampling location as close as 1-2 m apart (e.g., Lee et al. 2012, Tochen et al. 2016) or as far as 10-20 m apart (e.g., Landolt et al. 2012, Harris et al. 2014, Pelton et al. 2016, Wang et al. 2016). I suspended traps approximately $1 \mathrm{~m}$ off the ground and close to vegetation to minimize exposure to direct sun and increase likelihood of trap capture (Diepenbrock and Burrack 2017, Evans et al. 2017, Rice et al. 2017, Elsensohn and Loeb 2018). I placed traps at the beginning of each site visit following the opening of mist nets. 
I collected the contents of each trap for later SWD identification following the closing of mist nets at the end of the 2-day site visit. I strained all invertebrates from the trap medium and stored them in 70\% ethanol before later separating out and counting all adult SWD in each trap. I pooled counts of SWD from each trap at each sampling point to determine a single count of SWD at each mist net. If a trap fell or was damaged such that the contents were lost, I discarded the trap and saved no sample. To address differences in 1) number of trap samples at each net, and 2) number of days traps were out at a site due to adverse weather delaying banding by 1-2 days, I calculated the count of adult SWD captured/trap/day for each mist net.

\section{Vegetation Sampling}

To determine vegetation structure at each mist net, I surveyed the vegetation along each "inner" and "outer" transect used for fruit surveys once each year (Figure 3.3). At $3 \mathrm{~m}, 6 \mathrm{~m}$, and $9 \mathrm{~m}$ along each transect, I collected multiple vegetation cover measurements (Vitz and Rodewald 2006, 2007). I measured vegetation height directly (m), and I estimated vertical cover ( $0-2.5 \mathrm{~m})$ using a vegetation profile board (Nudds 1977). I measured vertical cover in 0.5 -m increments by approximating the amount of space within each increment on the board covered by vegetation. The proportion of each $0.5-\mathrm{m}$ increment covered by vegetation received a single-digit cover score $(1=0-20 \%$ cover, $2=21-40 \%, 3=41-60 \%, 4=61-80 \%, 5=81-100 \%)$. An observer took measurements at the transect on either side by facing the board from $15 \mathrm{~m}$ away. To obtain a single value at each mist net that captured the variation in vegetation height, I calculated the coefficient of variation (CV) using the 6 height values measured along both transects (3 per transect). I also calculated CV values for vertical cover at each mist net using the 12 ordinal values measured (6 per transect) for the greatest height interval $(2-2.5 \mathrm{~m})$ because 1$)$ it showed the greatest variation in values across all height intervals, and 2) it was strongly correlated with 
$\mathrm{CV}$ values calculated using the entire $0-2.5-\mathrm{m}$ range $(r=0.93)$. I also measured dbh of any residual trees within $25 \mathrm{~m}$ of the center of each mist net lane to calculate a residual tree basal area at each mist net. Because vegetation structure remained largely unchanged across all sampling periods, I applied the same vegetation covariate values to the same mist net for each sampling period.

\section{Data Analysis}

Prior to analysis, I tested for collinearity between predictor variables ( $r \geq 0.7$; Dormann et al. 2013). I chose the following final covariates for analyses: 1) count of unripe $R$. allegheniensis fruits ("unripe"), 2) count of ripening and ripe $R$. allegheniensis fruits ("ripen.ripe"), 3) maximum fruiting species richness ("max.richness"), 4) count of SWD/trap/24 hours ("swd"), 5) count of SWD/g of $R$. allegheniensis fruit ("infest"), 6) residual tree basal area ("BA"), 7) CV for vegetation height (“height”), 8) CV for vertical vegetation cover at 2-2.5m (“cover”), and 9) ordinal date ("date"; Table 3.1). The primary relationships of interest were those between bird relative abundance and variables associated with SWD activity (i.e., SWD counts ["swd"] and parasitism of fruits [“infest”]). I attempted to account for additional habitat characteristics known to influence habitat use by including them as additional factors in this study. I included date as an additional covariate to account for the temporal component to sampling and for possible phenological shifts in bird habitat use following the breeding season and during migration.

From bird capture data, I derived total captures and species richness for each dietary guild (frugivore and non-frugivore) at each mist net during each sampling period. I only included birds in analyses the first time they were captured during each 2-day sampling period. I also derived focal species captures for several species because guild-level analyses can mask speciesspecific responses (Mannan et al. 1984, Morrison 1986, discussed in Canterbury et al. 2000). I 
chose focal species for analyses that showed the greatest total captures for sampling periods 1 and 2. For frugivorous species, these were cedar waxwing (Bombycilla cedrorum), eastern towhee (Pipilo erythrophthalmus), gray catbird (Dumetella carolinensis), ovenbird (Seiurus aurocapilla), red-eyed vireo, and song sparrow (Melospiza melodia; Table 3.2). For nonfrugivorous species, I chose species lacking evidence for greater frugivory at the ANF based on species accounts and previous mist-netting (S. H. Stoleson, unpublished data): American redstart (Setophaga ruticilla), black-capped chickadee (Poecile atricapillus), black-throated blue warbler (Setophaga caerulescens), black-throated green warbler (Setophaga virens), chestnut-sided warbler (Setophaga pensylvanica), common yellowthroat (Geothlypis trichas), hooded warbler (Setophaga citrina), and magnolia warbler (Setophaga magnolia; Table 3.2).

For these analyses, I focused on sampling periods 1 and 2 and discarded period 3 for multiple reasons. First, focal species showed few to no captures during sampling period 3. Second, species that were major captures during period 3 were not caught until period 2 at the earliest. Third, fruit counts ("unripe" and "ripen.ripe") showed greatest variation during period 1, less during period 2, and were all 0 during period 3; values for parasitism of fruits by SWD ("infest") followed the same pattern (Table 3.3). Fourth, sampling periods 1 and 2 sufficiently cover the post-breeding season and beginning of fall migration for migratory songbirds in the region, respectively (S. H. Stoleson, unpublished data). Total number of observations for analyses was 105 mist net locations multiplied by 2 sampling periods $(n=210)$.

To model all bird capture variables (i.e., focal species captures, total guild captures, guild species richness), I fit generalized linear mixed models (GLMMs) using a Bayesian approach with Markov-chain Monte-Carlo (MCMC) parameter estimation techniques. I chose a Bayesian approach for its ability to provide less biased estimates with smaller sample sizes than frequentist 
approaches (Gelman and Hill 2007). I accounted for repeated observations at the same mist net using a random point (i.e., mist net) effect. To aid in model convergence, I first centered and scaled all covariates.

I first modeled bird relative abundance for each focal species and each dietary guild, and species richness of each dietary guild as Poisson random variables using simple Poisson regression:

$$
\begin{aligned}
& y_{i, j} \sim \operatorname{Pois}\left(\lambda_{i, j}\right), \\
& \log \left(\lambda_{i, j}\right)=\alpha_{i}+\beta_{1} \times \text { date }_{i, j}+\beta_{2} \times \text { unripe }_{i, j}+\beta_{3} \times \text { ripen. ripe }_{i, j}+
\end{aligned}
$$

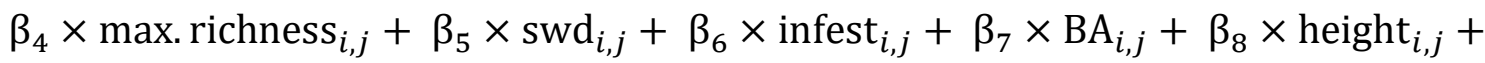

$$
\begin{aligned}
& \beta_{9} \times \text { cover }_{i, j},
\end{aligned}
$$

where $i$ is mist net identity, $j$ is sampling period number, $\alpha_{i}$ is the intercept for a random mist net effect, $y_{i, j}$ is count data for each mist net during each sampling period, and $\lambda_{i, j}$ is expected count for each mist net during each sampling period. To assess the goodness-of-fit (GOF) of individual models, I calculated a Bayesian p-value using the sum of squared Pearson residuals for every model run (Gelman et al. 2004). If the model for a response variable failed this GOF test (pvalue less than 0.1 or greater than 0.90 ), I treated that response variable as a negative binomial (NB) random variable and re-ran the model using NB regression:

$$
\begin{aligned}
& y_{i, j} \sim \mathrm{NB}\left(p_{i, j}, r\right) \text {, } \\
& p_{i, j}=\frac{r}{r+\lambda_{i, j}}, \\
& \log \left(\lambda_{i, j}\right)=\alpha_{i}+\beta_{1} \times \text { date }_{i, j}+\beta_{2} \times \text { unripe }_{i, j}+\beta_{3} \times \text { ripen.ripe } \text { i }_{i, j}+\beta_{4} \times \\
& \text { max. richness } i, j+\beta_{5} \times \operatorname{swd}_{i, j}+\beta_{6} \times \text { infest }_{i, j}+\beta_{7} \times \mathrm{BA}_{i, j}+\beta_{8} \times \text { height }_{i, j}+ \\
& \beta_{9} \times \text { cover }_{i, j},
\end{aligned}
$$


where $p_{i, j}$ is the probability of success at each mist net during each sampling period, and $r$ is the dispersion parameter. This allowed the mean and variance to differ from a Poisson regression, allowing for over-dispersion. Response variables with poor-fitting Poisson models successfully ran with NB models and passed the GOF test.

While running a simple Poisson or NB does not account for possible detection errors introduced by environmental conditions (Karr 1981, Keyes and Grue 1982, Royle 2004), I chose simple Poisson and NB regression over N-mixture modeling. By using mist-netting data to create count data, I had information on bird identity. It is unclear how to incorporate bird identity into $\mathrm{N}$-mixture modeling. This approach would fail to distinguish between 2 individuals captured on the first day of a 2-day sampling period and 2 different individuals on the second, underestimating true abundance. While mark-recapture models exist, recapture rates were too low in this analysis (approximately 2\%) for these models to be appropriate. Thus, because I did not model true abundance as a latent variable, I modeled counts of birds as an "index" of abundance, or a relative abundance, rather than an estimation of true abundance. In these analyses, I assumed that a greater count of birds captured at a mist net location indicated a greater number of birds present at that location.

To determine which covariates to conduct final inference on, I performed stepwise regression on each response variable. I chose a stepwise regression process because I had $a$ priori hypotheses about each covariate and reason to believe — based on previous studies of postbreeding and migratory habitat use — each would explain some of the variation observed in bird relative abundance. I used a strict process to conduct stepwise removal from a global model to a final reduced model for inference on individual covariates. First, I ran a global model for each response variable containing all 9 covariates. Second, I removed all covariates with a marginal 
posterior estimate for a slope coefficient $(\beta)$ that had a $90 \%$ credible interval (CI) overlapping 0 . The credible interval indicates the bounds within which the value of the parameter of interest $(\beta)$ lies at a certain probability (in this case 90\%), given the assumptions of the Bayesian model. I reran the reduced model and used the same criterion to remove covariates. I repeated this process until all remaining covariates had a 90\% CI that didn't overlap 0. I conducted covariate removal and final inference using $90 \%$ CIs in order to identify potentially weak but ecologically meaningful effects, while utilizing a small sample size and properly accounting for uncertainty through random effects. I conducted all stepwise regression for each response variable using the same distribution as the global model (i.e., Poisson or NB). All reduced models passed the GOF test regardless of distribution used for the response variable.

I ran all models using software JAGS version 4.3.0 (Plummer 2003) called from R version 4.0.3 (R Core Team 2021) using communicator package jagsUI (Kellner 2019). For all Poisson and NB models I specified vague (i.e., noninformative) priors (Kéry 2010). I drew random sampling point intercept terms $\left(\alpha_{i}\right)$ from a Normal distribution with a population-level intercept mean $\alpha$ and precision $\tau_{\alpha}(1 /$ variance $)$ :

$$
\alpha_{i} \sim \mathrm{N}\left(\alpha, \tau_{\alpha}\right)
$$

I specified Normal priors for the population-level intercept mean $(\alpha)$ :

$$
\alpha \sim \mathrm{N}(0,0.01)
$$

where 0 is the mean and 0.01 is the precision. I derived precision $\tau_{\alpha}$ from a standard deviation with a uniform prior:

$$
\begin{gathered}
\tau_{\alpha}=\frac{1}{\sigma_{\alpha}^{2}}, \\
\sigma_{\alpha} \sim \operatorname{Unif}(0,10) .
\end{gathered}
$$


I specified the same Normal priors for slope coefficients for each covariate as the hyper-prior for the intercept:

$$
\beta_{\mathrm{covs}} \sim \mathrm{N}(0,0.01)
$$

For NB models, I used a uniform prior for the dispersion parameter, $r$, with a large upper bound:

$$
r \sim \operatorname{Unif}(0,50)
$$

As $r$ becomes large (e.g., 50), the NB approaches a Poisson distribution (Jackman 2009). I used a uniform $(0,10)$ prior for $r$ if the upper limits of the posterior never approached 10.

I ran 3 MCMC chains for each model. I used traceplots to determine an appropriate burnin for each model, and I ran each model for a sufficient number of iterations to achieve convergence. I confirmed convergence of models by visually inspecting chain mixing and checking that Gelman-Rubin diagnostic (Rhat) values for all model parameters were below 1.1 (Gelman et al. 2004). Burn-in lengths and number of iterations necessary for convergence of all models ranged 3,000 to 13,000 and 9,000 to 26,000 , respectively. I thinned iterations by 2 to help reduce autocorrelation between posterior draws. I drew initial values for all parameters from a uniform distribution with parameters Unif $(-10,10)$.

\section{RESULTS}

\section{Bird Captures}

I captured 2,630 birds of 80 species during sampling periods 1 and 2 across 2019 and 2020. Of these, 951 were frugivores from 27 species, and 1,679 were non-frugivores from 53 species. Captures were dominated by catbirds (Family: Mimidae, 23\%), vireos (Family: Vireonidae, 21\%), sparrows (Family: Passerellidae, 17\%), and waxwings (Family: Bombycillidae, 12\%) for frugivores, and warblers (Family: Parulidae, 86\%) for non-frugivores (Appendices B and C). 
Several focal species chosen for modeling showed large differences in captures from sampling period 1 to 2 (Table 3.2).

\section{Model Results}

As a guild, total frugivore relative abundance at each mist net was negatively correlated to SWD trap captures $(0.13$ decrease in log expected count for every standard deviation increase in SWD trap captures, scaled; $\beta=-0.13[-0.25,-0.02]$; Table 3.4, Figure 3.5A). At the focal species level, only one showed a relationship to SWD trap captures: eastern towhee relative abundance was negatively correlated to SWD trap captures $(0.32$ decrease in log expected count, scaled; $\beta=$ $-0.13[-0.70,-0.02]$; Table 3.4, Figure 3.5B). Final models for frugivore species richness and the remaining focal frugivore species did not include SWD trap captures as a retained covariate (Table 3.4). Final models for non-frugivores as a guild and individual species also lacked the SWD trap capture covariate (Table 3.4).

Ovenbird was the only frugivore species that was correlated to infestation rates of $R$. allegheniensis fruit by SWD; specifically the relationship was positive $(0.20$ increase in log expected count for every standard deviation increase in infestation rate, scaled; $\beta=0.20[0.01$, 0.38]; Table 3.4, Figure 3.6A). Of the response variables for non-frugivores, only hooded warbler relative abundance was negatively correlated to SWD infestation rates, $(0.35$ decrease in $\log$ expected count, scaled; $\beta=-0.35[-0.64,-0.09]$; Table 3.4, Figure 3.6B). Final models for remaining frugivore and non-frugivore response variables (focal relative abundances, guild relative abundances, and guild species richness) lacked infestation rate (Table 3.4).

Frugivore species relative abundance was correlated to different combinations of date, fruit, and vegetation variables, which differed among species, guild totals, and species richness (Table 3.4). As a guild, frugivore and 3 focal species relative abundances (cedar waxwing, red- 
eyed vireo, song sparrow) were negatively correlated to ordinal date. Frugivore relative abundance and frugivore species richness were positively correlated to fruit counts, but only 2 species' relative abundance were correlated to a fruit variable; specifically, gray catbird relative abundance was positively correlated to fruiting species richness, while ovenbird was negatively correlated. Only 4 focal species (cedar waxwing, eastern towhee, red-eyed vireo, and song sparrow) were correlated to vegetation variables (Table 3.4).

Non-frugivores also showed varying relationships to date, fruit, and vegetation variables. Species richness and 4 focal species (black-capped chickadee, black-throated blue warbler, black-throated green warbler, and magnolia warbler) were positively correlated to ordinal date, while two (American redstart and chestnut-sided warbler) were negatively correlated. Total nonfrugivore captures were correlated to fruit counts, as were 2 focal species (black-capped chickadee and magnolia warbler). Only 2 species (American redstart and common yellowthroat) responded to vegetation variables (Table 3.4).

\section{DISCUSSION}

Relationships to SWD activity in regenerating timber harvests at the ANF mostly differed from predictions. Most species and guilds showed no relationship of relative abundance or species richness to SWD, though a few species-frugivorous and non-frugivorous-were an exception to this finding: eastern towhee, ovenbird, and hooded warbler. To my knowledge, this is the first study to identify connections of bird relative abundances (or lack thereof) to an agricultural pest in invaded forest ecosystems - specifically, the relative abundance of adult flies and the parasitism of fruit resources. Species connected to SWD also related to different SWD variables and mostly in directions I did not hypothesize, suggesting more nuanced relationships of birds to SWD. 
Eastern towhee showed strong, negative correlations to SWD trap captures as I hypothesized, but not parasitism of $R$. allegheniensis fruits. Total frugivore relative abundances showed a similar relationship to trap captures, but the lack of any relationships from other species suggests eastern towhee declines drove the response for the guild. Adult SWD visibly swarmed on plants, (D. Roche, personal observation), a previously nonexistent phenomenon at the ANF (S. H. Stoleson, personal communication), and birds would have encountered these swarms while foraging in low dense vegetation preferred by SWD (Diepenbrock and Burrack 2017, Evans et al. 2017, Rice et al. 2017). Literature investigating relationships between birds and insect swarms is limited, but others have proposed that birds would have their eyes and heads covered in insects, their flight disrupted, and more of their time dedicated to necessary preening for removal of insect remains (Forster 1979, Davenport 1981). Swarming SWD may similarly annoy and deter towhees. Alternatively, encountering SWD on fruits could have made fruits undesirable, decreasing consumption of fruits (Manzur and Courtney 1984) and leading to declines in birds (Major and Desrochers 2012). Other species, however, were correlated to the parasitism of fruits, rather than adult flies.

The 2 focal species correlated to infestation rates of $R$. allegheniensis fruits, ovenbird and hooded warbler, differed in dietary guild and the direction of their relationship. Parasitism by insects can introduce additional nutritional content to fruits, increasing their likelihood of consumption by frugivorous birds (Piper 1986; Drew 1988; Valburg 1992a, b). This may explain the positive correlation of relative abundance of ovenbird, a frugivore, to infestation rate, especially if differences with other frugivores in food preference or nutritional demands existed (Levey and Karasov 1989, Witmer and Van Soest 1998). Parasitism by SWD also increases fruit drop from the parent plant (Walsh et al. 2011), which may benefit a ground-foraging bird such as 
ovenbird (Porneluzi et al. 2020). In contrast, hooded warblers are foliage gleaners (Chiver et al. 2020) and correlated negatively with infestation rate, though it's unlikely they were consuming fruits on the plant or ground (non-frugivores). Alternatively, ovenbird and hooded warbler may have been linked to either increases or declines of arthropod foods resources in response to invasion by SWD (Adkins and Rieske 2013, Jennings et al. 2017). Accumulation of dropped fruits may have attracted frugivorous and predatory ground-dwelling arthropods (Sallabanks and Courtney 1992), including predators of SWD pupating in the fruits or soil (Kanzawa 1939, Woltz and Lee 2017), benefitting ground-foraging birds like ovenbird. Foliage-dwelling arthropods may have moved to the ground to utilize dropped fruits from the plant or dispersed from SWD infested plants as fewer fruits remained on the plant, negatively impacting foliage-gleaning birds like hooded warbler. Indeed, both ovenbird and hooded warbler associate positively with arthropod communities (McDermott and Wood 2010, Streby et al. 2011a), which occur in greater concentrations in early successional habitat compared to mature forest (Keller et al. 2003). Arthropods are an important food source for many songbirds, including frugivorous species, after the breeding season (Strong et al. 2005, Brown and Long 2006, Tietz and Johnson 2007, Diggs et al. 2011), influencing abundances during the post-breeding season and fall migration (Buler et al. 2007, Vitz and Rodewald 2007, McDermott and Wood 2010).

Native arthropods may interact with SWD in multiple ways, with implications for songbird predators. Adult SWD may outcompete native arthropods for fruit resources (Fridley and Sax 2014, Verble-Pearson and Pearson 2016, Goodman and Warren 2019). Moreover, decay and premature loss of fruits from larval feeding (Walsh et al. 2011), combined with lower predation or parasitism on SWD by native species (Mitchell and Power 2003, Torchin et al. 2003, Prior et al. 2015), may displace native arthropods that songbirds rely on as food. 
Alternatively, SWD activity could attract natural arthropod predators (Beddington et al. 1976, Pintor and Byers 2015, Ballman et al. 2017, Bourne et al. 2019, Lee et al. 2019) or expose fruits to additional arthropods (Walsh et al. 2011), attracting increased food for songbirds. If SWD is affecting fruit and arthropod resources in early successional habitat, it could directly and indirectly influence multiple trophic levels in forest ecosystems.

However, contrary to predictions, most frugivorous species and guild-level variables showed no relationship to SWD and wouldn't be expected to differ in relative abundances. For most species, parasitism of fruits may not have altered fruits, fruit consumption (Piper 1986, Nalepa and Piper 1994), or subsequent use of harvests. The utilization of non-fruit food resources may also support the lack of observed relationships. Frugivorous birds are flexible in their diets, consuming plant and animal foods to meet nutritional needs (McKinnon et al. 2017). Limitations in some food sources are often insufficient to alter habitat use (Alatalo 1980, Rotenberry 1980, Hutto 1981, Petit 2000). Additionally, birds can alter foraging behavior to meet energetic needs of migration (Loria and Moore 1990, Aamidor et al. 2011). As such, the flexibility of frugivorous birds in diet and foraging behavior may support the lack of relationships to SWD, even if SWD altered some food resources in regenerating timber harvests.

Dietary flexibility may also support the overall weaker relationships of frugivores to fruit resources than predicted. Frugivores as a guild and species richness positively correlated with fruit counts, consistent with previous work (Buler et al. 2007, McDermott and Wood 2010, Major and Desrochers 2012), but no species correlated with fruit counts as observed previously (Vitz and Rodewald 2007, McDermott and Wood 2010). Utilization of non-fruit resources might mask expected relationships to fruit resources. Additionally, birds may choose locations to forage with sufficient foods to meet energetic needs rather than seeking out locations with the 
greatest resources (Champlin et al. 2009, Cohen et al. 2012), also masking expected (i.e., linear) relationships to fruit resources. The spatial scale of resources is also important for predicting bird abundances (Buler et al. 2007, Labbe and King 2014), so measuring fruits at the harvest-level could identify predicted relationships.

Remaining relationships to fruit resources also largely differed from predictions. Gray catbirds occur in greater relative abundances in habitat with greater fruiting species richness (Mudrzynski and Norment 2013), consistent with predictions and results of this study. Ovenbird associations with fruiting species richness have not been documented previously. Neither species showed patterns with date, so it does not appear to be due to the fruiting of $R$. allegheniensis in July and August compared to later-fruiting species (e.g., Aralia). Ovenbird associate with arthropod resources (Streby et al. 2011a), and arthropods favor dense vegetation (Keller et al. 2003). At mist nets with fewer other fruiting species, R. allegheniensis was the dominant species, producing large, dense brambles. Ovenbird associations with reduced richness may have been an artefact of arthropods in dense $R$. allegheniensis thickets at mist nets. Interestingly, nonfrugivores at the guild level and some species also correlated to fruit counts at mist nets. Previous studies documented associations of entire bird communities to fruit resources (Vitz and Rodewald 2007, McDermott and Wood 2010), suggesting non-frugivorous birds specifically cued in on arthropods attracted to fruits (Sallabanks and Courtney 1992). I am unaware of any study documenting negative relationships to fruit resources, as observed for magnolia warbler with unripe fruit and total non-frugivores with ripening and ripe fruit. Competition for resources can dampen energy acquisition even when food resources are abundant (Moore and Yong 1991, Kelly et al. 2002), which may lead to shifts in habitat use if insufficient resources can be acquired (Moore and Simons 1992, Moore et al. 1995). It's unclear whether birds competed for 
resources at my sites, but competition between frugivorous and non-frugivorous birds for arthropods could explain some of the declines observed for non-frugivores. Overall, relationships to fruit were weaker than expected for frugivores and stronger than expected for non-frugivores.

Relationships of songbirds to vegetation structure were similarly complex and weaker than predicted. Frugivores and non-frugivores only showed strong relationships to vegetation structure at the species level, unlike many previous studies at the guild level (Vitz and Rodewald 2006, 2007; McDermott and Wood 2010; Chandler et al. 2012; Mudrzynski and Norment 2013; Labbe and King 2014). Common yellowthroat, eastern towhee, and song sparrow, 3 early successional, ground-nesting species (Arcese et al. 2020, Greenlaw et al. 2020, Guzy et al. 2020), favored more variable cover (positively correlated with cover CV). In contrast, American redstart, cedar waxwing, and red-eyed vireo, 3 forest and forest edge, tree-nesting species (Cimprich et al. 2020, Sherry et al. 2020, Witmer et al. 2020), favored more uniform cover (negatively correlated with cover CV). The vegetative structure in regenerating harvests resembles breeding habitat structure for the early successional nesting species, and less so for forest breeding species. The early successional breeding species may be better able to utilize different microhabitats for foraging and cover from predation than the forest breeders, which utilize uniformly dense cover for protection from predation (White et al. 2005). Alternatively, the early successional breeding species also utilize grasses and forbs for foraging (Arcese et al. 2020, Greenlaw et al. 2020, Guzy et al. 2020), unlike the forest breeding species (Cimprich et al. 2020, Sherry et al. 2020, Witmer et al. 2020). As such, the former group could favor more complex structure for foraging, whereas the latter would more likely associate with uniformly woody habitat for foraging. 
The only other relationship to vegetation structure was the negative relationship between song sparrows and basal area. Previous studies suggested song sparrows favor residual trees for perching (Labbe and King 2014). However, song sparrows nest in regenerating harvests and associate with more open habitats (Arcese et al. 2020), so residual trees may be undesirable for this species. Species that did not show relationships to vegetation structure in this study showed them in other studies (i.e., chestnut-sided warbler, gray catbird, hooded warbler, ovenbird; Vitz and Rodewald 2007, McDermott and Wood 2010, Chandler et al. 2012, Mudrzynski and Norment 2013). One possible explanation is my measurements assessed vertical structure and spatial heterogeneity around mist nets, rather than a single average measure of structure taken closer to the net as in previous studies. Alternatively, while I observed a range of values for vegetation metrics across mist net locations (Table 3.3), these structural conditions could have been equally sufficient for most species. I may not have found thresholds beyond which abundances for species decline. Indeed, vertical cover below $2 \mathrm{~m}$ showed less variation than the cover range used in analyses and cover below $1.5 \mathrm{~m}$ showed little to no variation. As such, exploring greater variation in vegetation structure could identify these relationships. Ultimately, microhabitat characteristics (i.e., vegetation and fruit) showed overall weaker patterns than those associated with time of year.

The phenological movements associated with the post-breeding and migratory seasons were strong drivers of relative abundance of songbirds using regenerating harvests at the ANF. Nine of 14 (approximately 64\%) species abundances correlated with ordinal date, reflecting phenological patterns for many species in the region. Species negatively correlated with ordinal date were present in regenerating harvests early in the season but declined as individuals migrated, or as newly independent juveniles dispersed from breeding grounds (e.g., American 
redstart, chestnut-sided warbler, red-eyed vireo, and song sparrow). Species that were positively correlated to ordinal date were species that moved into regenerating harvests from nearby breeding territories in mature forest or from post-breeding grounds farther north during migration (e.g., black-throated blue warbler, black-throated green warbler, and magnolia warbler). I rarely captured cedar waxwing after the first sampling period (18 Jul-25 Aug) when R. allegheniensis crops disappeared, though they often remained in large residual trees above harvests. Declines in cedar waxwing were not correlated with fruit counts. Rather, individuals regularly hawked for aerial insects above harvests (D. Roche, personal observations), suggesting a connection to arthropod food resources. Declines in total frugivores with date were likely due to declines in three of the most captured species: cedar waxwing, red-eyed vireo, and song sparrow (Table 3.2). The increase in non-frugivore species richness with date was likely the product of the influx of post-breeding mature forest birds and migrants, many of which were non-frugivorous warblers, arriving in regenerating harvests (Pagen et al. 2000, Marshall et al. 2003, Rodewald and Brittingham 2004).

Multiple strong relationships to date suggest migration timing is a major driver for bird abundances during the post-breeding season and migration for many birds. Migration timing is important for successfully reaching overwintering grounds (Moore and Kerlinger 1991, Moore and Yong 1991, Woodrey and Moore 1997, Moore 2000, Stutchbury et al. 2011), so many birds use a time-minimization strategy (Lindström and Alerstam 1992, Hedenström 2008). The ability of birds to adjust diet and foraging behavior to acquire foods would allow birds to reduce time spent searching for suitable sites and utilize sites with different levels of resources (Loria and Moore 1990, Aamidor et al. 2011), if foods were in sufficient supply to acquire necessary energy 
(Champlin et al. 2009, Cohen et al. 2012). As such, strength of date to abundances could support the lack of relationships to fruit, vegetation, or SWD variables for many birds.

While this study provides the first evidence of avian responses to an agricultural fruit pest in forest ecosystems, many important gaps in our understanding of this system remain.

For example, I did not include actual fruit consumption by birds in these regenerating harvests. This is a critical next step: to determine if birds are consuming fruit resources at mist nets. Songbirds associate with food resources in early successional habitat (e.g., Vitz and Rodewald 2006, 2007; McDermott and Wood 2010; Labbe and King 2014) and remain in that habitat for days at a time during the post-breeding season (Anders et al. 1997, Vega Rivera et al. 1998a), but bird presence alone may provide an incomplete picture of habitat quality for that bird (Van Horne 1983, Garshelis 2000), highlighting the need for direct observations of how songbirds use early successional habitat (Hutto 1990). Important next questions include the following: Do adult SWD show any deterrent capabilities for wildlife? Are arthropod communities affected by SWD activity? These questions are especially important for eastern towhee and hooded warbler, which are listed in Pennsylvania's 2015-2025 State Wildlife Action Plan (SWAP; PGC-PFBS 2015). Further questions include the following: Are birds in early successional habitat consuming local fruits and what proportion of their diets are fruits? Does consumption differ with SWD activity? Do birds select or reject fruits parasitized by SWD? By extension, do birds in locations with greater SWD activity show any differences in body condition? Birds may be forced to expend greater energy locating food resources if they are deterred from using habitats where they would be able to find food resources in the absence of SWD. Alternatively, birds may be able to molt and accumulate energy more effectively if parasitism of fruits provides additional nutritional content, such as increased protein (Piper 1986, Bairlein and Gwinner 1994, Bairlein and Simons 
1995, Drew 1998, Parrish 1997). Both scenarios may influence migration. Alterations to consumption of fruits may influence the ability of birds to complete molt and build energy deposits for migration. If invertebrate communities are also altered, this could affect a proteinrich resource valuable for completing migratory molt and building energy stores for migration.

\section{FUTURE DIRECTIONS}

While I did not identify broad relationships between SWD, a novel invasive insect fruit pest, and most frugivorous and non-frugivorous birds in early successional habitat, some speciesfrugivorous and non-frugivorous - showed relationships, including opposite reactions to the parasitism of fruits, with the exact mechanisms for these responses unclear. Thus, further investigation into the ecological consequences of SWD invasion is warranted, including the consumption of parasitized fruits by wildlife and responses of arthropod communities to SWD invasion. However, implementation of studies of ecological consequences of SWD in natural systems will be challenging, especially those aimed at monitoring wildlife communities. In this study, I lacked a comparison of invaded areas against a true "control" treatment at the ANF, where SWD was absent. Adult SWD and parasitized fruits were eventually present at all sites. Because SWD has been present in most of North America for a decade and is capable of rapid dispersal (Hauser 2011, Rota-Stabelli et al. 2013), locating truly uninvaded areas within the same landscape for such a comparison may require considerable time for extensive searching of microhabitats (S. H. Stoleson, personal communication) and may be impossible without artificial exclusion. Comparing habitats across larger spatial extents may provide opportunities to compare uninvanded and invaded areas at the cost of introducing a greater number of confounding factors. Alternatively, comparisons could be made in areas pre- and post-invasion. However, unless monitoring in ecosystems has been ongoing, conducting a temporally comparative study may 
also be challenging. If wildlife are still developing responses to SWD due to the relatively recent introduction of SWD to the eastern United States (Metzger et al. 2009, Hauser 2011, Watts et al. 2020), continued monitoring of SWD activity and wildlife communities now may provide opportunities to track responses to SWD invasion before more dramatic alterations to forest ecosystems occur.

\section{LITERATURE CITED}

Aamidor, S. E., U. Bauchinger, O. Mizrahy, S. R. McWilliams, and B. Pinshow. 2011. During stopover, migrating Blackcaps adjust behavior and intake of food depending on the content of protein in their diets. Integrative and Comparative Biology 51:385-393.

Adkins, J. K., and L. K. Rieske. 2013. Loss of a foundation forest species due to an exotic invader impacts terrestrial arthropod communities. Forest Ecology and Management 295:126-135.

Alatalo, R. V. 1980. Seasonal dynamics of resource partitioning among foliage-gleaning passerines in northern Finland. Oecologia 45:190-196.

Allen, M. C., J. Sheehan, T. L. Master, and R. S. Mulvihill. 2009. Responses of acadian flycatchers (Empidonax virescens) to hemlock woolly adelgid (Adelges tsugae) infestation in Appalachian riparian forests. Auk 126:543-553.

Anders, A. D., D. C. Dearborn, J. Faaborg, and F. R. Thompson III. 1997. Juvenile survival in a population of neotropical migrant birds. Conservation Biology 11:698-707.

Anders, A. D., J. Faaborg, and F. R. Thompson. 1998. Postfledging dispersal, habitat use, and home-range size of juvenile wood thrushes. Auk 115:349-358. 
Arcese, P., M. K. Sogge, A. B. Marr, and M. A. Patten .2020. Song sparrow (Melospiza melodia), version 1.0 in A. F. Poole and F. B. Gill, editors. Birds of the world. Cornell Lab of Ornithology, Ithaca, NY, USA.

Atallah, J., L. Teixeira, R. Salazar, G. Zaragoza, and A. Kopp. 2014. The making of a pest: the evolution of a fruit-penetrating ovipositor in Drosophila suzukii and related species. Proceedings of the Royal Society B: Biological Sciences 281:20132840.

Bairlein, F., and E. Gwinner. 1994. Nutritional mechanisms and temporal control of migratory energy accumulation in birds. Annual Review of Nutrition 14:187-215.

Bairlein, F., and D. Simons. 1995. Nutritional adaptations in migrating birds. Israel Journal of Zoology 41:357-367.

Baker, R. R. 1993. The function of post-fledging exploration: a pilot study of three species of passerines ringed in Britain. Scandinavian Journal of Ornithology 24:71-79.

Ballman, E. S., J. A. Collins, and F. A. Drummond. 2017. Pupation behavior and predation on Drosophila suzukii (Diptera: Drosophilidae) pupae in Maine wild blueberry fields. Journal of Economic Entomology 110:2308-2317.

Beddington, J. R., M. P. Hassell, and J. H. Lawton. 1976. The components of arthropod predation: II. The predator rate of increase. Journal of Animal Ecology 45:165-185.

Bell, J. L., and R. C. Whitmore. 1997. Eastern towhee numbers increase following defoliation by gypsy moths. Auk 114:708-716.

Bellamy, D. E., M. S. Sisterson, and S. S. Walse. 2013. Quantifying host potentials: indexing postharvest fresh fruits for spotted wing drosophila, Drosophila suzukii. PLoS ONE 8(4):e61227. 
Blake, J. G., and W. G. Hoppes. 1986. Influence of resource abundance on use of tree-fall gaps by birds in an isolated woodlot. Auk 103:328-340.

Blake, J. G., T. Moermond, and D. J. Levey. 1990. Quantifying abundance of fruits for birds in tropical habitats. Studies in Avian Biology 13:73-79.

Blem, C. R. 1976. Patterns of lipid storage and utilization in birds. American Zoology 16:671684.

Blem, C. R. 1980. The energetics of migration. Pages 175-224 in S. A. Gauthreaux, Jr., editor. Animal migration, orientation, and navigation. Academic Press, New York, New York, USA.

Bonier, F., P. R. Martin, J. P. Jensen, L. K. Butler, M. Ramenofsky, and J. C. Wingfield. 2007. Pre-migratory life history stages of juvenile arctic birds: costs, constraints, and trade-offs. Ecology 88:2729-2735.

Bourne, A., M. T. Fountain, H. Wijnen, and B. Shaw. 2019. Potential of the European earwig (Forficula auricularia) as a biocontrol agent of the soft and stone fruit pest Drosophila suzukii. Pest Management Science 75:3340-3345.

Briem, F., A. R. Dominic, B. Golla, C. Hoffmann, C. Englert, A. Herz, and H. Vogt. 2018. Explorative data analysis of Drosophila suzukii trap catches from a seven-year monitoring program in southwest Germany. Insects 9:125.

Brockerhoff, E. G., and A. M. Liebhold. 2017. Ecology of forest insect invasions. Biological Invasions 19:3141-3159.

Brose, P. 2011. Fate of the 2001 acorn crop at Clear Creek State Forest, Pennsylvania. Pages 253-261 in. Proceedings, 17th central hardwood forest conference. S. Fei, J. M. Lhotka, 
J. W. Stringer, K. W. Gottschalk, and G. W. Miller, editors. U.S. Forest Service General Technical Report NRS-P-78, Newtown Square, Pennsylvania, USA.

Brown, D. R., and J. A. Long. 2006. Experimental fruit removal does not affect territory structure of wintering Hermit Thrushes. Journal of Field Ornithology 77:404-408.

Buchanan, M. L., R. A. Askins, and C. C. Jones. 2016. Response of bird populations to longterm changes in local vegetation and regional forest cover. Wilson Journal of Ornithology 128:704-718.

Buler, J. J., F. R. Moore, and S. Woltmann. 2007. A multi-scale examination of stopover habitat use by birds. Ecology 88:1789-1802.

Burger, A. E. 1987. Fruiting and frugivory of Cornus canadensis in boreal forest in Newfoundland. Oikos 49:3-10.

Burke, A. D., F. R. Thompson, and J. Faaborg. 2017. Variation in early-successional habitat use among independent juvenile forest breeding birds. Wilson Journal of Ornithology 129:235-246.

Burrack, H. J., M. Asplen, L. Bahder, J. Collins, F. A. Drummond, C. Guédot, R. Isaacs, D. Johnson, A. Blanton, J. C. Lee, G. Loeb, C. Rodriguez-Saona, S. Van Timmeren, D. Walsh, and D. R. McPhie. 2015. Multistate comparison of attractants for monitoring Drosophila suzukii (Diptera: Drosophilidae) in blueberries and caneberries. Environmental Entomology 44:704-712.

Canterbury, G. E., T. E. Martin, D. R. Petit, L. J. Petit, and D. F. Bradford. 2000. Bird communities and habitats as ecological indicators of forest condition in regionals monitoring. Conservation Biology 14:544-558. 
Carlisle, J. D., K. L. Olmstead, C. H. Richart, and D. L. Swanson. 2012. Food availability, foraging behavior, and diet of autumn migrant landbirds in the Boise foothills of southwestern Idaho. Condor 114:449-461.

Carter, W. 1939. Injuries to plants caused by insect toxins. Botanical Review 5:273-326.

Champlin, T. B., J. C. Kilgo, and C. E. Moorman. 2009. Food abundance does not determine bird use of early-successional habitat. Ecology 90:1586-1594.

Chandler, C. C., D. I. King, and R. B. Chandler. 2012. Do mature forest birds prefer earlysuccessional habitat during the post-fledging period? Forest Ecology and Management 264:1-9.

Chirakkal, H., and L. R. Gerber. 2010. Short- and long-term population response to changes in vital rates: implications for population viability analysis. Ecological Applications 20:783-788.

Chiver, I., L. J. Evans Ogden, and B. J. Stutchbury. 2020. Hooded warbler (Setophaga citrina), version 1.0 in A. F. Poole and F. B. Gill, editors. Birds of the world. Cornell Lab of Ornithology, Ithaca, NY, USA.

Cimprich, D. A., F. R. Moore, and M. P. Guilfoyle. 2020. Red-eyed vireo (Vireo olivaceus), version 1.0. in P. G. Rodewald, editor. Birds of the world. Cornell Lab of Ornithology, Ithaca, NY, USA.

Cohen, E. B., F. R. Moore, and R. A. Fischer. 2012. Experimental evidence for the interplay of exogenous and endogenous factors on the movement ecology of a migrating songbird. PLoS ONE 7(7):e41818.

Cyr, N. E., M. Wikelski, and M. L. Romero. 2008. Increased energy expenditure but decreased stress responsiveness during molt. Physiological and Biochemical Zoology 81:452-462. 
Diepenbrock, L. M., and H. J. Burrack. 2017. Variation of within-crop microhabitat use by Drosophila suzukii (Diptera: Drosophilidae) in blackberry. Journal of Applied Entomology 141:1-7.

Diggs, N. E., P. P. Marra, and R. J. Cooper. 2011. Resource limitation drives patterns of habitat occupancy during the nonbreeding season for an omnivorous songbird. Condor 113:646654.

Dormann, C. F., J. Elith, S. Bacher, C. Buchmann, G. Carl, G. Carré, J. R. G. Marquéz, B. Gruber, B. Lafourcade, P. J. Leitão, et al. 2013. Collinearity: a review of methods to deal with it and a simulation study evaluating their performance. Ecography 36:027-046.

Drew, R. A. I. 1988. Amino acid increases in fruit infested by fruit flies of the family Tephritidae. Zoological Journal of the Linnaean Society 93:107-112.

Dunn, E. H., and C. J. Ralph. 2004. Use of mist nets as a tool for bird population monitoring. Studies in Avian Biology 29:1-6.

Elsensohn, J. E., and G. M. Loeb. 2018. Non-crop host sampling yields insights into small-scale population dynamics of Drosophila suzukii (Matsumura). Insects 9:5.

Evans, R. K., M. D. Toews, and A. A. Sial. 2017. Diel periodicity of Drosophila suzukii (Diptera: Drosophilidae) under field conditions. PLoS ONE 12(2):e0171718.

Eyre, F. H. 1980. Forest cover types of the United States and Canada. Society of American Foresters. Washington, DC, USA.

Fridley, J. D., and D. F. Sax. 2014. The imbalance of nature: revisiting a Darwinian framework for invasion biology. Global Ecology and Biogeography 23:1157-1166. 
Fusani, L., M. Cardinale, C. Carere, and W. Goymann. 2009. Stopover decision during migration: physiological conditions predict nocturnal restlessness in wild passerines. Biology Letters 5:302-305.

García, D., R. Zamora, J. M. Gomez, and J. A. Hodar. 1999. Bird rejection of unhealthy fruits reinforces the mutualism between juniper and its avian dispersers. Oikos 85:536-544.

Garshelis, D. L. 2000. Delusions in habitat evaluation: measuring use, selection, and importance. Pages 111-164 in L. Boitani and T. K. Fuller, editors. Research techniques in animal ecology: controversies and consequences. Columbia University Press, New York, New York, USA.

Gelman, A., J. B. Carlin, H. S. Stern, and D. B. Rubin. 2004. Bayesian data analysis. Second edition. Chapman and Hall/CRC, New York, New York, USA.

Gelman, A., and J. Hill. 2007. Data analysis using regression and multilevel/hierarchical models. Cambridge University Press, New York, NY, USA.

Goodman, M., and R. J. Warren. 2019. Non-native ant invader displaces native ants but facilitates non-predatory invertebrates. Biological Invasions 21:2713-2722.

Goymann, W., F. Spina, A. Ferri, L. Fusani, and D. Supplement. 2010. Body fat influences departure from stopover sites in migratory birds: evidence from whole-island telemetry. Biology Letters 6:478-481.

Greenlaw, J. S. 2020. Eastern towhee (Pipilo erythrophthalmus), version 1.0 in P. G. Rodewald, editor. Birds of the world. Cornell Lab of Ornithology, Ithaca, NY, USA.

Guglielmo, C. G., D. J. Cerasale, and C. Eldermire. 2005. A field validation of plasma metabolite profiling to assess refueling performance of migratory birds. Physiological and Biochemical Zoology 78:116-125. 
Guzy, M. J. and G. Ritchison. 2020. Common yellowthroat (Geothlypis trichas), version 1.0 in P. G. Rodewald, editor. Birds of the world. Cornell Lab of Ornithology, Ithaca, NY, USA.

Halevy, G. 1974. Effects of gazelles and seed beetles (Bruchiade) on germination and establishment of Acacia species. Israel Journal of Botany 23:120-126.

Harris, D. W., K. A. Hamby, H. E. Wilson, and F. G. Zalom. 2014. Seasonal monitoring of Drosophila suzukii (Diptera: Drosophilidae) in a mixed fruit production system. Journal of Asia-Pacific Entomology 17:857-864.

Hauser, M. 2011. A historic account of the invasion of Drosophila suzukii (Matsumura) (Diptera: Drosophilidae) in the continental United States, with remarks on their identification. Pest Management Science 67:1352-1357.

Hedenström, A. 2008. Adaptations to migration in birds: behavioural strategies, morphology and scaling effects. Philosophical Transactions of the Royal Society B 363:287-299.

Hedenström, A., and T. Alerstam. 1997. Optimum fuel loads in migratory birds: distinguishing between time and energy minimization. Journal of Theoretical Biology 189:227-234.

Heimerdinger, M. A., and R. C. Leberman. 1966. The comparative efficiency of 30 and $36 \mathrm{~mm}$. mesh in mist nets. Bird-Banding 37:280-285.

Hennig, E. I., and D. Mazzi. 2018. Spotted wing drosophila in sweet cherry orchards in relation to forest characteristics, bycatch, and resource availability. Insects 9:118.

Highland, H. A. 1964. Life history of Asphondylia ilicicola (Diptera: Cecidomyiidae), a pest of American holly. Journal of Economic Entomology 57:81-83.

Howe, H. F., and J. Smallwood. 1982. Ecology of seed dispersal. Annual Review of Ecology and Systematics 13:201-228. 
Hutto, R. L. 1981. Seasonal variation in the foraging behavior of some migratory western wood warblers. Auk 98:765-777.

Hutto, R. L. 1985a. Habitat selection by nonbreeding, migratory land birds. Pages 455-476 in M. L. Cody, editor. Habitat selection in birds. Academic Press, New York, New York, USA.

Hutto, R. L. 1985b. Seasonal changes in the habitat distribution of transient insectivorous birds in southeastern Arizona: competition mediated? Auk 102:120-132.

Hutto, R. L. 1990. Measuring the availability of food resources. Studies in Avian Biology 13:2028.

Jackman, S. 2009. Bayesian analysis for the social sciences. John Wiley and Sons, Chichester, United Kingdom.

Jennings, D. E., J. J. Duan, D. Bean, K. A. Rice, G. L. Williams, S. K. Bell, A. S. Shurtleff, and P. M. Shrewsbury. 2017. Effects of the emerald ash borer invasion on the community composition of arthropods associated with ash tree boles in Maryland, U.S.A. Agricultural and Forest Entomology 19:122-129.

Jordano, P. 1987. Avian fruit removal: effects of fruit variation, crop size, and insect damage. Ecology 68:1711-1723.

Kanzawa, T. 1939. Studies on Drosophila suzukii Mats. Kofu, Yamanashi agricultural experiment station. Abstract in Review of Applied Entomology 29: 622.

Karr, J. R. 1981. Surveying birds with mist nets. Studies in Avian Biology 6:62-67.

Keller, J. K., M. E. Richmond, and C. R. Smith. 2003. An explanation of patterns of breeding bird species richness and density following clearcutting in northeastern USA forests. Forest Ecology and Management 174:541-564. 
Kellner, K. 2019. jagsUI: a wrapper around "rjags" to streamline "JAGS" analyses (R package version 1.5.1). Retrieved from http://CRAN.R-project.org/package=jagsUI.

Kelly, J. F., L. S. DeLay, and D. M. Finch. 2002. Density-dependent mass gain by Wilson's Warblers during stopover. Auk 119:210-213.

Kenis, M., M. A. Auger-Rozenberg, A. Roques, L. Timms, C. Péré, M. J. W. Cock, J. Settele, S. Augustin, and C. Lopez-Vaamonde. 2009. Ecological effects of invasive alien insects. Biological Invasions 11:21-45.

Kenis, M., L. Tonina, R. Eschen, B. van der Sluis, M. Sancassani, N. Mori, T. Haye, and H. Helsen. 2016. Non-crop plants used as hosts by Drosophila suzukii in Europe. Journal of Pest Science 89:735-748.

Kéry, M. 2010. Introduction to WinBUGS for ecologists. Academic Press, Waltham, Massachusetts, USA.

Keyes, B. E. and C. E. Grue. 1982. Capturing birds with mist nets: a review. North American Bird Bander 7:2-14.

King, D. I., R. M. Degraaf, M. L. Smith, and J. P. Buonaccorsi. 2006. Habitat selection and habitat-specific survival of fledgling ovenbirds (Seiurus aurocapilla). Journal of Zoology 269:414-421.

Kirkpatrick, D. M., L. J. Gut, and J. R. Miller. 2018. Estimating monitoring trap plume reach and trapping area for Drosophila suzukii (Diptera: Drosophilidae) in Michigan tart cherry. Journal of Economic Entomology 111:1285-1289.

Klick, J., W. Q. Yang, V. M. Walton, D. T. Dalton, J. R. Hagler, A. J. Dreves, J. C. Lee, and D. J. Bruck. 2016. Distribution and activity of Drosophila suzukii in cultivated raspberry and surrounding vegetation. Journal of Applied Entomology 140:37-46. 
Krischik, V., E. S. McCloud, and J. A. Davidson. 1989. Selective avoidance by vertebrate frugivores of green holly berries infested with a cecidomyiid fly (Diptera: Cecidomyiidae). American Midland Naturalist 121:350-354.

Labbe, M. A., and D. I. King. 2014. The effect of local and landscape-level characteristics on the abundance of forest birds in early-successional habitats during the post-fledging season in Western Massachusetts. PLoS ONE 9(8):e106398.

Lamprey, H. F., G. Halevy, and S. Makacha. 1974. Interactions between Acacia, bruchid seed beetles and large herbivores. African Journal of Ecology 12:81-85.

Landolt, P. J., T. Adams, and H. Rogg. 2012. Trapping spotted wing drosophila, Drosophila suzukii (Matsumura) (Diptera: Drosophilidae), with combinations of vinegar and wine, and acetic acid and ethanol. Journal of Applied Entomology 136:148-154.

Lasa, R., E. Tadeo, R. A. Toledo-Hérnandez, L. Carmona, I. Lima, and T. Williams. 2017. Improved capture of Drosophila suzukii by a trap baited with two attractants in the same device. PLoS ONE 12(11):e0188350.

Lee, J. C., D. J. Bruck, H. Curry, D. Edwards, D. R. Haviland, R. A. Van Steenwyk, and B. M. Yorgey. 2011a. The susceptibility of small fruits and cherries to the spotted-wing drosophila, Drosophila suzukii. Pest Management Science 67:1358-1367.

Lee, J. C., D. J. Bruck, A. J. Dreves, C. Ioriatti, H. Vogt, and P. Baufeld. 2011b. In focus: Spotted wing drosophila, Drosophila suzukii, across perspectives. Pest Management Science 67:1349-1351.

Lee, J. C., H. J. Burrack, L. D. Barrantes, E. H. Beers, A. J. Dreves, K. A. Hamby, D. R. Haviland, R. Isaacs, T. A. Richardson, P. W. Shearer, et al. 2012. Evaluation of 
monitoring traps for Drosophila suzukii (Diptera: Drosophilidae) in North America. Journal of Economic Entomology 105:1350-1357.

Lee, J. C., A. J. Dreves, A. M. Cave, S. Kawai, R. Isaacs, J. C. Miller, S. Van Timmeren, and D. J. Bruck. 2015. Infestation of wild and ornamental noncrop fruits by Drosophila suzukii (Diptera: Drosophilidae). Annals of the Entomological Society of America 108:117-129.

Lee, J. C., P. W. Shearer, L. D. Barrantes, E. H. Beers, H. J. Burrack, D. T. Dalton, A. J. Dreves, L. J. Gut, K. A. Hamby, D. R. Haviland, et al. 2013. Trap designs for monitoring Drosophila suzukii (Diptera: Drosophilidae). Environmental Entomology 42:1348-1355.

Lee, J. C., X. Wang, K. M. Daane, K. A. Hoelmer, R. Isaacs, A. A. Sial, and V. M. Walton. 2019. Biological control of spotted-wing Drosophila (Diptera: Drosophilidae) - current and pending tactics. Journal of Integrated Pest Management 10:13.

Levey, D. J. 1988a. Tropical wet forest treefall gaps and distributions of understory birds and plants. Ecology 69:1076-1089.

Levey, D. J. 1988b. Spatial and temporal variation in Costa Rican fruit and fruit-eating bird abundance. Ecological Monographs 58:251-269.

Levey, D. J., and W. H. Karasov. 1989. Digestive responses of temperate birds switched to fruit or insect diets. Auk 106:675-686.

Lindenmayer, D. B., G. E. Likens, A. Andersen, D. Bowman, C. M. Bull, E. Burns, C. R. Dickman, A. A. Hoffmann, D. A. Keith, M. J. Liddell, et al. 2012. Value of long-term ecological studies. Austral Ecology 37:745-757.

Lindström, ̊., and T. Alerstam. 1992. Optimal fat loads in migrating birds: a test of the timeminimization hypothesis. American Naturalist 140:477-491. 
Loiselle, B. A., and J. G. Blake. 1991. Temporal variation in birds and fruits along an elevational gradient in Costa Rica. Ecology 72:180-193.

Long, L. C. 2013. Direct and indirect impacts of emerald ash borer on forest bird communities. Thesis, Ohio State University, Columbus, USA.

Loria, D. E., and F. R. Moore. 1990. Energy demands of migration on red-eyed vireos, Vireo olivaceus. Behavioral Ecology 1:24-35.

Lovett, G. M., M. Weiss, A. M. Liebhold, T. P. Holmes, B. Leung, K. F. Lambert, D. A. Orwig, F. T. Campbell, J. Rosenthal, D. G. McCullough, R. Wildova, M. P. Ayres, C. D. Canham, D. R. Foster, S. L. LaDeau, and T. Weldy. 2016. Nonnative forest insects and pathogens in the United States: impacts and policy options. Ecological Applications 26:1437-1455.

MacArthur, R. H., and A. T. MacArthur. 1974. On the use of mist nets for population studies of birds. Proceedings from the National Academy of Sciences 71:3230-3233.

Major, M., and A. Desrochers. 2012. Avian use of early-successional boreal forests in the postbreeding period. Auk 129:419-426.

Mannan, R. W., M. L. Morrison, and E. C. Meslow. 1984. Comment: the use of guilds in forest bird management. Wildlife Society Bulletin 12:426-430.

Manzur, M. I., and S. P. Courtney. 1984. Influence of insect damage in fruits of hawthorn on bird foraging and seed dispersal. Oikos 43:265-270.

Marques, J. T., M. J. Ramos Pereira, T. A. Marques, C. D. Santos, J. Santana, P. Beja, and J. M. Palmeirim. 2013. Optimizing sampling design to deal with mist-net avoidance in Amazonian birds and bats. PLoS ONE 8(9):e74505. 
Marshall, M. R., J. A. DeCecco, A. B. Williams, G. A. Gale, and R. J. Cooper. 2003. Use of regenerating clearcuts by late-successional bird species and their young during the postfledging period. Forest Ecology and Management 183:127-135.

Martin, T. E. 1985. Selection of second-growth woodlands by frugivorous migrating birds in Panama: an effect of fruit size and plant density? Journal of Tropical Ecology 1:157-170.

Martin, T. E., and J. R. Karr. 1986. Patch utilization by migrating birds: resource oriented? Scandinavian Journal of Ornithology 17:165-174.

McCarty, J. P., D. J. Levey, C. H. Greenberg, and S. Sargent. 2002. Spatial and temporal variation in fruit use by wildlife in a forested landscape. Forest Ecology and Management 164:277-291.

McCusker, C. E., M. P. Ward, and J. D. Brawn. 2010. Seasonal responses of avian communities to invasive bush honeysuckles (Lonicera spp.). Biological Invasions 12:2459-2470.

McDermott, M. E., and P. B. Wood. 2010. Influence of cover and food resource variation on post-breeding bird use of timber harvests with residual canopy trees. Wilson Journal of Ornithology 122:545-555.

McDermott, M. E., and P. B. Wood. 2011. Post-breeding bird responses to canopy tree retention, stand size, and edge in regenerating Appalachian hardwood stands. Forest Ecology and Management 262:547-554.

McDiarmid, R. W., R. E. Ricklefs, and M. S. Foster. 1977. Dispersal of Stemmadenia donnellsmithii (Apocynaceae) by birds. Biotropica 9:9-25.

McKinnon, E. A., T. Kurt Kyser, and B. J. M. Stutchbury. 2017. Does the proportion of arthropods versus fruit in the diet influence overwintering condition of an omnivorous songbird? Journal of Field Ornithology 88:65-79. 
McWilliams, S. R., C. Guglielmo, B. Pierce, and M. Klaassen. 2004. Flying, fasting, and feeding in birds during migration: a nutritional and physiological ecology perspective. Journal of Avian Biology 35:377-393.

Metcalf, J. L., and S. M. Emery. 2015. Non-native grass invasion associated with increases in insect diversity in temperate forest understory. Acta Oecologica 69:105-112.

Metzger, J. P., A. C. Martensen, M. Dixo, L. C. Bernacci, M. C. Ribeiro, A. M. G. Teixeira, and R. Pardini. 2009. Time-lag in biological responses to landscape changes in a highly dynamic Atlantic forest region. Biological Conservation 142:1166-1177.

Mitchell, C. E., and A. G. Power. 2003. Release of invasive plants from fungal and viral pathogens. Nature 421:625-627.

Mitsui, H., K. Beppu, and M. T. Kimura. 2010. Seasonal life cycles and resource uses of flowerand fruit-feeding drosophilid flies (Diptera: Drosophilidae) in central Japan. Entomological Science 13:60-67.

Mitsui, H., K. H. Takahashi, and M. T. Kimura. 2006. Spatial distributions and clutch sizes of Drosophila species ovipositing on cherry fruits of different stages. Population Ecology $48: 233-237$.

Moegenburg, S. M., and D. J. Levey. 2003. Do frugivores respond to fruit harvest? An experimental study of short-term responses. Ecology 84:2600-2612.

Moore, F. R. 2000. Stopover ecology of Nearctic-Neotropical landbird migrants: habitat relations and conservation implications. Studies in Avian Biology 20:1-3.

Moore, F. R., and D. A. Aborn. 2000. Mechanisms of en route habitat selection: how do migrants make habitat decisions during stopover? Studies in Avian Biology 20:34-42. 
Moore, F. R., S. A. Gauthreaux Jr., P. Kerlinger, and T. R. Simons. 1995. Habitat requirements during migration: important link in conservation. Pages 121-144 in T. E. Martin and D. M. Finch, editors. Ecology and management of neotropical migratory birds: a synthesis and review of critical issues. Oxford University Press, New York, New York, USA.

Moore, F. R., and P. Kerlinger. 1991. Nocturnality, long-distance migration, and ecological barriers. Pages 1122-1129 in B. D. Bell, editor. Acta XX Congressus Internationalis Ornithologici. New Zealand Ornithological Congress Trust Board, Wellington, New Zealand.

Moore, F. R., P. Kerlinger, and T. R. Simons. 1990. Stopover on a Gulf Coast barrier island by spring trans-gulf migrants. Wilson Bulletin 102:487-500.

Moore, F. R., and T. R. Simons. 1992. Habitat suitability and stopover ecology of neotropical landbird migrants. Pages 345-355 in J. M. Hagan III and D. W. Johnston, editors. Ecology and conservation of neotropical migrant landbirds. Smithsonian Institution Press. Washington, D.C., USA.

Moore, F. R., and W. Yong. 1991. Evidence of food-based competition among passerine migrants during stopover. Behavioral Ecology and Sociobiology 28:85-90.

Morin, R. S., A. M. Liebhold, K. W. Gottschalk, D. B. Twardus, R. E. Acciavatti, R. L. White, S. B. Horsley, W. D. Smith, and E. R. Luzader. 2006. Analysis of forest health monitoring surveys on the Allegheny National Forest (1998-2001). General Technical Report NE339. U.S. Forest Service, Northeastern Research Station, Newtown Square, Pennsylvania, USA.

Morrison, M. L. 1986. Bird populations as indicators of environmental change. Pages 429-445 in R. F. Johnston, editor. Current Ornithology. Plenum, New York, New York, USA. 
Mowbray, T. B. 1999. Scarlet Tanager (Piranga olivacea), version 2.0 in A. F. Poole and F. B. Gill, editors. The birds of North America. Cornell Lab of Ornithology, Ithaca, New York, USA.

Mudrzynski, B. M., and C. J. Norment. 2013. Influence of habitat structure and fruit availability on use of a northeastern stopover site by fall songbirds. Wilson Journal of Ornithology 125:744-754.

Murphy, M. E. 1996. Energetics and nutrition of molt. Pages 158-198 in Carey C., editor. Avian energetics and nutritional ecology. Springer, Boston, Massachusetts, USA.

Nalepa, C. A., and W. H. Piper. 1994. Bird dispersal of the larval stage of a seed predator. Oecologia 100:200-202.

Nudds, T. D. 1977. Quantifying the vegetative structure of wildlife cover. Wildlife Society Bulletin 5:113-117.

Packett, D. L., and J. B. Dunning. 2009. Stopover habitat selection by migrant landbirds in a fragmented forest-agricultural landscape. Auk 126:579-589.

Pagen, R. W., F. R. Thompson III, and D. E. Burhans. 2000. Breeding and post-breeding habitat use by forest migrant songbirds in the Missouri Ozarks. Condor 102:738-747.

Pardieck, K., and R. B. Waide. 1992. Mesh size as a factor in avian community studies using mist nets. Journal of Field Ornithology 63:250-255.

Parrish, J. D. 1997. Patterns of frugivory and energetic condition in Nearctic landbirds during autumn migration. Condor 99:681-697.

Parrish, J. D. 2000. Behavioral, energetic, and conservation implications of foraging plasticity during migration. Studies in Avian Biology 20:53-70. 
Pelton, E., C. Gratton, R. Isaacs, S. Van Timmeren, A. Blanton, and C. Guédot. 2016. Earlier activity of Drosophila suzukii in high woodland landscapes but relative abundance is unaffected. Journal of Pest Science 89:725-733.

Petit, D. R. 2000. Habitat use by landbirds along nearctic-neotropical migration routes: implications for conservation and stopover habitats. Studies in Avian Biology 20:15-33.

PGC (Pennsylvania Game Commission). 2014. State Game Lands No. 86. < https://www.pgc.pa.gov/HuntTrap/StateGameLands/Documents/SGL\%20Maps/SGL_0 86.pdf>. Accessed 29 Apr 2021.

PGC-PFBS (Pennsylvania Game Commission and Pennsylvania Fish \& Boat Commission). 2015. Pennsylvania Wildlife Action Plan 2015-2025, Species of Greatest Conservation Need Species Accounts, Appendix 1.4A-Birds. Harrisburg, Pennsylvania, USA.

Pintor, L. M., and J. E. Byers. 2015. Do native predators benefit from non-native prey? Ecology Letters 18:1174-1180.

Piper, J. K. 1986. Seasonality of fruit characters and seed removal. Oikos 46:303-310.

Plein, M., L. Längsfeld, E. L. Neuschulz, C. Schultheiß, L. Ingmann, T. Töpfer, K. BöhningGaese, and M. Schleuning. 2013. Constant properties of plant-frugivore networks despite fluctuations in fruit and bird communities in space and time. Ecology 94:1296-1306.

Plummer, M. 2003. JAGS: a program for analysis of Bayesian graphical models using Gibbs sampling. Proceedings of the 3rd International Workshop on Distributed Statistical Computing 124:1-10.

Porneluzi, P. A., R. Brito-Aguilar, R. L. Clawson, and J. Faaborg. 2014. Long-term dynamics of bird use of clearcuts in post-fledging period. Wilson Journal of Ornithology 126:623634. 
Porneluzi, P., M. A. Van Horn, and T. M. Donovan. 2020. Ovenbird (Seiurus aurocapilla), version 1.0 in A. F. Poole and F. B. Gill, editors. Birds of the world. Cornell Lab of Ornithology, Ithaca, NY, USA.

Poyet, M., V. Le Roux, P. Gibert, A. Meirland, G. Prévost, P. Eslin, and O. Chabrerie. 2015. The wide potential trophic niche of the Asiatic fruit fly Drosophila suzukii: the key of its invasion success in temperate Europe? PLoS ONE 10(11):e0142785.

Prior, K. M., T. H. Q. Powell, A. L. Joseph, and J. J. Hellmann. 2015. Insights from community ecology into the role of enemy release in causing invasion success: the importance of native enemy effects. Biological Invasions 17:1283-1297.

R Core Team. 2021. R: A language and environment for statistical computing. R Foundation for Statistical Computing, Vienna, Austria.

Rabenold, K. N., P. T. Fauth, B. W. Goodner, J. A. Sadowski, and P. G. Parker. 1998. Response of avian communities to disturbances by an exotic insect in spruce-fir forest of the Southern Appalachians. Conservation Biology 12:177-189.

Ralph, C. J., E. H. Dunn, W. J. Peach, and C. M. Handel. 2004. Recommendations for the use of mist nets for inventory and monitoring of bird populations. Studies in Avian Biology 29:187-196.

Rappole, J. H., and K. Ballard. 1987. Postbreeding movements of selected species of birds in Athens, Georgia. Wilson Bulletin 99:475-480.

Rey, P. J. 1995. Spatio-temporal variation in fruit and frugivorous bird abundance in olive orchards. Ecology 76:1625-1635. 
Rice, K. B., S. K. Jones, W. Morrison, and T. C. Leskey. 2017. Spotted wing drosophila prefer low hanging fruit: insights into foraging behavior and management strategies. Journal of Insect Behavior 30:645-661.

Roche, D. P., S. H. Stoleson, and C. M. Lituma. 2021. Invasion of eastern deciduous forests by the spotted wing Drosophila: impacts and knowledge gaps. Wildlife Society Bulletin:10.1002/wsb.1234.

Rodewald, P. G., and M. C. Brittingham. 2004. Stopover habitats of landbirds during fall: use of edge-dominated and early-successional forests. Auk 121:1040-1055.

Rodewald, A. D., and A. C. Vitz. 2005. Edge- and area-sensitivity of shrubland birds. Journal of Wildlife Management 69:681-688.

Rota-Stabelli, O., M. Blaxter, and G. Anfora. 2013. Drosophila suzukii. Current Biology 23:R8R9.

Rotenberry, J. T. 1980. Dietary relationships among shrub-steppe passerine birds: competition or opportunism in a variable environment. Ecological Monographs 50:93-110.

Royle, J. A. 2004. N-mixture models for estimating population size from spatially replicated counts. Biometrics 60:108-115.

Sallabanks, R., and S. P. Courtney. 1992. Frugivory, seed predation, and insect-vertebrate interactions. Annual Review of Entomology 37:377-400.

Saracco, J. F., J. A. Collazo, and M. J. Groom. 2004. How do frugivores track resources? Insights from spatial analyses of bird foraging in a tropical forest. Oecologia 139:235245.

Schemske, D. W., and N. Brokaw. 1981. Treefalls and the distribution of understory birds in a tropical forest. Ecology 62:938-945. 
Schmaljohann, H., and V. Dierschke. 2005. Optimal bird migration and predation risk: a field experiment with Northern Wheatears Oenanthe oenanthe. Journal of Animal Ecology 74:131-138.

Schmaljohann, H., and C. Eikenaar. 2017. How do energy stores and changes in these affect departure decisions by migratory birds? A critical view on stopover ecology studies and some future perspectives. Journal of Comparative Physiology A 203:411-429.

Sherry, T. W., R. T. Holmes, P. Pyle, and M. A. Patten (2020). American redstart (Setophaga ruticilla), version 1.0. in P. G. Rodewald, editor. Birds of the world. Cornell Lab of Ornithology, Ithaca, NY, USA.

Sillett, T. S., and R. T. Holmes. 2002. Variation in survivorship of a migratory songbird throughout its annual cycle. Journal of Animal Ecology 71:296-308.

Skrip, M. M., U. Bauchinger, W. Goymann, L. Fusani, M. Cardinale, R. R. Alan, and S. R. McWilliams. 2015. Migrating songbirds on stopover prepare for, and recover from, oxidative challenges posed by long-distance flight. Ecology and Evolution 5:3198-3209.

Snow, D. W. 1971. Evolutionary aspects of fruit-eating by birds. Ibis 113:194-202.

Stoleson, S. H. 2013. Condition varies with habitat choice in postbreeding forest birds. Auk 130:417-428.

Streby, H. M., S. M. Peterson, and D. E. Andersen. 2011a. Invertebrate availability and vegetation characteristics explain use of nonnesting cover types by mature-forest songbirds during the postfledging period. Journal of Field Ornithology 82:406-414.

Streby, H. M., S. M. Peterson, T. L. McAllister, and D. E. Andersen. 2011b. Use of earlysuccessional managed northern forest by mature-forest species during the post-fledging period. Condor 113:817-824. 
Strong, C. M., D. R. Brown, and P. C. Stouffer. 2005. Frugivory by wintering hermit thrush in Louisiana. Southeastern Naturalist 4:627-638.

Stutchbury, B. J. M., E. A. Gow, T. Done, M. MacPherson, J. W. Fox, and V. Afanasyev. 2011. Effects of post-breeding moult and energetic condition on timing of songbird migration into the tropics. Proceedings of the Royal Society B: Biological Sciences 278:131-137.

Suthers, H. B., J. M. Bickal, and P. G. Rodewald. 2000. Use of successional habitat and fruit resources by songbirds during autumn migration in central New Jersey. Wilson Bulletin 112:249-260.

Tait, G., A. Grassi, F. Pfab, C. M. Crava, D. T. Dalton, R. Magarey, L. Ometto, S. Vezzulli, M. V. Rossi-Stacconi, A. Gottardello, et al. 2018. Large-scale spatial dynamics of Drosophila suzukii in Trentino, Italy. Journal of Pest Science 91:1213-1224.

Thistlewood, H. M. A. B. Rozema, and S. Acheampong. 2019. Infestation and timing of use of non-crop plants by Drosophila suzukii (Matsumura) (Diptera: Drosophilidae) in the Okanagan Basin, Canada. Canadian Entomologist 151:34-48.

Thompson, J. N., and M. F. Willson. 1979. Evolution of temperate fruit/bird interactions: phenological strategies. Evolution 33:973-982.

Tietz, J. R., and M. D. Johnson. 2007. Stopover ecology and habitat selection of juvenile Swainson's thrushes during fall migration along the northern California coast. Condor 109:795-807.

Tingley, M. W., D. A. Orwig, R. Field, and G. Motzkin. 2002. Avian response to removal of a forest dominant: consequences of hemlock woolly adelgid infestations. Journal of Biogeography 29:1505-1516. 
Tochen, S., J. M. Woltz, D. T. Dalton, J. C. Lee, N. G. Wiman, and V. M. Walton. 2016. Humidity affects populations of Drosophila suzukii (Diptera: Drosophilidae) in blueberry. Journal of Applied Entomology 140:47-57.

Torchin, M. E., K. D. Lafferty, A. P. Dobson, V. J. McKenzie, and A. M. Kuris. 2003. Introduced species and their missing parasites. Nature 421:628-630.

Traveset, A. 1993. Weak interactions between avian and insect frugivores: the case of Pistacia terebinthus L. (Anacardiaceae). Vegetatio 107:191-203.

Traveset, A., M. F. Willson, and J. C. Gaither. 1995. Avoidance by birds of insect-infested fruits of Vaccinium ovalifolium. Oikos 73:381-386.

Turcotte, R. M., C. Larcenaire, R. Long, D. K. H. Martin, and L. Barringer. 2018. The spotted wing drosophila, Drosophila suzukii (Diptera: Drosophilidae): a new pest of concern for black cherry, Prunus serotina, on the High Allegheny Plateau in Pennsylvania. Entomological News 127:390-399.

Uchytil, R. J. 1991. U.S. Department of Agriculture, Forest Service, Rocky Mountain Research Station, Fire Sciences Laboratory (Producer). Prunus serotina. Fire effects information system. <https://www.fs.fed.us/database/feis/plants/tree/pruser/all.html>. Accessed 26 Jan 2019.

U.S. Forest Service. 2007. Allegheny National Forest record of decision for final environmental impact statement and the land and resource management plan. Warren, PA.

U.S. Forest Service. 2019. Allegheny National Forest GIS datasets. <https://www.fs.usda.gov/main/allegheny/landmanagement/gis>. Accessed 30 April 2020. 
Valburg, L. K. 1992a. Eating infested fruits: interactions in a plant-disperser-pest triad. Oikos $65: 25-28$.

Valburg, L. K. 1992b. Feeding preferences of common bush-tanagers for insect-infested fruits: avoidance or attraction? Oikos 65:29-33.

Van Horne, B. 1983. Density as a misleading indicator of habitat quality. Journal of Wildlife Management 47:893-901.

Vega Rivera, J. H., W. J. McShea, J. H. Rappole, and C. A. Haas. 1998a. Pattern and chronology of prebasic molt for the wood thrush and its relation to reproduction and migration departure. Wilson Bulletin 110:384-392.

Vega Rivera, J. H., J. H. Rappole, W. J. McShea, and C. A. Haas. 1998b. Wood thrush postfledging movements and habitat use in northern Virginia. Condor 100:69-78.

Verble-Pearson, R., and S. Pearson. 2016. European fire ant presence decreases native arboreal insect abundance in Acadia National Park, Maine, USA. Natural Areas Journal 36:162165.

Vitz, A. C., and A. D. Rodewald. 2006. Can regenerating clearcuts benefit mature-forest songbirds? An examination of post-breeding ecology. Biological Conservation 127:477486.

Vitz, A. C., and A. D. Rodewald. 2007. Vegetative and fruit resources as determinants of habitat use by mature-forest birds during the postbreeding period. Auk 124:494-507.

Walsh, D. B., M. P. Bolda, R. E. Goodhue, A. J. Dreves, J. Lee, D. J. Bruck, V. M. Walton, S. D. O’Neal, and F. G. Zalom. 2011. Drosophila suzukii (Diptera: Drosophilidae): invasive pest of ripening soft fruit expanding its geographic range and damage potential. Journal of Integrated Pest Management 2:G1-G7. 
Wang, X. G., T. J. Stewart, A. Biondi, B. A. Chavez, C. Ingels, J. Caprile, J. A. Grant, V. M. Walton, and K. M. Daane. 2016. Population dynamics and ecology of Drosophila suzukii in Central California. Journal of Pest Science 89:701-712.

Watts, K., R. C. Whytock, K. J. Park, E. Fuentes-Montemayor, N. A. Macgregor, S. Duffield, and P. J. K. McGowan. 2020. Ecological time lags and the journey towards conservation success. Nature Ecology and Evolution 4:304-311.

Wheelwright, N. T. 1986. A seven-year study of individual variation in fruit production in tropical bird-dispersed tree species in the family Lauraceae. Pages 19-35 in A. Estrada and T. H. Fleming, editors. Frugivores and seed dispersal. Tasks for vegetation science, Volume 15. Springer, Dordrecht, Netherlands.

White, J. D., T. Gardali, F. R. Thompson III, and J. Faaborg. 2005. Resource selection by juvenile Swainson's thrushes during the postfledging period. Condor 107:388-401.

Witmer, M. C., D. J. Mountjoy, and L. Elliott. 2020. Cedar waxwing (Bombycilla cedrorum), version 1.0. in A. F. Poole, editor. Birds of the world. Cornell Lab of Ornithology, Ithaca, NY, USA.

Witmer, M. C., and P. J. Van Soest. 1998. Contrasting digestive strategies of fruit-eating birds. Functional Ecology 12:728-741.

Wolfe, J. D., M. D. Johnson, and C. J. Ralph. 2014. Do birds select habitat or food resources? Nearctic-neotropic migrants in northeastern Costa Rica. PLoS ONE 9(1):e86221.

Woltz, J. M., and J. C. Lee. 2017. Pupation behavior and larval and pupal biocontrol of Drosophila suzukii in the field. Biological Control 110:62-69. 
Wong, J. S., A. C. Cave, D. M. Lightle, W. F. Mahaffee, S. E. Naranjo, N. G. Wiman, J. M. Woltz, and J. C. Lee. 2018. Drosophila suzukii flight performance reduced by starvation but not affected by humidity. Journal of Pest Science 91:1269-1278.

Woodrey, M. S., and F. R. Moore. 1997. Age-related differences in the stopover of fall landbird migrants on the coast of Alabama. Auk 114:695-707. 


\section{TABLES}

Table 3.1. Final covariates used to model bird captures at mist nets in regenerating harvests during the post-breeding season and fall migration (Jul-Sep) at Allegheny National Forest (ANF), Clear Creek State Forest (CCSF), and State Game Lands (SGL) 86,

Pennsylvania, in 2019 and 2020. Multiple measures were pooled for a single value of each covariate at each mist net and checked for collinearity $(r \geq 0.7)$. All covariates were included in a global model for each bird variable, which were then excluded from final models using a stepwise removal process.

Covariate

category Covariate name Description

\begin{tabular}{lll}
\hline Date & date & Ordinal date of first bird banding day of each 2-day banding session \\
Fruit & unripe & Count of unripe Allegheny blackberry (Rubus allegheniensis) fruits at each mist net \\
Fruit & ripen.ripe & Count of ripening and ripe $R$. allegheniensis fruits at each mist net \\
Fruit & max.richness & Maximum count (over all sampling periods) of plant species at each mist net that produce fleshy fruits \\
SWD & swd & Count of spotted wing Drosophila (Drosophila suzukii, SWD)/trap/24 hrs at each mist net \\
SWD & infest & Count of adult, larval, and pupal SWD/g of $R$. allegheniensis fruit at each mist net \\
Veg & BA & Residual tree basal area within $25 \mathrm{~m}$ of each mist net $\left(\mathrm{m}^{2}\right)$ \\
Veg & height & Coefficient of variation for vegetation height measurements $(\mathrm{m})$ at each mist net \\
Veg & cover & Coefficient of variation for cover score values at 2-2.5 $\mathrm{m}$ at each mist net
\end{tabular}


Table 3.2. Captures and dietary guild identity of focal bird species captured in regenerating harvests at Allegheny National Forest (ANF), Clear Creek State Forest (CCSF), and State Game Lands (SGL) 86, Pennsylvania, during the post-breeding season and fall migration (Jul-Sep) in 2019 and 2020. Sampling periods 1 and 2 correspond approximately to the post-breeding and migration periods, respectively.

\begin{tabular}{|c|c|c|c|c|c|}
\hline Common name & Scientific name & Family & Guild & $\begin{array}{l}\text { Period } 1 \\
\text { captures }\end{array}$ & $\begin{array}{l}\text { Period } 2 \\
\text { captures }\end{array}$ \\
\hline Cedar waxwing & Bombycilla cedrorum & Bombycillidae & Frugivore & 99 & 12 \\
\hline Eastern towhee & Pipilo erythrophthalmus & Passerellidae & Frugivore & 32 & 26 \\
\hline Gray catbird & Dumetella carolinensis & Mimidae & Frugivore & 134 & 80 \\
\hline Ovenbird & Seiurus aurocapilla & Parulidae & Frugivore & 36 & 35 \\
\hline Red-eyed vireo & Vireo olivaceus & Vireonidae & Frugivore & 124 & 51 \\
\hline Song sparrow & Melospiza melodia & Passerellidae & Frugivore & 86 & 19 \\
\hline American redstart & Setophaga ruticilla & Parulidae & Non-frugivore & 42 & 19 \\
\hline Black-capped chickadee & Poecile atricapillus & Paridae & Non-frugivore & 9 & 60 \\
\hline Black-throated blue warbler & Setophaga caerulescens & Parulidae & Non-frugivore & 46 & 82 \\
\hline Black-throated green warbler & Setophaga virens & Parulidae & Non-frugivore & 22 & 85 \\
\hline Chestnut-sided warbler & Setophaga pensylvanica & Parulidae & Non-frugivore & 346 & 129 \\
\hline Common yellowthroat & Geothlypis trichas & Parulidae & Non-frugivore & 87 & 110 \\
\hline Hooded warbler & Setophaga citrina & Parulidae & Non-frugivore & 35 & 38 \\
\hline Magnolia warbler & Setophaga magnolia & Parulidae & Non-frugivore & 34 & 107 \\
\hline
\end{tabular}


Table 3.3. Summary of covariate data collected at mist nets in regenerating harvests during the post-breeding season and fall migration (Jul-Sep) at Allegheny National Forest (ANF), Clear Creek State Forest (CCSF), and State Game Lands (SGL) 86, Pennsylvania, in 2019 and 2020. Data are separated into sampling period 1 (18 Jul-22 Aug 2019 and 20 Jul-25 Aug 2020), sampling period 2 (24 Aug-25 Sep 2019 and 27 Aug-25 Sep 2020), and both sampling periods combined. If values at each mist net did not differ from sampling period 1 to 2 , values are only reported for period 1 .

\begin{tabular}{|c|c|c|c|c|c|c|c|c|c|}
\hline \multirow[b]{2}{*}{ Covariate } & \multicolumn{3}{|l|}{ Period 1} & \multicolumn{3}{|l|}{ Period 2} & \multicolumn{3}{|l|}{ Periods 1 and 2} \\
\hline & Mean (SE) & Median & Range & Mean (SE) & Median & Range & Mean (SE) & Median & Range \\
\hline $\begin{array}{l}\text { Unripe Allegheny } \\
\text { blackberry } \\
\text { (Rubus } \\
\text { allegheniensis) } \\
\text { fruits }\end{array}$ & $66.22(6.88)$ & 45 & $0-386$ & $0.52(0.14)$ & 0 & $0-7$ & $33.37(4.12)$ & 0.5 & $0-386$ \\
\hline $\begin{array}{l}\text { Ripening and ripe } \\
R \text {. allegheniensis } \\
\text { fruits }\end{array}$ & $40.57(5.05)$ & 26 & $0-325$ & $2.54(0.60)$ & 0 & $0-37$ & $21.56(2.86)$ & 2.5 & $0-325$ \\
\hline $\begin{array}{l}\text { Fruiting species } \\
\text { richness }\end{array}$ & $2.53(0.11)$ & 2 & $1-5$ & & & & & & \\
\hline $\begin{array}{l}\text { SWD trap } \\
\text { captures/trap/day }\end{array}$ & 67.67 (9.97) & 23 & $1-569.5$ & 327.79 (44.47) & 153 & $1.5-2338.5$ & $197.73(24.45)$ & 61.25 & $1-2338.5$ \\
\hline $\begin{array}{l}\text { Infestation rates } \\
\text { (SWD/g of fruit) }\end{array}$ & $4.04(0.42)$ & 3.03 & $0-18.89$ & $0.67(0.16)$ & 0 & $0-7.05$ & $2.36(0.25)$ & 0 & $0-18.89$ \\
\hline $\begin{array}{l}\text { Residual tree } \\
\text { basal area }\left(\mathrm{m}^{2}\right)\end{array}$ & $0.40(0.05)$ & 0.27 & $0-2.51$ & & & & & & \\
\hline $\begin{array}{l}\text { Vegetation height } \\
\mathrm{CV}^{\mathrm{a}}\end{array}$ & $37.35(1.55)$ & 35.39 & $11.22-94.11$ & & & & & & \\
\hline $\begin{array}{l}\text { Vertical cover } \\
\mathrm{CV}^{\mathrm{a}}\end{array}$ & $39.30(1.98)$ & 38.38 & $0-87.09$ & & & & & & \\
\hline
\end{tabular}

${ }^{a}$ denotes a coefficient of variation $(\mathrm{CV})$ 
Table 3.4. Final regression models for bird captures by species and guild during the post-breeding season and fall migration (Jul-Sep) in regenerating harvests at Allegheny National Forest (ANF), Clear Creek State Forest (CCSF), and State Game Lands (SGL) 86, Pennsylvania, in 2019 and 2020. Each final model was created with a stepwise removal process of covariates from a global model containing all 9 covariates. Posterior estimates and 90\% credible intervals (CIs) are given for each covariate's slope coefficient.

\begin{tabular}{|c|c|c|}
\hline Response variable & Distribution & Covariate (Estimate $[90 \% \mathrm{CI}])$ \\
\hline \multicolumn{3}{|l|}{ Frugivore guild level } \\
\hline Total frugivores & Negative binomial & $\begin{array}{l}\text { date }(-0.152[-0.279,-0.028]) ; \text { unripe }(0.134[0.009,0.261]) \\
\quad \text { swd }(-0.133[-0.251,-0.016])\end{array}$ \\
\hline Frugivore species richness & Poisson & unripe $(0.158[0.096,0.217])$ \\
\hline \multicolumn{3}{|l|}{ Frugivore species } \\
\hline Cedar waxwing & Poisson & date $(-1.131[-1.394,-0.880]) ;$ cover $(-0.534[-0.856,-0.214])$ \\
\hline Eastern towhee & Poisson & $\operatorname{swd}(-0.322[-0.700,-0.021]) ; \operatorname{cover}(0.374[0.153,0.602])$ \\
\hline Gray catbird & Poisson & max.richness $(0.250[0.075,0.425])$ \\
\hline Ovenbird & Poisson & max.richness $(-0.349[-0.631,-0.088])$; infest $(0.199[0.009,0.380])$ \\
\hline Red-eyed vireo & Negative binomial & date $(-0.437[-0.649,-0.229]) ;$ cover $(-0.322[-0.558,-0.091])$ \\
\hline Song sparrow & Poisson & $\begin{array}{l}\text { date }(-0.819[-1.028,-0.608]) ; \mathrm{BA}(-0.431[-0.708,-0.160]) \\
\quad \text { cover }(0.329[0.129,0.542])\end{array}$ \\
\hline \multicolumn{3}{|l|}{ Non-frugivore guild level } \\
\hline Total non-frugivores & Negative binomial & unripe $(0.099[0.020,0.182])$; ripen.ripe $(-0.116[-0.205,-0.025])$ \\
\hline Non-frugivore species richness & Poisson & date $(0.096[0.039,0.153])$ \\
\hline \multicolumn{3}{|l|}{ Non-frugivore species } \\
\hline American redstart & Poisson & date $(-0.422[-0.653,-0.198]) ;$ cover $(-0.404[-0.745,-0.089])$ \\
\hline Black-capped chickadee & Poisson & date $(1.400[0.950,1.892]) ;$ unripe $(0.586[0.094,1.057])$ \\
\hline Black-throated blue warbler & Negative binomial & date $(0.365[0.206,0.526])$ \\
\hline Black-throated green warbler & Poisson & date $(0.797[0.599,0.997])$ \\
\hline Chestnut-sided warbler & Negative binomial & date $(-0.635[-0.760,-0.513])$ \\
\hline Common yellowthroat & Poisson & cover $(0.372[0.209,0.531])$ \\
\hline Hooded warbler & Poisson & infest $(-0.348[-0.639,-0.086])$ \\
\hline Magnolia warbler & Poisson & date $(0.524[0.309,0.774])$; unripe $(-0.490[-0.941,-0.099])$ \\
\hline
\end{tabular}




\section{FIGURES}

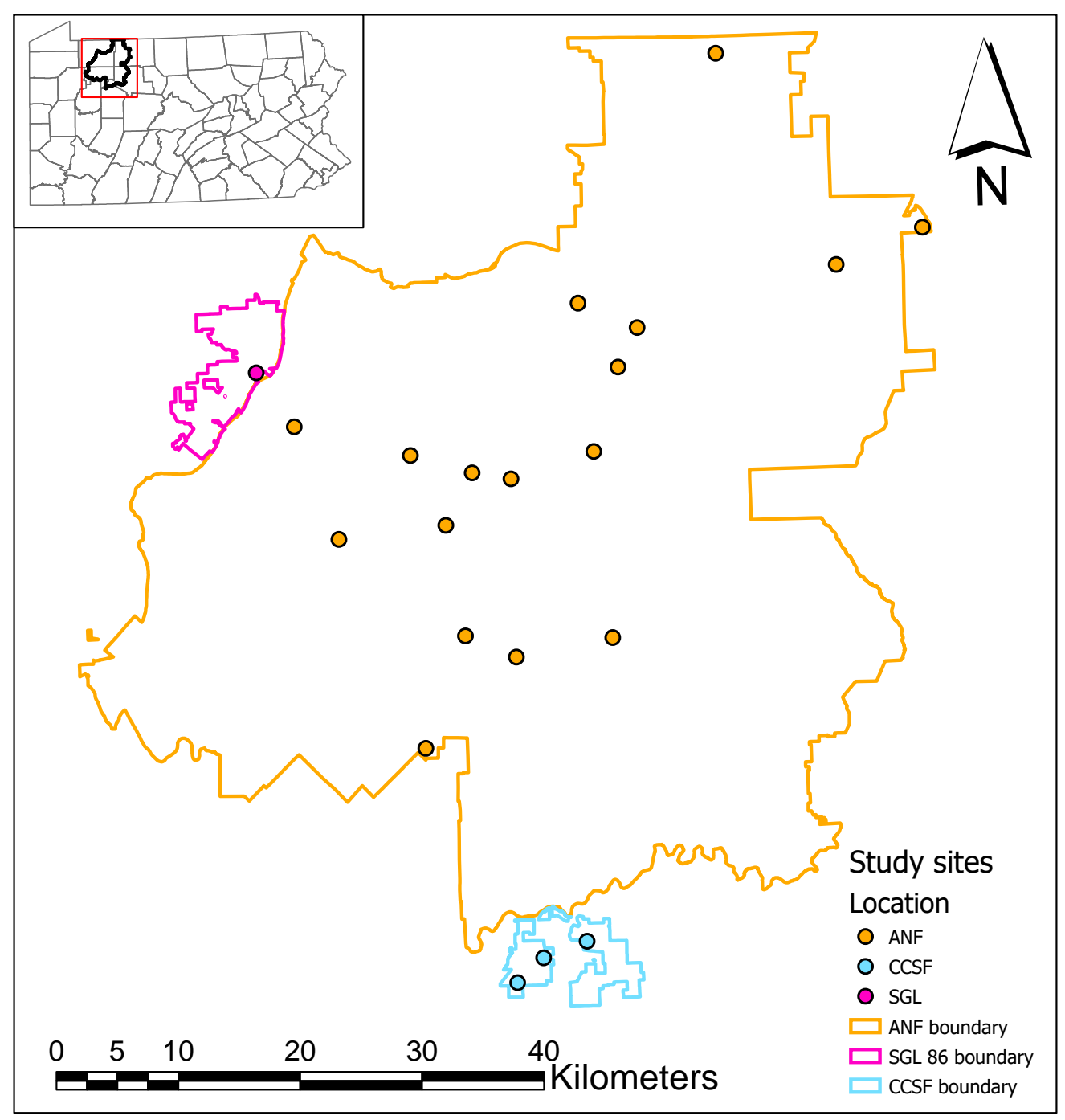

Figure 3.1. Study area used for surveys of forest bird communities and spotted wing Drosophila (Drosophila suzukii) during the post-breeding season and fall in Pennsylvania in 2019 and 2020. Twenty-one sites were surveyed across Allegheny National Forest (ANF), Clear Creek State Forest (CCSF) due south, and State Game Lands (SGL) 86 west of the ANF along the Allegheny River in northwestern Pennsylvania. 


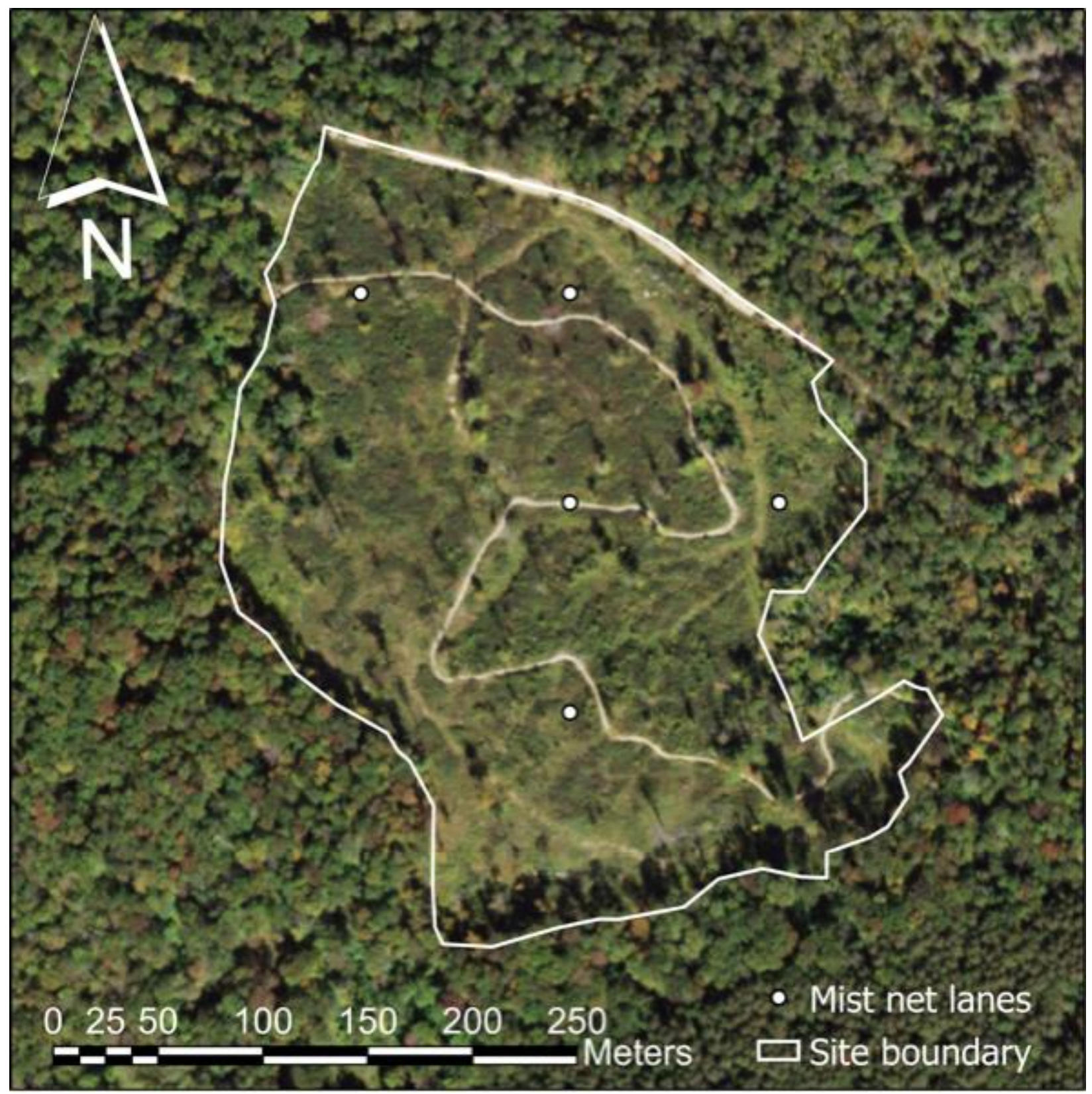

Figure 3.2. Example placement of mist nets used for sampling forest bird communities in regenerating harvests during the post-breeding season and fall migration at Allegheny National Forest (ANF), Clear Creek State Forest (CCSF), and State Game Lands (SGL) 86, Pennsylvania, in 2019 and 2020. 


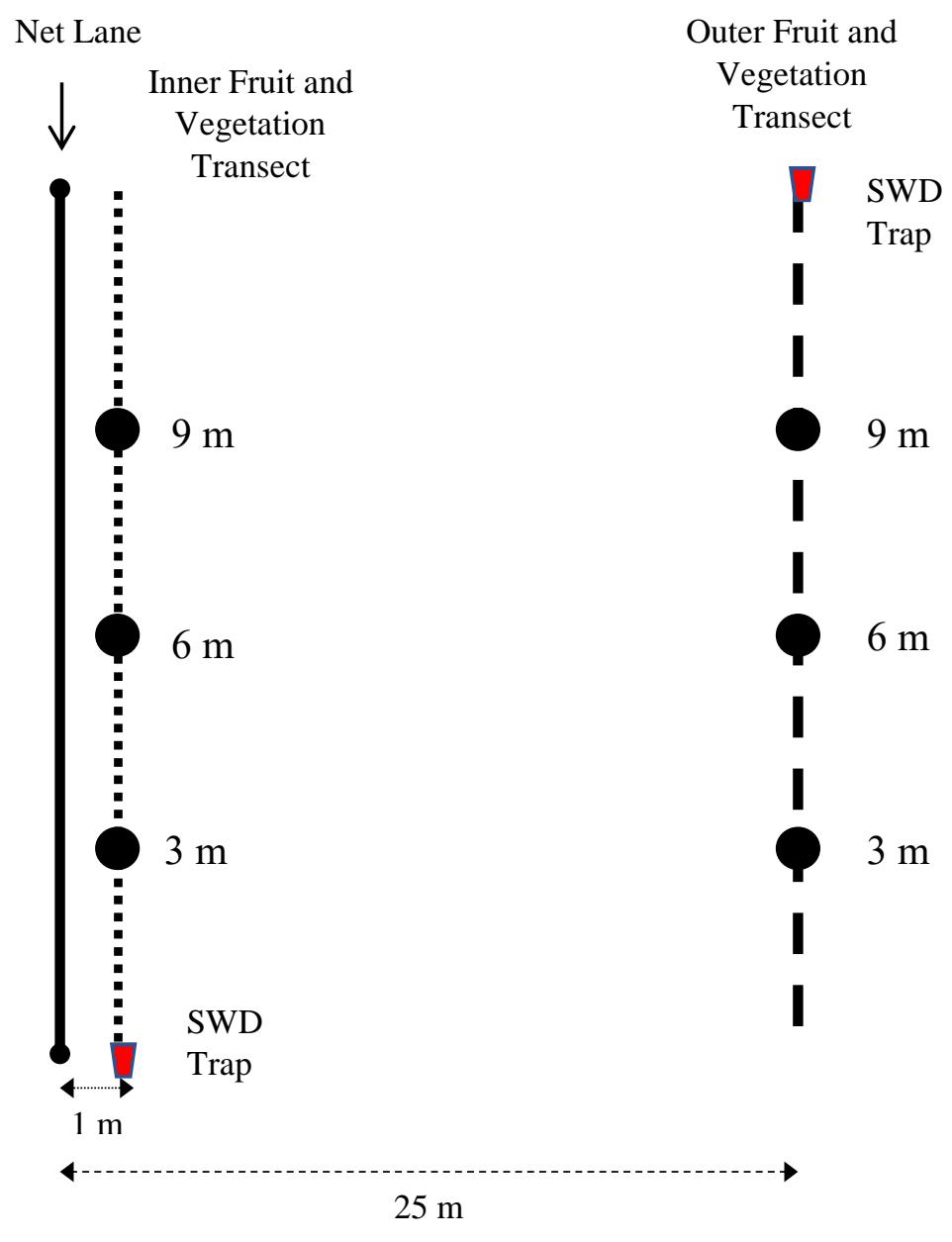

Figure 3.3. Transect survey design used to place spotted wing Drosophila (Drosophila suzukii, SWD) traps, count fruit resources, and measure vegetation structure at mist nets in regenerating harvests at Allegheny National Forest (ANF), Clear Creek State Forest (CCSF), and State Game Lands (SGL) 86, Pennsylvania, in 2019 and 2020. The side of the mist net each transect was placed and the side of the transect each SWD trap was placed were randomly chosen. 


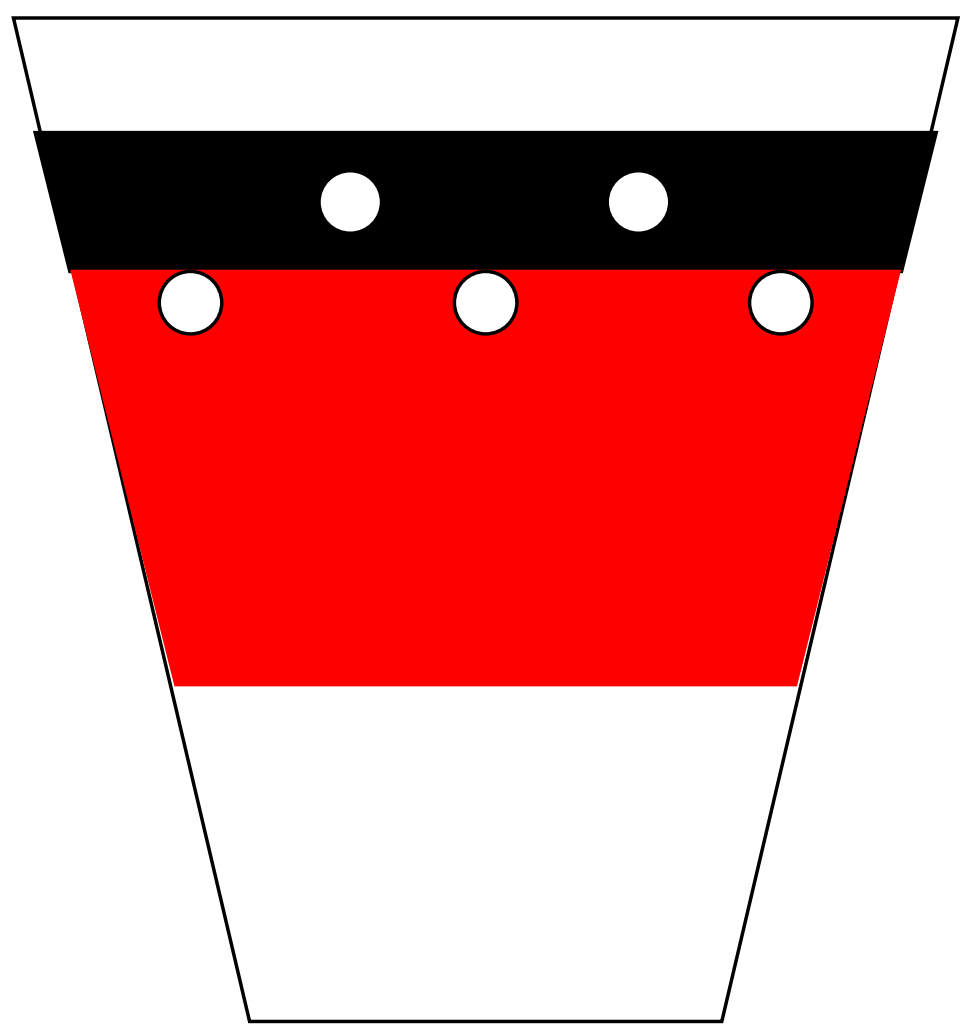

Figure 3.4. Trap design used to sample for spotted wing Drosophila (Drosophila suzukii) at mist nets during the post-breeding season and fall migration in regenerating harvests at Allegheny National Forest (ANF), Clear Creek State Forest (CCSF), and State Game Lands (SGL) 86, Pennsylvania, in 2019 and 2020. 

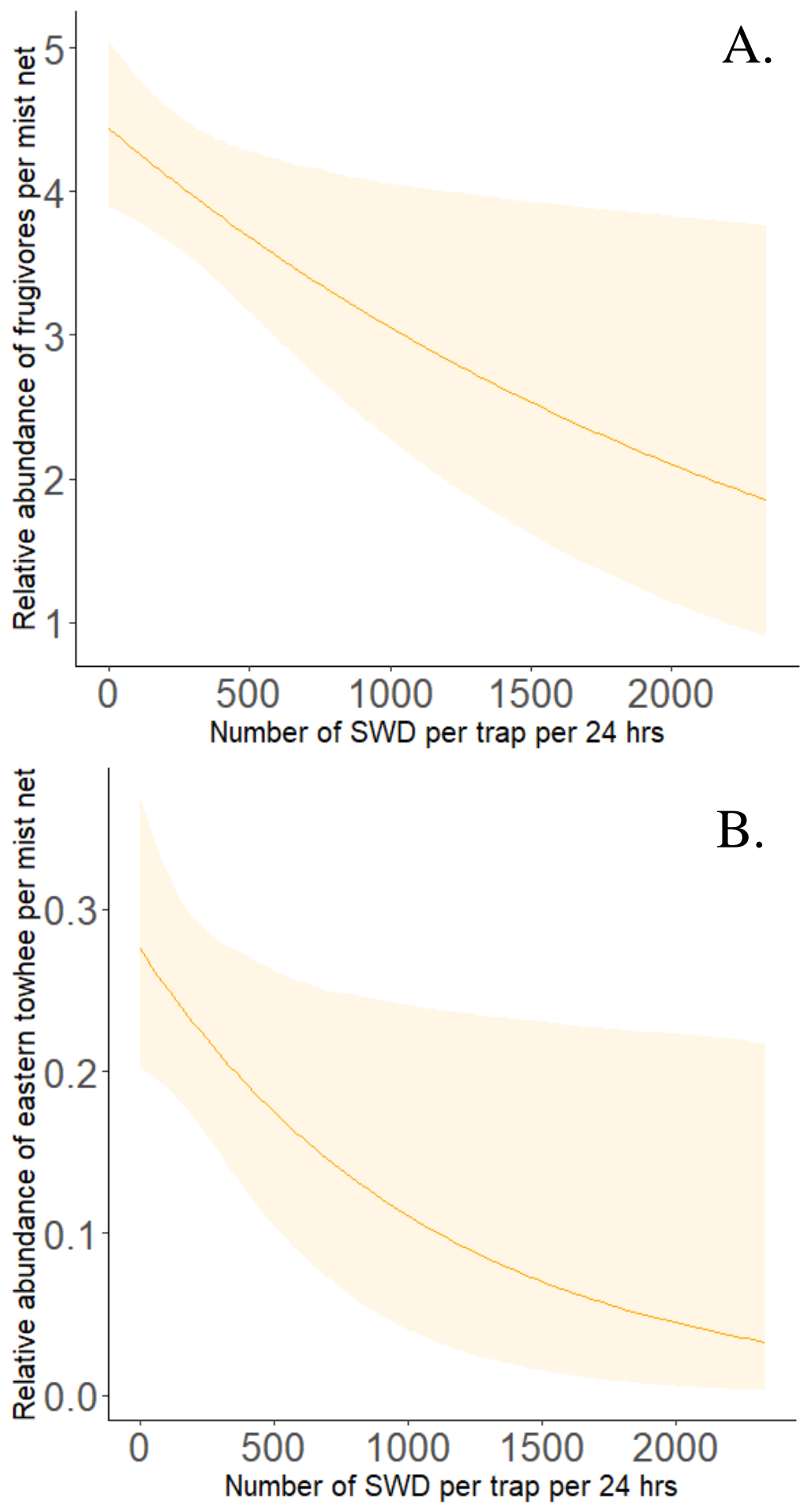

Figure 3.5. Relationship of trap captures of spotted wing Drosophila (Drosophila suzukii, SWD) with relative abundance of A) all frugivores and B) eastern towhee (including $90 \%$ credible intervals) per mist net in regenerating harvests during the post-breeding season and fall migration (Jul-Sep) at Allegheny National Forest (ANF), Clear Creek State Forest (CCSF), and State Game Lands (SGL) 86, Pennsylvania, in 2019 and 2020. 

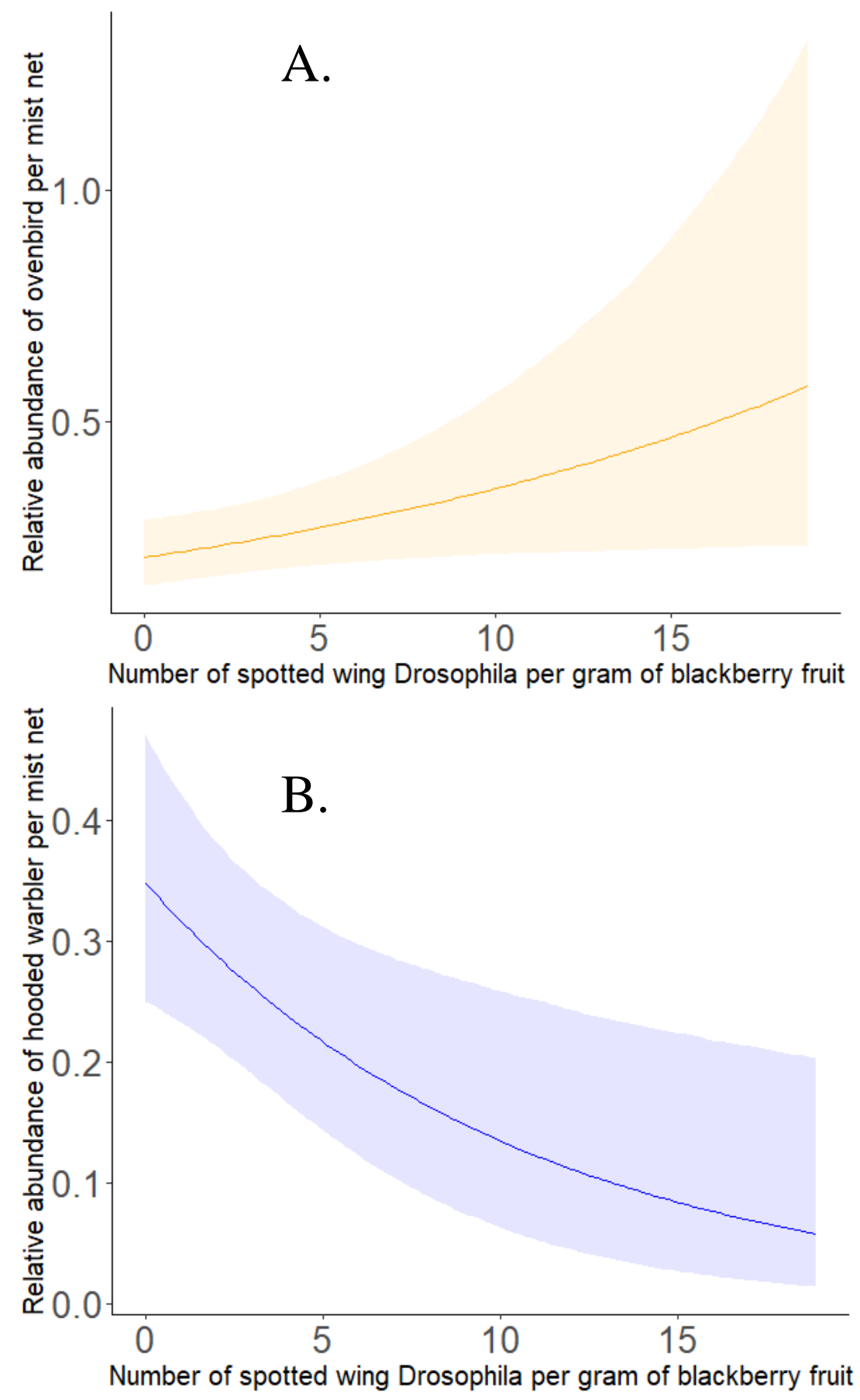

Figure 3.6. Relationship of infestation rates (counts of spotted wing Drosophila [Drosophila suzukii]/g) of Allegheny blackberry (Rubus allegheniensis) fruits with relative abundance of A) ovenbird and B) hooded warbler (including $90 \%$ credible intervals) per mist net in regenerating harvests during the post-breeding season and fall migration (Jul-Sep) and fall migration at Allegheny National Forest (ANF), Clear Creek State Forest (CCSF), and State Game Lands (SGL) 86, Pennsylvania, in 2019 and 2020. 


\section{CHAPTER 4. Differences in forest bird body condition and fruit consumption in relation to spotted wing Drosophila abundance and fruit parasitism at Allegheny National Forest}

\section{ABSTRACT}

Migratory bird species are under heavy energetic demands following the breeding season. Birds must first complete a pre-migratory feather molt and build fat deposits during the post-breeding season, and then maintain those deposits during migration. To ensure energy acquisition, many birds utilize early successional habitat, consuming fruit resources and using cover provided by vegetation. Spotted wing Drosophila (Drosophila suzukii, SWD), an increasingly prominent frugivorous non-native invasive insect pest in the United States, parasitizes the ripening fruits of many wild fruiting plants, which may reduce consumption of fruits by birds and alter the condition of those birds during a critical time of year. My objectives were to evaluate what factors, especially those related to SWD abundance and parasitism, related to body condition of several bird species and probability of consumption of fruits by frugivorous birds in regenerating harvests invaded by SWD during the post-breeding season and fall migration. I mist-netted for birds in regenerating harvests at Allegheny National Forest from July to October in 2019 and 2020 and measured multiple indices of body condition (subcutaneous fat, molt progression, and scaled mass index [SMI]) for several species. I also collected fecal samples from several frugivorous species for evidence of fruit consumption. I assessed fruit resources and vegetation structure at each mist net using transect surveys. I trapped SWD at each mist net for the duration of mist netting sessions and collected fruit samples to determine the extent of fruit parasitism by SWD at each mist net. Multiple condition indices for several species were correlated with relative abundance of SWD and parasitism of fruits, though the directions of relationships varied and were species-specific. Probability of Allegheny blackberry (Rubus allegheniensis) fruit consumption by frugivorous birds was positively correlated with parasitism of fruits at both the 
guild and species level. Frugivorous birds were more likely to consume parasitized fruits, and one species, gray catbird, experienced changes to nutritional intake and subsequent condition as a result. Fruit parasitism and greater abundances of adult SWD may have altered arthropod communities, altering composition and changing an additional food resource for both nonfrugivorous and frugivorous birds. Most species improved condition indices as the season progressed, likely due to dietary flexibility. Further investigation should include how bird condition changes in relation to foraging microhabitat selection and SWD, selection or rejection of SWD-parasitized fruits by frugivores, use of nutritional metrics to assess quality of SWD and SWD-parasitized fruits, arthropod community responses to SWD, and the possible long-term consequences of changes to fruit consumption and seed dispersal.

Keywords: body condition, Drosophila suzukii, frugivorous birds, fruit parasitism, fruit consumption, invasive species, migration, post-breeding, species interactions, spotted wing Drosophila.

\section{INTRODUCTION}

The time between breeding and arrival on overwintering grounds is an important time of year for migratory songbird species (Passeriformes). During the post-breeding season, which spans the time juveniles fledge until the onset of fall migration (Baker 1993, Pagen et al. 2000, Marshall et al. 2003, Chandler et al. 2012, Cox et al. 2014, Labbé and King 2014), both juvenile and adult birds must increase energy expenditure by $30 \%$ or more to complete a pre-migratory molt before building fat deposits for use during fall migration (Blem 1976, Murphy 1996, Bonier et al. 2007, Cyr et al. 2008). Migrant songbirds that survive the post-breeding season are then under immense energetic demands and elevated mortality risk to fly thousands of kilometers to overwintering grounds (Blem 1980, Moore et al. 1995, Sillett and Holmes 2002). Birds must 
make use of unfamiliar stopover sites to rest and replenish fat deposits burned during flight, expending as much as 2 times the energy used during flight (Hedenström and Alerstam 1997, McWilliams et al. 2004). Meeting these energy demands requires foraging for energy-rich food resources (Yong and Moore 1997), and failure to procure food resources first for pre-migratory molt completion might delay fat accumulation and initiation of migration (Vega Rivera et al. 1998b). Additionally, failure to procure food resources for fat accumulation puts birds at increased risk of starvation (Woodrey and Moore 1997) and increases the duration of migration (Yong and Moore 1997, Schaub and Jenni 2001, Goymann et al. 2010), which might have detrimental effects on the survival and condition of birds that defend non-breeding territories (Moore and Kerlinger 1991, Moore and Yong 1991, Woodrey and Moore 1997, Moore 2000, Stutchbury et al. 2011). The quality of habitat, therefore, can be an important factor determining timing (Stutchbury et al. 2011), duration (Guglielmo et al. 2005, Goymann et al. 2010), and ultimate success of migration (Schaub and Jenni 2001).

To ensure energy acquisition, many migratory bird species utilize early successional habitat (Rappole and Ballard 1987, Pagen et al. 2000, Marshall et al. 2003, Rodewald and Brittingham 2004, Packett and Dunning 2009) and consume abundant fruit resources available during the post-breeding season and fall migration (Snow 1971, McDiarmid et al. 1977, Thompson and Willson 1979, Parrish 2000, McCarty et al. 2002). While many studies identified the importance of cover against predation provided by vegetation in determining habitat use (King et al. 2006; Vitz and Rodewald 2006, 2007; McDermott and Wood 2010), fruit-consuming species utilize these habitats to exploit abundant food resources (Anders et al. 1998, Vega Rivera et al. 1998b, White et al. 2005, Vitz and Rodewald 2006, 2007; Buler et al. 2007, Streby et al. 2011, Labbé and King 2014), and respond to changes in fruit abundance by increasing or 
decreasing in abundance (Major and Desrochers 2012). Fruit resources can be critical for replenishing fat deposits (Bairlein and Gwinner 1994, Parrish 1997), improving body condition and increasing fat deposition rates, and decreasing duration of time spent at stopovers with abundant, high-quality fruit resources (Parrish 1997, 2000; Schaub and Jenni 2000, 2001; Smith and McWilliams 2010; Smith 2013; Smith et al. 2015). Abundant fruit resources might also provide additional energy required for pre-migratory molting birds (Jenni and Winkler 1994, McDermott and Wood 2010, but see Murphy and King 1992). Therefore, any changes to fruit resources could impact nutrient acquisition for necessary, energy-demanding processes.

Spotted wing Drosophila (Drosophila suzukii, SWD) is an increasingly prominent frugivorous non-native invasive insect pest in the United States with the potential to alter access to fruit resources and negatively affect fruit consumption by birds in forested ecosystems. Native to east Asia, this species of vinegar fly was first introduced to California in 2008 and has since colonized forested ecosystems in the eastern U.S. It affects soft-skinned fruits and is a documented parasite of $>100$ different fruiting plant species, including cultivated crops and ornamental and wild plants (Roche et al. 2021). Female SWD use a serrated ovipositor to pierce the firmer skin of ripe and ripening fruits and lay eggs within the pulp (Mitsui et al. 2006, Walsh et al. 2011), which can't normally be accessed by native fruit fly species. Larvae bore through fruits and consume pulp, resulting in a sunken, desiccated appearance, and parasitism by SWD can promote further infection by microbes (Walsh et al. 2011). Some birds discriminate against insect-infested fruits with a desiccated appearance (Traveset et al. 1995, García et al. 1999) and fruits rotting due to microbial infection (Buchholz and Levey 1990). Birds will also select plants for foraging based on traits including fruit size and pulpiness (Sallabanks 1993), and infestation of fruits by insect parasites reduces removal of unparasitized fruits by foraging birds (Manzur 
and Courtney 1984). By targeting fruits before they ripen, SWD might reduce abundance of ripe fruits for consumption by birds, which can affect the ability of birds to replenish energy for migration (Smith and McWilliams 2010). However, whether SWD infestation of fruits affects fruit consumption by vertebrate frugivores and frugivore body condition in SWD-infested habitat is unknown.

I investigated the body condition of several Neotropical migratory songbird species in early successional forest patches (i.e., regenerating timber harvests) invaded by SWD during the post-breeding season and fall migration. Here, I define body condition as energy capital in the body from feeding, assumed to be an indicator of health and quality (Peig and Green 2009). Additionally, I investigated fruit consumption by birds to determine whether birds consumed fruits in these regenerating harvests. My objectives were to: 1) quantify body condition of frugivorous and non-frugivorous birds in regenerating harvests; 2) evaluate whether relative SWD abundance, local fruit resources, fruit parasitism by SWD, and vegetation structure related to body condition of birds in regenerating harvests; and 3) examine whether the probability of consumption of fruits from locally-fruiting species by frugivorous birds varied with the abundance of nearby fruit resources, relative abundance of SWD, and parasitism of those fruit resources by SWD. For objective 2, I hypothesized that body condition, as measured by fat deposits, progression of molt, and body-mass indices, for frugivores, but not non-frugivores, would correlate with relative SWD abundance, parasitism of fruits by SWD, and relative abundance of fruits; both frugivore and non-frugivore condition would correlate with greater cover from vegetation. For objective 3, I hypothesized that the probability of frugivore fecal samples containing evidence of fruits (seeds, seed fragments, partial or entire fruits) would be 
positively correlated with the relative abundance of fruits, but negatively correlated with the relative abundance of SWD and the parasitism of fruits by SWD.

\section{METHODS}

\section{Study Area}

I conducted this study throughout the Allegheny National Forest (ANF) and nearby forest in the Allegheny High Plateau of northwestern Pennsylvania $\left(41^{\circ} 40\right.$ N, $\left.78^{\circ} 05^{\prime} \mathrm{W}\right)$. The ANF covers approximately 209,000 ha (187,500 forested, 17,000 non-forested, and 4,500 covered by water, mostly the Allegheny Reservoir) and includes land in Elk, Forest, McKean, and Warren counties. Elevation throughout the forest ranges from approximately $305 \mathrm{~m}$ above sea level to $700 \mathrm{~m}$ above sea level. Annual precipitation is approximately $1 \mathrm{~m}$ (Morin et al. 2006).

The Allegheny High Plateau was historically dominated by northern hardwoods until the late 1800s and early 1900s when industrialization and unregulated logging left much of the forest clear-cut and brush-covered (U.S. Forest Service 2007). The ANF was established in 1923, which led to a halt of these practices and the growth of an altered forest (U.S. Forest Service 2007). Timber harvest of hardwood species at the ANF (e.g., black cherry [Prunus serotina], oak [Quercus spp.], yellow poplar [Liriodendron tulipifera], red maple [Acer rubrum], sugar maple [Acer saccharum], white ash [Fraxinus americana]) is used for economic gains and for vegetation management to maintain a mix of habitat types for plants and animals, aimed at maintaining plant and animal diversity and overall ecosystem resilience.

Dominant forest types occurring at the ANF include the following: 1) Allegheny hardwoods (dominated by at least $50 \%$ basal area black cherry [greater than $70 \%$ in some stands; Eyre 1980], white ash [Fraxinus americana], yellow poplar, American beech [Fagus grandifolia], yellow birch [Betula alleghaniensis], red maple, sugar maple, and eastern hemlock 
[Tsuga canadensis]); 2) mixed upland hardwoods (similar to Allegheny hardwoods but dominated by red maple and containing fewer black cherry); 3) northern hardwoods (similar to upland hardwoods but dominated by eastern hemlock, American beech, and maple spp., and containing even fewer black cherry); and 4) oak-hickory (at least 25\% oak species, dominated by northern red oak [Quercus rubra]; U.S. Forest Service 2007).

Large blocks of contiguous and connected mature forest exist throughout the landscape. A diversity of forest structure also exists, including even-age forest with trees 90-110 years old and forest with a larger number of older, larger trees along with a greater amount of younger structural stages (U.S. Forest Service 2007). Extensive, long-term browsing by high deer densities has resulted in a loss of understory and midstory vegetation through much of the ANF (Morin et al. 2006). Because the ANF contains many forest compartments harvested for black cherry, maple, and yellow poplar timber or marked for even-aged management, there are many regenerating stands distributed throughout the forest (U.S. Forest Service 2007). However, less than $8 \%$ of forested land comprising the ANF is under 20 years old. Most harvests at the ANF use the shelterwood system, which involves an initial shelterwood seed cut, leaving half to most trees $(50-70 \%)$ as residual canopy trees, and a second shelterwood removal cut after a minimum of approximately 10 years. However, clear-cutting of all trees is also used under certain resource objectives (see U.S. Forest Service 2007). Minimum rotation age for final harvest (i.e., shelterwood removal cut, clear-cutting) is 100 years for the major forest types. Maximum size of openings created by even-aged management is approximately 16 ha, per Forest Service regulations. Regenerating harvests contain seedlings and saplings representative of adjacent forest types. These harvests also include many fruiting plants, including blackberry (Rubus spp.), pokeweed (Phytolacca decandra), pin cherry (Prunus pennsylvanica), and spikenard (Aralia 
spp). Mature forest stands typically have much lower numbers of these plants in the understory (Stoleson 2013).

I conducted additional sampling at Clear Creek State Forest (CCSF), located south of the ANF in Jefferson County in the Allegheny High Plateau $\left(41^{\circ} 18^{\prime} \mathrm{N}, 79^{\circ} 00^{\prime} \mathrm{W}\right)$. It is a property of approximately 5,460 ha managed by the Pennsylvania Department of Conservation and Natural Resources (DCNR). Geology and climate are similar to that of the ANF. Most of the mature forest stands within the CCSF are approximately 100 years old. There are 3 major forest types: Allegheny hardwood, mixed oak, and northern hardwood. Mixed oak is the dominant type, with northern red oak as the dominant species. Other species include white oak (Quercus alba), black oak (Quercus velutina), chestnut oak (Quercus montana), red maple, American beech, black cherry, and eastern hemlock (Brose 2011). Timber harvesting has created multiple regenerating harvests in the CCSF. Seedlings and saplings are representative of adjacent forest communities, and many herbaceous fruiting species can be found in these cuts, including blackberry, Vaccinium spp., partridgeberry (Mitchella repens), sassafras (Sassafras albidum), Smilax spp., serviceberry (Amelanchier spp.), pin cherry, devil's walking stick (Aralia spinosa), grapes (Vitis spp.), and elderberry (Sambucus spp.).

I conducted sampling at one site on Pennsylvania State Game Lands (SGL) 86, located west of the ANF along the western bank of the Allegheny River and within the Allegheny High Plateau $\left(41^{\circ} 43^{\prime} 31^{\prime \prime} \mathrm{N}, 079^{\circ} 21^{\prime} 29^{\prime \prime} \mathrm{W}\right)$. It is comprised of a single contiguous tract of land of approximately 5,800 ha in Warren County and lies within the Pennsylvania Game Commission's (PGC) Northwest Region. Lands along the Allegheny River, including SGL 86, contain large hills and steep slopes. The vast majority of SGL 86 was logged in the early 1900s (PGC 2014) and now contains a mix of plant communities from lower elevation streambed valleys dominated 
by conifers, maple, and birch to higher elevation (approximately $531 \mathrm{~m}$ ) plateaus dominated by oak, maple, hickory (Carya spp.), birch, and American beech. The regenerating harvest I used in this study was along a northern facing slope and contained seedlings and saplings representative of adjacent plant communities and a variety of herbaceous fruiting plants, including blackberry, pokeweed, maple leaf viburnum (Viburnum acerifolium), Vaccinium spp., partridgeberry, multiflora rose (Rosa multiflora), currants (Ribes sp.), grapes, and elderberry.

\section{Site Selection}

I conducted all sampling on sites within the ANF, CCSF, and SGL 86, 18 July-30 October in 2019 and 20 July-28 October in 2020. This timing coincided with post-breeding phenology (Jun-Aug; Pagen et al. 2000; McDermott and Wood 2010, 2011; Stoleson 2013; Labbé and King 2014; Burke et al. 2017), mid-August onset of migration (mid-Aug-Nov) of locally occurring bird species (S. H. Stoleson, Forest Service, unpublished data), and the observed emergence of SWD in previous years (Turcotte et al. 2018). Previous studies have also identified first captures of SWD in the first half of July (Elsensohn and Loeb 2018), with large increases occurring in August (Pelton et al. 2016) and captures continuing through mid-October (Briem et al. 2018, Thistlewood et al. 2019). Each site consisted of a regenerating harvest selected for this study using the following criteria. I defined regenerating harvests as forest stands aged 3 to 8 years post-timber harvest as of 2019 to ensure time for vegetative regrowth and fruiting plant regrowth (Labbé and King 2014, Porneluzi et al. 2014). I characterized these harvests as early successional habitat. Regenerating harvests on the ANF that fit these criteria ranged in size of 8-28 ha. From this list of all available harvests meeting my criteria, I randomly selected regenerating harvests for use as sites. I chose sites such that regenerating harvests within a season were at least $2 \mathrm{~km}$ apart (Vitz and Rodewald 2006, 2007). In 2019, I chose 4 regenerating harvests within 
Allegheny hardwood forest, 4 within mixed upland hardwood forest, and 4 within oak forest, representing a gradient of different forest types. In 2020, I chose 3 sites within Allegheny, 3 sites within mixed upland, and 3 sites within oak forest, giving 7 Allegheny sites, 7 mixed upland

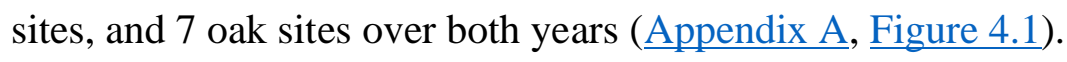

To determine locations of avian sampling points at each site, I covered each site with a grid of points placed $100 \mathrm{~m}$ apart and oriented north-south. I removed any points within each harvest that were less than $25 \mathrm{~m}$ from the harvest boundaries to avoid edge effects (Pagen et al. 2000, Chandler et al. 2012, Stoleson 2013, Labbé and King 2014). From these remaining points, I randomly selected 5 to serve as sampling points and standardize the avian surveying effort at each regenerating harvest (Figure 4.2). Therefore, each sampling point was at least $100 \mathrm{~m}$ from any other sampling point. I removed any regenerating harvests unable to fit at least 5 candidate sampling points from the list of candidate sites. I used the Vegetation dataset from the Allegheny National Forest Geographic Information System (GIS) Dataset collection (U.S. Forest Service 2019) in ArcGIS Pro v. 2.3.0 (ESRI, Redlands, CA, USA) to identify forest types for site selection and for placing sampling points. From 2019 to 2020, I sampled 105 points across 21 sites.

\section{Avian Sampling}

I used constant-effort, passive mist netting (Dunn and Ralph 2004) to sample the bird communities in each regenerating harvest. I used ground mist nets to capture individuals to collect data on body condition and foods consumed by individual birds. At each regenerating harvest, I used standard mist nets (12 m long, $2.6 \mathrm{~m}$ high, 30-mm mesh), a size useful for capturing small passerines (Heimerdinger and Leberman 1966). I placed individual nets at each of the 5 sampling points at least $100 \mathrm{~m}$ apart to minimize risk of recapture between nets (Figure 
4.2). Previous netting efforts in regenerating timber harvests at the ANF resulted in low individual recaptures (approximately $2 \%$ of all captures) between nets placed 50-100 m apart during the post-breeding season (S. H. Stoleson, unpublished data), and recaptures between nets were similarly low during my study (approximately $3 \%$ of all captures). Thus, I considered nets to be independent sample units. I sampled sites 2 days in a row (McDermott and Wood 2010, 2011) in each of 3 periods during the season (mid-Jul to late Oct), unless adverse weather required a delay of 1-2 days between sampling. Because net captures decline with each additional netting day (MacArthur and MacArthur 1974, Karr 1981, Marques et al. 2013), visits lasted 2 days to increase efficiency of detecting birds. Sampling period 1 spanned 18 July-22 August in 2019 and 20 July-25 August in 2020, sampling period 2 spanned 24 August-25 September in 2019 and 27 August-25 September in 2020, and sampling period 3 spanned 27 September-30 October in 2019 and 28 September-28 in October 2020.

I opened nets 30 minutes before sunrise, and kept nets open for 5 hours (Ralph et al. 2004). I banded all birds captured (except Ruby-throated hummingbird [Archilochus colubris]) with a United States Geological Survey (USGS) aluminum band. I also gathered information from each individual bird on age, sex (male, female, or unknown; Pyle 1997), un-flattened wing chord length (mm), tarsus length (mm), culmen length (mm; Pyle 1997), mass (g), fat stores, molt status, and breeding condition. I visually determined subcutaneous fat scores (range 0-3) according to the Powdermill Avian Research Center protocol, as it allowed for high repeatability among observers (Krementz and Pendleton 1990, Mulvihill et al. 2004). I determined molt status using a strategy employed by Stoleson (2013). Remiges, rectrices, and body feathers each received a score ranging from 0 for all old, worn feathers to 5 for all fully-grown new feathers (Newton 1996). I also used physiological characteristics related to breeding condition to 
determine whether individuals were breeders or nonbreeders (post-breeders or migrants; Pyle 1997, Vitz and Rodewald 2006). I classified breeders as individuals with either a vascularized brood patch or a cloacal protuberance. I classified all remaining birds as nonbreeders.

I grouped all captured birds into foraging guilds (non-frugivorous or frugivorous) using existing life history data (i.e., Birds of the World species account) and evidence of extensive frugivory from past mist-netting at the ANF (e.g., stains on bill or in fecal samples; S. H. Stoleson, unpublished data) to determine whether species' diet played a role in any changes to body condition (Table 4.1). I also collected fecal samples from each bird to determine whether fruit consumption was affected by SWD. Using fecal samples to assess consumption of different food materials by birds poses unique challenges, specifically assuming that all foods consumed are present in samples and proportionate (Rosenberg and Cooper 1990). However, it is faster and safer than more invasive alternatives, and fecal contents reliably contain foods known to have been consumed (Ralph et al. 1985). I kept birds in paper bags after extraction until a bird produced a fecal sample or until 15 minutes elapsed (Tietz and Johnson 2007), which increased the likelihood of obtaining a sample without holding birds longer than necessary. While studies have held birds longer (30 minutes; Mudrzynski and Norment 2013), passerines typically defecate soon after capture and retrieval — as quickly as 3-5 minutes (Ralph et al. 1985, Parrish et al. 1994, Knutie and Gotanda 2018). Additionally, rapid gut passage of songbirds would suggest fruits in fecal samples were consumed nearby (Herrera 1984, Karasov and Levey 1990). I transferred fecal samples from paper bags to $70 \%$ ethanol at the end of each banding day before later separating out the contents of each sample. I used a dissecting scope, seed vouchers collected from plants at the ANF, and existing seed identification guides (e.g., Seed Identification Guide [https://www.idseed.org/seedidguide/home.html], Fruit Seeds of Southern 
Michigan [http://seedguide.blogspot.com/p/index.html]) to identify all seeds and fruit material (when possible) to species.

\section{Fruit Sampling}

To determine the counts of fruit resources at each mist net, I conducted fruit surveys during mistnetting visits to each site immediately after the first day of netting (McDermott and Wood 2010). At each net lane, I placed 2 parallel transects on a randomly selected side: one "inner" transect 1 $\mathrm{m}$ away and one "outer" transect $25 \mathrm{~m}$ away from the net (Figure 4.3; modified from fruit sampling by Vitz and Rodewald 2006, Carlisle et al. 2012, vegetation sampling from Schemske and Brokaw 1981, McDermott and Wood 2010). At 3 m, 6 m, and 9 m along each inner and outer transect, I randomly chose a side and placed a $0.5-\mathrm{m} \times 0.5-\mathrm{m}$ quadrat. I identified all plants producing fruit within each quadrat $\left(0.75 \mathrm{~m}^{2} /\right.$ transect, $1.5 \mathrm{~m}^{2} / \mathrm{sampling}$ point $)$ and recorded the species and the count of fruits, separated into the following age categories: unripe (green, still growing), ripening (full size, undergoing color change), and ripe (full size, completed color change). I included unripe, ripening, and ripe fruits because only counting ripe fruits, especially for rapidly ripening plants such as Rubus spp., does not reflect the potential availability of fruits to birds (Blake et al. 1990, Rodewald and Vitz 2005, Vitz and Rodewald 2006).

I pooled all fruit counts at each mist net to determine a single count of fruits for each category. After pooling, I chose to focus on total counts of Allegheny blackberry (Rubus allegheniensis) because it was the most abundant fruit encountered across all fruit surveys, with few other species found fruiting during surveys (7.7\% of all surveys). Both unripe fruit and the sum of ripening and ripe fruit were strongly correlated with total fruit during sampling periods 1 and 2 ( $r=0.89$ and $r=0.76$, respectively); no $R$. allegheniensis fruits were found during period 3. 


\section{Fruit Parasitism Sampling}

To determine the extent that fruits on plants were parasitized by SWD at each mist net, I collected a random sample of ripening and ripe fruits from each fruiting plant species along each transect and monitored for emergence of adult, pupal, and larval SWD (20 fruits each, when possible). I weighed fruits within 2 hours of collection and stored them, separated by species and transect, at room temperature (approximately $20^{\circ} \mathrm{C}$ ) under ambient light in a sealed, vented 473$\mathrm{mL}$ clear container (Webstaurant Store, Lancaster, PA, USA). I checked after a minimum of 2 weeks for adult, larval, and pupal SWD (Walsh et al. 2011, Burrack et al. 2015). I used these counts and total fruit mass to determine the infestation rate of each plant species, measured as the count of SWD/g of fruit (Kenis et al. 2016, Elsensohn and Loeb 2018).

I pooled total SWD counts and fruit sample masses between transects to determine a single measure of infestation rates for each fruiting species at each mist net. While larvae and pupae of SWD are difficult to differentiate from other Drosophila species, I used total counts of all stages of SWD for multiple reasons. First, I found only SWD emerged from fruit samples as adults. Second, ripening and ripe fruits, unless damaged, are likely not susceptible to parasitism by most native Drosophila species, which lack a serrated ovipositor (Mitsui et al. 2006, Lee et al. 2011, Atallah et al. 2014). Third, counting only adult SWD would have underestimated actual parasitism rates of many samples. Finally, infestation rate using only adult SWD was strongly correlated with infestation rate using all life stages $(r=0.87)$. In some fruit samples, decay of fruit and growth of fungi made adult flies difficult to find and counts of adult SWD were lower than counts of pupal shells. Because pupal shells indicate an emerged adult fly and adult counts likely would have underestimated the total number of SWD, I used pupal shell counts rather than adult counts when calculating total SWD counts (all life stages) in these samples. I chose to 
focus on infestation rates of $R$. allegheniensis because most fruits surveyed and therefore sampled were R. allegheniensis (85.4\% of all fruit samples). If no R. allegheniensis fruit sample was collected (i.e., no fruit present), I considered infestation rate to be 0 .

\section{SWD Sampling}

I conducted sampling for SWD simultaneously with mist-netting at each site. To maximize the number of adult SWD captured during each 2-day mist-netting period, I made traps using a methodology described by Pelton et al. (2016; Figure 4.4). I made 10 evenly distributed 5-mm holes near the top of a clear 710-mL plastic cup with a lid (Webstaurant Store, Lancaster, PA, USA). The bait in each trap was a mixture of $3.5 \mathrm{~g}$ dry active baker's yeast, $14 \mathrm{~g}$ granulated white cane sugar, and $177 \mathrm{~mL}$ water, with a drop of unscented soap used to improve capture of SWD by reducing surface tension. I also lined the area directly below the holes with a strip of red tape and the area directly above the holes with a strip of black tape to improve captures (Lee et al. 2013, Lasa et al. 2017). I placed one trap at a single end of each "inner" $(1 \mathrm{~m})$ transect and one trap at a single end of each "outer" (25 m) transect (Figure 4.3). Previous studies have spaced traps at a single sampling location as close as 1-2 m apart (e.g., Lee et al. 2012, Tochen et al. 2016) or as far as 10-20 m apart (e.g., Landolt et al. 2012, Harris et al. 2014, Pelton et al. 2016, Wang et al. 2016). I suspended traps approximately $1 \mathrm{~m}$ off the ground and close to vegetation to minimize exposure to direct sun and increase likelihood of trap capture (Diepenbrock and Burrack 2017, Evans et al. 2017). I placed traps at the beginning of each site visit following the opening of mist nets.

I collected the contents of each trap for later SWD identification following the closing of mist nets at the end of the 2-day site visit. I strained all invertebrates from the trap medium and stored them in 70\% ethanol before later separating out and counting all adult SWD in each trap. I 
pooled counts of SWD from each trap at each sampling point to determine a single count of SWD at each mist net. If a trap fell or was damaged such that the contents were lost, I discarded the trap and saved no sample. To address differences in 1) number of trap samples at each net, and 2) number of days traps were out at a site due to adverse weather delaying banding by 1-2 days, I calculated a count index of adult SWD captured/trap/day for each mist net.

\section{Vegetation Sampling}

To determine vegetation structure at each mist net, I surveyed the vegetation along each "inner" and "outer" transect used for fruit surveys once each year (Figure 4.3). At $3 \mathrm{~m}, 6 \mathrm{~m}$, and $9 \mathrm{~m}$ along each transect, I estimated vertical cover $(0-2.5 \mathrm{~m})$ using a vegetation profile board in 0.5 $\mathrm{m}$ increments by approximating the amount of space within each increment on the board covered by vegetation (Nudds 1977). The proportion of each $0.5-\mathrm{m}$ increment covered by vegetation received a single-digit cover score $(1=0-20 \%$ cover, $2=21-40 \%, 3=41-60 \%, 4=61-80 \%, 5$ $=81-100 \%)$. An observer took measurements at the transect on either side by facing the board from $15 \mathrm{~m}$ away. To obtain a single value at each mist net that captured the variation in measured values, I calculated the coefficient of variation (CV) for vertical cover. I used the 12 ordinal values measured (6 per transect) for the greatest height interval $(2-2.5 \mathrm{~m})$ for the following reasons: 1) it showed the greatest variation in values across all height intervals; and 2) it was strongly correlated with $\mathrm{CV}$ values calculated using the entire $0-2.5-\mathrm{m}$ range $(r=0.93)$. Because vegetation structure remained largely unchanged across all sampling periods, I applied the same vegetation covariate values to the same mist net for each sampling period.

\section{Data Analysis}

Body Condition.-I chose 6 frugivore and 7 non-frugivore species for which to model fat, molt, and SMI condition indices (Table 4.1). I excluded late breeding individuals from analyses, 
as they had not reached the post-breeding stage of their annual cycle yet. I focused on birds captured during sampling periods 1 and 2 for multiple reasons. First, these species showed few to no captures during sampling period 3. Second, species that were major captures during period 3 were not caught until period 2 at the earliest. Third, fruit counts showed greatest variation during period 1, less during period 2, and were all 0 during period 3; values for parasitism of fruits by SWD followed the same pattern. Fourth, sampling periods 1 and 2 sufficiently cover the postbreeding season and beginning of fall migration for migratory songbirds in the region, respectively (S. H. Stoleson, unpublished data). For each species I modeled subcutaneous fat scores and body molt scores. To aid with low sample sizes of fat scores greater than 1, I recategorized fat score as a binary absence (0) or presence (1). I did not analyze fat scores for eastern towhee (Pipilo erythrophthalmus) and hooded warbler (Setophaga citrina), because only 1 and 3 individuals had any fat, respectively. I analyzed body molt rather than total molt score because 1) at least $97 \%$ of hatch year (HY; Pyle 1997) birds had complete or near-complete wing or tail molt, producing inflated total scores compared to after hatch year (AHY; Pyle 1997) birds; and 2) HY and AHY birds showed more similar variation in body molt scores. I recategorized body molt scores to create a "molt progression" index of condition, or "molt" $(1=$ early molt [original score: $0-1$ ], $2=$ mid molt [original score: $2-3$ ], $3=$ late molt [original score: $4-5$ ]). Because the 6 non-frugivorous warblers showed similar patterns of molt, I also modeled "molt" for "wood warblers," collectively.

Because fat and molt scoring are subjective indices and can suffer from intra- and interobserver variability (Krementz and Pendleton 1990, Dunn 2003), I also calculated a scaled mass index for each focal species (SMI; Peig and Green 2009). To do this, I conducted a standardized major axis (SMA) regression with log-transformed body mass and a log-transformed 
morphological measurement, the slope of which I used to calculate a scaled body mass measure for each bird as follows:

$$
\mathrm{SMI}=W_{i}\left[\frac{L_{0}}{L_{i}}\right]^{b_{\mathrm{SMA}}}
$$

where $W_{i}$ and $L_{i}$ are the body mass and length measurement (i.e., wing, tarsus, or culmen) for each individual bird, respectively, $L_{0}$ is a fixed length measurement (i.e., wing, tarsus, or culmen) chosen for the population of interest (mean value of all sampled birds), and $b_{\text {SMA }}$ is the scaling exponent and slope of the SMA regression. This approach separated body mass from body size to determine the relative size of energy stores compared to the structural size of the individual (Labocha and Hayes 2012, Tellería et al. 2013). Using SMI accounts for several assumptions made with similar regression techniques by devising a scaling relationship from the population of interest (Green 2001, Peig and Green 2009). The scaling relationship calculates the expected mass of each individual at a fixed body size, effectively standardizing all individuals and determining the relative size of energy stores compared to structural body components. I conducted SMA regressions using 1 of 3 different morphometric length measurements for each species: wing chord length, tarsus length, or culmen length (Green 2001). I selected whichever measurement was most strongly correlated with body mass on a log-log scale for each species to calculate SMI values (Table 4.1; Peig and Green 2009). Two species, cedar waxwing (Bombycilla cedrorum) and hooded warbler, yielded nonsignificant relationships between the most strongly correlated length measurement and body mass in SMA regression (Table 4.1). I conducted robust SMA regression using the smatr package in program $\mathrm{R}$ version 4.0.3 (R Core Team 2021) to downweigh outliers using Huber's M estimation (Warton et al. 2012).

For each condition index, I modeled the value for individual birds as a function of the values of covariates at the mist net where that bird was captured. Prior to analyses, I checked 
predictor variables for collinearity ( $r \geq 0.7$; Dormann et al. 2013). I chose 5 final covariates for condition analyses (Table 4.2). Black-capped chickadee (Poecile atricapillus) and black-throated green warbler (Setophaga virens) datasets showed high collinearity between ordinal date and total $R$. allegheniensis fruit counts ( $r=-0.86$ and -0.79 , respectively), so because I classified both species as non-frugivores and did not hypothesize a relationship to fruit resources, I dropped the "fruit" covariate for both species and retained "date" for analyses.

To model condition indices for each species, I fit generalized linear mixed models (GLMMs) using a Bayesian approach with Markov-chain Monte-Carlo (MCMC) parameter estimation techniques. I chose a Bayesian approach for its ability to provide less biased estimates with smaller sample sizes than frequentist approaches (Gelman and Hill 2007). I incorporated a random point (i.e., mist net) effect to nest birds within mist net location and account for repeated sampling at mist nets across sampling periods. To aid with model convergence, I first centered and scaled all covariates.

I modeled fat scores of each species as a Bernoulli random variable using logistic regression:

$$
\begin{aligned}
& y_{i} \sim \operatorname{Bern}\left(p_{i}\right), \\
& \log \left(\frac{p_{i}}{1-p_{i}}\right)=\alpha_{\text {net } i}+\beta_{1} \times \text { date }_{i}+\beta_{2} \times \text { fruit }_{i}+\beta_{3} \times \operatorname{swd}_{i}+\beta_{4} \times \text { infest }_{i}+\beta_{5} \times \text { cover }_{i},
\end{aligned}
$$

where $i$ is the individual bird identity, $y_{i}$ is the fat score value of each individual bird, $p_{i}$ is the probability of fat presence for an individual bird, and $\alpha_{\text {net_ } \_}$is the intercept for a random mist net effect for each bird $i$. For each fat model I specified vague (i.e., noninformative) priors (Kéry 2010). I specified Normal priors for population-level intercept terms $(\alpha)$ :

$$
\alpha \sim \mathrm{N}(0,0.01),
$$


where 0 is the mean and 0.01 is the precision (1/variance) for the Normal distribution. I drew random mist net intercept terms $\left(\alpha_{\text {net_i } i}\right)$ from the Normal hyper-prior distribution for $\alpha$ with precision of $\tau_{\alpha}$, which itself I derived from a standard deviation with a uniform prior:

$$
\begin{gathered}
\alpha_{\text {net } \_i} \sim \mathrm{N}\left(\alpha, \tau_{\alpha}\right), \\
\tau_{\alpha}=\frac{1}{\sigma_{\alpha}^{2}}, \\
\sigma_{\alpha} \sim \operatorname{Unif}(0,10) .
\end{gathered}
$$

I specified the same Normal priors for slope coefficients for each covariate in all fat models as the hyper-prior for the intercept:

$$
\beta_{\text {covs }} \sim \mathrm{N}(0,0.01)
$$

I modeled body molt scores ("molt") of each species as ordinal random variables using ordinal logistic regression:

$$
\begin{gathered}
y_{i} \sim \operatorname{ordinal}\left(\mu_{i}, c\right) \\
\mu_{i}=\alpha_{\text {net } \__{i}}+\beta_{1} \times \text { date }_{i}+\beta_{2} \times \text { fruit }_{i}+\beta_{3} \times \operatorname{swd}_{i}+\beta_{4} \times \text { infest }_{i}+\beta_{5} \times \text { cover }_{i},
\end{gathered}
$$

where $i$ is the individual bird identity, $y_{i}$ is the condition index value of each individual bird, $\mu_{i}$ is a location parameter and linear predictor, $\alpha_{\text {net } i}$ is the intercept for a random mist net effect for each bird $i$, and $c$ is an ordered vector containing 2 cutpoint values separating the 3 molt values. Ordinal logistic regression analyzes relationships of ordered categorical data with $>2$ values (i.e., data whose values have a meaningful order relative to each other), or an ordinal variable, to covariates, giving the cumulative probability of observing each possible value of the ordinal variable. The cutpoints serve as a set of threshold values that separate the real number line into $>2$ sections, each section corresponding to one of the possible values of the ordinal variable, and the realization of the linear predictor determines which value of the ordinal variable corresponds 
to each set of predictor variable values. Probabilities of observing each possible value of the ordinal variable can be found using the logistic function (McCullagh 1980). For each molt model I specified vague priors. I specified the same Normal priors for population-level intercept terms $(\alpha)$ as in fat models. I drew random mist net intercept terms $\left(\alpha_{\text {net_i } i}\right)$ from the Normal hyper-prior distribution for $\alpha$ as in fat models. I specified the same Normal priors for slope coefficients for each covariate as in all fat models. I specified a Normal prior for each cutpoint:

$$
\begin{gathered}
c_{1} \sim \mathrm{N}(0,0.1), \\
c_{2} \sim \mathrm{N}(0,0.1) \mathrm{T}\left(c_{1},\right),
\end{gathered}
$$

where $c_{2}$ is truncated below at the value of $c_{1}$.

I modeled SMI for each species as a Normal random variable using linear regression:

$$
\begin{gathered}
y_{i} \sim \mathrm{N}\left(\mu_{i}, \sigma^{2}\right), \\
\mu_{i}=\alpha_{\text {net } \_i}+\beta_{1} \times \text { date }_{i}+\beta_{2} \times \text { fruit }_{i}+\beta_{3} \times \text { swd }_{i}+\beta_{4} \times \text { infest }_{i}+\beta_{5} \times \text { cover }_{i},
\end{gathered}
$$

where $i$ is the individual bird identity, $y_{i}$ is the SMI value of each individual bird, $\mu_{i}$ is the expected SMI score for birds, $\sigma^{2}$ is the variance of SMI scores, and $\alpha_{\text {net } \_i}$ is the intercept for a random mist net effect for each bird $i$. For each SMI model I specified vague priors. I specified the same Normal priors for population-level intercept terms $(\alpha)$ as in fat models. I drew random mist net intercept terms $\left(\alpha_{\text {net_i } i}\right)$ from the Normal hyper-prior distribution for $\alpha$ as in fat models. I specified the same Normal priors for slope coefficients for each covariate as in all fat and molt models.

To assess the goodness-of-fit (GOF) of individual models for each condition index for each species, I calculated a Bayesian p-value using the sum of squared Pearson residuals for every model run (Gelman et al. 2004). Models for 9 response variables failed to converge on posterior estimates for a Bayesian p-value (fat presence: ovenbird, red-eyed vireo, and magnolia 
warbler; molt progress: cedar waxwing, ovenbird, song sparrow, black-capped chickadee, blackthroated green warbler, and hooded warbler; Table 4.3). To aid in convergence, I dropped the random point effect from those models. Only one model (eastern towhee molt progression) failed the GOF test after dropping the random point effect, so I excluded this from analyses.

I performed a stepwise regression model approach on each response variable. I chose a stepwise regression process because I had a priori hypotheses about each covariate and reason to believe - based on previous studies of body condition in post-breeding and migratory songbirds - each would explain some of the variation observed in bird condition indices. I used a strict process to conduct stepwise removal from a global model to a final reduced model for inference on individual covariates. First, I ran a global model for each response variable containing all covariates specified for that response variable. Second, I removed all covariates with a marginal posterior estimate for a slope coefficient $(\beta)$ that had a $90 \%$ credible interval (CI) overlapping 0 . The credible interval indicates the bounds within which the value of the parameter of interest $(\beta)$ lies at a certain probability (in this case $90 \%$ ), given the assumptions of the Bayesian model. I re-ran the reduced model and used the same criterion to remove covariates. I repeated this process until all remaining covariates had a $90 \%$ CI that did not overlap $0 . \mathrm{I}$ conducted covariate removal and final inference using $90 \%$ CIs to identify potentially weak but ecologically meaningful effects, while utilizing a small sample size and properly accounting for uncertainty through random effects. If I removed a random point effect for a global model, I excluded a random point effect from any reduced model.

I ran all models using software JAGS version 4.3.0 (Plummer 2003) called from R version 4.0.3 (R Core Team 2021) using communicator package jagsUI (Kellner 2019). I ran 3 MCMC chains for each model. I used traceplots to determine an appropriate burn-in for each 
model, and I ran each model for a sufficient number of iterations to achieve convergence. I confirmed convergence of models by visually inspecting chain mixing and checking that Gelman-Rubin diagnostic (Rhat) values for all model parameters were below 1.1 (Gelman et al. 2004). For all fat response variable models, burn-in lengths and number of iterations necessary for convergence of all models ranged 5,000 to 60,000 and 10,000 to 120,000, respectively. For all molt models, burn-in lengths and number of iterations necessary for convergence of all models ranged 5,000 to 70,000 and 10,000 to 140,000, respectively. For all SMI models, burn-in lengths and number of iterations necessary for convergence of all models ranged 500 to 1,000 and 1,000 to 2,000 , respectively. I thinned iterations by 2 to help reduce autocorrelation between posterior values. To aid model initialization for fat and molt models, I set initial values for hyperpriors for intercepts and all covariate slope coefficients as 0. For SMI models, I drew initial values for hyper-priors for intercepts and all covariate slope coefficients from a uniform distribution with parameters Unif(-10,10). I drew initial values for cutpoints in ordinal regression models using the seq() function in $\mathrm{R}$, with start and end values equal -0.5 and 0.5 , respectively. For all models I specified initial values for each random point effect as 0 .

Fruit consumption.--I investigated fruit consumption by frugivorous birds as a guild and for each focal frugivore species. I defined a fecal sample as any defecated or regurgitated sample (Blake and Loiselle 1992) produced by a bird that contained solid or semi-solid material. Because birds were kept in bags, I could not identify whether samples were defecated or regurgitated and therefore included both. I excluded samples collected from unbanded birds and birds recaptured during the same 2-day sampling period to avoid double-sampling individual birds. I collected 687 fecal samples from frugivore species, $80 \%$ of which (547 of 687) came from focal species (Appendix D). To avoid potential issues regarding an incomplete picture of 
fruit intake, I classified fecal sample contents as presence-absence through identification of seeds, seed fragments, or other fruit material consumed (Strong et al. 2005). Because of the dominance of $R$. allegheniensis in fruit surveys, I only examined fecal samples for evidence of $R$. allegheniensis, which are indigestible by songbirds and identifiable in feces using seed vouchers. From the total number of fecal samples at each mist net during each 2-day sampling period, I determined the number of fecal samples containing evidence of $R$. allegheniensis consumption. If no fecal samples were collected from frugivores or focal species captured at a mist net, I excluded that location from the respective analysis. I collected few fecal samples containing evidence of frugivory for 3 focal species—ovenbird ( 1 of 38 [3\%]), red-eyed vireo (5 of 121 [4\%]), and song sparrow (1 of $78[1 \%])$. As a result, I did not analyze these species separately.

Prior to analyses, I checked for collinearity among predictor variables $(r \geq 0.7$; Dormann et al. 2013). I chose 3 covariates for analyses (Table 4.2). To model frugivore fecal samples containing $R$. allegheniensis, I fit GLMMS to implement a Bayesian approach with MCMC parameter estimation techniques. To aid with model convergence, I centered and scaled all covariates. I modeled fecal samples containing $R$. allegheniensis as a binomial random variable using logistic regression:

$$
\begin{gathered}
y_{i} \sim \operatorname{Bin}\left(N_{i}, p_{i}\right), \\
\log \left(\frac{p_{i}}{1-p_{i}}\right)=\alpha_{i}+\beta_{1} \times \text { fruit }_{i}+\beta_{2} \times \operatorname{swd}_{i}+\beta_{3} \times \text { infest }_{i},
\end{gathered}
$$

where $i$ is mist net identity, $N_{i}$ is the total number of frugivore or focal species fecal samples at each mist net, $p_{i}$ is the probability of a fecal sample containing $R$. allegheniensis at each mist net, and $\alpha_{i}$ is the intercept for a random mist net effect. For each model I specified vague priors. I specified the same Normal priors for population-level intercept terms $(\alpha)$ and random mist net intercept terms $\left(\alpha_{i}\right)$ from the Normal hyper-prior distribution for $\alpha$ as in condition models: 


$$
\begin{gathered}
\alpha \sim \mathrm{N}(0,0.01), \\
\alpha_{\mathrm{i}} \sim \mathrm{N}\left(\alpha, \tau_{\alpha}\right), \\
\tau_{\alpha}=\frac{1}{\sigma_{\alpha}^{2}}, \\
\sigma_{\alpha} \sim \operatorname{Unif}(0,10) .
\end{gathered}
$$

I specified the same Normal priors for slope coefficients for each covariate as in all condition models:

$$
\beta_{\text {covs }} \sim \mathrm{N}(0,0.01)
$$

To assess the goodness-of-fit (GOF) of each model, I calculated a Bayesian p-value. The models for 2 focal species, cedar waxwing and eastern towhee, failed to converge on posterior estimates for a Bayesian p-value. To aid in convergence, I dropped the random point effect from those models. I performed the same stepwise regression model approach on each response variable as in condition analyses. If I removed a random point effect for a global model, I excluded a random point effect from any reduced model.

I ran all models using software JAGS version 4.3.0 called from $\mathrm{R}$ version 4.0.3 using communicator package jagsUI. I ran $3 \mathrm{MCMC}$ chains for each model. I used traceplots to determine an appropriate burn-in for each model, and I ran each model for a sufficient number of iterations to achieve convergence. I confirmed convergence of models by visually inspecting chain mixing and checking that Gelman-Rubin diagnostic (Rhat) values for all model parameters were below 1.1. Burn-in lengths and number of iterations necessary for convergence of all models were 2,000 or 5,000 and 4,000 or 10,000 , respectively. I thinned iterations by 2 to help reduce autocorrelation between posterior values. To aid model initialization, I set initial values for hyper-priors for intercepts and all covariate slope coefficients from a uniform distribution with parameters Unif(-10,10). 


\section{RESULTS}

\section{Body Condition}

All final models exhibited good fit. Two species showed relationships of the probability of having fat to infestation rates of $R$. allegheniensis fruits: black-throated green warbler (6.69 decrease in log odds of success with each standard deviation increase in infestation rate, scaled; $\beta$ $=-6.69[-15.62,-0.86])$ and gray catbird (Dumetella carolinensis; 0.71 increase in log odds of success; $\beta=0.71[0.14,1.30]$; Table 4.3, Figure 4.5A). Four species showed relationships to SWD trap captures: black-capped chickadee (5.71 decrease in log odds of success with each standard deviation increase in SWD trap captures, scaled; $\beta=-5.71[-12.36,-0.99])$, common yellowthroat (Geothlypis trichas; 0.89 decrease in log odds of success; $\beta=-0.89[-1.83,-0.15]$ ), magnolia warbler (Setophaga magnolia; 0.50 increase in log odds of success; $\beta=0.50[0.08$, $0.92]$ ), and ovenbird (Seiurus aurocapilla; 2.30 increase in log odds of success; $\beta=2.30[1.05$, 3.88]; Table 4.3, Figure 4.5B). Only one species, red-eyed vireo (Vireo olivaceus), showed a relationship to $R$. allegheniensis fruit counts (1.30 increase in log odds of success with each standard deviation increase in fruit counts, scaled; $\beta=1.30$ [0.47, 2.16]; Table 4.3, Figure 4.5C). Three species showed a relationship to vegetation cover: black-throated blue warbler (Setophaga caerulescens; 1.62 increase in log odds of success with each standard deviation increase in cover, scaled; $\beta=1.62[0.32,3.64])$, ovenbird (1.36 increase in log odds of success; $\beta=1.36[0.09$, 2.77]), and red-eyed vireo ( 0.59 increase in log odds of success; $\beta=0.59$ [0.13, 1.08]; Table 4.3, Figure 4.5D). Eight species showed positive relationships to ordinal date (Table 4.3, Figure 4.5E). For 2 species (cedar waxwing and song sparrow) there were no relationships to covariates.

Two species showed relationships between probability of having a higher molt progress score and infestation rates of $R$. allegheniensis fruits: black-capped chickadee (1.93 decrease in 
$\log$ odds of success with each standard deviation increase in infestation rate, scaled; $\beta=-1.93[-$ $2.99,-1.08])$ and red-eyed vireo $(0.50$ increase in $\log$ odds of success; $\beta=0.50[0.02,1.04]$;

Table 4.3, Figure 4.6A). Two species showed molt progress relationships to SWD trap captures: cedar waxwing (0.82 increase in log odds of success with each standard deviation increase in SWD trap captures, scaled; $\beta=0.82[0.30,1.39])$ and song sparrow $(0.90$ decrease in log odds of success; $\beta=-0.90[-1.77,-0.20]$; Table 4.3, Figure 4.6B). Two species showed molt progress relationships to $R$. allegheniensis fruit counts: gray catbird (0.53 increase in log odds of success with each standard deviation increase in fruit counts, scaled; $\beta=0.53[0.09,0.98])$ and magnolia warbler (0.52 decrease in log odds of success; $\beta=-0.52[-1.10,-0.04]$; Table 4.3, Figure 4.6C). Two species showed a molt progress relationship to cover: hooded warbler $(0.59$ decrease in log odds of success with each standard deviation increase in cover, scaled; $\beta=-0.59[-1.16,-0.04])$ and song sparrow $(0.58$ increase in $\log$ odds of success; $\beta=0.58[0.15,1.04]$; Table 4.3, Figure 4.6D). All but one species (black-capped chickadee) showed a positive molt progress relationship to ordinal date (Table 4.3, Figure 4.6E).

The SMI of one species, black-capped chickadee, was correlated with infestation rate of R. allegheniensis fruits (0.21 decrease in expected SMI with each standard deviation increase in infestation rate, scaled; $\beta=-0.21[-0.40,-0.02]$; Table 4.3; Figure 4.7A). Three species showed a relationship between SMI score and SWD trap captures: black-capped chickadee $(0.27$ increase in expected SMI with each standard deviation increase in SWD trap captures, scaled; $\beta=0.27$ $[0.03,0.49]$ ), chestnut-sided warbler (Setophaga pensylvanica; 0.11 increase in expected SMI; $\beta$ $=0.11[0.02,0.18])$, and eastern towhee $(0.98$ increase in expected SMI; $\beta=0.98[0.11,1.95]$; Table 4.3; Figure 4.7B). Chestnut-sided warbler SMI was correlated with $R$. allegheniensis fruit counts $(0.13$ decrease in expected SMI with each standard deviation increase in fruit counts, 
scaled; $\beta=-0.13[-0.24,-0.03]$; Table 4.3, Figure 4.7C) and cover $(0.15$ decrease in expected SMI with each standard deviation increase in cover, scaled; $\beta=-0.15[-0.28,-0.03]$; $\underline{\text { Table } 4.3}$, Figure 4.7D). Two species' SMI was positively correlated to ordinal date: gray catbird (0.95 increase in expected SMI with each standard deviation increase in date, scaled; $\beta=0.95[0.45$,

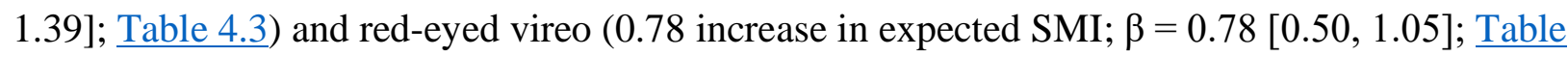
4.3, Figure 4.7E). Chestnut-sided warbler SMI was negatively correlated to ordinal date (0.32 decrease in expected SMI; $\beta=-0.32[-0.42,-0.22]$; Table 4.3, Figure 4.7E). For 8 species there was no relationship of SMI to covariates.

\section{Fruit Consumption}

The models for all frugivores, cedar waxwing, and eastern towhee exhibited good fit. The probability of a fecal sample containing $R$. allegheniensis was positively correlated with infestation rate of $R$. allegheniensis fruits for all frugivores (0.57 increase in log odds of success with each standard deviation increase in infestation rate, scaled; $\beta=0.57[0.41,0.74]$; Table 4.3, Figure 4.8A), cedar waxwing (1.35 increase in log odds of success; $\beta=1.35[0.73,2.04]$; Table $\underline{4.3}$, Figure 4.8B), and eastern towhee (0.71 increase in log odds of success; $\beta=0.71[0.11,1.36]$; Table 4.3, Figure 4.8C). The probability of a frugivore's fecal sample containing $R$. allegheniensis was also positively correlated with $R$. allegheniensis fruit counts $(0.20$ increase in $\log$ odds of success with each standard deviation increase in fruit counts, scaled; $\beta=0.20[0.04$, 0.36]; Table 4.3). The model for gray catbird failed the GOF test (Bayesian p-value $<0.1$ ). The probability of a gray catbird fecal sample containing $R$. allegheniensis was positively correlated with all 3 covariates: infestation rate of $R$. allegheniensis fruits (1.24 increase in log odds of success with each standard deviation increase in infestation rate, scaled; $\beta=1.24[0.69,1.85]$; Table 4.3, Figure 4.8D), SWD trap captures (0.61 increase in log odds of success with each 
standard deviation increase in trap captures, scaled; $\beta=0.61[0.13,1.16]$; Table 4.3), and $R$. allegheniensis fruit counts (0.65 increase in log odds of success with each standard deviation increase in fruit counts, scaled; $\beta=0.65[0.26,1.08]$; $\underline{\text { Table } 4.3}$ ).

\section{DISCUSSION}

To my knowledge, this is the first study to show relationships of songbird body condition indices to a non-native agricultural fruit pest in invaded forest ecosystems. Importantly, relationships did not show any broad, guild-level patterns. Rather, most relationships varied among species, though patterns in species traits existed for those associating with infestation rate. Contrary to predictions, condition indices of few species showed relationships to infestation rate. Fat presence for gray catbird and molt progress for red-eyed vireo correlated similarly to infestation rate (Figures 4.5A and $\underline{4.6 \mathrm{~A}})$. These species, both regular consumers of fruit during the postbreeding season and fall migration (Cimprich et al. 2020, Smith et al. 2020), correlated similarly with fruit resources, though for a different condition index (gray catbird: molt progress, and redeyed vireo: fat presence; Figures 4.5C and 4.6C). As such, parasitism of fruits by SWD appeared to introduce a relationship to a second condition index that $R$. allegheniensis fruits alone did not for these fruit-consuming species. Additionally, gray catbird and red-eyed vireo were the only species to improve all 3 condition indices as the season progressed (Figures 4.5E, $\underline{4.6 \mathrm{E}}$, and 4.7E). As both gray catbird and red-eyed vireo are frugivorous, any differences in condition indices may have been the result of alterations to fruit resources. Parasitism can reduce fruit attractiveness and consumption by birds (Manzur and Courtney 1984, Traveset et al. 1995). However, parasitism can make fruits more attractive (Valburg et al. 1992a, $b$ ), introducing nutritional benefits such as protein (Piper 1986, Drew 1988). Fruits are useful for building fat and may aid in satisfying energy requirements during feather molt (Snow 1971, Martin 1985, 
Parrish 2000, McDermott and Wood 2010), but additional proteins in parasitized fruits could further enhance a bird's ability to improve condition (Murphy and King 1992, Bairlein and Simons 1995, Smith et al. 2007).

Contrary to predictions, fecal analysis results showed a greater probability of fruit consumption by frugivores with greater infestation rates of $R$. allegheniensis fruits (Figure 4.8A). This same relationship extended to cedar waxwing, eastern towhee, and gray catbird, specifically (Figures 4.8B, 4.8C, and 4.8D); although, the gray catbird model experienced poor fit. To my knowledge, this is the first documented evidence of a non-native insect pest increasing the likelihood of fruit consumption by vertebrate consumers at both the dietary guild and species level via parasitism in invaded forest ecosystems. While I did not observe consumption of parasitized fruits, frugivores clearly consumed parasitized fruits. However, it does not appear eastern towhee or cedar waxwing experienced any impacts to condition because of differences in fruit consumption, since condition did not correlate to infestation rate for either species. The only frugivores with condition indices correlated with infestation rate were gray catbird and red-eyed vireo. This result and observed relationships to infestation rate, fruit, and date may suggest consumption of fruits by gray catbird increased due to SWD parasitism, potentially including SWD-parasitized fruits, with implications for multiple condition indices. Red-eyed vireo, by contrast, consumed few $R$. allegheniensis fruits in this study (4\% of birds captured), showing less frugivory than expected. Whether this was due to parasitism by SWD remains unclear. As such, there may be a different mechanism of infestation rate on condition for red-eyed vireo. Additionally, different relationships to infestation rate existed for other species.

Condition indices of 2 non-frugivorous species, black-throated green warbler (fat presence) and black-capped chickadee (molt progress and SMI), showed similar relationships to 
infestation rate, opposite those of the 2 frugivorous species (Figures 4.5A, 4.6A, and 4.7A). While condition indices differed between species, both species forage together in mixed-species flocks following the breeding season (Morse and Poole 2020), supporting the similar relationship to infestation rate. Neither species consumes large numbers of fruits during the post-breeding season or fall migration (Foote et al. 2020, Morse and Poole 2020). Instead of effects on fruit resources, relationships of condition indices to infestation rate could be an indirect effect of fruit parasitism by SWD altering arthropod communities in invaded habitat (Adkins and Rieske 2013, Jennings et al. 2017). Further, gray catbird and red-eyed vireo occasionally do regularly feed on or near the ground following the breeding season (Cimprich et al. 2020, Smith et al. 2020), while black-throated green warbler and black-capped chickadee foliage-glean and rarely forage on the ground (Foote et al. 2020, Morse and Poole 2020). Parasitism by SWD increases fruit drop (Walsh et al. 2011), which could directly affect ground-foraging bird species. Alternatively, fruits on the ground may have attracted arthropods (Sallabanks and Courtney 1992), including predators of SWD pupating in dropped fruit or the soil (Kanzawa 1939, Bal et al. 2017, Woltz and Lee 2017). With fewer fruits remaining on the plant, foliage-dwelling arthropods may have moved to the ground or searched out plants with larger fruit crops. As such, birds utilizing different foraging microhabitats could see differences in native arthropod resources, with implications for condition indices.

Arthropods are more common in early successional habitat (e.g., regenerating timber harvests) than mature forest (Keller et al. 2003), are a regular component of summer and fall diets for non-frugivorous and frugivorous birds, including red-eyed vireo (Strong et al. 2005, Brown and Long 2006, Tietz and Johnson 2007, Diggs et al. 2011, Cimprich et al. 2020), and provide protein for feather molt and fat accumulation (Moermond and Denslow 1985, Murphy 
and King 1992, Bairlein and Simons 1995, Robel et al. 1995, Smith et al. 2007). Parasitism by SWD may displace native arthropod foods for birds through competitive exclusion (Fridley and Sax 2014, Verble-Pearson and Pearson 2016, Goodman and Warren 2019), by reducing fruit resources through premature decay (Walsh et al. 2011), or due to lower predation or parasitism on SWD by native species (Mitchell and Power 2003, Torchin et al. 2003, Prior et al. 2015). Alternatively, SWD larvae and pupae may attract arthropod predators or parasitoids (Beddington et al. 1976, Pintor and Byers 2015, Ballman et al. 2017, Bourne et al. 2019, Lee et al. 2019) or expose fruits to additional arthropods (Walsh et al. 2011), each for birds to prey on. Non-native insects can impact condition of migratory birds in invaded ecosystems indirectly through alterations to native arthropod communities (Smith and Hatch 2017). Such a trophic cascading effect may extend to other relationships between SWD and birds in regenerating timber harvests.

Even more so than with infestation rate, relationships of condition indices to SWD trap captures were variable among species. Previous work has documented differences in condition of native vertebrates following invasion by a non-native arthropod pest (Smith and Hatch 2017), but no previous study has documented differences in condition connected to a non-native fruit parasite. Of note is that SWD trap captures also increased the probability of fruit consumption by gray catbird (Table 4.3). If the presence of adult SWD somehow made fruits more attractive to gray catbird (e.g., SWD-covered fruits), it did not appear to have any connection to condition. Eight species showed nonzero relationships of SWD trap captures to condition (Figures 4.5B, $\underline{4.6 \mathrm{~B}}$, and $\underline{4.7 \mathrm{~B}}$ ), but contrary to my predictions, no clear guild-specific patterns were apparent. Species with similar dietary preferences (i.e., frugivorous or non-frugivorous), foraging behaviors and microhabitats, or breeding habitats did not group based on directional relationship of SWD trap captures to condition indices. As such, it is unclear the mechanism by which a 
variety of species show a connection to adult SWD. Relationships to SWD trap captures may be species-specific, rather than easily generalized to broad behavioral patterns shared by species. Bird species express preferences for food items (Streby et al. 2013, Jirinec et al. 2016, Ruhl et al. $2020 a, b)$, and alterations to those food items could influence the ability of birds to meet energetic needs. Each of the species connected to SWD trap captures, including frugivores, regularly consume arthropods following the breeding season. While I did not observe predation of SWD, the introduction of a new arthropod may provide a new food resource for birds in regenerating timber harvests (Showalter and Whitmore 2002, Barber et al. 2008, Koenig et al. 2013). However, invasive species may not provide the same nutritional quality as native species (Labbé and King 2020, Van Volkom et al. 2021), harming the ability of some consumers to improve condition (Pothoven et al. 2001, Pintor and Byers 2015, Oguchi et al. 2017). Adult SWD may also alter existing native arthropod foods for birds in regenerating timber harvests, attracting (Pintor and Byers 2015) or deterring (Fridley and Sax 2014, Verble-Pearson and Pearson 2016, Goodman and Warren 2019) different arthropod species and altering important protein resources for improving condition for both frugivore and non-frugivore songbird species (Moermond and Denslow 1985, Murphy and King 1992, Bairlein and Simons 1995, Robel et al. 1995, Smith et al. 2007). Initial research suggests different relationships of some native arthropod taxonomic groups to adult SWD (Maceda-Veiga et al. 2021). As such, the role of SWD in influencing food resources for birds may be multi-faceted and have implications for body condition of many species.

Compared to SWD, condition for fewer species than predicted correlated with fruit resources. Aside from gray catbird and red-eyed vireo, no frugivorous species correlated with $R$. allegheniensis fruit counts, as expected from previous studies (Vitz and Rodewald 2006, 2007; 
Streby et al. 2011; Labbé and King 2014). Despite this finding, fecal sample analyses showed consumption probability of fruits by frugivores increased as $R$. allegheniensis crops increased (Table 4.3). Of the 3 focal species I analyzed for fruit consumption, only gray catbird showed increased probability of consumption (Table 4.3), demonstrating a difference in guild- and species-level patterns in fruit consumption (Mannan et al. 1984, Morrison 1986, Canterbury et al. 2000). Condition and consumption results are consistent with gray catbird consuming fruits and experiencing a change in condition from those fruits. The relationship of condition to fruit counts for red-eyed vireo is unclear and particularly interesting, since few individuals captured showed evidence of $R$. allegheniensis consumption. I cannot identify the reason for lower-than-expected frugivory by red-eyed vireo in this study. Condition indices of 2 non-frugivores, magnolia warbler (molt progress) and chestnut-sided warbler (SMI), also associated with fruits (Figures 4.6C and 4.7C). I am unaware of such observations in previous studies. If fruit abundance indirectly estimated arthropod abundance, as hypothesized in previous studies (Sallabanks and Courtney 1992, Vitz and Rodewald 2007, McDermott and Wood 2010), the relationships of magnolia warbler, chestnut-sided warbler, and red-eyed vireo condition to fruits could reflect utilization of arthropods by these species to complete molt and build energy reserves, both of which are facilitated by proteins from arthropods (Moermond and Denslow 1985, Murphy and King 1992). Because direction of relationships differed for red-eyed vireo and the 2 nonfrugivore species, further investigation of this possibility is required. Condition indices of most focal frugivore species (cedar waxwing, eastern towhee, ovenbird, and song sparrow) showed no relationship with fruit resources. Additionally, based on fecal sample collection, 3 frugivore species showed few instances of frugivory in this study: ovenbird (3\% of birds captured), redeyed vireo ( $4 \%$ of birds captured), and song-sparrow ( $1 \%$ of birds captured). While fruits at 
larger spatial scales can be more important for predicting relationships to birds (Buler et al. 2007, Labbé and King 2014), a lack of relationship to fruit resources for most species may indicate that birds utilized other food resources (Alatalo 1980, Rotenberry 1980), masking any relationship of condition indices birds to food resources observed in previous studies (Tietz and Johnson 2007, McDermott and Wood 2010). When food is sufficiently high in an area, birds may simply choose locations with sufficient food rather than the most abundant food (Champlin et al. 2009, Cohen et al. 2012), further masking possible relationships.

As with other microhabitat features, relationships were rarer than predicted for vegetative cover. Six bird species showed strong, species-specific relationships of condition to vegetative cover complexity. The association of 4 species from both dietary guilds (fat presence: blackthroated blue warbler, ovenbird, and red-eyed vireo; molt progression: song sparrow; Figures 4.5D and 4.6D) with more complex vegetation structure is consistent with birds in better condition (i.e., further in molt or possessing fat) prioritizing vegetative cover from predation during post-breeding and migratory periods (Moore and Aborn 2000, McDermott and Wood 2010). Vegetatively complex habitats provide greater cover than uniform habitats (Moore et al. 1995), giving birds protection from predation (White et al. 2005, King et al. 2006). Condition of hooded warbler (molt progress) and chestnut-sided warbler (SMI) also correlated with cover, but in the opposite direction (Figures 4.6D and 4.7D). Vegetatively complex habitats also provide more food (Moore et al. 1995), and complexity may serve as a proxy for arthropod food resources, which can be cryptic and more difficult to assess than fruit resources (Wolfe et al. 2014). As predominately arthropod consumers foraging off leaves in dense vegetation following the breeding season (Byers et al. 2020, Chiver et al. 2020), hooded warbler and chestnut-sided warbler condition may have reflected arthropod resources. Most condition indices for species 
were unrelated to vegetative cover, meaning fatter, fully molted, or greater SMI birds were in similarly complex vegetation compared to skinnier or earlier-molting birds. If the range of vegetation complexity at mist net locations was sufficient to provide both cover and food resources, relationships would have been unlikely to emerge (Champlin et al. 2009, Cohen et al. 2012). Exploring a greater range of vegetation cover could identify relationships I predicted but failed to identify.

Regardless of strong relationships of some bird species to SWD variables, fruit, and vegetative cover, most condition indices for most birds improved as the season progressed (Figures 4.5E, 4.6E, and $\underline{4.7 \mathrm{E}}$ ), some apparently facilitated by or despite SWD. Increased difficulty with resource acquisition can delay and extend the length of migration (Yong and Moore 1997, Vega Rivera et al. 1998b, Schaub and Jenni 2001, Goymann et al. 2010), with negative consequences for condition and survival on wintering grounds (Moore and Kerlinger 1991, Moore and Yong 1991, Woodrey and Moore 1997, Moore 2000, Stutchbury et al. 2011). Birds may not have experienced any dramatic changes to resource acquisition for feather molt or fat accumulation, likely due to a flexible diet. This is supported by the overall weaker relationships to fruit and lower than expected instances of frugivory, combined with temporal increases in most condition indices for most frugivorous species. Because birds need both proteins and lipids for feather molt and fat accumulation and can acquire them from fruits and arthropods (Snow 1971, Martin 1985, Moermond and Denslow 1985, Jenni and Winkler 1994, Parrish 2000), individuals were likely flexible enough in their diet such that a limitation of some food resources, such as fewer fruits or alterations to arthropod communities, would be insufficient for birds to change where they foraged (Alatalo 1980, Rotenberry 1980, Hutto 1981, Petit 2000). Birds can improve condition using fruit (Bairlein and Gwinner 1994, Parrish 1997), 
arthropods (Moermond and Denslow 1985), or both (Bairlein and Simons 1995). Many different diets may be sufficient to meet pre-migratory nutritional needs (McKinnon et al. 2017), and birds in poorer condition can meet energy and nutritional demands and reduce stopover duration (Wang and Moore 2005, Moore 2018) by increasing foraging pace (Loria and Moore 1990) and food intake (Aamidor et al. 2011). As such, birds may be unlikely to alter microhabitat use because of the ability to utilize a variety of foods and still meet energetic demands, even if activity of SWD possibly alters quality of some resources and some birds are less likely to improve condition due to SWD.

However, not all species improved all condition indices over the course of the season. Of the species I was able to model, three were not more likely to possess fat later in the season (Figure 4.5E). Two species, cedar waxwing and song sparrow, were less common during the second sampling period ( $14 \%$ and $26 \%$ of all captures, respectively), while black-capped chickadee were less common during the first sampling period (13\% of captures). Only 9 cedar waxwings and song sparrows possessed fat, most of which were captured during sampling period 1. In contrast, only 7 chickadees possessed fat. This was likely too early to see seasonal fattening in these species, which don't show migratory movement until September or October (Arcese et al. 2020, Witmer et al. 2020). Black-capped chickadee are non-migratory but experience strong variation in daily fat loads (Foote et al. 2020). Fat presence of black-capped chickadee also correlated with SWD trap captures, but whether this is responsible for the lack of a temporal relationship is unclear. Black-capped chickadee was the only species not more likely to be further in molt progress (Figure 4.6E). As with fat presence and SWD, molt progress of blackcapped chickadee also correlated with infestation rates of fruits, but it is unclear whether the lack of a temporal component to molt progression can be explained by this relationship. Additionally, 
chickadees molt between July and October and, as non-migratory, would be under less pressure to complete energy-demanding molt and improve flight performance quickly (Murphy 1996, Pyle 1997, Vega Rivera et al. 1998a, Leu and Thompson 2002). In contrast to fat and molt, SMI of only 3 species changed with date (Figure 4.7E). While the increase in SMI with date for gray catbird and red-eyed vireo may be connected to fruit resources and fruit parasitism by SWD, declines in SMI with date for chestnut-sided warbler appear connected to the relationship of SMI with fruit resources, vegetation cover, SWD trap captures, or a combination of these predictors (Figures 4.7B-4.7D). The lack of improvement in SMI for most species appears contradictory to fat modeling results, since SMI should incorporate differences in body mass due to fat. However, SMI also includes additional sources of difference in body mass separate from structural size that simple fat scoring cannot identify, including fat that cannot be seen with traditional fat scoring techniques (Peig and Green 2009). As such, weak relationships could be due partly to weak correlations of body mass and length measurements (e.g., cedar waxwing and hooded warbler; Table 4.1) or other morphological features contributing to body mass (e.g., muscle mass).

\section{FUTURE DIRECTIONS}

Even though I detected fewer relationships than predicted, the results of this study identified several relationships of avian condition indices to microhabitat characteristics, including SWD. Because 1) there is not currently evidence of a causal relationship between SWD presence or fruit parasitism and resource quality for birds, and 2) I measured single condition index values

for birds rather than a change in indices at sites, I do not know whether condition as I measured it determined where birds were captured, was determined by microhabitat characteristics, or was correlated with a third, underlying factor. As such, I cannot clearly argue the causal nature of the relationships of bird condition to SWD or other microhabitat characteristics. To clarify these 
relationships, further investigation is warranted. Further work should track individual birds, their initial condition when settling at a location in SWD-invaded habitat, and whether condition changes at those locations. Direct manipulation of food resources and monitoring of subsequent changes to bird location use and condition may also clarify the mechanism of condition and habitat use at the ANF. In addition to condition, fruit consumption by frugivores was strictly observational in this study. Fruit choice or preference experiments with SWD-parasitized fruits will confirm whether parasitized fruits are preferentially consumed by frugivores. Determining nutritional contents of SWD-parasitized fruits and monitoring condition of birds that consume SWD-parasitized fruits will confirm whether birds benefit from consumption of these fruits. Finally, full diet analysis and foraging observations may provide further detail on the range of food resources birds utilize in SWD-invaded forest and how plastic birds are in their diets while foraging in SWD-invaded forest. Environmental DNA sampling in feces may prove especially useful for identifying whether birds consume SWD directly, though nutritional analyses and monitoring of birds consuming SWD would be necessary to determine the nutritional quality of flies. Such studies may provide opportunities to clarify the causes for observed relationships in this study and the broader implications for different species, especially eastern towhee, gray catbird, and black-throated green warbler, 3 species listed in Pennsylvania's 2015-2025 State Wildlife Action Plan (SWAP; PGC-PFBS 2015). However, broader ecological questions remain. The ecological consequences of SWD activity may extend beyond fruit consumption and require further investigation. How SWD invasion influences arthropod communities in forest ecosystems is largely unknown (Maceda-Veiga et al. 2021), but the potential for a trophic cascade effect of SWD on condition of vertebrate consumers of arthropods warrants further study of arthropods in different foraging microhabitats. Influences of SWD on fruit consumption 
may extend beyond arthropod communities. If probability of fruit consumption by frugivorous birds increases with parasitism by SWD, then parasitism of fruits may have important consequences for seed dispersal and regeneration of fruiting plants (Roche et al. 2021).

Therefore, further research should investigate this interaction among SWD, fruit consumption, seed dispersal, and plant recruitment.

\section{LITERATURE CITED}

Aamidor, S. E., U. Bauchinger, O. Mizrahy, S. R. McWilliams, and B. Pinshow. 2011. During stopover, migrating Blackcaps adjust behavior and intake of food depending on the content of protein in their diets. Integrative and Comparative Biology 51:385-393.

Adkins, J. K., and L. K. Rieske. 2013. Loss of a foundation forest species due to an exotic invader impacts terrestrial arthropod communities. Forest Ecology and Management 295:126-135.

Alatalo, R. V. 1980. Seasonal dynamics of resource partitioning among foliage-gleaning passerines in northern Finland. Oecologia 45:190-196.

Anders, A. D., J. Faaborg, and F. R. Thompson III. 1998. Postfledging dispersal, habitat use, and home-range size of juvenile wood thrushes. Auk 115:349-358.

Arcese, P., M. K. Sogge, A. B. Marr, and M. A. Patten. 2020. Song sparrow (Melospiza melodia), version 1.0 in A. F. Poole and F. B. Gill, editors. Birds of the world. Cornell Lab of Ornithology, Ithaca, New York, USA.

Atallah, J., L. Teixeira, R. Salazar, G. Zaragoza, and A. Kopp. 2014. The making of a pest: the evolution of a fruit-penetrating ovipositor in Drosophila suzukii and related species. Proceedings of the Royal Society B: Biological Sciences 281:20132840. 
Bairlein, F., and E. Gwinner. 1994. Nutritional mechanisms and temporal control of migratory energy accumulation in birds. Annual Review of Nutrition 14:187-215.

Bairlein, F., and D. Simons. 1995. Nutritional adaptations in migrating birds. Israel Journal of Zoology 41:357-367.

Baker, R. R. 1993. The function of post-fledging exploration: a pilot study of three species of passerines ringed in Britain. Scandinavian Journal of Ornithology 24:71-79.

Bal, H. K., C. Adams, and M. Grieshop. 2017. Evaluation of Off-season Potential Breeding Sources for Spotted Wing Drosophila (Drosophila suzukii Matsumura) in Michigan. Journal of Economic Entomology 110:2466-2470.

Ballman, E. S., J. A. Collins, and F. A. Drummond. 2017. Pupation behavior and predation on Drosophila suzukii (Diptera: Drosophilidae) pupae in Maine wild blueberry fields. Journal of Economic Entomology 110:2308-2317.

Barber, N. A., R. J. Marquis, and W. P. Tori. 2008. Invasive prey impacts the abundance and distribution of native predators. Ecology 89:2678-2683.

Beddington, J. R., M. P. Hassell, and J. H. Lawton. 1976. The components of arthropod predation: II. The predator rate of increase. Journal of Animal Ecology 45:165-185.

Blake, J. G., and B. A. Loiselle. 1992. Fruits in the diets of neotropical migrant birds in Costa Rica. Biotropica 24:200-210.

Blake, J. G., T. Moermond, and D. J. Levey. 1990. Quantifying abundance of fruits for birds in tropical habitats. Studies in Avian Biology 13:73-79.

Blem, C. R. 1976. Patterns of lipid storage and utilization in birds. American Zoology 16:671684. 
Blem, C. R. 1980. The energetics of migration. Pages 175-224 in S. A. Gauthreaux, Jr., editor. Animal migration, orientation, and navigation. Academic Press, New York, New York, USA.

Bonier, F., P. R. Martin, J. P. Jensen, L. K. Butler, M. Ramenofsky, and J. C. Wingfield. 2007. Pre-migratory life history stages of juvenile arctic birds: costs, constraints, and trade-offs. Ecology 88:2729-2735.

Bourne, A., M. T. Fountain, H. Wijnen, and B. Shaw. 2019. Potential of the European earwig (Forficula auricularia) as a biocontrol agent of the soft and stone fruit pest Drosophila suzukii. Pest Management Science 75:3340-3345.

Briem, F., A. R. Dominic, B. Golla, C. Hoffmann, C. Englert, A. Herz, and H. Vogt. 2018. Explorative data analysis of Drosophila suzukii trap catches from a seven-year monitoring program in southwest Germany. Insects 9:125.

Brose, P. 2011. Fate of the 2001 acorn crop at Clear Creek State Forest, Pennsylvania. Pages 253-261 in. Proceedings, 17th central hardwood forest conference. S. Fei, J. M. Lhotka, J. W. Stringer, K. W. Gottschalk, and G. W. Miller, editors. U.S. Forest Service General Technical Report NRS-P-78, Newtown Square, Pennsylvania, USA.

Brown, D. R., and J. A. Long. 2006. Experimental fruit removal does not affect territory structure of wintering Hermit Thrushes. Journal of Field Ornithology 77:404-408.

Buchholz, R., and D. J. Levey. 1990. The evolutionary triad of microbes, fruits, and seed dispersers: an experiment in fruit choice by cedar waxwings, Bombycilla cedrorum. Oikos 59:200-204.

Buler, J. J., F. R. Moore, and S. Woltmann. 2007. A multi-scale examination of stopover habitat use by birds. Ecology 88:1789-1802. 
Burke, A. D., F. R. Thompson III, and J. Faaborg. 2017. Variation in early-successional habitat use among independent juvenile forest breeding birds. Wilson Journal of Ornithology 129:235-246.

Burrack, H. J., M. Asplen, L. Bahder, J. Collins, F. A. Drummond, C. Guédot, R. Isaacs, D. Johnson, A. Blanton, J. C. Lee, G. Loeb, C. Rodriguez-Saona, S. Van Timmeren, D. Walsh, and D. R. McPhie. 2015. Multistate comparison of attractants for monitoring Drosophila suzukii (Diptera: Drosophilidae) in blueberries and caneberries. Environmental Entomology 44:704-712.

Byers, B. E., M. Richardson, and D. W. Brauning. 2020. Chestnut-sided warbler (Setophaga pensylvanica), version 1.0 in A. F. Poole, editor. Birds of the world. Cornell Lab of Ornithology, Ithaca, New York, USA.

Canterbury, G. E., T. E. Martin, D. R. Petit, L. J. Petit, and D. F. Bradford. 2000. Bird communities and habitats as ecological indicators of forest condition in regionals monitoring. Conservation Biology 14:544-558.

Carlisle, J. D., K. L. Olmstead, C. H. Richart, and D. L. Swanson. 2012. Food availability, foraging behavior, and diet of autumn migrant landbirds in the Boise foothills of southwestern Idaho. Condor 114:449-461.

Champlin, T. B., J. C. Kilgo, and C. E. Moorman. 2009. Food abundance does not determine bird use of early-successional habitat. Ecology 90:1586-1594.

Chandler, C. C., D. I. King, and R. B. Chandler. 2012. Do mature forest birds prefer earlysuccessional habitat during the post-fledging period? Forest Ecology and Management 264:1-9. 
Chiver, I., L. J. Evans Ogden, and B. J. Stutchbury. 2020. Hooded warbler (Setophaga citrina), version 1.0 in P. G. Rodewald, editor. Birds of the world. Cornell Lab of Ornithology, Ithaca, New York, USA.

Cimprich, D. A., F. R. Moore, and M. P. Guilfoyle. 2020. Red-eyed vireo (Vireo olivaceus), version 1.0 in P. G. Rodewald, editor. Birds of the world. Cornell Lab of Ornithology, Ithaca, New York, USA.

Cohen, E. B., F. R. Moore, and R. A. Fischer. 2012. Experimental evidence for the interplay of exogenous and endogenous factors on the movement ecology of a migrating songbird. PLoS ONE 7(7):e41818.

Cox, W. A., F. R. Thompson, A. S. Cox, and J. Faaborg. 2014. Post-fledging survival in passerine birds and the value of post-fledging studies to conservation. Journal of Wildlife Management 78:183-193.

Cyr, N. E., M. Wikelski, and M. L. Romero. 2008. Increased energy expenditure but decreased stress responsiveness during molt. Physiological and Biochemical Zoology 81:452-462.

Diepenbrock, L. M., and H. J. Burrack. 2017. Variation of within-crop microhabitat use by Drosophila suzukii (Diptera: Drosophilidae) in blackberry. Journal of Applied Entomology 141:1-7.

Diggs, N. E., P. P. Marra, and R. J. Cooper. 2011. Resource limitation drives patterns of habitat occupancy during the nonbreeding season for an omnivorous songbird. Condor 113:646654.

Dormann, C. F., J. Elith, S. Bacher, C. Buchmann, G. Carl, G. Carré, J. R. G. Marquéz, B. Gruber, B. Lafourcade, P. J. Leitão, T. Münkemüller, C. Mcclean, P. E. Osborne, B. Reineking, B. Schröder, A. K. Skidmore, D. Zurell, and S. Lautenbach. 2013. 
Collinearity: A review of methods to deal with it and a simulation study evaluating their performance. Ecography 36:027-046.

Drew, R. A. I. 1988. Amino acid increases in fruit infested by fruit flies of the family Tephritidae. Zoological Journal of the Linnaean Society 93:107-112.

Dunn, E. H. 2003. Recommendations for fat scoring. North American Bird Bander 28:58-63.

Dunn, E. H., and C. J. Ralph. 2004. Use of mist nets as a tool for bird population monitoring. Studies in Avian Biology 29:1-6.

Elsensohn, J. E., and G. M. Loeb. 2018. Non-crop host sampling yields insights into small-scale population dynamics of Drosophila suzukii (Matsumura). Insects 9:5.

Evans, R. K., M. D. Toews, and A. A. Sial. 2017. Diel periodicity of Drosophila suzukii (Diptera: Drosophilidae) under field conditions. PLoS ONE 12(2):e0171718.

Eyre, F. H. 1980. Forest cover types of the United States and Canada. Society of American Foresters. Washington, DC, USA.

Foote, J. R., D. J. Mennill, L. M. Ratcliffe, and S. M. Smith. 2020. Black-capped chickadee (Poecile atricapillus), version 1.0 in A. F. Poole, editor. Birds of the world. Lab of Ornithology, Ithaca, New York, USA.

Fridley, J. D., and D. F. Sax. 2014. The imbalance of nature: revisiting a Darwinian framework for invasion biology. Ecological Sounding 23:1157-1166.

García, D., R. Zamora, J. M. Gomez, and J. A. Hodar. 1999. Bird rejection of unhealthy fruits reinforces the mutualism between juniper and its avian dispersers. Oikos 85:536-544.

Gelman, A., J. B. Carlin, H. S. Stern, and D. B. Rubin. 2004. Bayesian data analysis. Second edition. Chapman and Hall/CRC, New York, New York, USA. 
Gelman, A., and J. Hill. 2007. Data analysis using regression and multilevel/hierarchical models. Cambridge University Press, New York, New York, USA.

Goodman, M., and R. J. Warren. 2019. Non-native ant invader displaces native ants but facilitates non-predatory invertebrates. Biological Invasions 21:2713-2722.

Goymann, W., F. Spina, A. Ferri, L. Fusani, and D. Supplement. 2010. Body fat influences departure from stopover sites in migratory birds: evidence from whole-island telemetry. Biology Letters 6:478-481.

Green, A. 2001. Mass/length residuals: measures of body condition or generators of spurious results? Ecology 82:1473-1483.

Guglielmo, C. G., D. J. Cerasale, and C. Eldermire. 2005. A field validation of plasma metabolite profiling to assess refueling performance of migratory birds. Physiological and Biochemical Zoology 78:116-125.

Harris, D. W., K. A. Hamby, H. E. Wilson, and F. G. Zalom. 2014. Seasonal monitoring of Drosophila suzukii (Diptera: Drosophilidae) in a mixed fruit production system. Journal of Asia-Pacific Entomology 17:857-864.

Hedenström, A., and T. Alerstam. 1997. Optimum fuel loads in migratory birds: distinguishing between time and energy minimization. Journal of Theoretical Biology 189:227-234.

Heimerdinger, M. A., and R. C. Leberman. 1966. The comparative efficiency of 30 and $36 \mathrm{~mm}$. mesh in mist nets. Bird-Banding 37:280-285.

Herrera, C. M. 1984. Adaption to frugivory of Mediterranean avian seed dispersers. Ecology 65:609-617.

Hutto, R. L. 1981. Seasonal variation in the foraging behavior of some migratory western wood warblers. Auk 98:765-777. 
Jenni, L., and R. Winkler. 1994. Moult and ageing of European passerines. Academic Press, London, United Kingdom.

Jennings, D. E., J. J. Duan, D. Bean, K. A. Rice, G. L. Williams, S. K. Bell, A. S. Shurtleff, and P. M. Shrewsbury. 2017. Effects of the emerald ash borer invasion on the community composition of arthropods associated with ash tree boles in Maryland, U.S.A. Agricultural and Forest Entomology 19:122-129.

Jirinec, V., R. E. Isdell, and M. Leu. 2016. Prey availability and habitat structure explain breeding space use of a migratory songbird. Condor 118:309-328.

Kanzawa, T. 1939. Studies on Drosophila suzukii Mats. Kofu, Yamanashi agricultural experiment station. Abstract in Review of Applied Entomology 29: 622.

Karasov, W. H., and D. J. Levey. 1990. Trade-offs and digestive system adaptations of frugivorous passerine birds. Physiological Zoology 63:1248-1270.

Karr, J. R. 1981. Surveying birds with mist nets. Studies in Avian Biology 6:62-67.

Keller, J. K., M. E. Richmond, and C. R. Smith. 2003. An explanation of patterns of breeding bird species richness and density following clearcutting in northeastern USA forests. Forest Ecology and Management 174:541-564.

Kellner, K. 2019. jagsUI: a wrapper around "rjags" to streamline "JAGS" analyses (R package version 1.5.1). Retrieved from http://CRAN.R-project.org/package=jagsUI.

Kenis, M., L. Tonina, R. Eschen, B. van der Sluis, M. Sancassani, N. Mori, T. Haye, and H. Helsen. 2016. Non-crop plants used as hosts by Drosophila suzukii in Europe. Journal of Pest Science 89:735-748.

Kéry, M. 2010. Introduction to WinBUGS for ecologists. Academic Press, Waltham, Massachusetts, USA. 
King, D. I., R. M. Degraaf, M. L. Smith, and J. P. Buonaccorsi. 2006. Habitat selection and habitat-specific survival of fledgling ovenbirds (Seiurus aurocapilla). Journal of Zoology 269:414-421.

Knutie, S. A., and K. M. Gotanda. 2018. A non-invasive method to collect fecal samples from wild birds for microbiome studies. Microbial Ecology 76:851-855.

Koenig, W. D., A. M. Liebhold, D. N. Bonter, W. M. Hochachka, and J. L. Dickinson. 2013. Effects of the emerald ash borer invasion on four species of birds. Biological Invasions 15:2095-2103.

Krementz, D. G., and G. W. Pendleton. 1990. Fat scoring: sources of variability. Condor 92:500507.

Labbé, M. A., and D. I. King. 2014. The effect of local and landscape-level characteristics on the abundance of forest birds in early-successional habitats during the post-fledging season in Western Massachusetts. PLoS ONE 9(8):e106398.

Labbé, M. A., and D. I. King. 2020. Songbird use of native and invasive fruit in the Northeastern USA. Wildlife Society Bulletin 44:570-578.

Labocha, M. K., and J. P. Hayes. 2012. Morphometric indices of body condition in birds: a review. Journal of Ornithology 153:1-22.

Landolt, P. J., T. Adams, and H. Rogg. 2012. Trapping spotted wing drosophila, Drosophila suzukii (Matsumura) (Diptera: Drosophilidae), with combinations of vinegar and wine, and acetic acid and ethanol. Journal of Applied Entomology 136:148-154.

Lasa, R., E. Tadeo, R. A. Toledo-Hérnandez, L. Carmona, I. Lima, and T. Williams. 2017. Improved capture of Drosophila suzukii by a trap baited with two attractants in the same device. PLoS ONE 12(11):e0188350. 
Lee, J. C., D. J. Bruck, A. J. Dreves, C. Ioriatti, H. Vogt, and P. Baufeld. 2011. In focus: Spotted wing drosophila, Drosophila suzukii, across perspectives. Pest Management Science 67:1349-1351.

Lee, J. C., H. J. Burrack, L. D. Barrantes, E. H. Beers, A. J. Dreves, K. A. Hamby, D. R. Haviland, R. Isaacs, T. A. Richardson, P. W. Shearer, C. A. Stanley, D. B. Walsh, V. M. Walton, F. G. Zalom, and D. J. Bruck. 2012. Evaluation of monitoring traps for Drosophila suzukii (Diptera: Drosophilidae) in North America. Journal of Economic Entomology 105:1350-1357.

Lee, J. C., P. W. Shearer, L. D. Barrantes, E. H. Beers, H. J. Burrack, D. T. Dalton, A. J. Dreves, L. J. Gut, K. A. Hamby, D. R. Haviland, et al. 2013. Trap designs for monitoring Drosophila suzukii (Diptera: Drosophilidae). Environmental Entomology 42:1348-1355.

Lee, J. C., X. Wang, K. M. Daane, K. A. Hoelmer, R. Isaacs, A. A. Sial, and V. M. Walton. 2019. Biological control of spotted-wing Drosophila (Diptera: Drosophilidae) - current and pending tactics. Journal of Integrated Pest Management 10:13.

Leu, M., and C. W. Thompson. 2002. The potential importance of migratory stopover sites as flight feather molt staging areas: a review for neotropical migrants. Biological Conservation 106:45-56.

Loria, D. E., and F. R. Moore. 1990. Energy demands of migration on red-eyed vireos, Vireo olivaceus. Behavioral Ecology 1:24-35.

MacArthur, R. H., and A. T. MacArthur. 1974. On the use of mist nets for population studies of birds. Proceedings from the National Academy of Sciences 71:3230-3233.

Maceda-Veiga, A., S. Albacete, M. Carles-Tolrá, J. Pujade-Villar, J. Máca, and R. Mac Nally. 2021. Streams and rural abandonment are related to the summer activity of the invasive 
pest Drosophila suzukii in protected European forests. Forest Ecology and Management 485:118942.

Major, M., and A. Desrochers. 2012. Avian use of early-successional boreal forests in the postbreeding period. Auk 129:419-426.

Mannan, R. W., M. L. Morrison, and E. C. Meslow. 1984. Comment: the use of guilds in forest bird management. Wildlife Society Bulletin 12:426-430.

Manzur, M. I., and S. P. Courtney. 1984. Influence of insect damage in fruits of hawthorn on bird foraging and seed dispersal. Oikos 43:265-270.

Marques, J. T., M. J. Ramos Pereira, T. A. Marques, C. D. Santos, J. Santana, P. Beja, and J. M. Palmeirim. 2013. Optimizing sampling design to deal with mist-net avoidance in Amazonian birds and bats. PLoS ONE 8(9):e74505.

Marshall, M. R., J. A. DeCecco, A. B. Williams, G. A. Gale, and R. J. Cooper. 2003. Use of regenerating clearcuts by late-successional bird species and their young during the postfledging period. Forest Ecology and Management 183:127-135.

Martin, T. E. 1985. Selection of second-growth woodlands by frugivorous migrating birds in Panama: an effect of fruit size and plant density? Journal of Tropical Ecology 1:157-170. McCarty, J. P., D. J. Levey, C. H. Greenberg, and S. Sargent. 2002. Spatial and temporal variation in fruit use by wildlife in a forested landscape. Forest Ecology and Management $164: 277-291$.

McDermott, M. E., and P. B. Wood. 2010. Influence of cover and food resource variation on post-breeding bird use of timber harvests with residual canopy trees. Wilson Journal of Ornithology 122:545-555. 
McDermott, M. E., and P. B. Wood. 2011. Post-breeding bird responses to canopy tree retention, stand size, and edge in regenerating Appalachian hardwood stands. Forest Ecology and Management 262:547-554.

McDiarmid, R. W., R. E. Ricklefs, and M. S. Foster. 1977. Dispersal of Stemmadenia donnellsmithii (Apocynaceae) by birds. Biotropica 9:9-25.

McKinnon, E. A., T. Kurt Kyser, and B. J. M. Stutchbury. 2017. Does the proportion of arthropods versus fruit in the diet influence overwintering condition of an omnivorous songbird? Journal of Field Ornithology 88:65-79.

McWilliams, S. R., C. Guglielmo, B. Pierce, and M. Klaassen. 2004. Flying, fasting, and feeding in birds during migration: a nutritional and physiological ecology perspective. Journal of Avian Biology 35:377-393.

Mitchell, C. E., and A. G. Power. 2003. Release of invasive plants from fungal and viral pathogens. Nature 421:625-627.

Mitsui, H., K. H. Takahashi, and M. T. Kimura. 2006. Spatial distributions and clutch sizes of Drosophila species ovipositing on cherry fruits of different stages. Population Ecology 48:233-237.

Moermond, T. C., and J. S. Denslow. 1985. Neotropical avian frugivores: patterns of behavior, morphology, and nutrition, with consequences for fruit selection. Ornithological Monographs 36:865-897.

Moore, F. R. 2000. Stopover ecology of Nearctic-Neotropical landbird migrants: habitat relations and conservation implications. Studies in Avian Biology 20:1-3.

Moore, F. R. 2018. Biology of landbird migrants: a stopover perspective. Wilson Journal of Ornithology 130:1-12. 
Moore, F. R., and D. A. Aborn. 2000. Mechanisms of en route habitat selection: how do migrants make habitat decisions during stopover? Studies in Avian Biology 20:34-42.

Moore, F. R., S. A. Gauthreaux Jr., P. Kerlinger, and T. R. Simons. 1995. Habitat requirements during migration: important link in conservation. Pages 121-144 in T. E. Martin and D. M. Finch, editors. Ecology and management of neotropical migratory birds: a synthesis and review of critical issues. Oxford University Press, New York, New York, USA.

Moore, F. R., and P. Kerlinger. 1991. Nocturnality, long-distance migration, and ecological barriers. Pages 1122-1129 in B. D. Bell, editor. Acta XX Congressus Internationalis Ornithologici. New Zealand Ornithological Congress Trust Board, Wellington, NZ.

Moore, F. R., and W. Yong. 1991. Evidence of food-based competition among passerine migrants during stopover. Behavioral Ecology and Sociobiology 28:85-90.

Morin, R. S., A. M. Liebhold, K. W. Gottschalk, D. B. Twardus, R. E. Acciavatti, R. L. White, S. B. Horsley, W. D. Smith, and E. R. Luzader. 2006. Analysis of forest health monitoring surveys on the Allegheny National Forest (1998-2001). General Technical Report NE339. U.S. Forest Service, Northeastern Research Station, Newtown Square, Pennsylvania, USA.

Morrison, M. L. 1986. Bird populations as indicators of environmental change. Pages 429-445 in R. F. Johnston, editor. Current Ornithology. Plenum, New York, New York, USA.

Morse, D. H., and A. F. Poole. 2020. Black-throated green warbler (Setophaga virens), version 1.0 in P. G. Rodewald, editor. Birds of the world. Cornell Lab of Ornithology, Ithaca, New York, USA. 
Mudrzynski, B. M., and C. J. Norment. 2013. Influence of habitat structure and fruit availability on use of a northeastern stopover site by fall songbirds. Wilson Journal of Ornithology $125: 744-754$.

Mulvihille, R. S., R. C. Leberman, and A. J. Leppold. 2004. Relationships aming body mass, fat, wing length, age, and sex for 170 species of birds banded at Powdermill Nature Reserve. Eastern Bird Banding Association Monograph no. 1.

Murphy, M. E. 1996. Energetics and nutrition of molt. Pages 158-198 in Carey C., editor. Avian energetics and nutritional ecology. Springer, Boston, Massachusetts, USA.

Murphy, M. E., and J. R. King. 1992. Energy and nutrient use during moult by White-crowned Sparrows Zonotrichia leucophrys gambelii. Ornis Scandinavica 23:304-313.

Newton, I. 1966. The moult of the bullfinch Pyrrhula pyrrhula. Ibis 108:41-67.

Nudds, T. D. 1977. Quantifying the vegetative structure of wildlife cover. Wildlife Society Bulletin 5:113-117.

Oguchi, Y., R. J. Smith, and J. C. Owen. 2017. Fruits and migrant health: consequences of stopping over in exotic- vs. native-dominated shrublands on immune and antioxidant status of Swainson's Thrushes and Gray Catbirds. Condor 119:800-816.

Packett, D. L., and J. B. Dunning. 2009. Stopover habitat selection by migrant landbirds in a fragmented forest-agricultural landscape. Auk 126:579-589.

Pagen, R. W., F. R. Thompson III, and D. E. Burhans. 2000. Breeding and post-breeding habitat use by forest migrant songbirds in the Missouri Ozarks. Condor 102:738-747.

Parrish, J. D. 1997. Patterns of frugivory and energetic condition in Nearctic landbirds during autumn migration. Condor 99:681-697. 
Parrish, J. D. 2000. Behavioral, energetic, and conservation implications of foraging plasticity during migration. Studies in Avian Biology 20:53-70.

Parrish, J. D., M. L. Whitman, and S. B. Comings. 1994. A facilitated method for collection of fecal samples from mist-netted birds. North American Bird Bander 19:49-51.

Peig, J., and A. J. Green. 2009. New perspectives for estimating body condition from mass/length data: the scaled mass index as an alternative method. Oikos 118:1883-1891.

Pelton, E., C. Gratton, R. Isaacs, S. Van Timmeren, A. Blanton, and C. Guédot. 2016. Earlier activity of Drosophila suzukii in high woodland landscapes but relative abundance is unaffected. Journal of Pest Science 89:725-733.

Petit, D. R. 2000. Habitat use by landbirds along Nearctic-neotropical migration routes: implications for conservation and stopover habitats. Studies in Avian Biology 20:15-33.

PGC (Pennsylvania Game Commission). 2014. State Game Lands No. 86. < https://www.pgc.pa.gov/HuntTrap/StateGameLands/Documents/SGL\%20Maps/SGL_0 86.pdf>. Accessed 29 Apr 2021.

PGC-PFBS (Pennsylvania Game Commission and Pennsylvania Fish \& Boat Commission). 2015. Pennsylvania Wildlife Action Plan 2015-2025, Species of Greatest Conservation Need Species Accounts, Appendix 1.4A-Birds. Harrisburg, Pennsylvania, USA.

Piper, J. K. 1986. Seasonality of fruit characters and seed removal. Oikos 46:303-310.

Pintor, L. M., and J. E. Byers. 2015. Do native predators benefit from non-native prey? Ecology Letters 18:1174-1180.

Plummer, M. 2003. JAGS: a program for analysis of Bayesian graphical models using Gibbs sampling. Proceedings of the 3rd International Workshop on Distributed Statistical Computing 124:1-10. 
Porneluzi, P. A., R. Brito-Aguilar, R. L. Clawson, and J. Faaborg. 2014. Long-term dynamics of bird use of clearcuts in post-fledging period. Wilson Journal of Ornithology 126:623634.

Pothoven, S. A., T. F. Nalepa, P. J. Schneeberger, and S. B. Brandt. 2001. Changes in diet and body condition of lake whitefish in Southern Lake Michigan associated with changes in benthos. North American Journal of Fisheries Management 21:876-883.

Prior, K. M., T. H. Q. Powell, A. L. Joseph, and J. J. Hellmann. 2015. Insights from community ecology into the role of enemy release in causing invasion success: the importance of native enemy effects. Biological Invasions 17:1283-1297.

Pyle, P. 1997. Identification guide to North American birds: Columbidae to Ploceidae. Slate Creek Press, Bolina, California, USA.

R Core Team. 2021. R: A language and environment for statistical computing. R Foundation for Statistical Computing, Vienna, Austria.

Ralph, C. J., E. H. Dunn, W. J. Peach, and C. M. Handel. 2004. Recommendations for the use of mist nets for inventory and monitoring of bird populations. Studies in Avian Biology 29:187-196.

Ralph, C., S. Nagata, and J. Ralph. 1985. Analysis of droppings to describe diets of small birds. Journal of Field Ornithology 56:165-174.

Rappole, J. H., and K. Ballard. 1987. Postbreeding movements of selected species of birds in Athens, Georgia. Wilson Bulletin 99:475-480.

Robel, R. J., B. M. Press, B. L. Henning, K. W. Johnson, H. D. Blocker, and K. E. Kemp. 1995. Nutrient and energetic characteristics of sweepnet-collected invertebrates. Journal of Field Ornithology 66:44-53. 
Roche, D. P., S. H. Stoleson, and C. M. Lituma. 2021. Invasion of eastern deciduous forests by the spotted wing Drosophila: impacts and knowledge gaps. Wildlife Society Bulletin:10.1002/wsb.1234.

Rodewald, P. G., and M. C. Brittingham. 2004. Stopover habitats of landbirds during fall: use of edge-dominated and early-successional forests. Auk 121:1040-1055.

Rodewald, A. D., and A. C. Vitz. 2005. Edge- and area-sensitivity of shrubland birds. Journal of Wildlife Management 69:681-688.

Rosenberg, K. V, and R. J. Cooper. 1990. Approaches to avian diet analysis. Studies in Avian Biology 13:80-90.

Rotenberry, J. T. 1980. Dietary relationships among shrub-steppe passerine birds: competition or opportunism in a variable environment. Ecological Monographs 50:93-110.

Ruhl, P. J., E. A. Flaherty, and J. B. Dunning. 2020a. Using stable isotopes of plasma, red blood cells, feces, and feathers to assess mature-forest bird diet during the post-fledging period. Canadian Journal of Zoology 98:39-46.

Ruhl, P. J., K. F. Kellner, and J. B. Dunning. 2020b. Ecological factors explain habitat associations of mature-forest songbirds in regenerating forest clearcuts. Wilson Journal of Ornithology 132:145-158.

Sallabanks, R. 1993. Hierarchical mechanisms of fruit selection by an avian frugivore. Ecology 74:1326-1336.

Sallabanks, R., and S. P. Courtney. 1992. Frugivory, seed predation, and insect-vertebrate interactions. Annual Review of Entomology 37:377-400.

Schaub, M., and L. Jenni. 2000. Fuel deposition of three passerine bird species along the migration route. Oecologia 122:306-317. 
Schaub, M., and L. Jenni. 2001. Stopover durations of three warbler species along their autumn migration route. Oecologia 128:217-227.

Schemske, D. W., and N. Brokaw. 1981. Treefalls and the distribution of understory birds in a tropical forest. Ecology 62:938-945.

Showalter, C. R., and R. C. Whitmore. 2002. The effect of gypsy moth defoliation on cavitynesting bird communities. Forest Science 48:273-281.

Sillett, T. S., and R. T. Holmes. 2002. Variation in survivorship of a migratory songbird throughout its annual cycle. Journal of Animal Ecology 71:296-308.

Smith, S. B. 2013. A physiological assessment of seasonal differences in spring and autumn migration stopover at Braddock Bay, Lake Ontario. Condor 115:273-279.

Smith, R. J., and M. I. Hatch. 2017. Loss of southern arrowwoods (Viburnum dentatum) is associated with changes in species composition and mass gain by spring migrants using early successional habitat. Wilson Journal of Ornithology 129:247-258.

Smith, R. J., M. I. Hatch, D. A. Cimprich, and F. R. Moore. 2020. Gray catbird (Dumetella carolinensis), version 1.0 in A. F. Poole, editor. Birds of the world. Cornell Lab of Ornithology, Ithaca, New York, USA.

Smith, S. B., K. H. McPherson, J. M. Backer, B. J. Pierce, D. W. Podlesak, and S. R. McWilliams. 2007. Fruit quality and consumption by songbirds during autumn migration. Wilson Journal of Ornithology 119:419-428.

Smith, S. B., and S. R. McWilliams. 2010. Patterns of fuel use and storage in migrating passerines in relation to fruit resources at autumn stopover sites. Auk 127:108-118. 
Smith, S. B., A. C. Miller, C. R. Merchant, and A. F. Sankoh. 2015. Local site variation in stopover physiology of migrating songbirds near the south shore of Lake Ontario is linked to fruit availability and quality. Conservation Physiology 3:cov036.

Snow, D. W. 1971. Evolutionary aspects of fruit-eating by birds. Ibis 113:194-202.

Stoleson, S. H. 2013. Condition varies with habitat choice in postbreeding forest birds. Auk 130:417-428.

Streby, H. M., S. M. Peterson, T. L. McAllister, and D. E. Andersen. 2011. Use of earlysuccessional managed northern forest by mature-forest species during the post-fledging period. Condor 113:817-824.

Streby, H. M., S. M. Peterson, B. Scholtens, A. P. Monroe, and D. E. Andersen. 2013. The ovenbird (Seiurus aurocapilla) as a model for testing food-value theory. American Midland Naturalist 169:214-220.

Strong, C. M., D. R. Brown, and P. C. Stouffer. 2005. Frugivory by wintering hermit thrush in Louisiana. Southeastern Naturalist 4:627-638.

Stutchbury, B. J. M., E. A. Gow, T. Done, M. MacPherson, J. W. Fox, and V. Afanasyev. 2011. Effects of post-breeding moult and energetic condition on timing of songbird migration into the tropics. Proceedings of the Royal Society B: Biological Sciences 278:131-137.

Tellería, J. L., I. L. A. Hera, and J. Pérez-Tris. 2013. Morphological variation as a tool for monitoring bird populations: A review. Ardeola 60:191-224.

Thistlewood, H. M. A. B. Rozema, and S. Acheampong. 2019. Infestation and timing of use of non-crop plants by Drosophila suzukii (Matsumura) (Diptera: Drosophilidae) in the Okanagan Basin, Canada. Canadian Entomologist 151:34-48. 
Thompson, J. N., and M. F. Willson. 1979. Evolution of temperate fruit/bird interactions: phenological strategies. Evolution 33:973-982.

Tietz, J. R., and M. D. Johnson. 2007. Stopover ecology and habitat selection of juvenile Swainson's thrushes during fall migration along the northern California coast. Condor 109:795-807.

Tochen, S., J. M. Woltz, D. T. Dalton, J. C. Lee, N. G. Wiman, and V. M. Walton. 2016. Humidity affects populations of Drosophila suzukii (Diptera: Drosophilidae) in blueberry. Journal of Applied Entomology 140:47-57.

Torchin, M. E., K. D. Lafferty, A. P. Dobson, V. J. McKenzie, and A. M. Kuris. 2003. Introduced species and their missing parasites. Nature 421:628-630.

Traveset, A., M. F. Willson, and J. C. Gaither. 1995. Avoidance by birds of insect-infested fruits of Vaccinium ovalifolium. Oikos 73:381-386.

Turcotte, R. M., C. Larcenaire, R. Long, D. K. H. Martin, and L. Barringer. 2018. The spotted wing drosophila, Drosophila suzukii (Diptera: Drosophilidae): a new pest of concern for black cherry, Prunus serotina, on the High Allegheny Plateau in Pennsylvania.

Entomological News 127:390-399.

U.S. Forest Service. 2007. Allegheny National Forest record of decision for final environmental impact statement and the land and resource management plan. Warren, PA.

U.S. Forest Service. 2019. Allegheny National Forest GIS datasets. <https://www.fs.usda.gov/main/allegheny/landmanagement/gis>. Accessed 30 April 2020.

Valburg, L. K. 1992a. Eating infested fruits: interactions in a plant-disperser-pest triad. Oikos $65: 25-28$. 
Valburg, L. K. 1992b. Feeding preferences of common bush-tanagers for insect-infested fruits: avoidance or attraction? Oikos 65:29-33.

Van Volkom, K. S., L. G. Harris, and J. A. Dijkstra. 2021. The influence of invasive ascidian diets on the growth of the sea star Henricia sanguinolenta. Journal of the Marine Biological Association of the United Kingdom 101:151-157.

Vega Rivera, J. H., W. J. McShea, J. H. Rappole, and C. A. Haas. 1998a. Pattern and chronology of prebasic molt for the wood thrush and its relation to reproduction and migration departure. Wilson Bulletin 110:384-392.

Vega Rivera, J. H., J. H. Rappole, W. J. McShea, and C. A. Haas. 1998b. Wood thrush postfledging movements and habitat use in northern Virginia. Condor 100:69-78.

Verble-Pearson, R., and S. Pearson. 2016. European fire ant presence decreases native arboreal insect abundance in Acadia National Park, Maine, USA. Natural Areas Journal 36:162165.

Vitz, A. C., and A. D. Rodewald. 2006. Can regenerating clearcuts benefit mature-forest songbirds? An examination of post-breeding ecology. Biological Conservation 127:477486.

Vitz, A. C., and A. D. Rodewald. 2007. Vegetative and fruit resources as determinants of habitat use by mature-forest birds during the postbreeding period. Auk 124:494-507.

Walsh, D. B., M. P. Bolda, R. E. Goodhue, A. J. Dreves, J. Lee, D. J. Bruck, V. M. Walton, S. D. O’Neal, and F. G. Zalom. 2011. Drosophila suzukii (Diptera: Drosophilidae): invasive pest of ripening soft fruit expanding its geographic range and damage potential. Journal of Integrated Pest Management 2:G1-G7. 
Wang, Y., and F. R. Moore. 2005. Long-distance bird migrants adjust their foraging behavior in relation to energy stores. Acta Zoologica Sinica 51:12-23.

Wang, X. G., T. J. Stewart, A. Biondi, B. A. Chavez, C. Ingels, J. Caprile, J. A. Grant, V. M. Walton, and K. M. Daane. 2016. Population dynamics and ecology of Drosophila suzukii in Central California. Journal of Pest Science 89:701-712.

Warton, D. I., R. A. Duursma, D. S. Falster, and S. Taskinen. 2012. smatr 3- an R package for estimation and inference about allometric lines. Methods in Ecology and Evolution $3: 257-259$.

White, J. D., T. Gardali, F. R. Thompson III, and J. Faaborg. 2005. Resource selection by juvenile Swainson's thrushes during the postfledging period. Condor 107:388-401.

Wolfe, J. D., M. D. Johnson, and C. J. Ralph. 2014. Do birds select habitat or food resources? Nearctic-neotropic migrants in northeastern Costa Rica. PLoS ONE 9(1):e86221.

Woltz, J. M., and J. C. Lee. 2017. Pupation behavior and larval and pupal biocontrol of Drosophila suzukii in the field. Biological Control 110:62-69.

Woodrey, M. S., and F. R. Moore. 1997. Age-related differences in the stopover of fall landbird migrants on the coast of Alabama. Auk 114:695-707.

Yong, W., and F. R. Moore. 1997. Spring stopover of intercontinental migratory thrushes along the northern coast of the Gulf of Mexico. Auk 114:263-278. 


\section{TABLES}

Table 4.1. Sample sizes of species for each condition index (subcutaneous fat ["fat"], body molt progression ["molt"], and scaled mass index ["SMI"]) captured in regenerating harvests at Allegheny National Forest (ANF), Clear Creek State Forest (CCSF), and State Game Lands (SGL) 86, Pennsylvania, during the post-breeding season and fall migration (Jul-Sep) in 2019 and 2020. The morphological measurement most strongly correlated on the log-log scale with body mass and used in scaled major axis (SMA) regression is specified. The coefficient of determination $\left(R^{2}\right)$ for the SMA regression using the morphological measurement and body mass is also specified. The SMA regression slope was used to calculate SMI values for individual birds.

\begin{tabular}{|c|c|c|c|c|c|c|c|c|}
\hline \multirow[b]{2}{*}{ Common name } & \multirow[b]{2}{*}{ Scientific name } & \multirow[b]{2}{*}{ Family } & \multirow[b]{2}{*}{ Guild } & \multicolumn{3}{|c|}{ Number of birds } & \multirow[b]{2}{*}{ Measurement } & \multirow[b]{2}{*}{ SMA R ${ }^{2}$} \\
\hline & & & & Fat & Molt & SMI & & \\
\hline Cedar waxwing & Bombycilla cedrorum & Bombycillidae & Frugivore & 73 & 73 & 73 & Culmen & 0.02 \\
\hline Eastern towhee & Pipilo erythrophthalmus & Passerellidae & Frugivore & 52 & 52 & 52 & Tarsus & $0.26^{\mathrm{a}}$ \\
\hline Gray catbird & Dumetella carolinensis & Mimidae & Frugivore & 184 & 183 & 182 & Wing & $0.06^{\mathrm{a}}$ \\
\hline Ovenbird & Seiurus aurocapilla & Parulidae & Frugivore & 67 & 67 & 66 & Culmen & $0.06^{\mathrm{a}}$ \\
\hline Red-eyed vireo & Vireo olivaceus & Vireonidae & Frugivore & 125 & 125 & 125 & Wing & $0.04^{\mathrm{a}}$ \\
\hline Song sparrow & Melospiza melodia & Passerellidae & Frugivore & 72 & 72 & 69 & Tarsus & $0.07^{\mathrm{a}}$ \\
\hline Black-capped chickadee & Poecile atricapillus & Paridae & Non-frugivore & 69 & 69 & 69 & Wing & $0.1^{\mathrm{a}}$ \\
\hline Black-throated blue warbler & Setophaga caerulescens & Parulidae & Non-frugivore & 128 & 128 & 128 & Wing & $0.16^{\mathrm{a}}$ \\
\hline $\begin{array}{l}\text { Black-throated green } \\
\text { warbler }\end{array}$ & Setophaga virens & Parulidae & Non-frugivore & 104 & 104 & 103 & Wing & $0.16^{\mathrm{a}}$ \\
\hline Chestnut-sided warbler & Setophaga pensylvanica & Parulidae & Non-frugivore & 402 & 400 & 402 & Wing & $0.08^{\mathrm{a}}$ \\
\hline Common yellowthroat & Geothlypis trichas & Parulidae & Non-frugivore & 174 & 173 & 170 & Wing & $0.13^{\mathrm{a}}$ \\
\hline Hooded warbler & Setophaga citrina & Parulidae & Non-frugivore & 69 & 69 & 67 & Wing & 0.02 \\
\hline Magnolia warbler & Setophaga magnolia & Parulidae & Non-frugivore & 138 & 138 & 137 & Wing & $0.07^{\mathrm{a}}$ \\
\hline
\end{tabular}

adenotes a significant relationship $(P<0.05)$ 
Table 4.2. Final covariates used to model bird condition indices (subcutaneous fat ["fat"], body molt progression ["molt"], and scaled mass index ["SMI"]) and proportions of frugivore fecal samples containing evidence of Allegheny blackberry (Rubus allegheniensis) fruit consumption ("fecal") at mist nets in regenerating harvests during the post-breeding season and fall migration (Jul-Sep) at Allegheny National Forest (ANF), Clear Creek State Forest (CCSF), and State Game Lands (SGL) 86, Pennsylvania, in 2019 and 2020. Multiple measures were pooled for a single value of each covariate at each mist net and checked for collinearity ( $r \geq 0.7)$. All covariates were included in a global model for each bird variable, which were then excluded from final models using a stepwise removal process.

\begin{tabular}{|c|c|c|c|}
\hline $\begin{array}{l}\text { Covariate } \\
\text { category }\end{array}$ & $\begin{array}{l}\text { Covariate } \\
\text { name }\end{array}$ & Description & Analyses \\
\hline Date & date & Ordinal date of first bird banding day of each 2-day banding session & fat, molt, SMI \\
\hline Fruit & fruit $^{\mathrm{a}}$ & Count of Allegheny blackberry (Rubus allegheniensis) fruits at each mist net & fat, molt, SMI, fecal \\
\hline SWD & swd & $\begin{array}{l}\text { Count of spotted wing Drosophila (Drosophila suzukii, SWD)/trap/24 hrs at each } \\
\text { mist net }\end{array}$ & fat, molt, SMI, fecal \\
\hline SWD & infest & Count of adult, larval, and pupal SWD/g of $R$. allegheniensis fruit at each mist net & fat, molt, SMI, fecal \\
\hline Veg & cover & Coefficient of variation for cover score values at $2-2.5 \mathrm{~m}$ at each mist net & fat, molt, SMI \\
\hline
\end{tabular}


Table 4.3. Final regression models for bird condition indices (subcutaneous fat ["fat"], body molt score ["molt"], scaled mass index ["SMI"]) and proportions of frugivore fecal samples containing evidence of Allegheny blackberry (Rubus allegheniensis) fruit consumption ("fecal") at mist nets during the post-breeding season and fall migration (Jul-Sep) in regenerating harvests at Allegheny National Forest (ANF), Clear Creek State Forest (CCSF), and State Game Lands (SGL) 86, Pennsylvania, in 2019 and 2020. Each final model was created with a stepwise removal process of covariates from global models containing 5 (condition indices) or 3 (fecal) initial covariates. If no covariates were retained for a species, no model is presented. Posterior estimates and $90 \%$ credible intervals (CIs) are given for each covariate's slope coefficient.

\begin{tabular}{|c|c|c|}
\hline Species & $\begin{array}{l}\text { Response } \\
\text { variable }\end{array}$ & Covariates (Estimate $[90 \% \mathrm{CI}]$ ) \\
\hline \multicolumn{3}{|l|}{ Frugivore species } \\
\hline Gray catbird & Fat & date $(2.09[1.33,2.95]) ;$ infest $(0.71[0.14,1.30])$ \\
\hline Ovenbird $^{\mathrm{a}}$ & Fat & date $(4.43[0.85,8.72]) ; \operatorname{swd}(2.30[1.05,3.88])$; cover $(1.36[0.09,2.77])$ \\
\hline Red-eyed vireo ${ }^{a}$ & Fat & date $(2.69[1.73,3.78])$; fruit $(1.30[0.47,2.16])$; cover $(0.59[0.13,1.08])$ \\
\hline \multicolumn{3}{|l|}{ Non-frugivore species } \\
\hline Black-capped chickadee & Fat & $\operatorname{swd}(-5.71[-12.36,-0.99])$ \\
\hline Black-throated blue warbler & Fat & date $(3.77[1.31,7.72]) ;$ cover $(1.62[0.32,3.64])$ \\
\hline Black-throated green warbler & Fat & date $(1.93[0.62,3.71]) ;$ infest $(-6.69[-15.62,-0.86])$ \\
\hline Chestnut-sided warbler & Fat & date $(0.45[0.14,0.76])$ \\
\hline Common yellowthroat & Fat & date $(1.21[0.67,1.84]) ;$ swd $(-0.89[-1.83,-0.15])$ \\
\hline Magnolia warbler ${ }^{\mathrm{a}}$ & Fat & date $(2.55[1.42,3.91]) ;$ swd $(0.50[0.08,0.92])$ \\
\hline \multicolumn{3}{|l|}{ Frugivore species } \\
\hline Cedar waxwing ${ }^{\mathrm{a}}$ & Molt & date $(0.59[0.07,1.11]) ; \operatorname{swd}(0.82[0.30,1.39])$ \\
\hline Gray catbird & Molt & date $(1.42[0.97,1.91]) ;$ fruit $(0.53[0.09,0.98])$ \\
\hline Ovenbird $^{\text {a }}$ & Molt & date $(2.27[1.23,3.49])$ \\
\hline Red-eyed vireo & Molt & date $(2.86[2.09,3.78]) ;$ infest $(0.50[0.02,1.04])$ \\
\hline Song sparrow ${ }^{\mathrm{a}}$ & Molt & date $(0.64[0.18,1.13]) ; \operatorname{swd}(-0.90[-1.77,-0.20])$; cover $(0.58[0.15,1.04])$ \\
\hline \multicolumn{3}{|l|}{ Non-frugivore species } \\
\hline Black-capped chickadee ${ }^{a}$ & Molt & infest $(-1.93[-2.99,-1.08])$ \\
\hline Black-throated blue warbler & Molt & date $(1.01[0.53,1.57])$ \\
\hline Black-throated green warbler ${ }^{\mathrm{a}}$ & Molt & date $(0.90[0.52,1.30])$ \\
\hline Chestnut-sided warbler & Molt & date $(1.14[0.90,1.40])$ \\
\hline Common yellowthroat & Molt & date $(1.62[1.25,2.02])$ \\
\hline Hooded warbler ${ }^{\mathrm{a}}$ & Molt & date $(1.37[0.71,2.10])$; cover $(-0.59[-1.16,-0.04])$ \\
\hline
\end{tabular}




\begin{tabular}{|c|c|c|}
\hline $\begin{array}{l}\text { Magnolia warbler } \\
\text { Wood warblers }\end{array}$ & $\begin{array}{l}\text { Molt } \\
\text { Molt }\end{array}$ & $\begin{array}{l}\text { date }(1.02[0.45,1.60]) ; \text { fruit }(-0.52[-1.10,-0.04]) \\
\text { date }(1.14[0.96,1.32])\end{array}$ \\
\hline $\begin{array}{l}\text { Frugivore species } \\
\text { Eastern towhee } \\
\text { Gray catbird } \\
\text { Red-eyed vireo }\end{array}$ & $\begin{array}{l}\text { SMI } \\
\text { SMI } \\
\text { SMI }\end{array}$ & $\begin{array}{l}\text { swd }(0.98[0.11,1.95]) \\
\text { date }(0.95[0.45,1.39]) \\
\text { date }(0.78[0.50,1.05])\end{array}$ \\
\hline $\begin{array}{l}\text { Non-frugivore species } \\
\text { Black-capped chickadee } \\
\text { Chestnut-sided warbler }\end{array}$ & $\begin{array}{l}\text { SMI } \\
\text { SMI }\end{array}$ & $\begin{array}{l}\text { swd }(0.27[0.03,0.49]) ; \text { infest }(-0.21[-0.40,-0.02]) \\
\text { date }(-0.32[-0.42,-0.22]) ; \text { fruit }(-0.13[-0.24,-0.03]) ; \text { swd }(0.11[0.02,0.18]) \text {; } \\
\text { cover }(-0.15[-0.28,-0.03])\end{array}$ \\
\hline $\begin{array}{l}\text { Frugivores } \\
\text { Cedar waxwing } \\
\text { Eastern towhee } \\
\text { Gray catbird }\end{array}$ & $\begin{array}{l}\text { fecal } \\
\text { fecal }^{\mathrm{a}} \\
\text { fecal }^{\mathrm{a}} \\
\text { fecal }^{\mathrm{b}}\end{array}$ & $\begin{array}{l}\text { fruit }(0.20[0.04,0.36]) ; \text { infest }(0.57[0.41,0.74]) \\
\text { infest }(1.35[0.73,2.04]) \\
\text { infest }(0.71[0.11,1.36]) \\
\text { fruit }(0.65[0.26,1.08]) ; \operatorname{swd}(0.61[0.13,1.16]) ; \operatorname{infest}(1.24[0.69,1.85])\end{array}$ \\
\hline
\end{tabular}

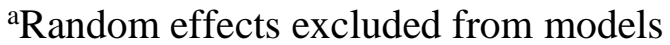

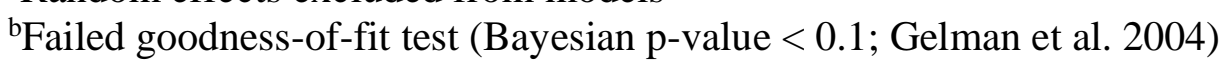




\section{FIGURES}

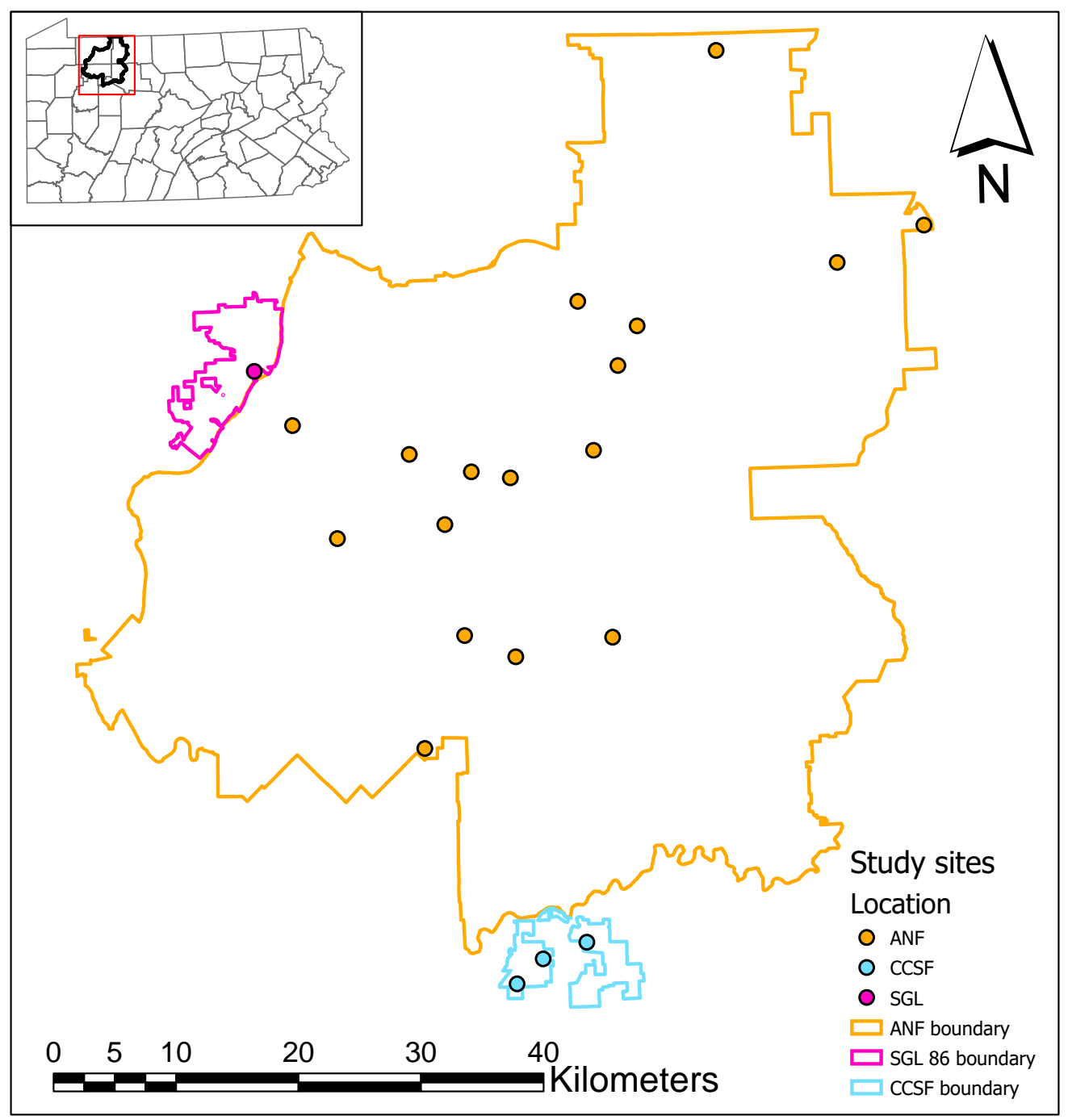

Figure 4.1. Study area used for sampling forest bird body condition and fruit consumption and spotted wing Drosophila (Drosophila suzukii) during the post-breeding season and fall in Pennsylvania in 2019 and 2020. Twenty-one sites were used across Allegheny National Forest (ANF), Clear Creek State Forest (CCSF) due south, and State Game Lands (SGL) 86 west of the ANF along the Allegheny River in northwestern Pennsylvania. 


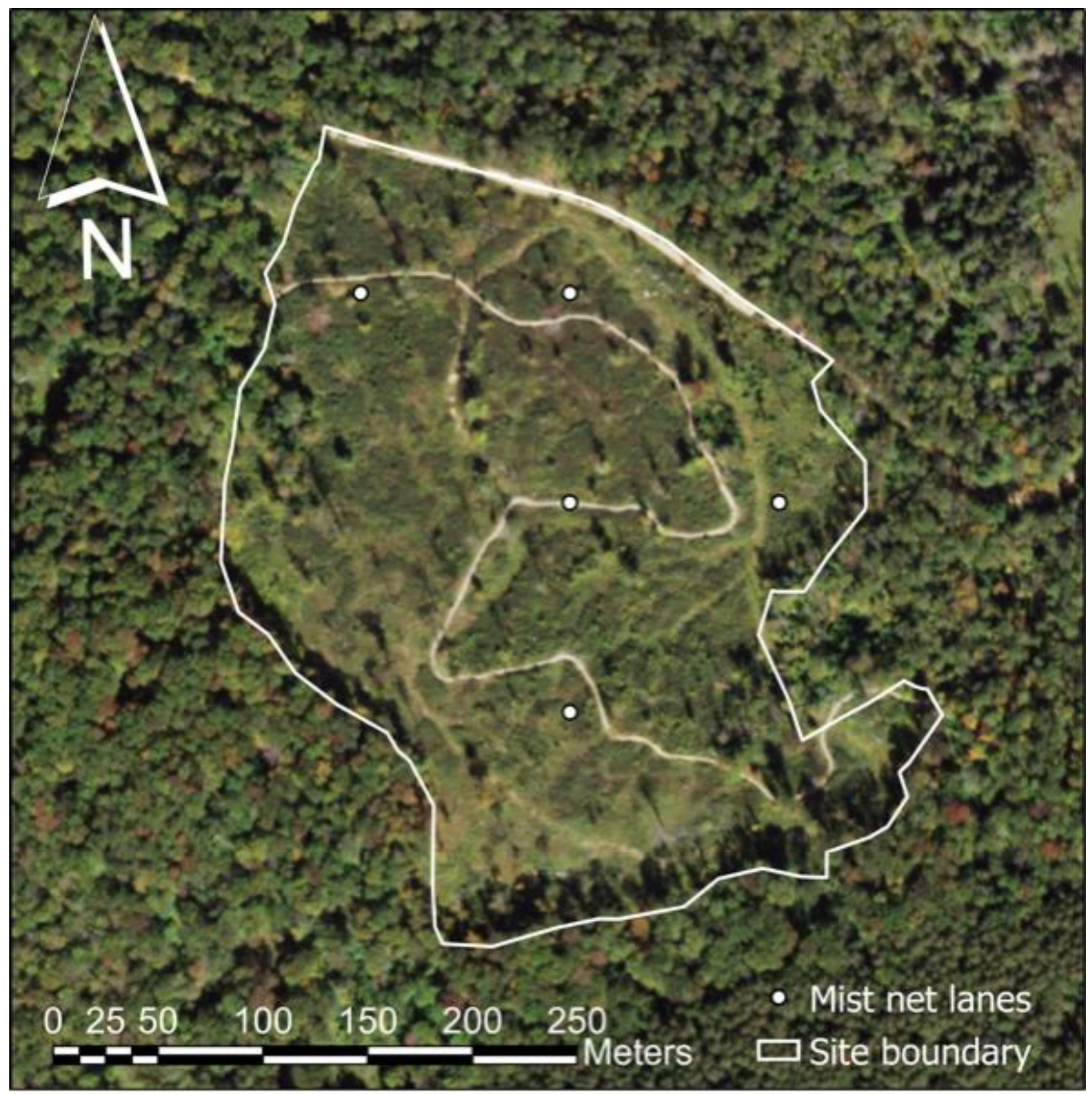

Figure 4.2. Example placement of mist nets used for sampling forest birds in regenerating timber harvests during the post-breeding season and fall migration at Allegheny National Forest (ANF), Clear Creek State Forest (CCSF), and State Game Lands (SGL) 86, Pennsylvania, in 2019 and 2020. 


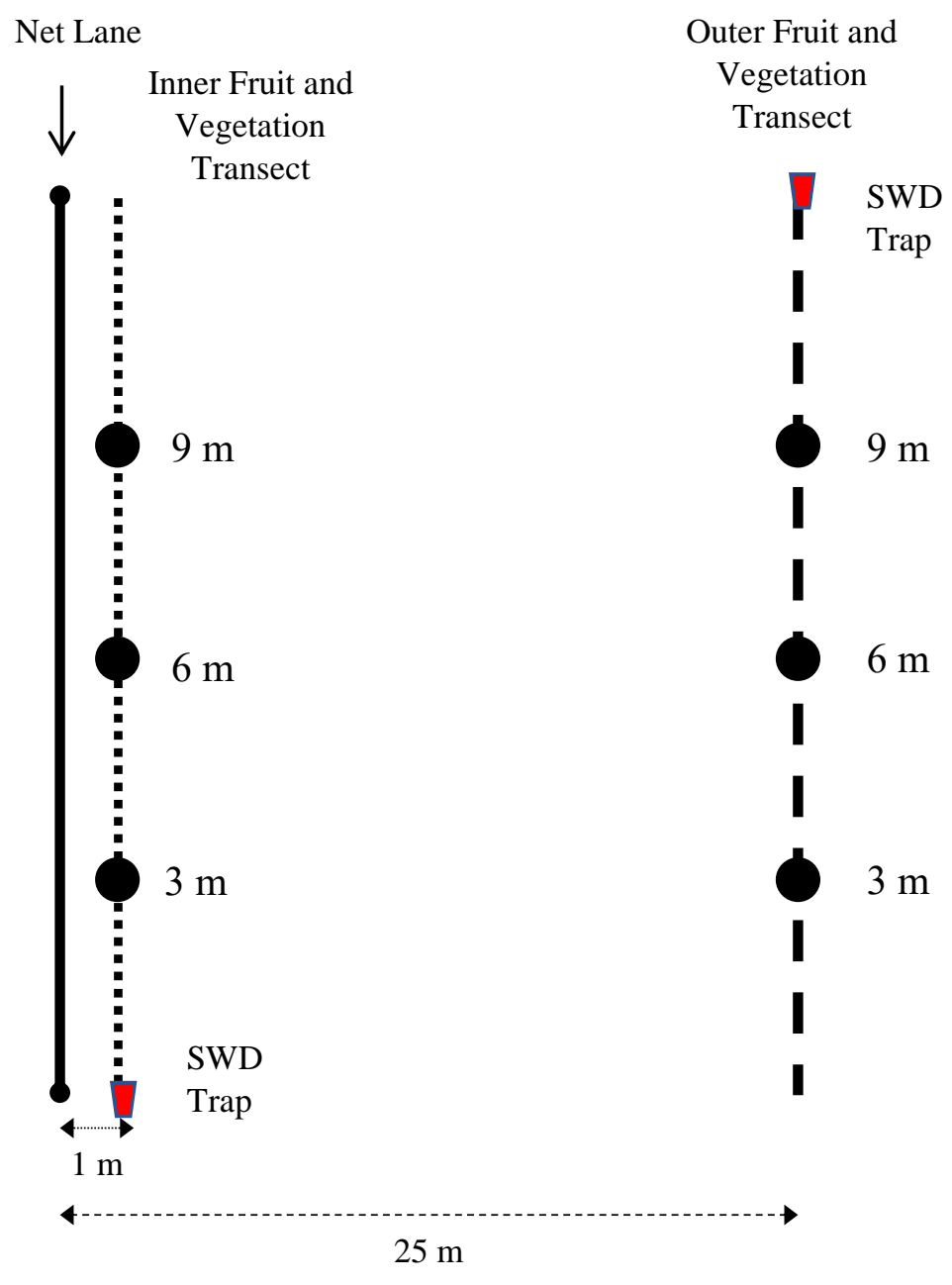

Figure 4.3. Transect survey design used to place spotted wing Drosophila (Drosophila suzukii, SWD) traps, count fruit resources, and measure vegetation structure at mist nets in regenerating timber harvests at Allegheny National Forest (ANF), Clear Creek State Forest (CCSF), and State Game Lands (SGL) 86, Pennsylvania, in 2019 and 2020. The side of the mist net each transect was placed and the side of the transect each SWD trap was placed were randomly chosen. 


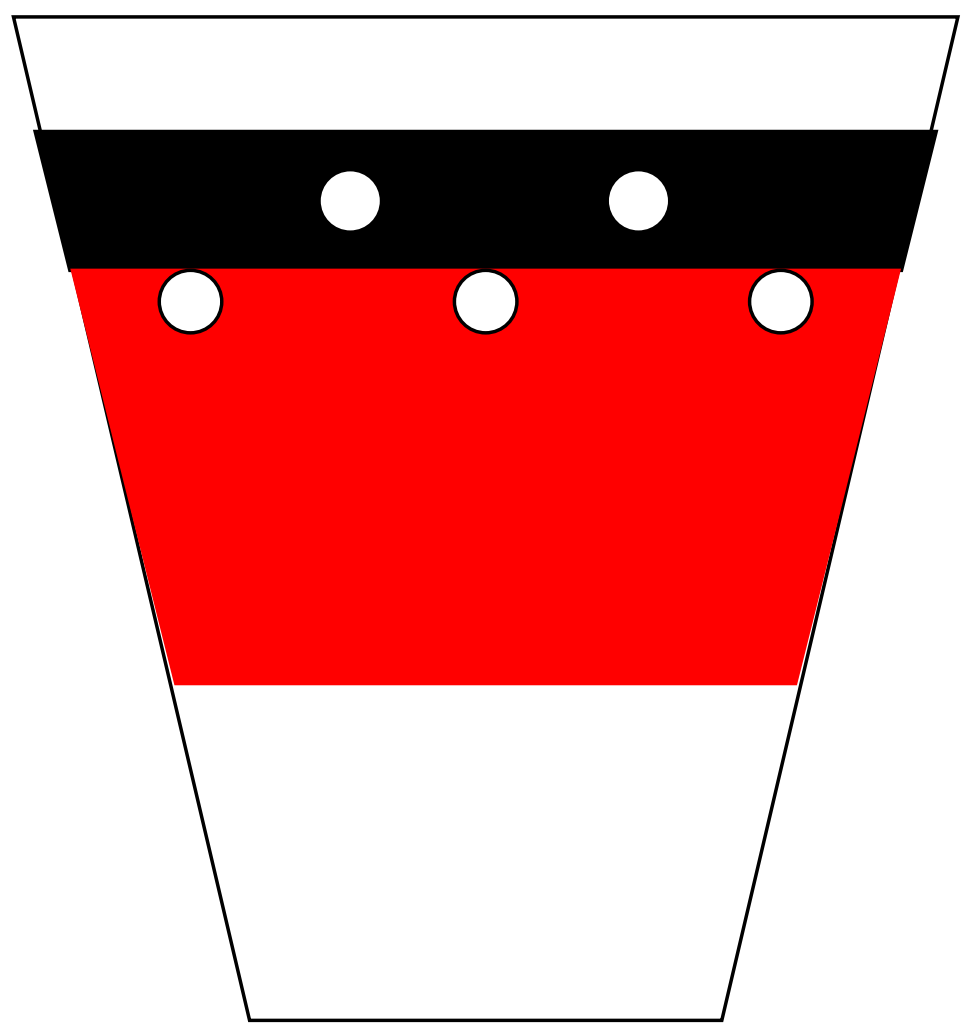

Figure 4.4. Trap design used to sample for spotted wing Drosophila (Drosophila suzukii) at mist nets during the post-breeding season and fall migration in regenerating timber harvests at Allegheny National Forest (ANF), Clear Creek State Forest (CCSF), and State Game Lands (SGL) 86, Pennsylvania, in 2019 and 2020. 

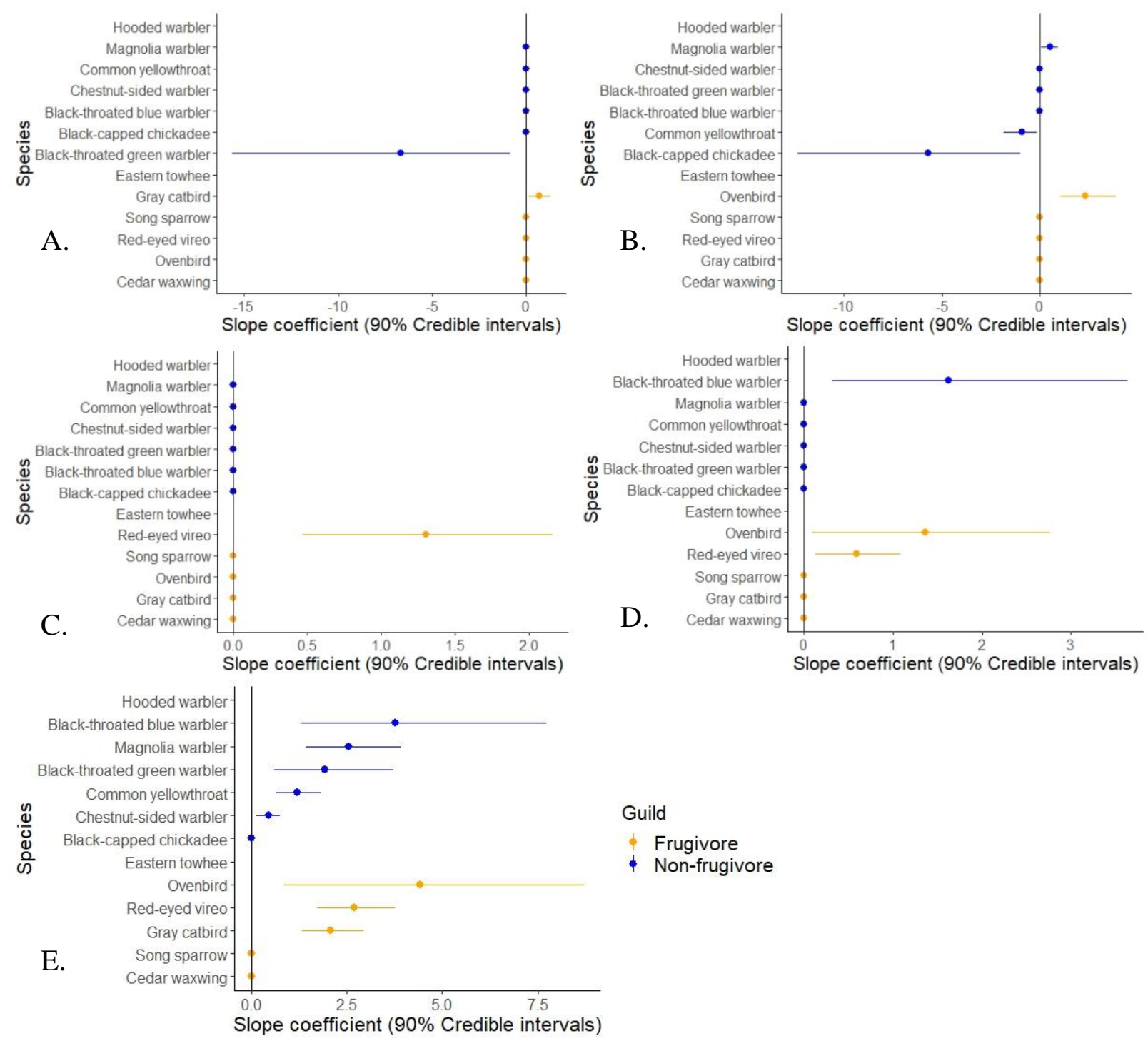

Figure 4.5. Bayesian posterior estimates for relationships between probability of the presence of subcutaneous fat and A) infestation rate of Allegheny blackberry (Rubus allegheniensis) fruits by spotted wing Drosophila (Drosophila suzukii, SWD), B) SWD trap captures, C) R. allegheniensis fruit counts, D) coefficient of variation for vertical vegetation cover, and E) ordinal date (including $90 \%$ credible intervals) for focal frugivorous and non-frugivorous bird species in regenerating harvests during the post-breeding season and fall migration (Jul-Sep) at Allegheny National Forest (ANF), Clear Creek State Forest (CCSF), and State Game Lands (SGL) 86, Pennsylvania, in 2019 and 2020. Vertical lines are fixed at 0 to represent lack of a relationship. Species for which a covariate was dropped during stepwise regression are fixed at 0 on that covariate plot. Species for which fat was not modeled are present on the plot but have no point estimate. 


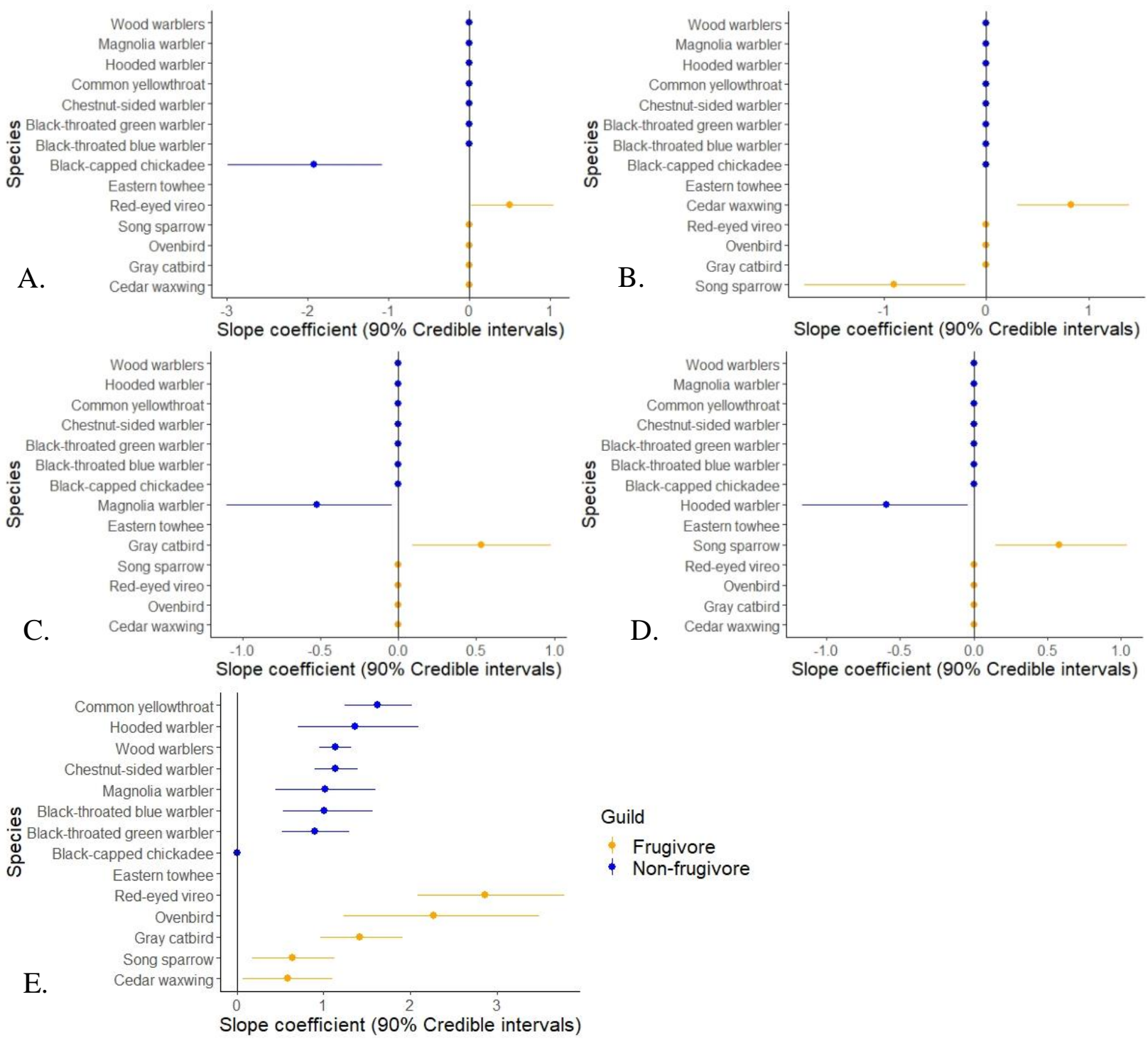

Figure 4.6. Bayesian posterior estimates for relationships between probability of being in later stages of molt progression and A) infestation rate of Allegheny blackberry (Rubus allegheniensis) fruits by spotted wing Drosophila (Drosophila suzukii, SWD), B) SWD trap captures, C) $R$. allegheniensis fruit counts, D) coefficient of variation for vertical vegetation cover, and E) ordinal date (including $90 \%$ credible intervals) for focal frugivorous bird species, non-frugivorous bird species, and all focal non-frugivorous wood warblers pooled in regenerating harvests during the post-breeding season and fall migration (Jul-Sep) at Allegheny National Forest (ANF), Clear Creek State Forest (CCSF), and State Game Lands (SGL) 86, Pennsylvania, in 2019 and 2020. Vertical lines are fixed at 0 to represent lack of a relationship. Species for which a covariate was dropped during stepwise regression are fixed at 0 on that covariate plot. Species for which molt was not modeled are present on the plot but have no point estimate. 

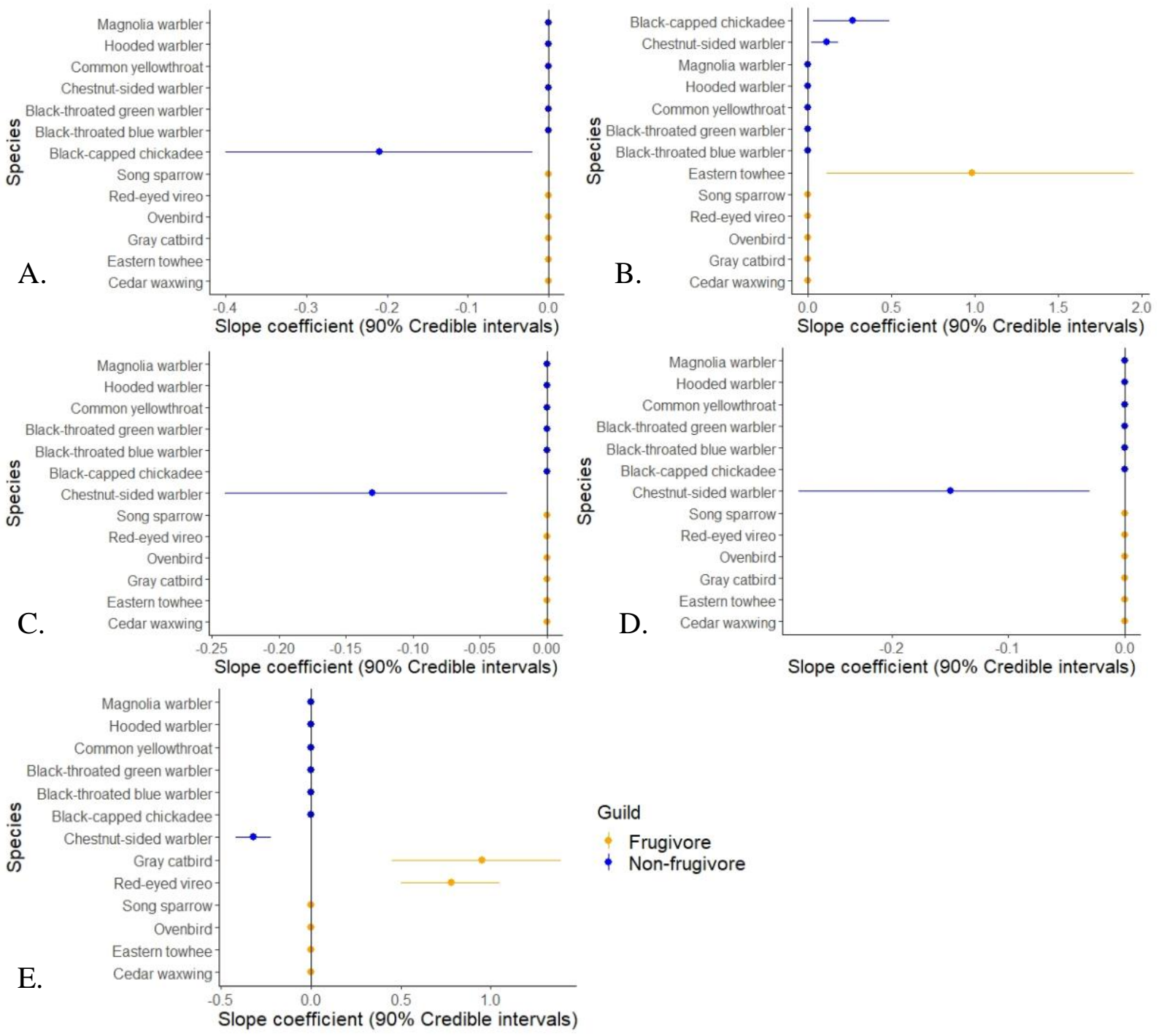

Figure 4.7. Bayesian posterior estimates for relationships between scaled mass index and A) infestation rate of Allegheny blackberry (Rubus allegheniensis) fruits by spotted wing Drosophila (Drosophila suzukii, SWD), B) SWD trap captures, C) R. allegheniensis fruit counts, D) coefficient of variation for vertical vegetation cover, and E) ordinal date (including $90 \%$ credible intervals) for focal frugivorous and non-frugivorous bird species in regenerating harvests during the post-breeding season and fall migration (Jul-Sep) at Allegheny National Forest (ANF), Clear Creek State Forest (CCSF), and State Game Lands (SGL) 86, Pennsylvania, in 2019 and 2020. Vertical lines are fixed at 0 to represent lack of a relationship. Species for which a covariate was dropped during stepwise regression are fixed at 0 on that covariate plot. 

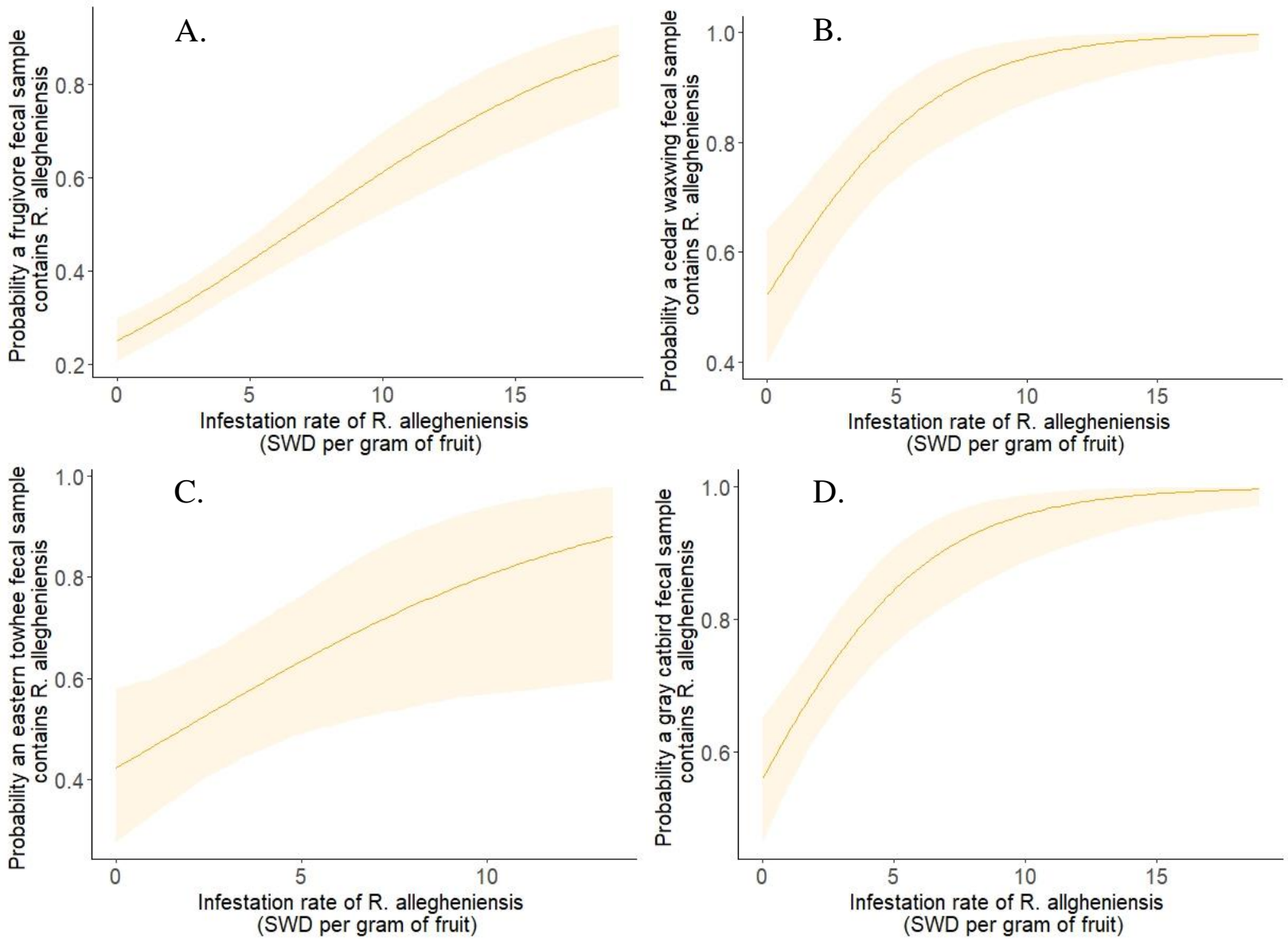

Figure 4.8. Relationship between infestation rates of Allegheny blackberry (Rubus allegheniensis) fruits (spotted wing Drosophila [Drosophila suzukii, SWD]/g of fruit) and probability a fecal sample from A) a frugivore, B) a cedar waxwing, C) an eastern towhee, or D) a gray catbird contained $R$. allegheniensis (including $90 \%$ credible intervals) at each mist net in regenerating harvests during the post-breeding season (Jul-Sep) and fall migration at Allegheny National Forest (ANF), Clear Creek State Forest (CCSF), and State Game Lands (SGL) 86, Pennsylvania, in 2019 and 2020. 


\section{THESIS APPENDICES}

Appendix A. Regenerating timber harvest sites used for avian mist netting and spotted wing Drosophila (Drosophila suzukii) trapping at Allegheny National Forest (ANF), Clear Creek State Forest (CCSF), and State Game Lands 86 (SGL) during the post-breeding season and fall migration (Jul-Sep) in 2019 and 2020.

\begin{tabular}{llllll} 
Site ID & Size (ha) & Location & Latitude & Longitude & Year Sampled \\
\hline Ma06 & 8.49 & ANF & 41.54 & -79.06 & 2020 \\
A29 & 15.38 & ANF & 41.67 & -79.07 & 2020 \\
O18 & 14.36 & ANF & 41.99 & -78.85 & 2020 \\
Ma05 & 12.82 & ANF & 41.69 & -78.98 & 2020 \\
A25 & 8.30 & ANF & 41.48 & -79.15 & 2020 \\
O20 & 12.91 & CCSF & 41.33 & -79.00 & 2020 \\
M32 & 7.56 & ANF & 41.56 & -79.11 & 2020 \\
Ma03 & 8.41 & ANF & 41.78 & -78.94 & 2020 \\
O21 & 11.95 & SGL & 41.76 & -79.31 & 2020 \\
A10 & 11.69 & ANF & 41.69 & -79.16 & 2019 \\
O01 & 21.65 & ANF & 41.63 & -79.24 & 2019 \\
M16 & 10.79 & ANF & 41.64 & -79.13 & 2019 \\
M12 & 14.68 & ANF & 41.80 & -79.00 & 2019 \\
A13 & 16.70 & ANF & 41.76 & -78.96 & 2019 \\
O05 & 9.60 & ANF & 41.72 & -79.28 & 2019 \\
A14 & 11.41 & ANF & 41.68 & -79.10 & 2019 \\
A09 & 8.96 & ANF & 41.85 & -78.65 & 2019 \\
M11 & 13.98 & ANF & 41.83 & -78.74 & 2019 \\
M30 & 7.98 & ANF & 41.56 & -78.97 & 2019 \\
O15 & 21.80 & CCSF & 41.32 & -79.04 & 2019 \\
O16 & 16.27 & CCSF & 41.30 & -79.07 & 2019
\end{tabular}


Appendix B. Frugivorous bird species captured using mist nets during the post-breeding season and fall migration (Jul-Sep) in regenerating timber harvests at Allegheny National Forest (ANF), Clear Creek State Forest (CCSF), and State Game Lands (SGL) 86, Pennsylvania, in 2019 and 2020. Species are separated by guild and family. Percent composition of all captures are provided in parentheses for each family and each focal species during sampling periods 1 and 2 .

Frugivores $(\mathrm{F})$

\begin{tabular}{cc}
\hline Order Passeriformes & Family Fringillidae $(0.42 \%)$ \\
Family Vireonidae $(21.14 \%)$ & Purple finch \\
Blue-headed vireo & Family Passerellidae $(17.35 \%)$ \\
Philadelphia vireo & Fox sparrow \\
Warbling vireo & White-throated sparrow \\
Red-eyed vireo $(18.4 \%)$ & Song sparrow $(11.0 \%)$ \\
Family Corvidae $(0.63 \%)$ & Eastern towhee $(6.1 \%)$ \\
Blue jay & Family Icteridae $(1.58 \%)$ \\
Family Mimidae $(22.5 \%)$ & Baltimore oriole \\
Gray catbird & Family Parulidae $(7.67 \%)$ \\
Family Turdidae $(7.78 \%)$ & Ovenbird $(7.5 \%)$ \\
Eastern bluebird & Myrtle warbler \\
Veery & Family Cardinalidae $(9.25 \%)$ \\
Gray-cheeked thrush & Scarlet tanager \\
Swainson's thrush & Northern cardinal \\
Hermit thrush & Rose-breasted grosbeak \\
Wood thrush & Indigo bunting \\
American robin & \\
Cedar waxwing &
\end{tabular}


Appendix C. Non-frugivorous bird species captured using mist nets during the post-breeding season and fall migration (Jul-Sep) in regenerating timber harvests at Allegheny National Forest (ANF), Clear Creek State Forest (CCSF), and State Game Lands (SGL) 86, Pennsylvania, in 2019 and 2020. Species are separated by guild and family. Percent composition of all captures are provided in parentheses for each family and each focal species during sampling periods 1 and 2.

Non-frugivores $(\mathrm{N})$

Order Cuculiformes
Family Cuculidae $(0.18 \%)$
Black-billed cuckoo
Order Caprimulgiformes
Family Caprimulgidae $(0.06 \%)$
Eastern whip-poor-will
Order Piciformes
Family Picidae $(1.31 \%)$
Yellow-bellied sapsucker
Downy woodpecker
Hairy woodpecker
Northern flicker
Order Passeriformes
Family Tyrannidae (4.88\%)
Eastern wood-pewee
Yellow-bellied flycatcher
Acadian flycatcher
Alder flycatcher
Least flycatcher
Eastern phoebe
Family Paridae (4.11\%)
Black-capped chickadee (4.1\%)
Tufted titmouse
Family Regulidae (0.18\%)
Ruby-crowned kinglet
Golden-crowned kinglet

Family Certhiidae (0.06\%)

Brown creeper

Family Troglodytidae $(0.3 \%)$

House wren

Winter wren

Carolina wren

Family Fringillidae (0.24\%)

American goldfinch

Family Passerellidae (2.26\%)

Chipping sparrow

Field sparrow

Slate-colored junco

White-crowned sparrow

Lincoln's sparrow

Swamp sparrow

Family Parulidae (86.42\%)

Golden-winged warbler

Blue-winged warbler

Black-and-white warbler

Tennessee warbler

Orange-crowned warbler

Nashville warbler

Connecticut warbler

Mourning warbler

Common yellowthroat (11.7\%)

Hooded warbler (4.35\%)
Family Parulidae (contd)

American redstart

Cape May warbler

Cerulean warbler

Northern parula

Magnolia warbler (8.4\%)

Bay-breasted warbler

Blackburnian warbler

Chestnut-sided warbler (28.3\%)

Blackpoll warbler

Black-throated blue warbler $(7.62 \%)$

Western palm warbler

Yellow palm warbler Prairie warbler

Black-throated green warbler (6.37\%)

Canada warbler

Wilson's warbler 
Appendix D. Number of fecal samples from each frugivore species included in analyses of Allegheny blackberry (Rubus allegheniensis) fruit consumption by birds in regenerating timber harvests at Allegheny National Forest (ANF), Clear Creek State Forest (CCSF), and State Game Lands 86 (SGL) during the post-breeding season and fall migration (Jul-Sep) in 2019 and 2020.

\begin{tabular}{lll} 
Common name & Scientific name & Number of samples \\
\hline American robin & Turdus migratorius & 4 \\
Baltimore oriole & Icterus galbula & 9 \\
Blue-headed vireo & Vireo solitarius & 11 \\
Blue jay & Cyanocitta cristata & 2 \\
Cedar waxwing & Bombycilla cedrorum & 97 \\
Eastern towhee & Pipilo erythrophthalmus & 48 \\
Gray catbird & Dumetella carolinensis & 165 \\
Hermit thrush & Catharus guttatus & 2 \\
Indigo bunting & Passerina cyanea & 20 \\
Myrtle warbler & Setophaga coronata & 2 \\
Ovenbird & Seiurus aurocapilla & 38 \\
Philadelphia vireo & Vireo philadelphicus & 2 \\
Rose-breasted grosbeak & Pheucticus ludovicianus & 23 \\
Red-eyed vireo & Vireo olivaceus & 121 \\
Scarlet tanager & Piranga olivacea & 28 \\
Song sparrow & Melospiza melodia & 78 \\
Swainson's thrush & Catharus ustulatus & 22 \\
Veery & Catharus fuscescens & 12 \\
Warbling vireo & Vireo gilvus & 1 \\
Wood thrush & Hylocichla mustelina & 1 \\
White-throated sparrow & Zonotrichia albicollis & 1
\end{tabular}

